\title{
DESIGN RULES FOR HOLLOW CONCRETE MASONRY WALLS SUBJECTED TO CONCENTRATED LOADS
}

by

$$
\text { Junyi Yi }
$$

\author{
A DISSERTATION \\ SUBMITTED TO THE FACULTY OF GRADUATE STUDIES \\ IN PARTIAL FULFILLMENT OF THE REQUIREMENTS FOR THE \\ DEGREE OF DOCTOR OF PHILOSOPHY
}

DEPARTMENT OF CIVIL ENGINEERING

CALGARY, ALBERTA

January, 2002

(c) Junyi Yi 2002 


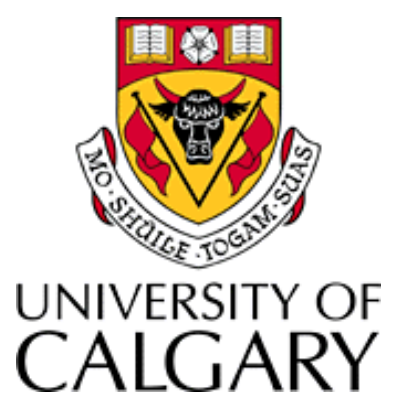

The author of this thesis has granted the University of Calgary a non-exclusive license to reproduce and distribute copies of this thesis to users of the University of Calgary Archives.

Copyright remains with the author.

Theses and dissertations available in the University of Calgary Institutional Repository are solely for the purpose of private study and research. They may not be copied or reproduced, except as permitted by copyright laws, without written authority of the copyright owner. Any commercial use or re-publication is strictly prohibited.

The original Partial Copyright License attesting to these terms and signed by the author of this thesis may be found in the original print version of the thesis, held by the University of Calgary Archives.

Please contact the University of Calgary Archives for further information:

E-mail: uarc@ucalgary.ca

Telephone: (403) 220-7271

Website: http://archives.ucalgary.ca 


\begin{abstract}
3D non-linear elasto-plastic finite element models have been developed for hollow concrete masonry to simulate their structural behaviour when subjected to concentric and eccentric compressive concentrated loads. For every kind of hollow masonry for which experimental results are available (such as hollow masonry prisms, plain hollow masonry walls, walls with bond beams, and walls with grouted details), models were developed and verified first. The models were then used to predict situations where the masonry geometry and loading locations are not described in the literature. The failure mechanism of hollow masonry without vertical columns of grout under in-plane concentrated loading is by progressive web splitting of the hollow block units in the region beneath the loading plate, followed by spalling of the face-shells and/or mortar crushing. When the eccentricity of the load increases, the ultimate capacity decreases. When a concentrated load is applied over a grouted core in partially grouted hollow masonry, the failure mechanism is through splitting/spalling of the face-shells of the hollow block units attached to the columns of grout, followed by column crushing. An experimental study was performed to assess the critical predictions from the finite element models. The good agreements confirmed that the non-linear behaviour of the hollow masonry could be modelled successfully. Based on the available numerical and experimental studies, design rules for hollow masonry subjected to in-plane concentrated loads were proposed. Two possible failure zones were considered. Four important factors influencing the bearing strength were taken into account. When compared to the available numerical and experimental results, safe estimates of ultimate strength were obtained in all cases.
\end{abstract}




\section{PREFACE}

This dissertation is the result of three and a half years of research work under the supervision of Dr. Nigel Shrive, Killam Memorial Professor, in the Department of Civil Engineering, University of Calgary. The following papers have been published or submitted for publication during the course of the research:

Yi, J., and Shrive, N. G. 2000. 3D finite element models of face-shell bedded hollow masonry prisms subjected to eccentric loading. Proceedings of the $12^{\text {th }}$ International Brick/Block Masonry Conference, Madrid, Spain, pp. 1677-1686.

Yi, J., and Shrive, N. G. 2001a. 3D finite element models of plain and bond-beamed hollow masonry walls subjected to concentric and eccentric concentrated loading. Proceedings of the $9^{\text {th }}$ Canadian Masonry Conference, Fredericton, Canada, 12pp on $\mathrm{CD}$.

Yi, J., and Shrive, N. G. 2001b. Numerical analyses of partially grouted hollow masonry walls subjected to concentric and eccentric concentrated loading. Proceedings of the $6^{\text {th }}$ Australasian Masonry Conference, Adelaide, Australia, pp. $403-412$.

Yi, J., and Shrive, N. G. 2001c. Behaviour of hollow concrete masonry walls with onecourse bond beams, subjected to concentrated loading. Submitted to Canadian Journal of Civil Engineering.

Yi, J., and Shrive, N. G. 2001d. Behaviour of partially grouted hollow concrete masonry walls, subjected to concentrated loading. Submitted to Canadian Journal of Civil Engineering. 
Yi, J., and Shrive, N. G. 2001e. Design rules for hollow concrete masonry walls, subjected to concentrated loading. Submitted to Canadian Journal of Civil Engineering 


\section{ACKNOWLEDGEMENTS}

I wish to express my deepest gratitude to my supervisor Dr. Nigel Shrive for his continuous guidance, generous support, constructive criticisms, and endless encouragement throughout the entire programme. The fruitful discussions with Dr. David Laird are also very much appreciated. I would like to extend my gratitude to Dr. Shelley Lissel who provided valuable advice and help at all stages of this programme, and to Dr. Ezz Sayed-Ahmed whose work offered a sound base for this study.

Many thanks to the technical staff of the Department of Civil Engineering, University of Calgary for their cooperation in the numerical and experimental work. The expertise and assistance of Mr. Cory Clark and Mr. Dan Tilleman was especially appreciated.

The financial support provided by NSERC (Natural Sciences and Engineering Research Council of Canada), and the Department of Civil Engineering, University of Calgary, is gratefully acknowledged. Thanks to Calgary Masonry Supply and IXI Industries Ltd., for generously donating materials used in the experiments. Thanks to Masonry Contractor Association of Alberta (Southern Division) for their support of a qualified mason to build the masonry. Special thanks go to Mark Masia, David Dechka, Mahmoud Reda Taha, Terry Quinn, Don Anson, Rames Gayed, Otakar Vacin, Jing Wang, Peng Xu, Xiaosong Xiao, and Dong Chen for their support and encouragement throughout the project.

Finally, my deepest appreciation goes to my dear family whose continuous sacrifice, unlimited love, unconditional support, patience, and encouragement throughout all my study period I could not have done without. 
My Family 


\section{TABLE OF CONTENTS}

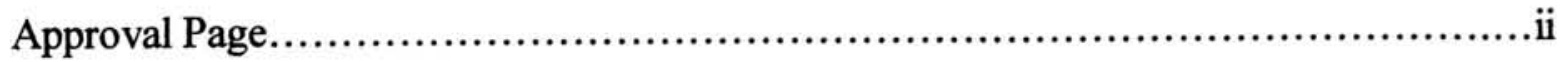

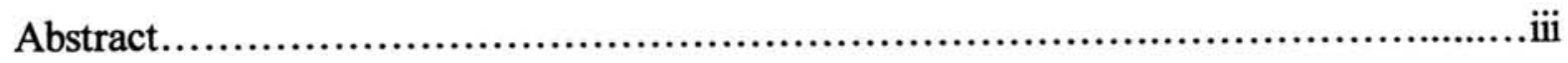

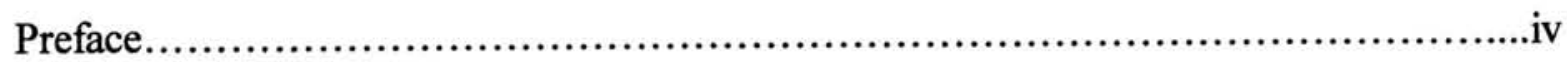

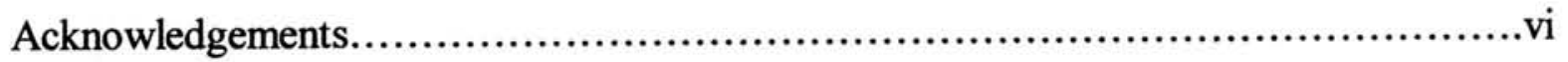

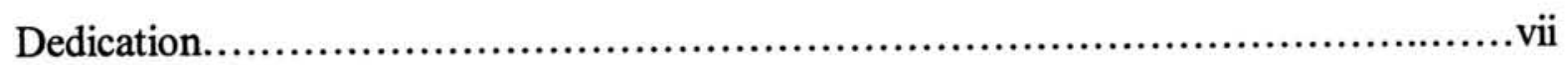

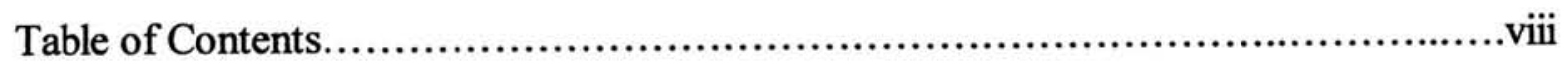

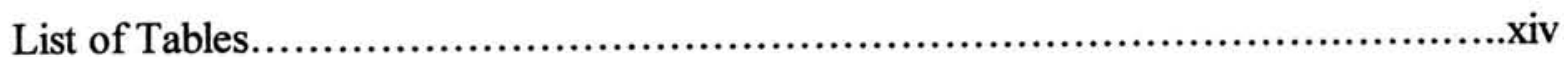

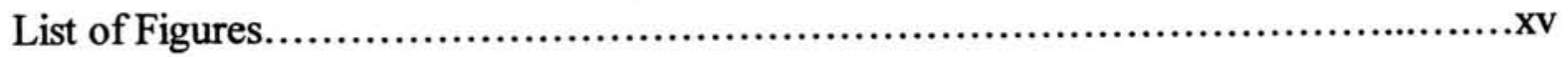

\section{CHAPTER 1: INTRODUCTION}

1.1 General..............................................................................

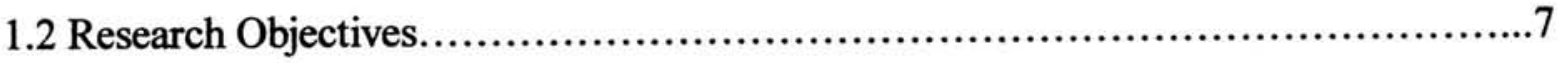

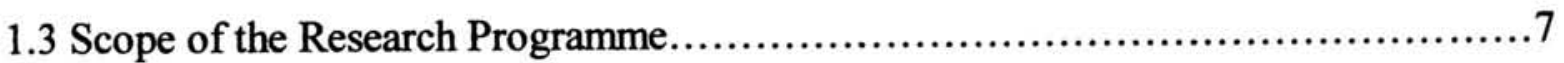

\section{CHAPTER 2: LITERATURE REVIEW}

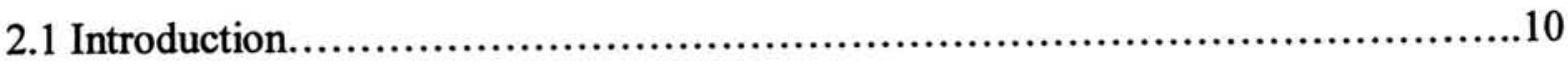

2.2 Failure Mechanism of Masonry Subjected to Concentrated Loads.................10

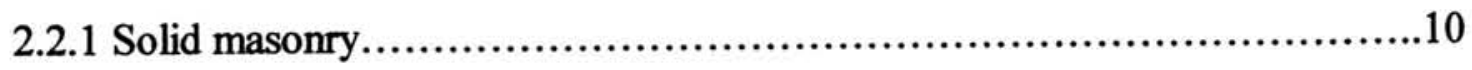

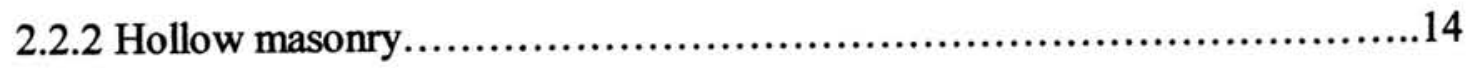

2.3 Finite Element Models for Masonry........................................ 17

2.3.1 Finite element models for solid masonry.............................17 
2.3.2 Finite element models for hollow masonry .................................20

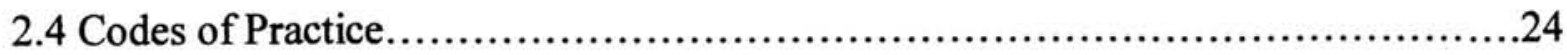

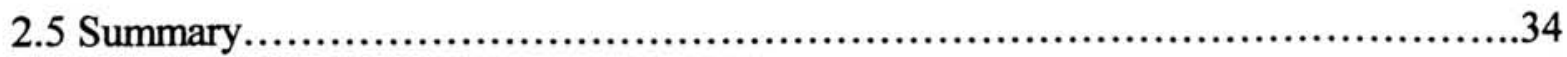

\section{CHAPTER 3: ELASTO-PLASTIC FINITE ELEMENT MODEL}

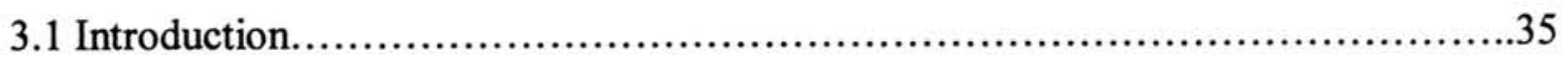

3.2 Constitutive Material Model........................................................36

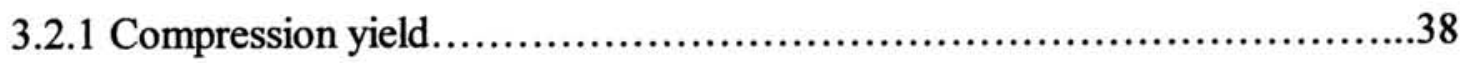

3.2.2 Crack detection surface ....................................................40

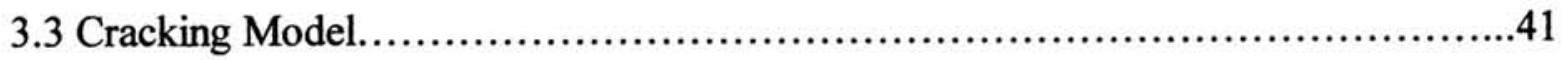

3.3.1Smeared crack modelling ......................................................41

3.3.2 Discrete crack modelling......................................................

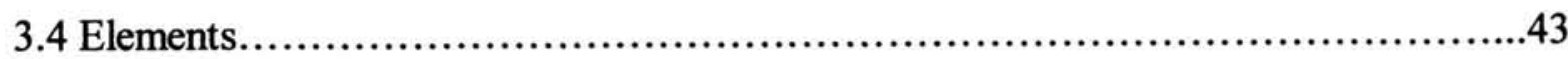

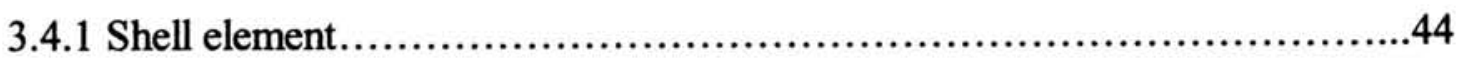

3.4.2 Solid element....................................................................

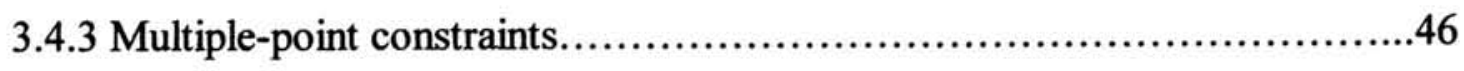

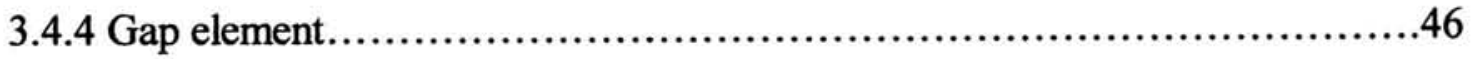

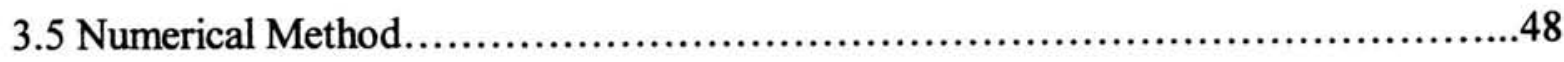

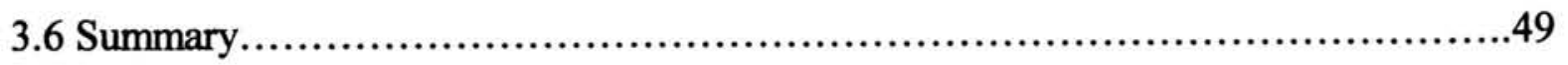

CHAPTER 4: 3D NON-LINEAR FINITE ELEMENT MODELS OF FACE-SHELL BEDDED HOLLOW CONCRETE MASONRY PRISMS

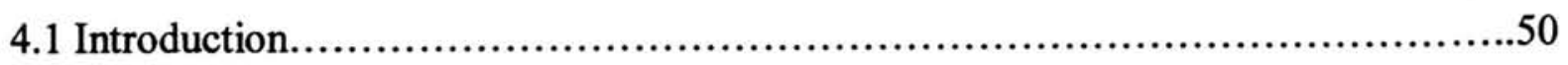




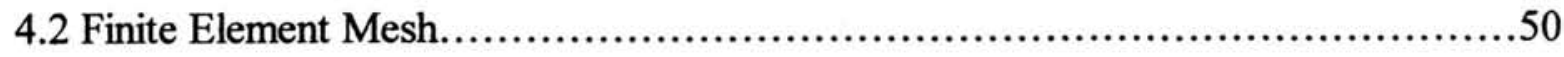

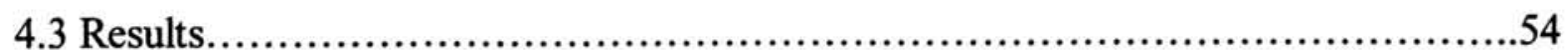

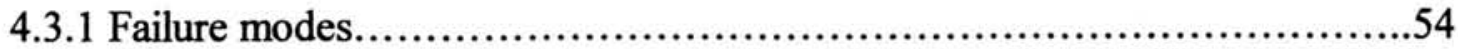

4.3.1.1 Under concentric compressive load...............................55

4.3.1.2 Under eccentric compressive load (single curvature) ...............60

4.3.1.3 Under eccentric compressive load (double curvature)...............69

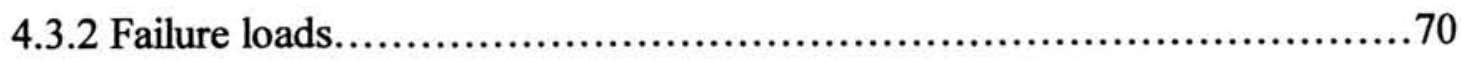

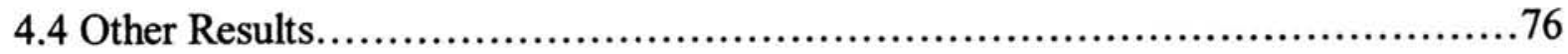

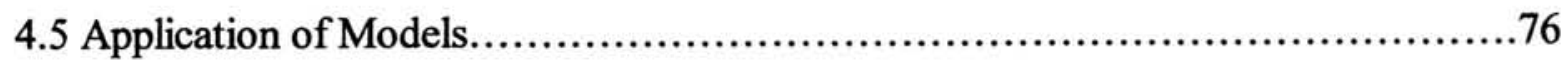

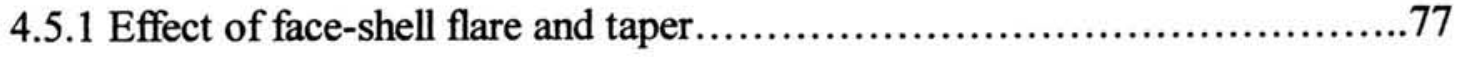

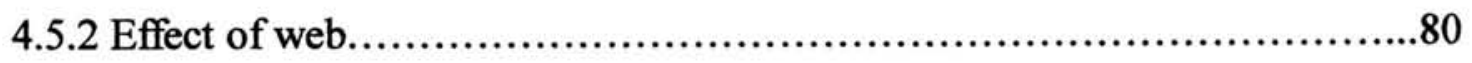

4.5.2.1 Effect of web flare and taper....................................8

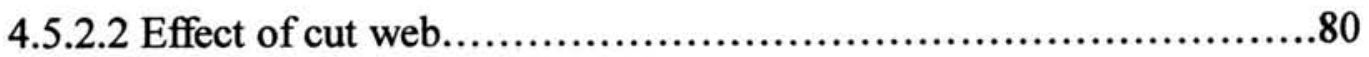

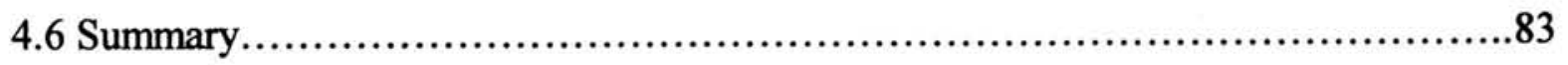

CHAPTER 5: 3D NON-LINEAR FINITE ELEMENT MODELS OF HOLLOW CONCRETE MASONRY WALLS SUBJECTED TO CONCENTRATED LOADS

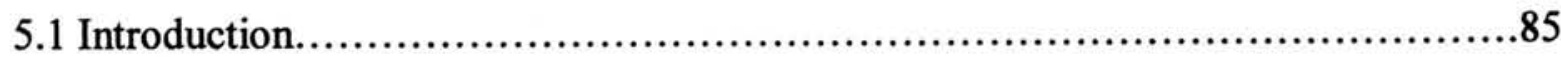

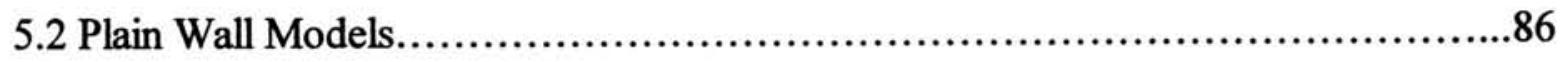

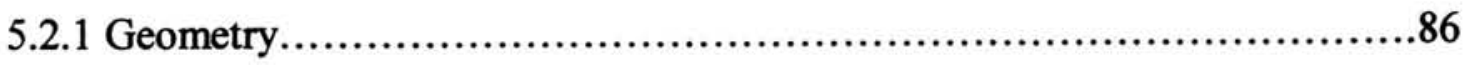

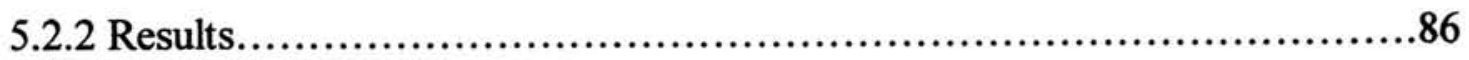

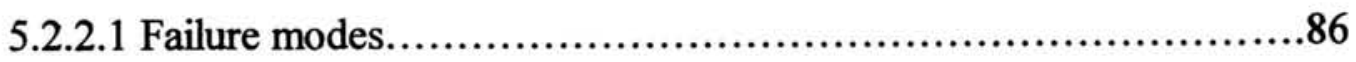

5.2.2.2 Failure loads..................................................... 94 


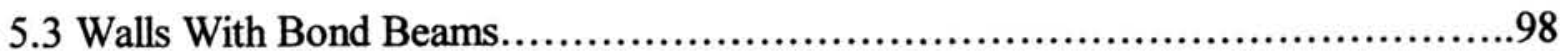

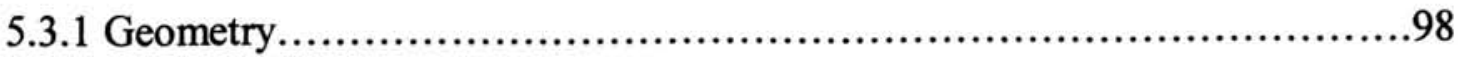

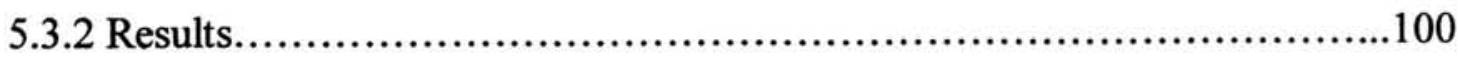

5.3.2.1 Failure modes................................................... 100

5.3.2.2 Failure loads.....................................................

5.4 Wall Models With One-Course Bond Beams, Subjected to Concentrated Load at

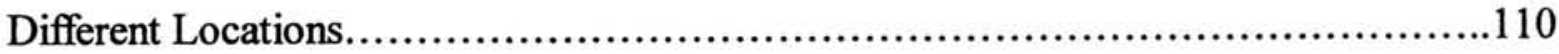

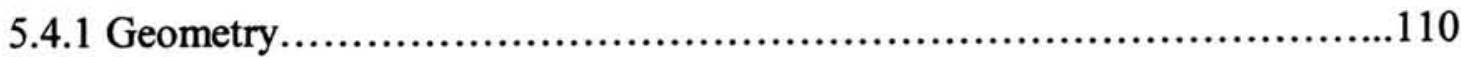

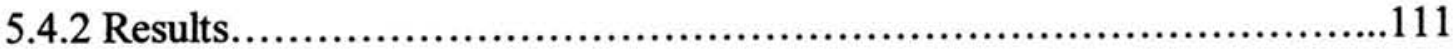

5.4.2.1 Effects of out-of-plane eccentricities..............................113

5.4.2.2 Effects of loading locations.......................................115

5.4.2.3 Concentrated load at the end of wall..............................120

5.5 Partially Grouted Hollow Concrete Masonry Walls and Walls with Grouted Details

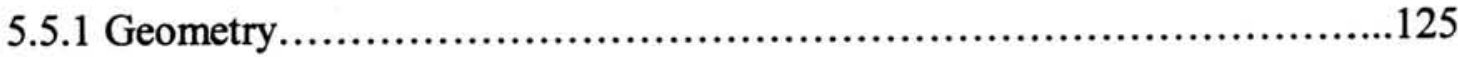

5.5.2 Verification of models....................................................131

5.5.3 Application of models....................................................

5.5.3.1 Models without vertical grout columns............................135

5.5.3.2 Strength variation................................................ 139

5.5.3.3 Models with vertical columns of grout.............................142

5.6 Dispersion of Concentric Concentrated Load..................................143

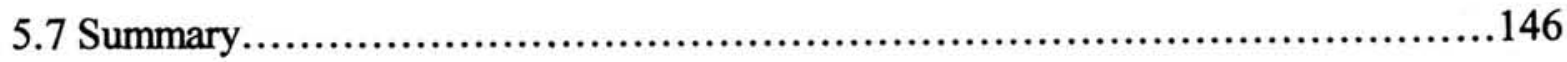

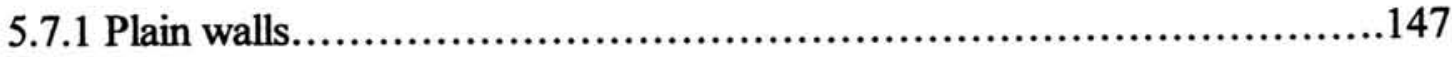


5.7.2 Walls with bond beams.

\section{CHAPTER 6: EXPERIMENTS OF PARTIALLY GROUTED HOLLOW CONCRETE MASONRY SUBJECTED TO CONCENTRATED LOADS}

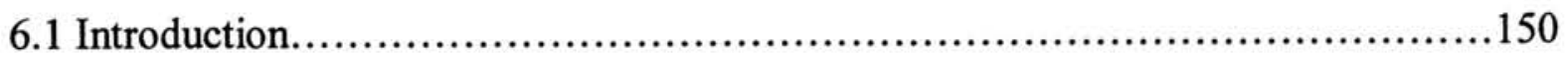

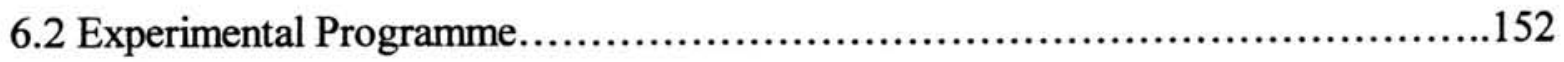

6.2.1 Sample test.................................................................

6.2.1.1 Hollow block unit test............................................153

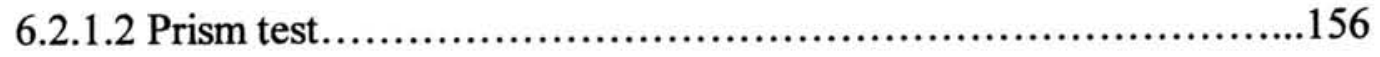

6.2 .2 Wallette test.......................................................... 160

6.3 Wallette Test Results and Discussions........................................167

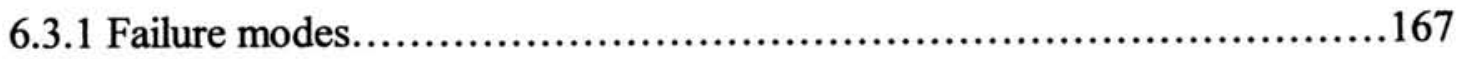

6.3.1.1 Concentrated loads on bond beams (Series 1).....................167

6.3.1.2 Concentrated loads on end columns (Series 2).....................177

6.3.1.3 Concentrated loads on middle columns (Series 3).................193

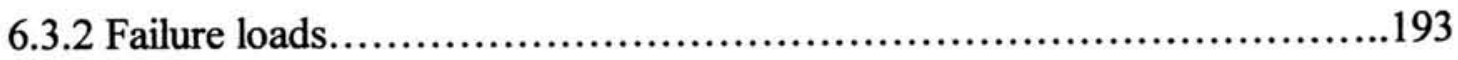

6.3.3 Dispersion of load through the bond beam................................201

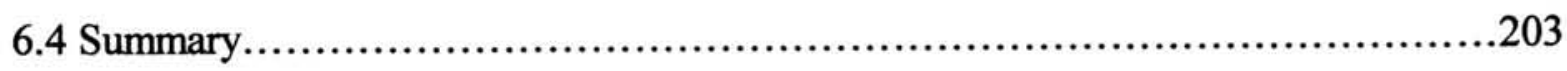

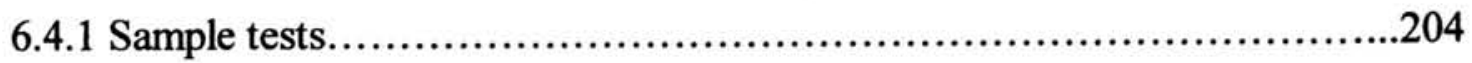

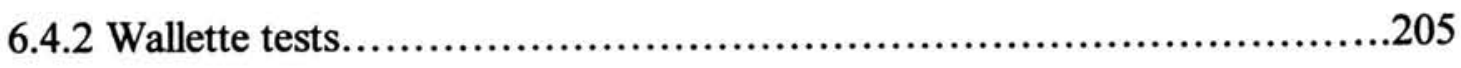




\section{CHAPTER 7: DESIGN RULES FOR HOLLOW CONCRETE MASONRY WALLS SUBJECTED TO CONCENTRATED LOADS}

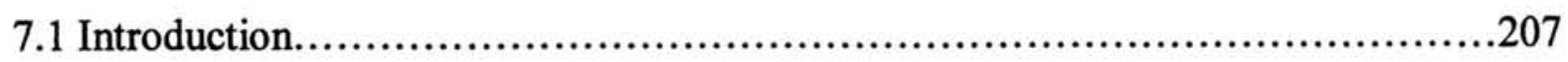

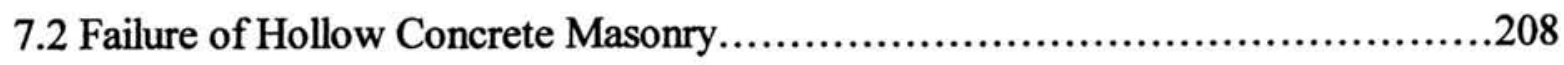

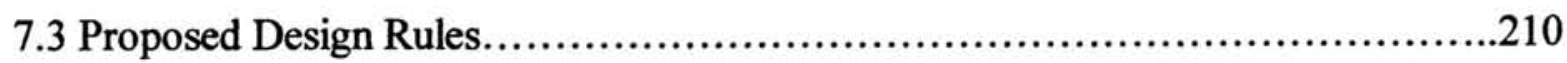

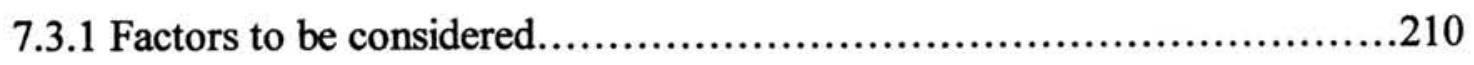

7.3.2 Design rules for solid/grouted masonry ................................210

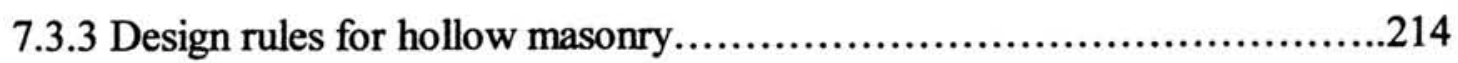

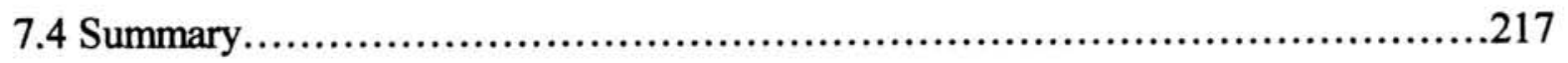

\section{CHAPTER 8: SUMMARY AND CONCLUSIONS}

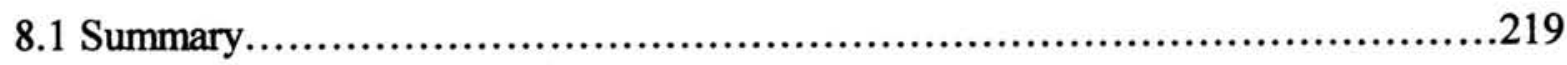

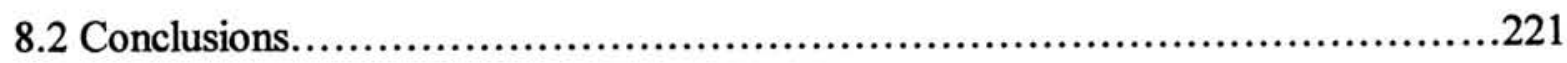

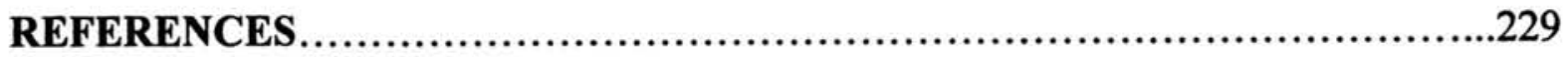




\section{LIST OF TABLES}

Table 5.1 Predicted and experimental results for plain hollow concrete masonry walls subjected to concentrated loads.

Table 5.2 Predicted and experimental results for hollow concrete masonry walls with one-course bond beams subjected to concentrated loads.

Table 5.3 Predicted and experimental results for hollow concrete masonry walls with two-course bond beams subjected to concentrated loads.

Table 5.4 Capacities of hollow masonry walls with one-course bond beams, subjected to concentrated loads with various loading locations and eccentricities

Table 5.5 Results of hollow concrete masonry walls with one-course bond beams and various lengths, subjected to concentrated loads at the end

Table 5.6 Comparison of theoretical and experimental strength of partially grouted hollow masonry walls subjected to concentric concentrated loads.

Table 5.7 Capacities of partially grouted hollow concrete masonry walls and walls with grouted details subjected to concentrated loads....

Table 5.8 Dispersion of concentric concentrated load through bond-beams or grouted hollow blocks

Table 6.1 Compressive strengths of hollow concrete block units, together with 28-day strengths of grout cylinders and masonry prisms. 153

Table 6.2 Summary of wallette test series and results 166

Table 6.3 Dispersion of concentrated load through the bond beam in partially grouted hollow concrete masonry walls. .203 


\section{LIST OF FIGURES}

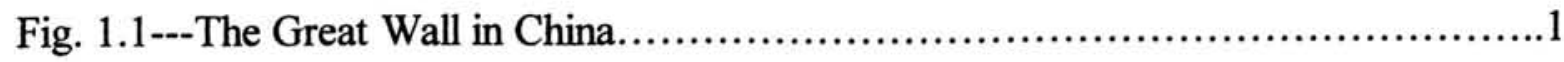

Fig. 1.2---The Great Pyramid in Egypt...................................................

Fig. 1.3---Typical standard concrete block................................................

Fig. 2.1---Failure modes of solid masonry subjected to concentrated loads..............13

Fig. 2.2---Failure of face-shell bedded hollow masonry starting by web cracking.........16

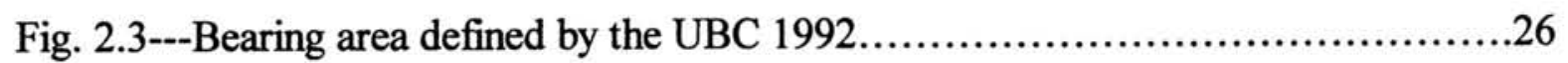

Fig. 2.4---Load dispersion and bearing area of concentrated loads - MSJC code.........27

Fig. 2.5---Loading position and effective areas of dispersion defined by AS 3700-1998.30

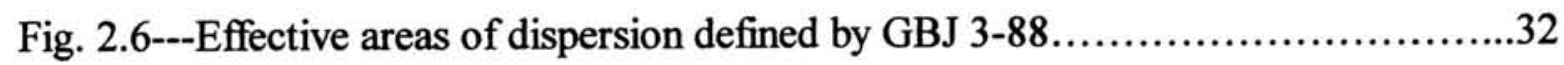

Fig. 3.1---Uniaxial behaviour of mortar, concrete block unit and grout..................37

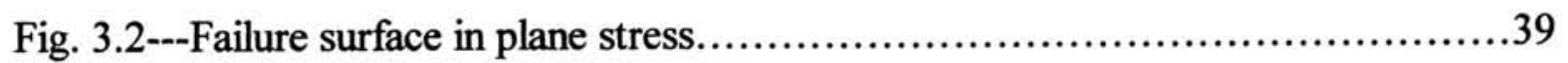

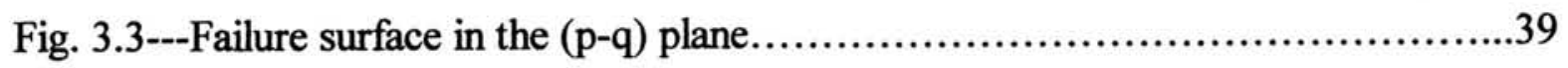

Fig. 3.4---Idealization of a single crack in smeared crack modelling...................42

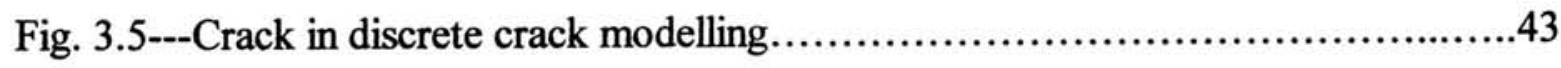

Fig. 3.6---3D 4-node doubly curved general-purpose shell element (S4)...............45

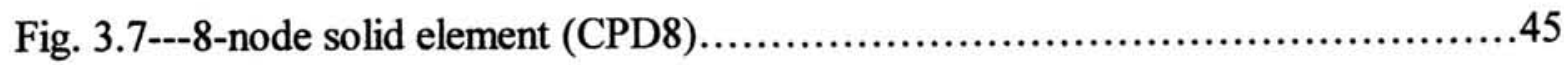

Fig. 3.8---Multiple point constraint between shell and solid element...................46

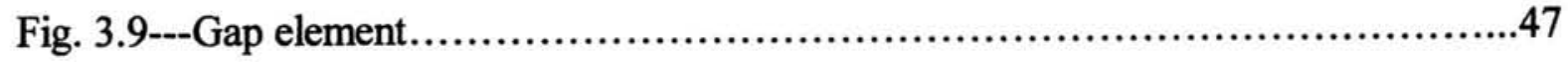

Fig. 3.10---Mechanical interaction model for gap element..............................48

Fig. 4.1---Face-shell bedded stack-bonded hollow concrete masonry prism..............51 
Fig. 4.2---Finite element mesh for three-block-high stack-bonded face-shell bedded hollow concrete masonry prisms. .52

Fig. 4.3---Simplified model of face-shell and web taper and flare.

Fig. 4.4---Stress-strain relations in uniaxial compression for concrete block units and mortar .54

Fig. 4.5----Comparison of failure modes of prisms under concentric compression..........56 Fig. 4.6---The horizontal stress distribution in the webs of the prism under concentric compression (smeared model).

Fig. 4.7---Stresses in the face-shells and mortar around the mortar joint for prism under concentric compression. 58

Fig. 4.8---Failure pattern of hollow concrete masonry prism under concentric compression .59

Fig. 4.9---Comparison of failure modes of hollow concrete masonry prisms under eccentric compression (single curvature with $\mathrm{e}=\mathrm{t} / 6$ ).

Fig. 4.10---Stresses in the face-shells and mortar around the heavily loaded mortar joint for prisms under eccentric compression (single curvature with $\mathrm{e}=\mathrm{t} / 6$ )

Fig. 4.11---Comparison of failure modes of prisms under eccentric compression (single curvature with $\mathrm{e}=\mathrm{t} / 3$ )

Fig. 4.12---The horizontal stress distribution in the webs of hollow concrete masonry prism under eccentric compression (single curvature $\mathrm{e}=\mathrm{t} / 3$ ). 64

Fig. 4.13---Stresses in the face-shell and mortar around the heavily loaded mortar joint for prisms under eccentric compression (single curvature with $\mathrm{e}=\mathrm{t} / 3$ ) 
Fig. 4.14---Comparison of failure modes of prisms under eccentric compression (single

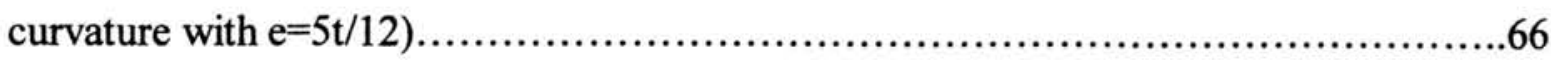

Fig. 4.15---Stresses in the face-shells and mortar around the heavily loaded mortar joint for prisms under eccentric compression (single curvature $e=5 t / 12$ )

Fig. 4.16---Failure patterns of hollow concrete masonry prisms under eccentric compression (single curvature) .68

Fig. 4.17---Comparison of failure modes of hollow concrete masonry prisms under eccentric compression (double curvature). .71

Fig. 4.18---The horizontal stress distribution in the webs of the prism under eccentric compression (double curvature $\mathrm{e}=\mathrm{t} / 3$ ) . .72

Fig. 4.19---Stresses in the face-shells and mortar around the mortar joint for prisms under eccentric compression (double curvature).

Fig. 4.20---Failure patterns of hollow concrete masonry prisms under eccentric compression (double curvature).

Fig. 4.21---Comparison of failure load ratio (single curvature eccentric compression)...75

Fig. 4.22---Comparison of failure load ratio (double curvature eccentric compression)..75

Fig. 4.23---Simplified model without face-shell taper and flare but with web taper and

flare .78

Fig. 4.24---Stresses in the face-shells and mortar around the mortar joint in the model without face-shell flare and taper, under concentric compression .79

Fig. 4.25---Stresses in the face-shells and mortar around the mortar joint in the model without face-shell flare and taper, under eccentric compression. .79 
Fig. 4.26---Comparison of failure modes of prisms with web cut to $1 / 3$ of the web height under concentric compression .82

Fig. 4.27---Stresses in the face-shells and mortar around the mortar joint in the model with cut webs, under concentric compression.

Fig. 5.1---Plain hollow concrete masonry wall model (load over central web).

Fig. 5.2---Plain hollow concrete masonry wall model (load over two end webs)

Fig. 5.3---Plain hollow concrete masonry wall model (load over core). .88

Fig. 5.4---Connection details between hollow block unit and loading plate. .88

Fig. 5.5---Cracking pattern of plain hollow masonry walls subjected to concentrated load

(a) concentric concentrated load, (b) eccentric concentrated load. .90

Fig. 5.6---Failure modes of plain hollow masonry walls subjected to concentrated load (a) load over central web; (b) load over core. .90

Fig. 5.7---The vertical compressive stress distribution of plain wall subjected to concentric concentrated load over central web.

Fig. 5.8---The horizontal tensile stress distribution underneath the loading plate subjected to concentric concentrated load over central web.

Fig. 5.9a---The failure loads from predicted and experimental results for plain walls (loading plate length $160 \mathrm{~mm}$ ). .96

Fig. 5.9b---Ultimate strength variation with increasing eccentricity from predicted and experimental results for plain walls. .96

Fig. 5.9c---Strength enhancement factor for plain hollow concrete masonry walls subjected to concentrated loading over central web .98

Fig. 5.10---Model of hollow concrete masonry wall with one-course bond beams .99 
Fig. 5.11---Model of hollow concrete masonry wall with two-course bond beams.

Fig. 5.12---Connection between hollow blocks and grouted bond beam blocks.

Fig. 5.13---Cracking pattern of hollow concrete masonry walls with bond beams (a) concentric concentrated load (b) eccentric concentrated load.

Fig. 5.14---Failure modes of hollow concrete masonry walls with bond beams, subjected to concentrated load.

Fig. 5.15---The vertical compressive stress distribution of hollow masonry wall with onecourse bond beams subjected to concentric concentrated load. 104

Fig. 5.16---The vertical compressive stress distribution of hollow masonry wall with twocourse bond beams subjected to concentric concentrated load. 105

Fig. 5.17---The horizontal tensile stress distribution in the hollow masonry underneath the bond beams subjected to concentric concentrated load. 106

Fig. 5.18a---The failure loads from predicted and experimental results for hollow concrete masonry walls with one-course bond beams. 108

Fig. 5.18b---Ultimate strength variation from predicted and experimental results for walls with one-course bond beams. 108

Fig. 5.19a---The failure loads from predicted and experimental results for hollow concrete masonry walls with two-course bond beams.

Fig. 5.19b---Ultimate strength variation from predicted and experimental results for walls with two-course bond beams 109

Fig. 5.20---Wall models with one-course bond beams, subjected to concentrated load at different locations (a) $\mathrm{L}=1200 \mathrm{~mm}$ (b) $\mathrm{L}=800 \mathrm{~mm}$ (c) $\mathrm{L}=400 \mathrm{~mm}$ (d) $\mathrm{L}=0$. 
Fig. 5.21---Effect of out-of-plane eccentricities on the strengths for different loading locations and different loading plate lengths. 114

Fig. 5.22---Vertical compressive stress distribution of hollow concrete masonry wall with one-course bond beams, subjected to concentrated load with $\mathrm{L}=800 \mathrm{~mm}$. 116

Fig. 5.23---Vertical compressive stress distribution of hollow concrete masonry wall with one-course bond beams, subjected to concentrated load with $\mathrm{L}=400 \mathrm{~mm}$.

Fig. 5.24---Effect of loading locations on the ultimate strengths for different out-of-plane eccentricities and different loading plate lengths.

Fig. 5.25---Discrete models of hollow masonry walls with one-course bond beams, subjected to concentrated load at the end (a) 4-blocks long (b) 5-blocks long

Fig. 5.26---Vertical compressive stress distribution of hollow masonry wall with a onecourse bond beam and 4-blocks long, subjected to concentrated load at the end.

Fig. 5.27---Failure modes of hollow concrete masonry walls with one-course bond beams and 4-blocks long, subjected to concentrated loads at the end 124

Fig. 5.28a---Hollow concrete masonry walls with grouted details (PGW1, 2)...........126

Fig. 5.28b---Hollow concrete masonry walls with grouted details (PGW3, 4) ..........127

Fig. 5.28c---Hollow concrete masonry walls with grouted details (PGW5, 6) ...........128

Fig. 5.29a---Partially grouted hollow masonry walls with vertical grout column (PGW7, 8).

Fig. 5.29b---Partially grouted hollow masonry walls with vertical grout column (PGW9, 10) .130

Fig. 5.30---Cracking pattern of hollow masonry walls with grouted details, subjected to concentrated load (a) concentric concentrated load (b) eccentric concentrated load.....132 
Fig. 5.31---Vertical compressive stress distribution of PGW1 (pyramid grouting pattern) subjected to concentrated load.

Fig. 5.32---Vertical compressive stress distribution of PGW2 (wedge grouting pattern) subjected to concentrated load.

Fig. 5.33---Vertical compressive stress distribution of PGW3 (one-block grouting pattern) subjected to concentrated load.

Fig. 5.34---Vertical compressive stress distribution of PGW4 (end pyramid grouting pattern) subjected to concentrated load. 140 Fig. 5.35---Strength variation for hollow concrete masonry walls with wedge, pyramid and one-block rectangular grouting patterns (PGW1, 2, 3).

Fig. 5.36---Strength variation for hollow concrete masonry walls with end wedge, end pyramid and end rectangular grouting patterns (PGW4, 5, 6).

Fig. 5.37----Concentric concentrated load dispersion. 145

Fig. 6.1---Typical construction of partially grouted hollow concrete masonry walls (with bond beams and vertical grouting every three cores) 151

Fig. 6.2---Standard hollow block units. 154

Fig. 6.3---Block units with "knock-out" webs. 154

Fig. 6.4---Test set-up for hollow block units.

Fig. 6.5---Failure mode of standard hollow block units. 155

Fig. 6.6---Failure mode of hollow block units with "knock-out" webs. 156

Fig. 6.7---Prisms built of standard units (a) hollow, (b) grouted.

Fig. 6.8---Prisms built of units with "knock-out" webs (a) hollow, (b) grouted. 157

Fig. 6.9---Test set-up for prisms. 158 
Fig. 6.10---Failure mode of hollow prism with standard units.......................158

Fig. 6.11---Failure mode of hollow prism with "knock-out" webs.....................158

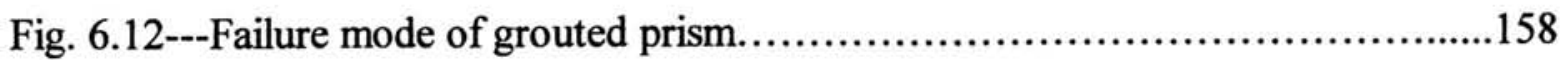

Fig. 6.13---Series 1, load on the bond beam above hollow blocks.....................161

Fig. 6.14---Series 2, load above the end column of grout...............................161

Fig. 6.15---Series 3, load above the middle column of grout............................162

Fig. 6.16---Concentric and eccentric loading........................................162

Fig. $6.17 \mathrm{a}$---Test set-up for wallettes loaded in the middle............................163

Fig. 6.17b---Test set-up for wallettes loaded at the end..............................164

Fig. 6.18---LPDTs arrangement for Series 1 test......................................164

Fig. 6.19---LPDTs arrangement for Series 2 test.....................................165

Fig. 6.20---LPDTs arrangement for Series 3 test.....................................165

Fig. 6.21a---Load versus web cracking for C160M...............................168

Fig. 6.21b---Load versus vertical cracking for C160M.............................169

Fig. 6.21c---Load versus vertical displacement for C160M...........................169

Fig. 6.22a---Typical web-splitting occurred in the hollow blocks beneath the bond beam: concentric loading (seen after cutting the face-shells)................................170

Fig. 6.22b---Typical web-splitting occurred in the hollow blocks beneath the bond beam:

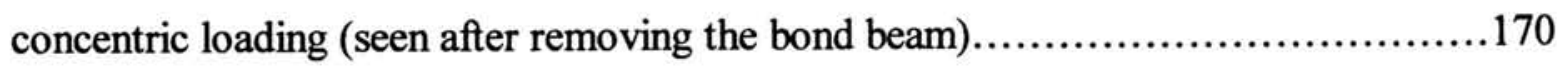

Fig. 6.23---Vertical cracking normal to the wall plane: concentric loading.............171

Fig. 6.24a---Load versus web cracking for 1E160M................................172

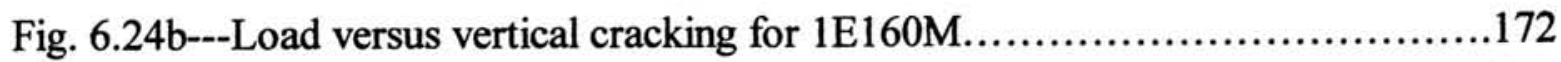

Fig. 6.24c---Load versus vertical displacement for 1E160M........................173 
Fig. 6.25---Typical failure mode of wallette under eccentric concentrated load $(\mathrm{e}=32 \mathrm{~mm})$

Fig. 6.26a---Load versus web cracking for 2E160M 174

Fig. 6.26b---Load versus vertical cracking for 2E160M. 174

Fig. 6.26c---Load versus vertical displacement for 2E160M 175

Fig. 6.27---Typical failure mode of wallette under eccentric concentrated load $(\mathrm{e}=64 \mathrm{~mm})$

Fig. 6.28---Shrinkage of grout in the bond beam. 176

Fig. 6.29a---Load versus vertical cracking for C240E............................178

Fig. 6.29b---Load versus vertical displacement for C240E.........................178

Fig. 6.29c---Load versus web cracking of hollow blocks for C240E...................179

Fig. 6.29d---Load versus lateral dilation of column for C240E......................179

Fig. 6.30a---Load versus vertical cracking for C160E.............................180

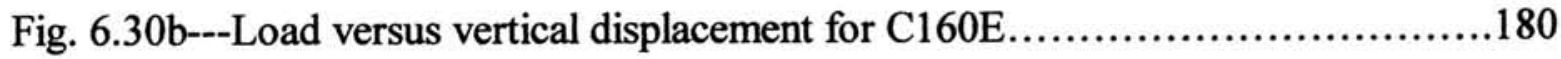

Fig. 6.31a---Load versus vertical displacement for C80E............................181

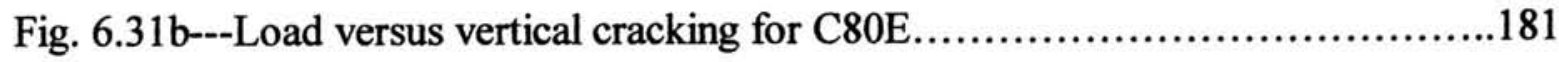

Fig. 6.31c---Load versus web cracking of hollow blocks for C80E $\ldots \ldots \ldots \ldots \ldots \ldots \ldots \ldots 182$

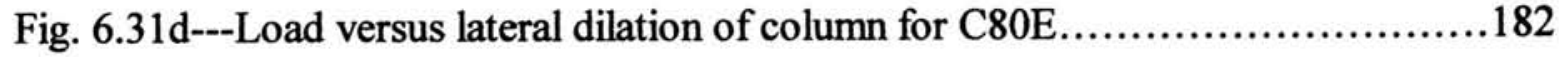

Fig. 6.32a---Vertical cracking and face-shell spalling of wallette under concentric

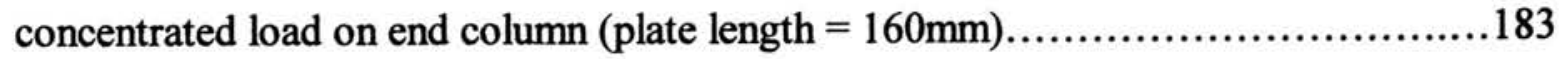

Fig. 6.32b---Vertical cracking and face-shell spalling of wallette under concentric concentrated load on end column (plate length $=240 \mathrm{~mm}$ ). 
Fig. 6.33a---Web splitting of wallette under concentric concentrated load on end column (seen after removing the bond beam and column, plate length $=160 \mathrm{~mm}$ ). 184

Fig. 6.33b---Vertical cracking and web splitting of wallette under concentric concentrated load on end column (seen after removing the bond beam, plate length $=240 \mathrm{~mm}$ ). 184

Fig. 6.34---Local crushing/splitting of wallette under concentric concentrated load on end column (plate length $=80 \mathrm{~mm}$ ).

Fig. 6.35a---Load versus vertical cracking for 1E240E .186

Fig. 6.35b---Load versus vertical displacement for 1E240E .186

Fig. 6.36a---Load versus vertical cracking for 1E160E. 187

Fig. 6.36b---Load versus vertical displacement for $1 \mathrm{E} 160 \mathrm{E}$ 187

Fig. 6.37a---Load versus vertical cracking for 1E80E. .188

Fig. 6.37b---Load versus vertical displacement for $1 \mathrm{E} 80 \mathrm{E}$ .188

Fig. 6.38---Failure mode of wallette under eccentric concentrated load on end column $(\mathrm{e}=32 \mathrm{~mm})$.

Fig. 6.39a---Load versus vertical cracking for 2E240E.

Fig. 6.39b---Load versus vertical displacement for 2E240E

Fig. 6.40a---Load versus vertical cracking for $2 \mathrm{E} 160 \mathrm{E}$

Fig. 6.40b---Load versus vertical displacement for 2E160E

Fig. 6.41---Failure modes of wallette under eccentric concentrated load on end column $(\mathrm{e}=64 \mathrm{~mm})$

Fig. 6.42a---Load versus vertical (inclined) cracking for $\mathrm{C} 160 \mathrm{C}$

Fig. 6.42b---Load versus vertical displacement for C160C.

Fig. 6.42c---Load versus web cracking in the hollow blocks for C160C .195 
Fig. 6.42d---Load versus lateral dilation of column for C160C

Fig. 6.43a---Load versus vertical (inclined) cracking for 1E160C 196

Fig. 6.43b---Load versus vertical displacement for 1E160C............................196

Fig. 6.44a---Load versus vertical (inclined) cracking for 2E160C....................197

Fig. 6.44b---Load versus vertical displacement for 2E160C..........................197

Fig. 6.45---Failure modes of wallette under concentrated load above middle columns..198 Fig. 6.46---Ultimate strength variation with increasing eccentricity for partially grouted wallettes with concentrated load on the bond beam above the hollow masonry..........200 Fig. 6.47---Ultimate strength variation with increasing eccentricity for partially grouted wallettes with the concentrated load applied above a column of grout. .201

Fig. 6.48---Dispersion of concentrated load through the bond beam in partially grouted hollow concrete masonry walls. 202

Fig. 7.1---Failure modes of hollow concrete masonry subjected to concentrated loads (a) hollow masonry failure, (b) solid/grouted masonry failure 209

Fig. 7.2---Effective bearing area (within solid/grouted masonry) for concentrated load

Fig. 7.3a---Comparison of proposed method to experimental results $\left(\mathrm{K}_{1}=1.0\right) \ldots \ldots \ldots . .213$

Fig. 7.3b---Comparison of proposed method to experimental results $\left(\mathrm{K}_{2}=1.0\right) \ldots \ldots \ldots \ldots .213$ Fig. 7.4---Dispersion of concentrated load through solid/grouted masonry to hollow masonry .214

Fig. 7.5---Comparison of proposed method to numerical and experimental results (a) $\mathrm{a}=160 \mathrm{~mm}(\mathrm{~b}) \mathrm{a}=240 \mathrm{~mm}$ (c) $\mathrm{a}=320 \mathrm{~mm}$ 217 


\section{CHAPTER 1}

\section{INTRODUCTION}

\subsection{General}

People have been building significant masonry structures for about ten millennia, with the earliest evidence of this method of construction coming from the Cradle of Civilization - the Middle East. Many spectacular examples of masonry constructed in ancient times are still in good shape, and would be very difficult and extremely expensive to duplicate today -- even with our advanced design skills, modern machines, and modern materials. Typical examples are the Great Wall in China (Fig. 1.1) and the Great Pyramid in Egypt (Fig. 1.2). Masonry plays a splendid role in the history of the development of building.

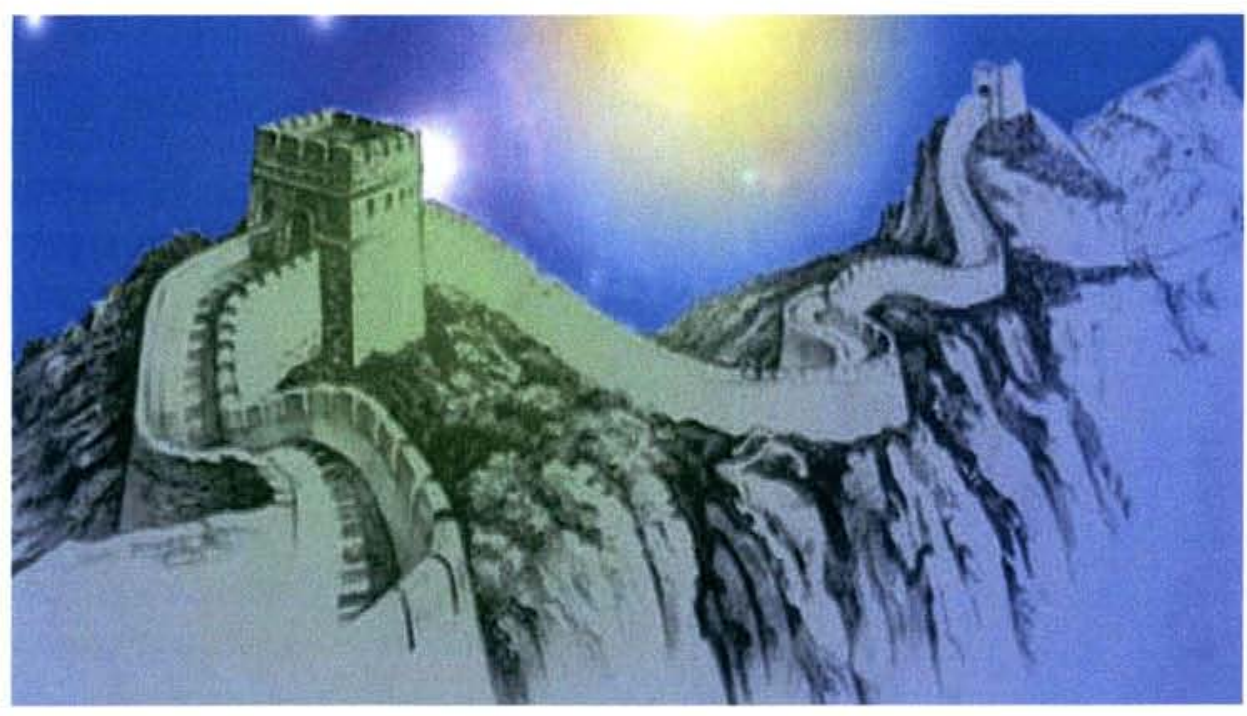

Fig. 1.1---The Great Wall in China 


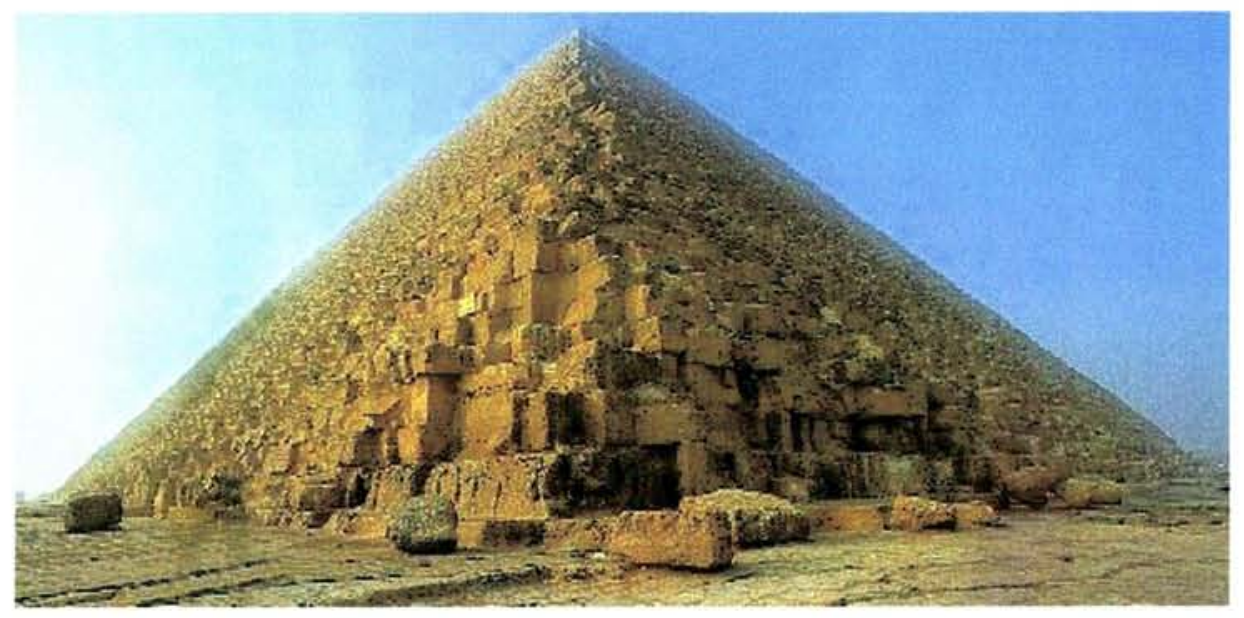

Fig. 1.2---The Great Pyramid in Egypt

Masonry is a combination of different materials: for example, fired clay units or concrete units joined together by another material (mortar) through thin joints. Many materials have been used for the masonry construction, those locally available being most convenient. Whenever civilizations developed in river plains, the alluvial deposits were used to create brick architecture. Where civilizations existed in the vicinity of mountains or rocky outcrops, stone was used. In the arctic regions, ice blocks are used to make igloos. The common masonry materials used today are units made from stone, clay, calcium silicate, and concrete, joined by mortar.

Stone was probably first used to make masonry. A crude stack of selected natural stones mortared together simply with packed earth made the first masonry. Then, refinement developed where stones were roughly trimmed, stacked, and wedged with smaller stones and bedded in clay. Clay bricks have been in use for at least 10,000 years. The earliest bricks were made by pressing mud or clay into small lumps and allowing them to dry in air or under the sun. Calcium silicate (sand-lime) bricks were made in ancient times by 
moulding lime mortar into brick shapes and allowing them to dry in air, but air-drying was slow. In 1866, accelerated hardening of calcium silicate units by the application of steam was introduced in the United States. Concrete masonry units were first made at about the same time as the steam-cured calcium silicate units, and as better quality cements were developed. The first concrete blocks were unpopular because they were solid and heavy to handle. Hollow concrete block units were then developed and soon gained popular use.

Early mortars might have been clay, bitumen, lime, or clay-straw mixtures, and were basically used to fill cracks and provide uniform bedding for masonry units. No significant developments in mortars took place until the eighteenth century when hydraulic lime was introduced to provide a durable mortar that would set and harden under water. The next important development was achieved in the mid-nineteenth century when Portland cement was combined with sand, lime, and water to produce much stronger mortars than previously possible.

The geometry of masonry constructions varies tremendously. Mortar can be applied to the whole bedding of the units (full bedding) or only as a strip along the units' edges (face-shell bedding). The units can be manufactured in different geometric configurations and dimensions, containing cores and webs of irregular geometry. The most commonly used concrete block unit for load-bearing masonry structures in North America is the two-core $390 \times 190 \times 190 \mathrm{~mm}$ hollow concrete block unit, as shown in Figure 1.3 . The concrete blocks are generally manufactured by vibrating a mixture of Portland cement, 
sand, and aggregate in a mould under pressure, followed by curing with low-pressure or high-pressure steam. In some cases, units are then exposed to carbon dioxide in the curing chamber to reduce their subsequent shrinkage. Hollow concrete masonry is typically constructed with mortar applied only to the face-shells of the units (face-shell bedding).
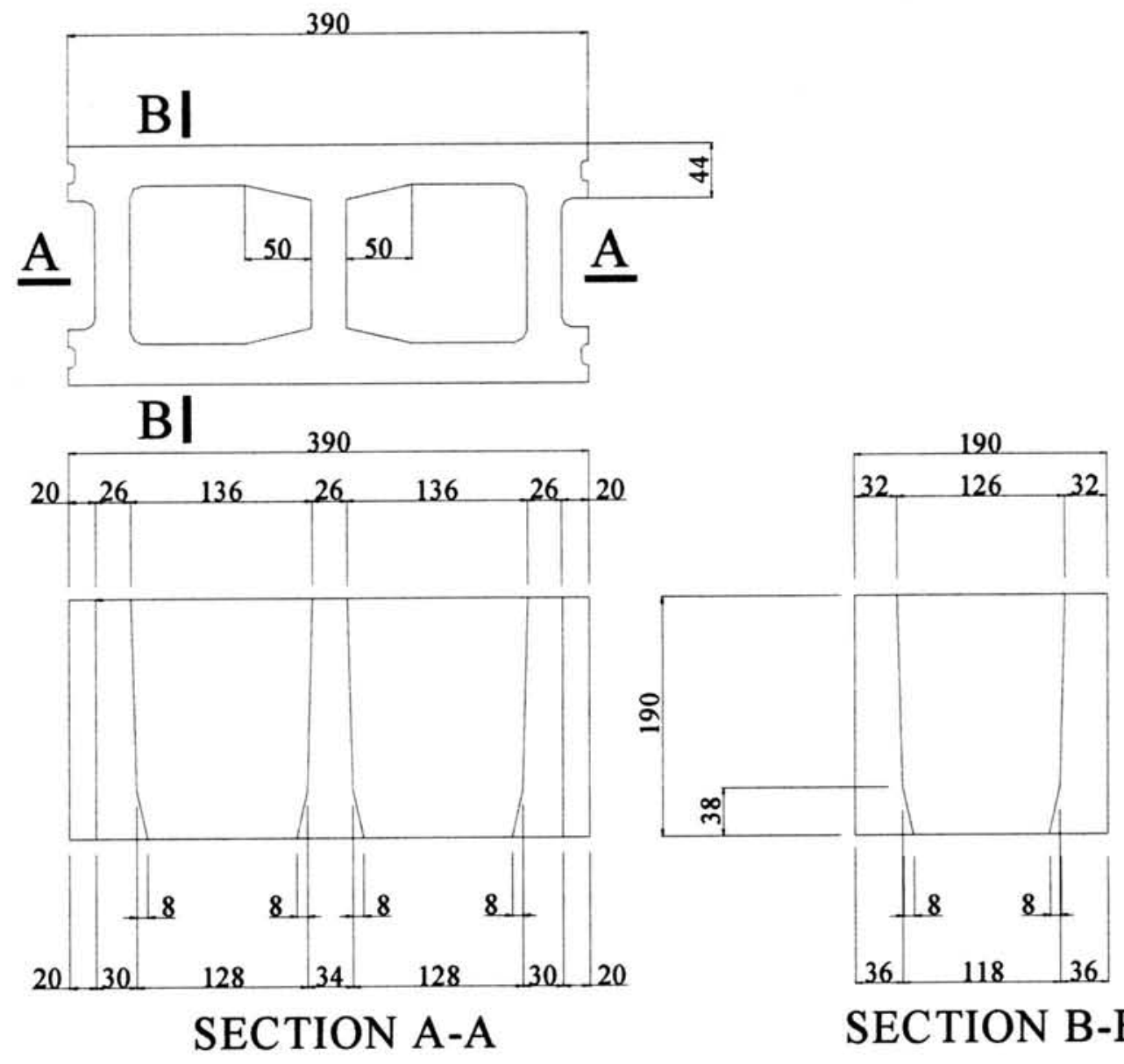

SECTION A-A

SECTION B-B

Fig. 1.3---Typical standard concrete block 
Masonry has been used traditionally to resist compression, and it is in this role that it is still used most extensively. The compression elements where masonry is most commonly used are load-bearing walls, although masonry can also be used for columns and beams when suitably reinforced. In recent decades, the number of stories in masonry buildings has increased substantially and the bearing wall thickness has decreased by an even larger factor. This has been made possible through improved methods of analysis, improved materials and the use of steel reinforcing. However, innovative applications of structural masonry are hindered by the fact that the development of design rules has not kept pace with changes in industry products and practice. One underlying reason is the lack of insight into the complex behaviour of units, mortar, joints, grout, and masonry as a composite material.

Concentrated loads are often applied to load-bearing masonry walls through various structural elements such as cross beams, roof trusses, joists, and prestressing anchorages. For solid masonry, the state of stress immediately under a concentrated load is one of biaxial compression and the effective compression strength within the local bearing area is increased. As a result, enhancement of masonry strength is usually allowed for the masonry immediately under the load. In the case of hollow masonry, however, this enhancement is open to question because of the stress complexity under the concentrated load and the lack of the knowledge on its behaviour. Despite the wide use of hollow masonry, only a little is known about its behaviour when subjected to concentric concentrated loads (Page and Shrive 1990; Sayed-Ahmed and Shrive 1996; Shrive and 
Sayed-Ahmed 1997), and virtually nothing when subjected to eccentric concentrated loads (Xie et al. 1993).

Owing to the distinct and substantial lack of knowledge on the subject, no strength enhancement is allowed for hollow masonry walls under concentrated loads in both the Australian and Canadian codes of practice. Further, there is no mention of eccentric concentrated loading. However, in practice, compressive loads may not be applied uniformly and are frequently applied with out-of-plane eccentricities. Indeed, the Canadian Masonry Design Standard requires that a minimum eccentricity (0.1t) of load be considered in structure analysis and design (CSA S304.1-94).

To establish more rational design rules for hollow masonry walls subjected to concentrated loads, a large number of analytical studies and experiments are required because of the large number of geometric, material, and load variables involved. With the development of the finite element method, research into the structural behaviour of hollow masonry such as its failure mechanisms and strength under compression can be performed with numerical analyses. Satisfactory results can be obtained provided that the material constitutive laws are adequate to simulate the failure mechanisms observed experimentally, the geometric shape is modelled accurately, the finite element mesh is sufficiently fine, and the models are verified by specific tests. Realistic finite element models capable of simulating the structural behaviour of hollow masonry would save the cost of a large experimental programme, and also lead to an excellent understanding of the behaviour of hollow masonry. 


\subsection{Objectives of the Research Programme}

The objectives of this research are, therefore:

(1) To develop 3D non-linear finite element models for face-shell bedded hollow concrete masonry, which have the ability to simulate actual structural behaviour under both concentric and eccentric loads.

(2) To investigate the failure mechanisms of hollow masonry under both concentric and eccentric loads.

(3) To obtain the strength of hollow masonry under both concentric and eccentric loads.

(4) To obtain the stress distribution and load dispersion in hollow masonry under concentrated load.

(5) To suggest design rules for codes of practice and ways to improve masonry performance.

\subsection{Scope of the Research Programme}

Several typical types of face-shell bedded hollow masonry were first modelled. An experimental programme was then performed to verify numerical predictions. Finally, design rules are proposed.

1. 3D non-linear finite element models capable of simulating the structural behaviour of face-shell bedded hollow concrete masonry prisms under both concentric and eccentric compressive loading are developed first. Two different kinds of crack modelling (smeared and discrete) approaches are used. The blocks 
and mortar are modelled separately. Shell elements and gap elements are used. Geometric and material non-linearity as well as damage due to progressive cracking are taken into account in the models. The model results are compared to the experimental behaviour of similar prisms (Becica et al 1983; Drysdale and Hamid 1983; Maurenbrecher 1983 and 1990; Guo 1991; Xie 1998). Some applications are also made to investigate some important parameters affecting structural behaviour of hollow masonry.

2. Six-unit wide by nine-course high face-shell bedded hollow masonry walls with and without bond beams subjected to both concentric and eccentric concentrated loads are then modelled. The results are compared to the experimental behaviour of similar wall tests available (Page and Shrive 1990) and verified. The models are analyzed to investigate their structural behaviour under eccentric concentrated load and when concentrated loads approach to the end of the wall.

3. 3D non-linear finite element models of partially grouted hollow masonry walls subjected to both concentric and eccentric concentrated loads are consequently analyzed. The grouting patterns immediately beneath the loading plate include rectangular (one-block), pyramid and wedge patterns. The results are compared to the experimental behaviour of similar wall tests available (Shrive and SayedAhmed 1997) and verified first. The models are then used to investigate their structural behaviour under eccentric concentrated load and when concentrated loads and grouting patterns approach to the end of the wall. Wall models with vertical columns of grout are also developed. When the concentrated load is 
applied on the column, the results show different failure modes from that when the load is applied on the bond beam and on the hollow blocks.

4. An experimental programme is performed to investigate the structural behaviour of hollow masonry walls with vertical columns of grout, subjected to concentric and eccentric concentrated loads applied on the bond beam and on the vertical columns. The experimental results confirm the model results.

5. Finally design rules for hollow masonry walls subjected to concentrated loads are proposed, including checking two possible zones of failure: the grouted/solid masonry immediately beneath the loading plate, and hollow blockwork beneath the grouted/solid masonry. 


\section{CHAPTER 2}

\section{LITERATURE REVIEW}

\subsection{Introduction}

The trend towards ultimate strength methods of design and analysis of masonry structures has focused attention on the need for a better understanding of the failure mechanisms of masonry. To develop realistic finite element models for masonry, the structural behaviour of masonry under load also has to be kept clearly in mind so that the development of finite element models can be followed. Many theories were presented to explain the failure mechanisms in masonry and to describe the modes of failure. A review is given of published research results such as failure mechanisms of masonry under compression, and finite element models for masonry. Some current codes of practice from different countries are also introduced in this chapter.

\subsection{Failure Mechanism of Masonry Subjected to Concentrated Loads}

To improve the analysis and design methods of masonry structure, understanding of the failure mechanisms is the first important issue.

\subsubsection{Solid masonry}

The failure mechanism of solid masonry walls subjected to in-plane concentrated loads is well documented. A brief summary of these studies is introduced here. 
Hendry (1981) carried out a series of tests on solid clay brick masonry piers subjected to concentrated loads. He concluded from these tests that the load position is less important than the degree of concentration of the loading and suggested simplified rules for the strength enhancement under the load: an increase of $10 \%$ in compressive strength for each $10 \%$ by which the loaded area is less than $50 \%$ of pier area.

Dai-Xin (1985) studied the bearing strength of solid clay brick masonry by testing a large number of wallettes with and without reinforcement subjected to concentric and eccentric load using different loaded area ratios. Different modes of failure were observed depending on the size of the loading plate. Three basic failure modes were reported: failure due to vertical cracking, splitting failure and local failure within the bearing area. Mann et al. (1985) proposed a failure theory for solid masonry walls subjected to concentrated loads based on elastic theory and a simplified failure criterion. They compared their theory with published experimental results and found good agreement. Arora (1986) performed an experimental investigation consisting of concentrated loading tests on over 50 masonry wall specimens, which were mainly $1.8 \mathrm{~m}$ wide and $1.4 \mathrm{~m}$ high. The program involved varying the position and length of the loaded area, with the width of the loaded area covering the full wall thickness. The compressive strength enhancement, the failure modes and the load dispersion aspects were investigated. He found that the failure mode is a function of the bearing area of the concentrated load and its position of application on the wall. When the loaded area was small, the failure was initiated by a tensile crack along a vertical line directly under the load, followed by diagonal cracking from the edges of the load and finally culminating in local crushing 
under the load. When the loaded area was large, the final failure was by more general cracking. He also found the strength enhancement under concentrated load to be a parabolic function of the wall compressive strength, and the variation of strength enhancement over the wall length to be parabolic. A general formula was proposed for the prediction of strength enhancement.

Malek and Hendry (1986) tested 296 brickwork masonry wallettes (nominally $665 \mathrm{~mm}$ in length, $590 \mathrm{~mm}$ in height and with two thicknesses, $102.5 \mathrm{~mm}$ and $215 \mathrm{~mm}$ ) subjected to concentrated load. The effects of loaded area ratio, load position, brick strength and masonry strength were examined with reference to the strength enhancement factor, based on the characteristic compressive strength. They found that the appearance of the primary vertical crack in relation to failure of the specimen depended on the loaded area ratio, and that the failure modes were like those observed by Arora (1986). They also found that the strength enhancement was principally affected by loaded area ratio, and dependent on load position and brick strength. They derived some curves statistically giving the relationship between the enhancement factor and load area ratio.

Page and Ali (1987) carried out a numerical study of the behaviour of 48 solid concrete block masonry walls subjected to concentrated loads using a non-linear finite element model, with various combinations of loaded area ratio, load location and wall geometry being considered. They showed that in many cases the bearing strength of the masonry wall beneath the concentrated load was significantly enhanced by the constraining effect of the more lightly stressed surrounding material, with the degree of enhancement being a function of the loaded area ratio, the load location and the wall size. 
Deriving from all previously reported experimental and analytical studies, Page and Hendry (1988) presented comprehensive design rules for the degree of bearing strength enhancement in solid masonry walls subjected to concentrated load. The bearing strength enhancement is a function of the loaded area ratio and the load location, with all other variables such as material type, load type and specimen geometry being absorbed in the general scatter of test results. The design rules are incorporated in the current Australian code of practice (AS 3700-1998).

In general, the behaviour of solid masonry subjected to concentrated load is like that of concrete, with a typical failure by vertical splitting in the region beneath the load, as shown in Fig. 2.1.

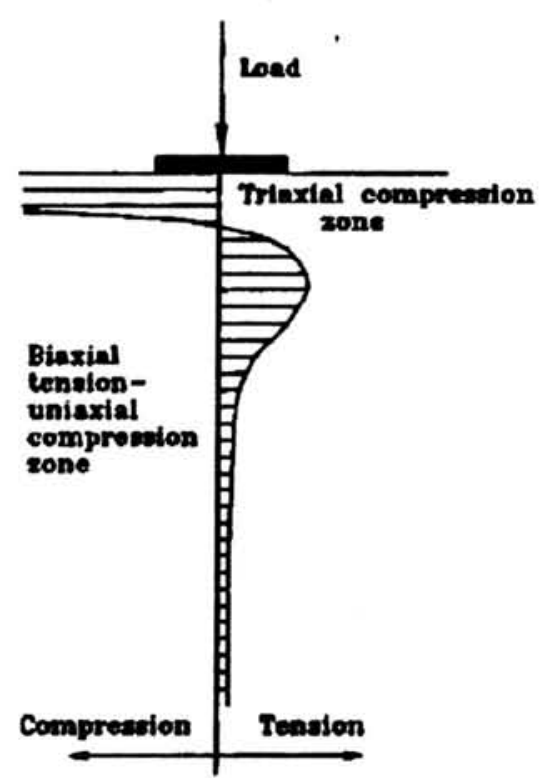

a) Tranoverse strens dirtributlons directely under the lond.

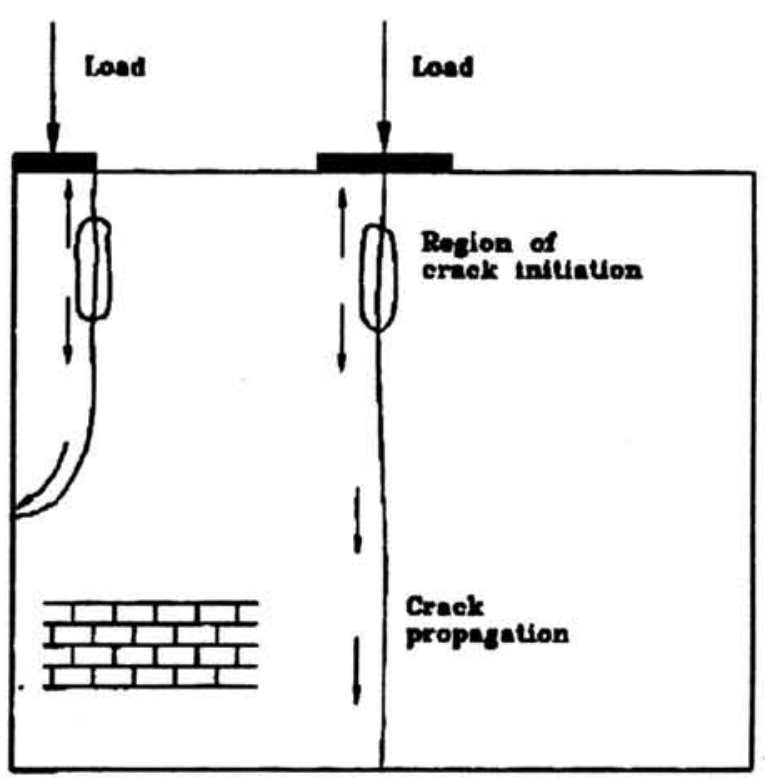

b) Typical crackins patlorns for conoentrated loods ipplied at the edze and at the cemtre line of a wall.

Fig. 2.1---Failure modes of solid masonry subjected to concentrated loads 


\subsubsection{Hollow masonry}

In contrast to the extensive research performed on the behaviour of solid masonry subjected to concentrated load, very few investigations have been performed on hollow concrete masonry. And in contrast to a solid homogeneous material, the mechanism of load transfer in face-shell bedded hollow concrete masonry is complex due to three dimensional effects - the load below the loading plate is transferred to the face-shells and webs, and also to the grout; and then transferred to the face-shells beneath, with secondary effects being induced by local bending of the webs and face-shells.

Kirtschig et al. (1979) tested masonry walls subjected to three types of concentrated loads: load over the whole width of the wall, load over one half of the wall width and load at the end of the wall. They made their tests on hollow brick, sand lime brick, hollow block stone and concrete block walls. They showed that a higher pressure stability was present with partial surface load independent of the type of bricks and that the breakage stress increased with smaller load surfaces. Simple empirical relations were obtained in terms of the loading plate size and the eccentricity.

Simbeya (1985) studied the distribution of stresses in concrete block masonry subjected to concentrated load using three dimensional finite element analyses. He assumed homogeneous, isotropic linear elastic material with perfect bond between mortar and units. The bulk of the analyses were carried out on hypothetical walls and only a limited number of tests on actual walls were performed. Three kinds of concrete block walls were investigated: solid masonry, hollow masonry and hollow masonry with bond beam. 
Simbeya predicted that hollow masonry subjected to concentrated load would fail with the same failure mechanism as hollow masonry subjected to uniform compression.

Page and Shrive (1990) tested 49 wallettes to study the behaviour of face-shell bedded hollow masonry walls subjected to concentrated loads. Some of the wallettes were plain and some with one-course or two-course bond-beam, having dimensions $1600 \times 1400 \times 200$ $\mathrm{mm}$. They found that failure started by web splitting at about $50 \%$ of the ultimate load, and at approximately the same load a vertical crack formed normal to the wallette plane and in line with the load as found in the solid masonry wall. They concluded that the failure mode is by progressive splitting of the webs of the hollow block units in the region beneath the load, and the vertical cracking seems not to affect the failure of hollow masonry wall. In the rest of their work, Page and Shrive studied the effect of other parameters on the failure of hollow block masonry wall and found that neither the ultimate load nor the mode of failure were significantly affected by a wide variation in the bond beam grout strength. They confirmed by this work that the theory of failure of solid masonry walls subjected to concentrated loads does not apply to hollow masonry walls.

Shrive and Sayed-Ahmed (1997) executed an experimental program to study the effect of the grout configuration on the behaviour of hollow concrete masonry walls subjected to concentrated load. They tested 18 walls having dimensions of $2400 \times 2000 \times 200 \mathrm{~mm}$ with 6 different grout configurations used. The investigation confirmed that grouting some of the hollow block units under the concentrated load does increase the wall capacity, and that a pyramid configuration of the grout provided a higher bearing capacity than a wedge 
configuration. They also confirmed that the failure mechanism starts by web splitting at a load level about $50 \%$ of the maximum bearing capacity of the wall, followed by faceshell rotation leading to either mortar crushing or local spalling of the face-shells underneath the load.

In general, the failure mode of hollow masonry is like that shown in Fig. 2.2, different from solid masonry.

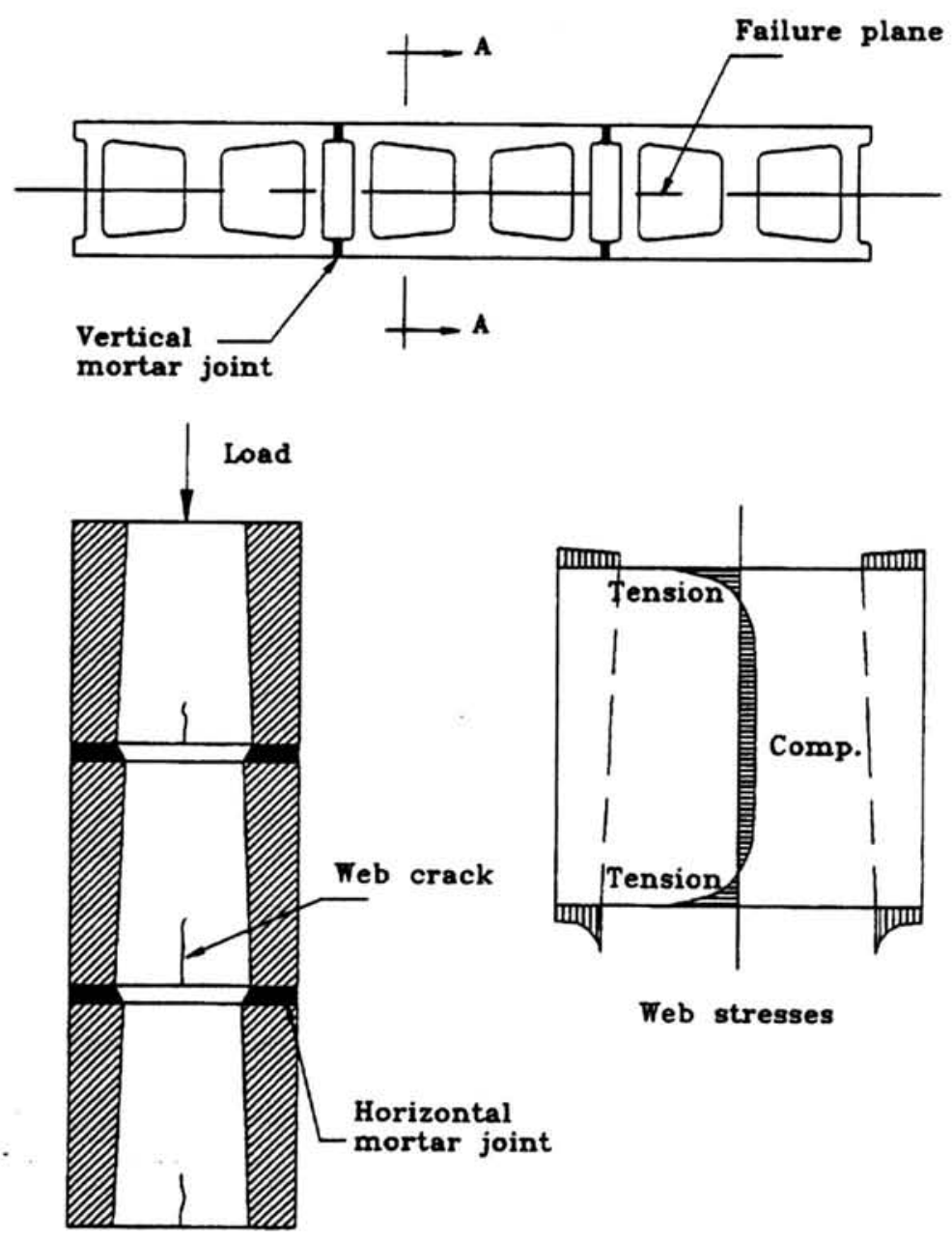

Section A-A

Fig. 2.2---Failure of face-shell bedded hollow masonry starting by web cracking 


\subsection{Finite Element Models for Masonry}

The finite element method is a general technique of structural analysis by means of which the solution of a problem in continuum mechanics may be approximated by considering the continuum as an assemblage of interconnected finite elements. Normally the structure geometry, material properties, element types and boundary conditions are used as input in finite element models. While nodal displacements and reactions, internal stresses and strains in the structural elements are the main output. Realistic finite element models can lead to an excellent understanding of the structural behaviour.

\subsubsection{Finite element models for solid masonry}

A two-dimensional finite element model can generally be used to simulate the structural behaviour of solid masonry subjected to concentrated load, as its failure mechanism is just by vertical cracking down the wall. Many numerical models were proposed for solid masonry; only a brief summary is presented here.

Khoo (1972) used plane stress finite element analyses to study lateral stress distribution in axially loaded masonry prisms. He used a recycling technique for region of stress concentration to achieve a higher degree of accuracy.

Ganju (1977, 1981) proposed a non-linear finite element model for predicting the ultimate load and cracking sequence of brick masonry walls. He used constant strain triangular elements for both bricks and joints with a Mohr-Coulomb criterion for yielding and a limiting tensile strain criterion with brittle collapse. 
Page (1978) proposed a non-linear, non-homogenous finite element model capable of predicting the non-linear deformations and progressive cracking of the joints. He used plane stress elements for bricks and one-dimensional interface elements for mortar joints. Non-linear deformation, cracking under tensile stresses and sliding under shear and compressive stresses were all considered for joint elements, while brick elements were assumed to remain elastic.

Ali and Page $(1987,1988,1989)$ developed a non-linear model for solid block masonry subjected to concentrated loads. They modelled blocks and mortar separately by plane stress elements. A constitutive material model, which had non-linear material characteristics and was capable of modelling progressive cracking failure of blocks and mortar joints, was used. They also used the substructuring technique for large size walls. They checked the numerical results by performing a limited experimental program on some masonry wallettes subjected to concentrated loads. The numerical results compared well with the experimental results.

Riddington and Naom (1994) described a finite element program for the purpose of predicting the ultimate compressive strength of masonry. In their program, bricks and mortar were represented separately by 4-node plane stress rectangular elements, and the brick-mortar interface was represented by a series of link elements which were fictitious linear elements with zero length and very high stiffness that join a node on the brick with the opposite node on the mortar along an interface. The failure criteria for brick tension, mortar tension and brick-mortar interface were included. The non-linearities due to mortar and progressive failure were taken into account. Their numerical results showed 
good agreement with experimental results. They found that when mortar non-linearity was not included, the ultimate compressive strength was overestimated. Their study also showed a decrease in the ultimate compressive capacity with an increase in the mortar thickness, and that an increase in brick tensile strength results in an increase in the compressive capacity.

Lotfi and Shing (1994) developed a dilatant interface constitutive model capable of simulating the initiation and propagation of interface fracture under combined normal and shear stresses in both tension-shear and compression-shear regions. They used the interface elements to model mortar joints in unreinforced masonry structures subjected to lateral loads, together with smeared crack elements for masonry units. Mehrabi and Shing (1997) used this model in their study of the performance of masonry-infilled RC frame. They showed that the models could simulate the failure mechanism and the ultimate strength in good agreement with those obtained from the tests.

Lourenco et al. $(1997,1998)$ presented an anisotropic continuum model for analysis of masonry structures. The approach they adopted consisted of an extension of conventional formulations for isotropic quasibrittle material to describe orthotropic behaviour. They developed the constitutive model in a plasticity framework according to a phenomenological approach in which the observed mechanisms are represented in such a fashion that simulations are in reasonable agreement with experiments. A Rankine-type yield criterion for tension and a Hill-type yield criterion for compression were included in the model. The model was shown to predict efficiently the behaviour of masonry structures. 


\subsubsection{Finite element models for hollow masonry}

Many attempts have also been made to simulate the structural behaviour of hollow concrete blockwork using finite element method. Unfortunately, some of them used two dimensional plane elements and modelled the behaviour of hollow concrete blockwork as a whole rather than monitoring the behaviour according to its geometric shape and making distinction between block units and mortar joints; some others used threedimensional linear elastic models only.

Rahman (1986) and Rahman and Suter (1993) examined thermal stress in hollow masonry using a linear two-dimensional finite element macro-model. They used layered shell elements with smeared material properties for both blocks and joints. Three layers were used: two outer layers represent face-shells and mortar joints, and inner layer represents the block webs and the grout columns (if any).

Hosny et al. (1990) used one-dimensional joint elements in a two-dimensional finite element model to analyze hollow masonry wallettes. They used layered plane stress elements for the blocks, grout and bond-beams beside joint elements modelling the bed and head joints. In this model, they introduced the non-linear behaviour of both blocks and joints. Failure of mortar joints due to slipping or debonding was also considered.

Middelton et al. (1991) introduced a smeared macro-model. Their main objective was to develop a finite element model capable of dealing with the overall behaviour of a large wall instead of tracing the failure of small specimens. By assuming that the wall size is much larger than the size of units or joints, they derived a stress-strain relationship by 
averaging the properties of both units and joints. They assumed linear isotropic behaviour for masonry. Two-dimensional plane stress elements were used.

Maksoud and Drysdale (1992) developed another smeared macro-element non-linear finite element model, which accounted for material and geometric non-linearities for hollow masonry walls subjected to axial and out-of-plane loading. The macro-element included three-layer 9-node shell element with the mid-layer representing the webs, cores and grout. Each macro-element had dimensions of $400 \times 400 \mathrm{~mm}$ which included a total of $20 \mathrm{~mm}$ thickness of mortar joint and two blocks.

Cerioni and Donida (1994) presented a materially non-linear layered finite element model for the analysis of reinforced and/or prestressed masonry wall. The model was based on a macro-level composite steel/concrete model, which adopts a smeared coaxial rotating representation of cracks and accounts for tension stiffening, strain softening, stress degrading effect for concrete parallel to crack direction, interlock, and dowel-action.

Wang et al. (1997) developed a non-linear finite element model to simulate the behaviour of tall masonry cavity walls subjected to eccentric loads. They used three-node quadratic beam elements for masonry assemblages and three-node quadratic beam elements with hybrid formulation for the shear connector. In their model, all element property matrices were obtained using a two-point Gaussian integration rule along the beam element axis and a five-point Simpson integration rule across the thickness at each of the Gauss point. The non-linear material behaviour of all components as well as the large displacement, small strain characteristics of the deformation were accounted for. 
Liu and Dawe (2000) introduced another finite element model simulating the beamcolumn response of masonry walls, using beam elements. In their model, a masonry wall was divided into several beam elements of equal length along its height. Equilibrium conditions for a cross-section subjected to axial load and moment were used to establish a moment-curvature relationship, which recognize the non-linear stress-strain nature of masonry in compression, the presence of steel reinforcing, and the effects of cracking.

In all of the previous models, hollow masonry was simplified as a whole and its structural behaviour was modelled by using two-dimensional analyses. However, the failure mechanism of face-shell bedded hollow masonry under compression is by progressive splitting of the webs and followed by spalling of face-shells and/or crushing of mortar, its structural behaviour need to be simulated by three-dimensional numerical model.

Shrive (1982) used three-dimensional twenty-node continuum elements to analyze twoblock high face-shell bedded prisms. The taper of the face-shells and webs, and the change in the horizontal mortar joint thickness were all considered in this model. A linear elastic analysis was done.

Khalil (1983) performed linear elastic three-dimensional finite element analyses on grouted and ungrouted concrete block prisms and wallettes. He provided insight to the stress distribution in hollow masonry at the working stress level.

Cheema and Klingner (1986) introduced a three-dimensional numerical model for concrete masonry prisms, with geometric shape of the block unit considered, and mortar 
and block unit modelled separately. Only linear material properties were included in the model with material non-linearity was accounted for by using secant moduli for all materials.

Afshari and Kaldjian (1989) introduced a three-dimensional finite element model for concrete masonry prisms, in which the physical and geometric properties of mortar and concrete block unit were considered and failure envelopes for mortar and block unit were established from relevant experiments, to predict the behaviour and ultimate strength of concrete block masonry prisms or assemblage under axial compressive loading. Again, only linear material properties for concrete blocks, grout, and mortar were included in the model.

Ganesan and Ramamurthy (1992) used a finite element program adopting 8-node isoparametric solid element for three-dimensional analysis of hollow block masonry prisms. The effect of different parameters (such as type of hollow-block geometry, bonding arrangements, type of mortar bedding, and mortar material properties) on the behaviour of masonry prisms under axial compression was investigated. Unfortunately, it was still a linear elastic analysis.

The linear elastic analyses showed that the stresses in the mortar joints and some locations in the block units are high enough to start the non-linear behaviour of both materials, and it was reported that the ultimate compressive strength would be overestimated when mortar non-linearity was not included (Riddington and Naom, 1994). On the other hand, progressive web cracking causes the face-shell to rotate and thus 
geometric non-linearity occurs. Hence, linear elastic finite element models of hollow masonry cannot predict realistic behaviour of the failure of hollow masonry. Non-linear finite element modelling is required.

Sayed-Ahmed and Shrive $(1995,1996)$ developed a three-dimensional non-linear finite element model for face-shell bedded hollow masonry, with concrete block units and mortar being modelled separately, and face-shell and web taper included. The non-linear behaviour of the hollow masonry in compression due to progressive web cracking and the geometric and material non-linearities are monitored in this model. The model showed the ability to track the behaviour of face-shell bedded hollow masonry from the first appearance of web cracking almost to final failure under concentric load. However, the use of symmetry limited this model only to being able to simulate the behaviour of hollow masonry under axial concentric load.

In practice, compressive loads may not be applied uniformly and are frequently applied with out-of-plane eccentricities. Therefore, in order to design concentrated load-bearing details safely, it is necessary to understand the structural behaviour of hollow concrete masonry subjected to eccentric loading. A more general and realistic three-dimensional non-linear finite element model for face-shell bedded hollow masonry needs to be developed.

\subsection{Codes of Practice}


1. The British code of practice (BS 5628: 1978) allows $25-50 \%$ increase in the permissible stress for masonry subjected to concentrated load depending on the type of bearing. The load is dispersed into the wall at an angle equal to $45^{\circ}$ from the edge of the loaded area.

2. The German code of practice (DIN 1053: 1985) incorporates a formula for the magnification factor to allow the strengthening effect beneath the concentrated load. This formula takes into consideration the loaded area ratio as well as loading position.

3. In the Swedish code (Lattbetong Ab: 1974), local pressure is considered to occur when the length of the contact area in the longitudinal direction of the wall is less than twice the thickness of the wall or one third of its width.

4. The Danish code of practice (DS 414: 1984) allows the compressive strength to be increased by $50 \%$ for concentrated load action when the surrounding masonry gives sufficient lateral support. The vertical reaction from the concentrated load is distributed evenly with a slope $1: 2$ (horizontal to vertical) in the plane of the wall as well as perpendicular to the wall.

5. The uniform building code (American TMS: 1992) allows an enhancement of about $46 \%$ for bearing stresses if one third-or less- of the total area is loaded, using the following design rule: 
When the full area is loaded: $\mathrm{F}_{\mathrm{br}}=0.26 \mathrm{f}_{\mathrm{m}}{ }^{\prime}$

When one third of the area is loaded: $\mathrm{F}_{\mathrm{br}}=0.38 \mathrm{fm}^{\prime}$

where $\mathrm{F}_{\mathrm{br}}$ is the allowable bearing stress, $\mathrm{f}_{\mathrm{m}}$ ' is the specified 28 -day masonry compressive strength. The enhancement is only allowed when the distance (the loading plate edge to the wall edge) exceeds one fourth of the plate width, as shown in Fig. 2.3.

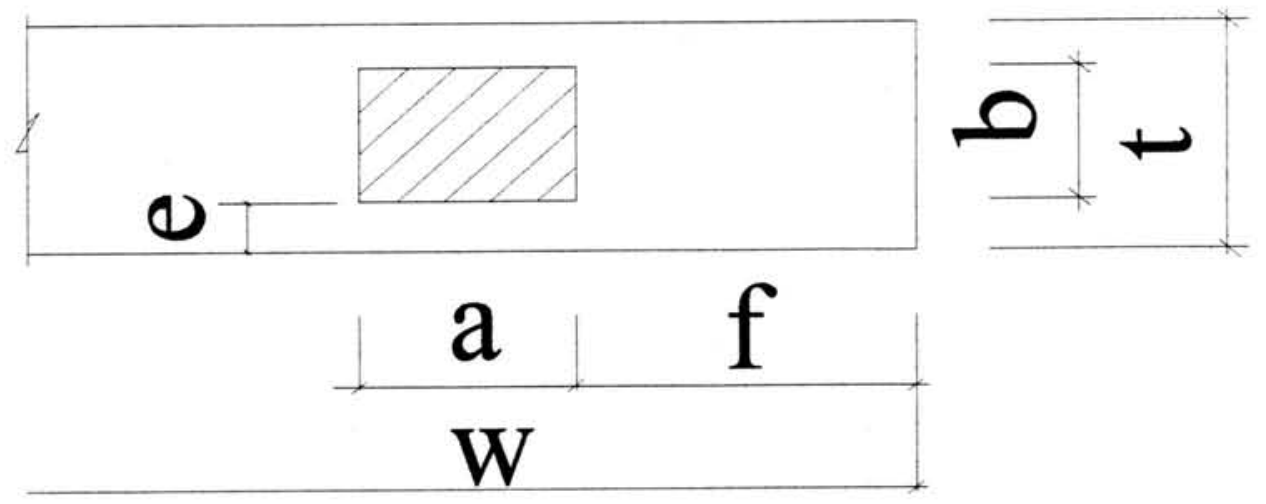

Strength enhancement is allowed if $\mathrm{e}>\mathrm{b} / 4, \mathrm{f}>\mathrm{a} / 4, \mathrm{w} \times \mathrm{t} / 3 \geq \mathrm{a} \times \mathrm{b}$

Fig. 2.3---Bearing area defined by the UBC 1992

6. The Masonry Standard Joint Committee (ACI 530/ASCE 5/TMS 402, 1999) design provisions (MSJC) for calculating compressive stresses under concentrated loads are illustrated in Fig. 2.4, in which local bearing stress under a load needs to be checked to safeguard against local crushing or splitting. For cases where there is no bond-beam under the load, the MSJC calculation for bearing stress under the load distributes the load over an area determined as follows: 

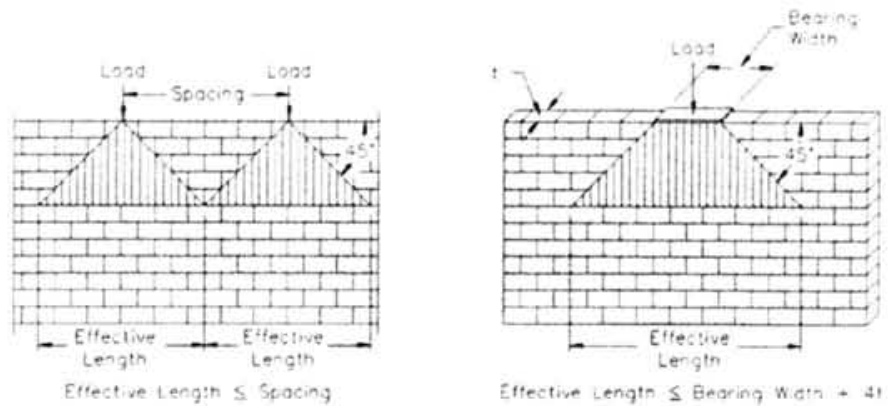

(a) Running Bond
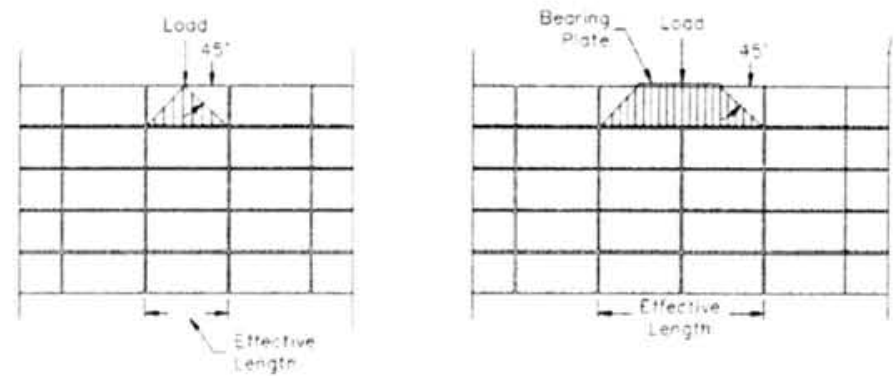

(b) Other than Runn ng Eord
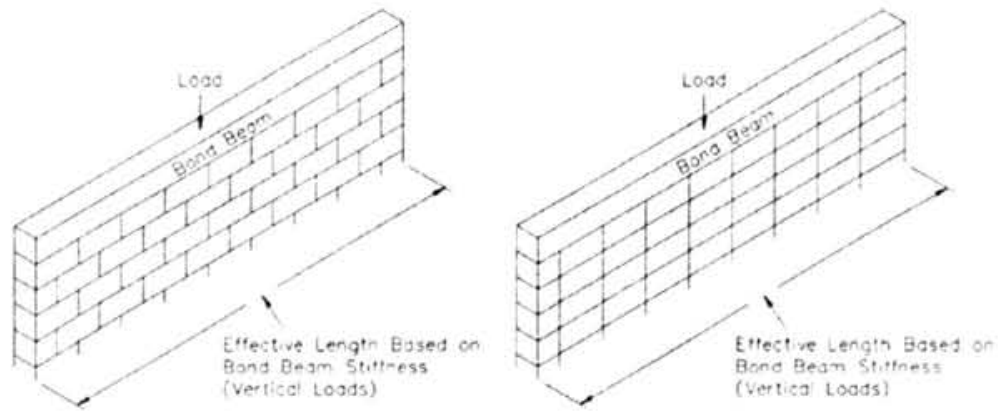

(c) Win Bong Bear
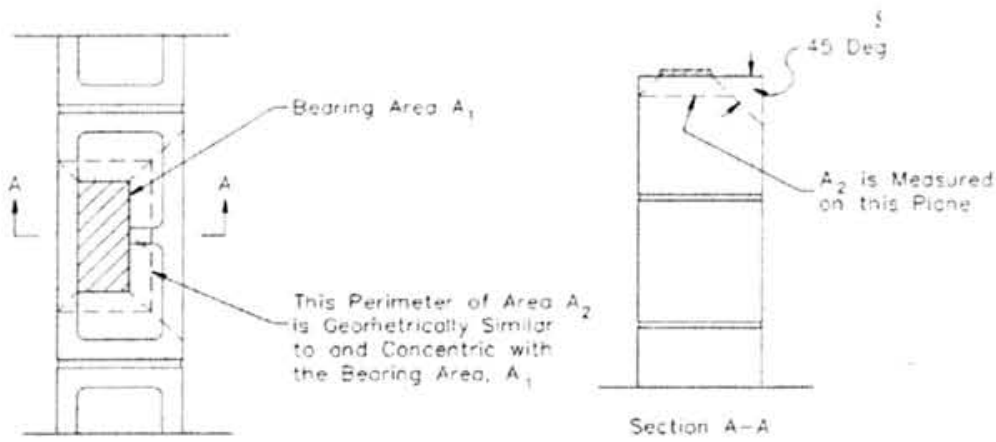

Plan

Fig. 2.4---Load dispersion and bearing area of concentrated loads - MSJC code 
(a) The direct bearing area $A_{1}$ or;

(b) $A_{1} \times\left(A_{2} / A_{1}\right)^{1 / 2} \leq 2 A_{1}$, where $A_{2}$ is the supporting surface wider than $A_{1}$ on all sides, or $\mathrm{A}_{2}$ is the area of the lower base of the largest frustum of a right pyramid or cone having $A_{1}$ as upper base, sloping at $45^{\circ}$ from the horizontal and wholly contained within the wall (the line connecting the centroids of area $A_{1}$ and $A_{2}$ must be vertical). For walls in other than running bond, area $A_{2}$ should terminate at the head joints.

According to the MSJC code, the calculated bearing stress should not exceed $25 \%$ of the specific masonry compressive strength for working stress design. For cases when bondbeams are included, the dispersion of bearing stress can be determined on the basis of relative stiffness (e.g.: a beam on an elastic foundation).

7. The Australian code of practice (AS 3700-1998) assumes an angle of dispersion equal to $45^{\circ}$ (from the horizontal) starting from the edge of the loaded area, but the dispersion shall not extend into the dispersion zone of an adjacent concentrated load or beyond the structural end of the masonry. The code allows strength enhancement when subjected to concentrated load where the design bearing strength of the member $F_{d}$ is increased by

$$
\mathrm{F}_{\mathrm{d}} \leq \mathrm{k}_{\mathrm{b}} \mathrm{F}_{\mathrm{o}}
$$

where $F_{o}$ is the basic compressive strength capacity of the cross-section, $k_{b}$ is the concentrated load bearing factor. The bearing factor $\mathrm{k}_{\mathrm{b}}$ is defined as follows:

(a) Other than in solid or cored unit masonry or grouted masonry, $\mathrm{k}_{\mathrm{b}}=1.00$;

(b) In solid or cored unit masonry, or in grouted masonry, 


$$
\begin{aligned}
& k_{b}=0.55 \frac{\left(1+0.5 \frac{a_{1}}{L}\right)}{\left(\frac{A_{d s}}{A_{d e}}\right)^{0.33}} \\
& \text { or } \quad k_{b}=1.50+\frac{a_{1}}{L}
\end{aligned}
$$

whichever is less, but $\mathrm{k}_{\mathrm{b}}$ is not less than 1.00 .

where:

$a_{1}=$ the distance from the end of the wall or pier to the nearest end of the bearing area;

$\mathrm{A}_{\mathrm{ds}}=$ the bearing area of a concentrated load in a member;

$A_{d e}=$ the effective area of dispersion of the concentrated load on the member at midheight, where concentrated loads are applied in close proximity to each other, the value of $A_{d e}$ is $L_{e} t$;

$\mathrm{L}=$ the clear length of the wall or pier;

$L_{e}=$ the effective dispersion length of the load;

$t=$ the overall thickness of a masonry member cross-section perpendicular to the principal axis under consideration.

The parameters are shown in Fig. 2.5. 

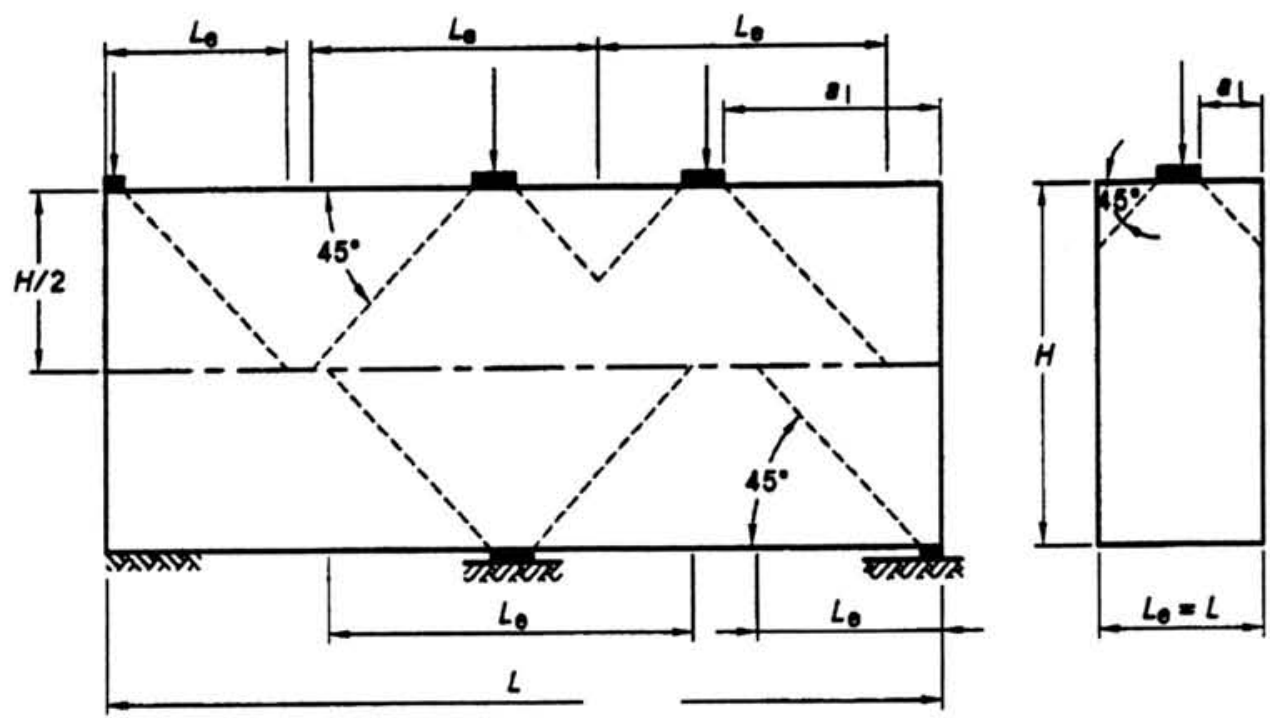

Fig. 2.5---Loading position and effective areas of dispersion defined by AS 3700-1998

8. The Canadian code of practice (CAN S304.1-94) assumes the load dispersion to occur at an angle of $45^{\circ}$ from the outer edge of the bearing plate for solid unit brick masonry and an angle of $30^{\circ}$ to the vertical for all other masonry. The dispersion downward shall not extend into the dispersion zone of an adjacent concentrated load or beyond the structural end of the masonry such as movement joint. The factored bearing resistance of masonry, $\mathrm{B}_{\mathrm{r}}$, is calculated as

$$
B_{r}=0.85 \phi_{m} f_{m}^{\prime} A_{1}
$$

where $\phi_{\mathrm{m}}$ is the resistance factor for masonry, and is 0.55 if used in checking ultimate limit states for compression, tension, shear and bearing; $f_{m}^{\prime}$ is compressive strength of masonry at 28-day; $A_{1}$ is the bearing area. 
9. The Chinese code of practice (GBJ 3-88) allows strength enhancement for solid and grouted hollow masonry when subjected to concentrated load, where the design bearing strength of the member $N_{1}$ is determined by

$$
\mathrm{N}_{1} \leq \gamma \mathrm{f} \mathrm{A}_{1}
$$

where $f$ is design value of compressive strength of masonry at 28 -day; $A_{1}$ is the bearing area; $\gamma$ is the enhancement bearing factor for concentrated load and can be calculated as

$$
\gamma=1+0.35 \sqrt{\frac{A_{0}}{A_{1}}-1}
$$

where $A_{0}$ is the effective area of dispersion of the concentrated load. $A_{0}$ and $\gamma$ are as:

for Fig. 2.6a: $A_{0}=(a+c+h) h, \gamma \leq 2.5$;

for Fig. 2.6b: $A_{0}=(a+h) h, \gamma \leq 1.25$;

for Fig. 2.6c: $A_{0}=(a+2 h) h, \gamma \leq 2.0$;

for Fig. 2.6d: $A_{0}=(a+h) h+\left(b+h_{1}-h\right) h_{1}, \gamma \leq 1.5$;

For grouted hollow brick/block masonry, $\gamma \leq 1.5$, and the hollow masonry in the effective area $\mathrm{A}_{0}$ must be grouted at least three-block units in depth. The strength of grouting concrete/grout must be higher than that of the block units.

For ungrouted hollow brick/block masonry, $\gamma=1.0$. 
(a)

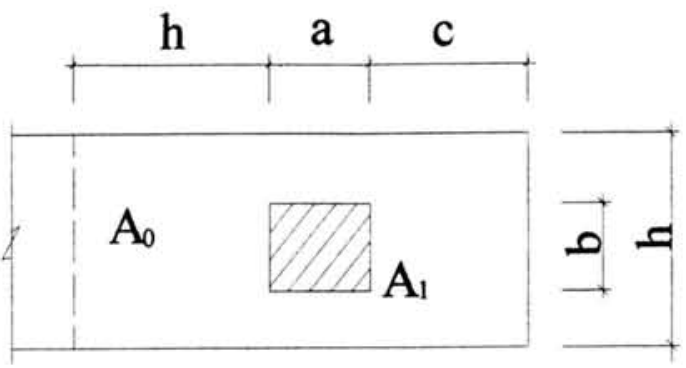

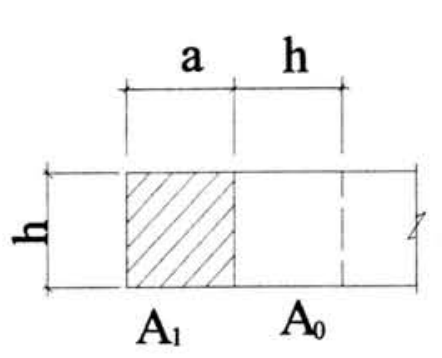

(b)

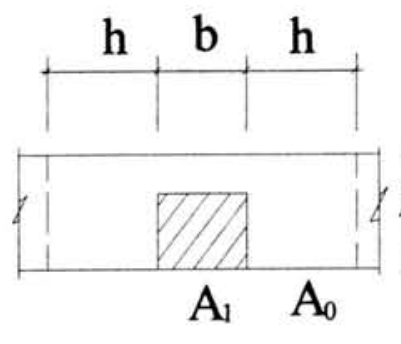

(c)

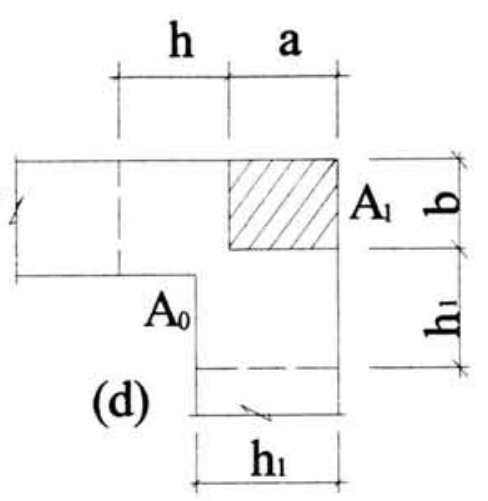

Fig. 2.6---Effective areas of dispersion defined by GBJ 3-88

From the codes of practice listed above, we can see the following deficiencies:

1. Hollow masonry is treated the same as solid masonry in some codes of practice. Because the structural behaviour of solid masonry is different from that of hollow masonry, different treatment should be considered. For example, if a hollow masonry wall subjected to concentrated load is partially grouted or a bond beam is incorporated to obtain extra capacity, the solid masonry (grouted hollow masonry or bond beam) immediately beneath the loading plate and the hollow masonry under the solid masonry should be considered separately, as failure may occur in either part or both.

2. No strength enhancement is allowed in some codes of practice for hollow concrete masonry subjected to concentrated loads. Because of the confining effect of the more 
lightly stressed surrounding material away from the concentrated load, strength enhancement should inevitably exist. Experiments and numerical results have shown that the enhancement factor is in the range of 1.2 to 1.5 for ungrouted hollow concrete masonry walls (Page and Shrive 1990, Sayed-Ahmed and Shrive 1995, 1996). Therefore, the concentrated load bearing factors for hollow masonry in these codes are conservative.

3. When subjected to concentrated load, the stresses throughout a solid masonry wall are determined based on a load dispersion angle equal to $45^{\circ}$ starting from the end of the load bearing area. This dispersion angle was obtained from numerical and experimental results for solid masonry. However, the dispersion angle $45^{\circ}$ is applied by almost all codes of practice to hollow masonry (except the Canadian code using $30^{\circ}$ for hollow masonry) without verification, despite the difference in the structural behaviour of the masonry types when subjected to concentrated loads.

4. There is nothing in the codes about the influence of eccentricity of the concentrated loads on the capacity of face-shell bedded hollow masonry. According to the experiments with hollow masonry prisms performed by Xie et al. (1993 and 1998), a 10\% eccentricity of the applied load leads to a decrease of $6 \sim 18 \%$ of the prism capacity (single or double curvature). Similar conclusions were also obtained by other researchers (Becica et al. 1983, Drysdale and Hamid 1983, Maurenbrecher 1983 and 1990, and Guo 1991).

Hence, more rational design rules for hollow masonry walls subjected to concentrated loads are required. 


\subsection{Summary}

Published research results on the structural behaviour of solid and hollow masonry wall subjected to concentrated loads are reviewed, together with the finite element models for masonry and some current masonry codes of practice from different countries.

The failure mechanism of solid masonry wall subjected to concentrated load is just by vertical cracking down the wall. A two-dimensional finite element model can generally be used to simulate its structural behaviour. However, failure of hollow masonry starts by web splitting in the plane of the wall and ends by face-shell spalling and/or mortar crushing. Three-dimensional finite element model is required to simulate its structural behaviour.

In the current codes of practice for masonry subjected to concentrated loads, either hollow masonry is treated the same as solid masonry, or no strength enhancement is allowed for hollow masonry. There is nothing on the influence of eccentricity of load on hollow masonry.

To establish more rational design rules for hollow masonry walls subjected to concentrated loads, a large number of analytical studies and experiments are required because of the wide ranges of the influencing variables involved. It would be distinctly advantageous if this research could be performed with finite element modelling.

Realistic finite element models capable of simulating the structural behaviour of hollow masonry subjected to both concentric and eccentric concentrated loads need to be developed. 


\section{CHAPTER 3}

\section{ELASTO-PLASTIC FINITE ELEMENT MODEL}

\subsection{Introduction}

Realistic finite element models could help understand the stress distribution, offer insight into the failure mechanism, and can be used for prediction if verified by specific tests, and thus enhance the paucity of experimental results and save the cost of a large experimental programme.

To develop the realistic model for hollow masonry wall subjected to concentrated loads, the failure mechanism and the non-linear responses under load have to be kept in mind. Failure of face-shell bedded hollow masonry wall under compression is initiated from tensile stresses generated at the top and bottom of each web due to a "deep beam" bending mechanism (Shrive 1982), which leads to the splitting of webs of the blocks in the plane of the wall. This, in turn, leads to the relief of web tensile stresses and allows vertical curvature to develop in the face-shells of the hollow masonry. As a result, the mortar joints become highly stressed at the inside edge of the face-shells. Further web cracking in the wall increases the face-shell curvature and leads to local crushing of the mortar joints and/or face-shell spalling, especially in the zones closer to the webs. The non-linear response of face-shell bedded hollow masonry results from non-linear behaviour of its components and progressive cracking. 
Hence, the following should be included in the model: suitable elements able to simulate the face-shell curvature, appropriate cracking methods capable of tracking progressive cracking, geometric non-linearity due to progressive cracking and deformation, inelastic material behaviour and suitable failure criteria, and both concentric and eccentric loading conditions.

Here, non-linear material constitutive laws used in the models are introduced briefly, together with crack modelling methods, finite elements, and non-linear numerical method.

\subsection{Constitutive Material Model}

An appropriate constitutive material model is essential to a meaningful finite element analysis as material properties determine how stiff the elements are and how they will deform. A complete constitutive material model requires the definition of constitutive relations before and after yield, and suitable failure criteria. Hollow masonry consists of at least two materials: block units and mortar, and grout and reinforcement when necessary to obtain extra capacity. Knowledge of material behaviour of each component and their interaction in an assemblage is essential for understanding and modelling the structural behaviour of masonry.

The uniaxial cracking and compression responses of all mortar, concrete block unit, and grout incorporated in the models are illustrated in Fig. 3.1. When the material is loaded in compression, it initially exhibits elastic response. As the stress is increased, some 
irrecoverable (inelastic) straining occurs, and the response of the material softens. An ultimate stress is reached, after which the material softens until it can no longer carry any stress. When a material is loaded in uniaxial tension, it responds elastically until at the ultimate tensile stress, cracks form and the material loses strength through a softening mechanism. In multiaxial stress states these failure responses can be generalized through the concept of a failure surface and of ultimate strength in stress space.

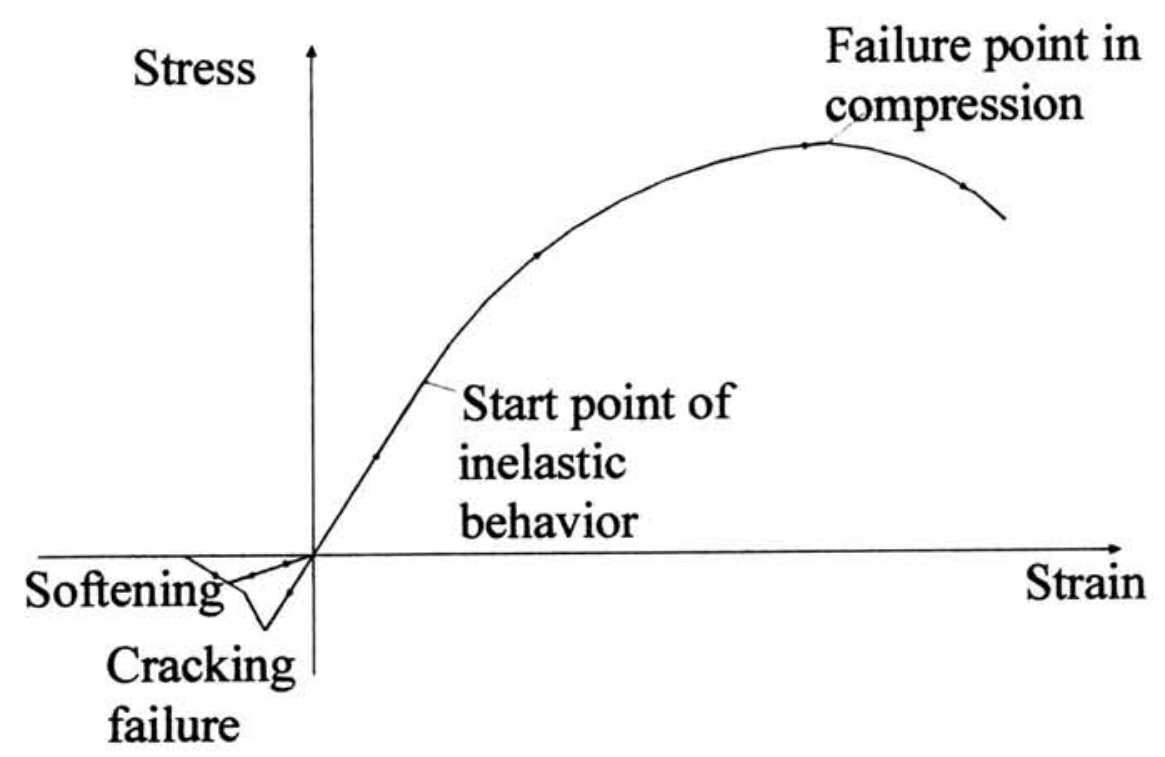

Fig. 3.1---Uniaxial behaviour of mortar, concrete block unit and grout

When the principal stress components are dominantly compressive, all the mortar, concrete block units and grout are modelled by elasto-plastic theory. Simple forms of yield surfaces written in terms of the first two stress invariants are used together with associate flow and isotropic hardening. 


\subsubsection{Compression yield}

The compression yield surface is

$$
f_{c}=q-\sqrt{3} a_{0} p-\sqrt{3} \tau_{c}\left(\lambda_{c}\right)=0
$$

where $p$ is the effective hydrostatic component of stress, defined as

$$
p=-\frac{1}{3} \operatorname{trace}([\sigma])=-\frac{1}{3} \sigma_{i i}
$$

and $\mathrm{q}$ is the Mises equivalent deviatoric stress, defined as

$$
q=\sqrt{\frac{3}{2}[S]:[S]}=\sqrt{\frac{3}{2} S_{i j} S_{i j}}
$$

where $[\mathrm{S}]=[\sigma]+p[\mathrm{I}]$ are the deviatoric stress components; $[\sigma]$ is the stress; $[\mathrm{I}]$ is a unit matrix; $\mathrm{S}_{\mathrm{ij}}=\sigma_{\mathrm{ij}}+\mathrm{p} \delta_{\mathrm{ij}}$ and $\delta_{\mathrm{ij}}$ is the Kronecker delta; $\tau_{\mathrm{c}}\left(\lambda_{\mathrm{c}}\right)$ is a hardening parameter $\left(\tau_{\mathrm{c}}\right.$ is the size of the yield surface on the $\mathrm{q}$-axis at $\mathrm{p}=0$, so that $\tau_{\mathrm{c}}$ is the yield stress in a state of pure shear stress when all components of $\sigma$ are zero except $\sigma_{12}=\sigma_{21}=\tau_{c}$ ); $a_{0}$ is a constant which is chosen from the ratio of the ultimate stress reached in biaxial compression to the ultimate stress reached in uniaxial compression, and is given by

$$
a_{0}=\sqrt{3} \frac{1-\gamma_{b c}^{\sigma}}{1-2 \gamma_{b c}^{\sigma}}
$$

where $\gamma_{b c}{ }^{\sigma}$ is a material constant which is the ratio of biaxial compressive strength to the uniaxial compressive strength:

$$
\gamma_{b c}^{\sigma}=\frac{\sigma_{b c}^{u}}{\sigma_{c}^{u}}
$$

The compression surface is shown in Fig. 3.2 and Fig. 3.3. 


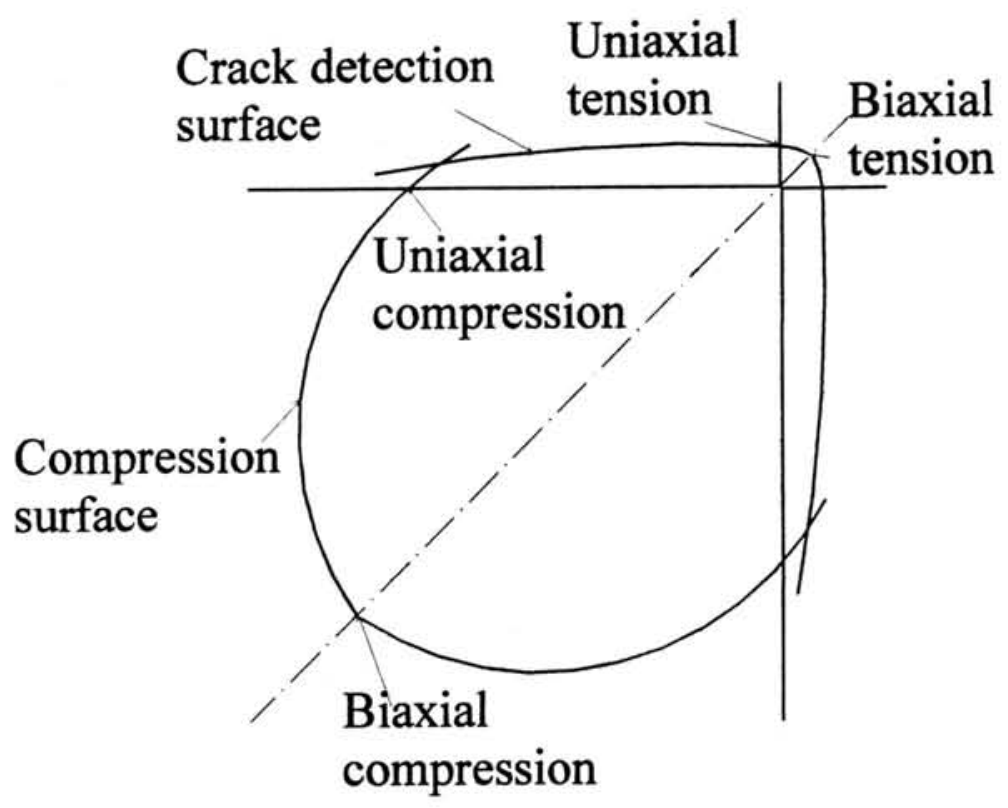

Fig. 3.2---Failure surface in plane stress

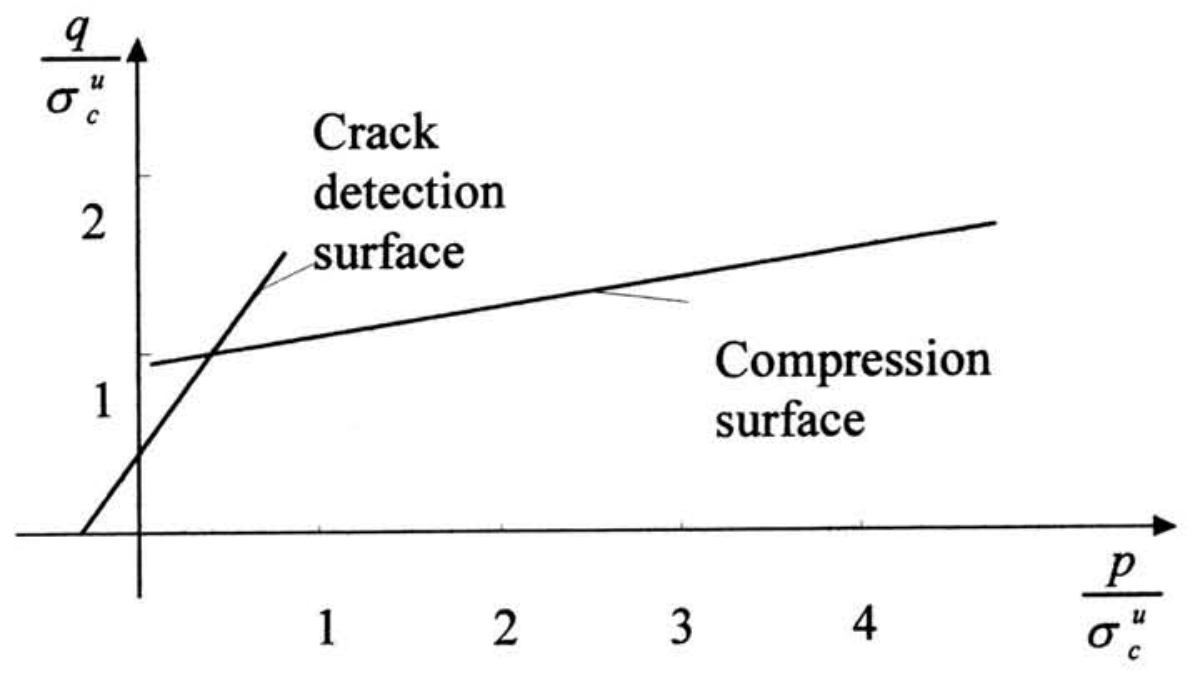

Fig. 3.3---Failure surface in the (p-q) plane 


\subsubsection{Crack detection surface}

The crack detection surface is the Coulomb line

$$
f_{t}=q^{\prime}-\left(3-b_{0} \frac{\sigma_{t}\left(\lambda_{t}\right)}{\sigma_{t}^{u}}\right) p^{\prime}-\left(2-\frac{b_{0}}{3} \frac{\sigma_{t}\left(\lambda_{t}\right)}{\sigma_{t}^{u}}\right) \sigma_{t}\left(\lambda_{t}\right)=0
$$

where $\sigma_{t}{ }^{u}$ is the failure stress in uniaxial tension and $\sigma_{t}\left(\lambda_{t}\right)$ is a hardening parameter $\left(\sigma_{t}\right.$ is the equivalent uniaxial tensile stress). The hardening is measured by $\lambda_{t}$. The stress measures p' and q' are defined in the same way as p and q, they are invariants in the subspace of the stress space which excludes the stress components $\sigma_{\alpha \beta}$ associated with open cracks ( $\alpha$ or $\beta$ is a crack direction). $b_{0}$ is a constant that is defined from the value of the tensile failure stress, $\sigma_{\mathrm{I}}$, in a state of biaxial stress when the other nonzero principal stress, $\sigma_{\mathrm{II}}$, is at the uniaxial compression ultimate stress value $\sigma_{\mathrm{c}}{ }^{\mathrm{u}}$. The value of $b_{0}$ is obtained as follows

$$
\begin{aligned}
& \sigma_{I}=f \sigma_{t}^{u}=f \gamma_{t}^{\sigma} \sigma_{c}^{u}, \\
& \sigma_{I I}=-\sigma_{c}^{u}, \\
& b_{0}=3 \frac{1+(2-f) \gamma_{t}^{\sigma}-\sqrt{1+\left(f \gamma_{t}^{\sigma}\right)^{2}+f \gamma_{t}^{\sigma}}}{1+\gamma_{t}^{\sigma}(1-f)}
\end{aligned}
$$

where $f$ is a material constant which defines the shape of the surface at the transition between biaxial compression and biaxial tension, $\gamma_{t}{ }^{\sigma}$ is ratio between the tensile and compressive strengths.

The crack detection surface is also shown in Fig. 3.2 and Fig. 3.3.

The above elasto-plastic models are implemented in ABAQUS (Habbitt et al. 1998). 


\subsection{Cracking Model}

Cracking is the most important aspect of the nonlinear behaviour, and it dominates the modelling. When the state of stress is predominantly tensile, cracking dominates the material behaviour. In this research, cracking has been modelled by two techniques: one smearing the effects of the crack over the width of relevant element, and the other making appropriate adjustments to the element topology by separation of the appropriate nodes.

\subsubsection{Smeared crack modelling}

In the smeared cracking approach, cracking is assumed to occur when the stress reaches a failure surface, which is called the crack detection surface (Fig. 3.2 and Fig. 3.3). The crack material is assumed to remain as a continuum. Rather than representing a single crack, the crack is represented as an infinite number of parallel fissures across the cracked element as shown in Fig. 3.4.

The crack direction, $\alpha$, is taken to be the direction orthogonal to the directions of any existing cracks at the same point. This crack orientation is stored for subsequent calculations. Cracking is irrecoverable in the sense that once a crack has occurred, it remains throughout the rest of the calculation. Following crack detection, the crack affects the calculations through a reduction in the modulus of elasticity (a measure of damage). The constitutive calculations are performed independently at each integration point of the finite element. The presence of cracks enters into these calculations by the way the cracks affect the stress and material modulus associated with the integration point. 
One of the important necessities for the smeared approach to be valid is that the mesh must be fine enough, so that "cracking" appears in a relatively small zone compared to the overall mesh.

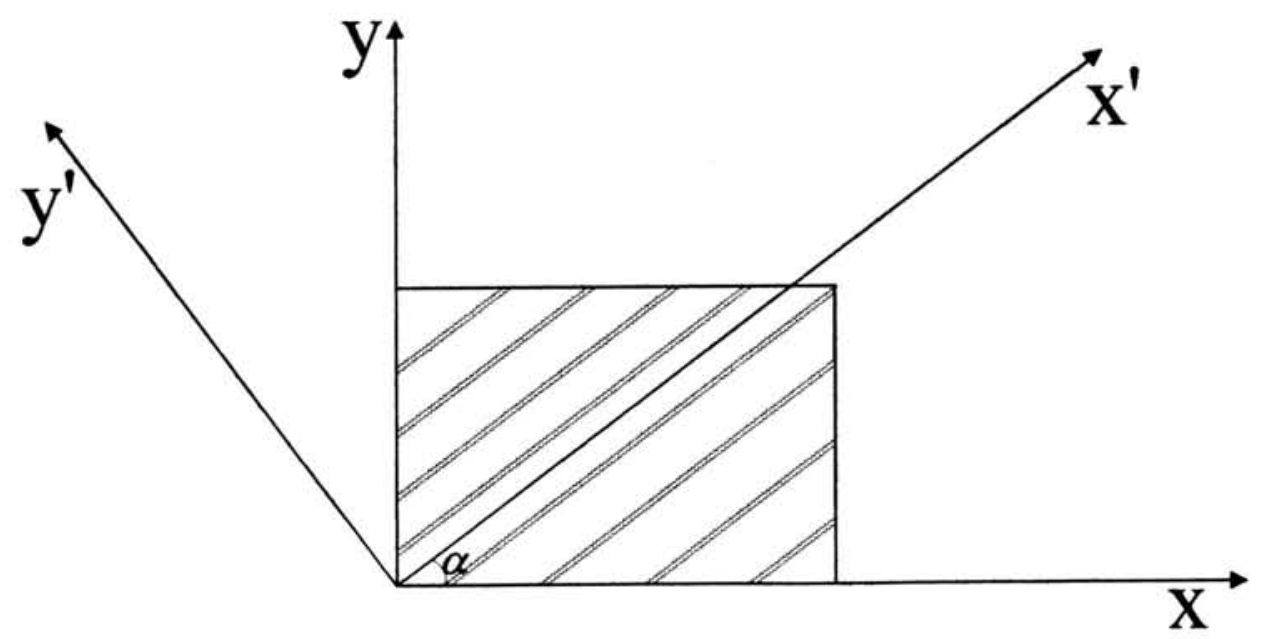

Fig. 3.4---Idealization of a single crack in smeared crack modelling

\subsubsection{Discrete crack modelling}

In the discrete cracking approach, cracking is assumed to occur when the stress reaches the ultimate tensile stress. Cracking of materials is modelled by separation of the appropriate nodes of adjoining elements. In the model, gap elements are used to simulate this cracking by disconnecting the shell elements from each other. The discrete modelling is only used in the webs of block units. When the normal stress in a gap element exceeds the block tensile stress, the gap opens, simulating cracking at this location. Once a gap opens, the appropriate nodes of the adjacent shell elements are disconnected, as depicted in Fig. 3.5, the stiffness of gap elements is reduced to be zero. The effect of such detected 
crack propagation on the other gap elements and shell elements is checked to account for any chain effect of the cracking.

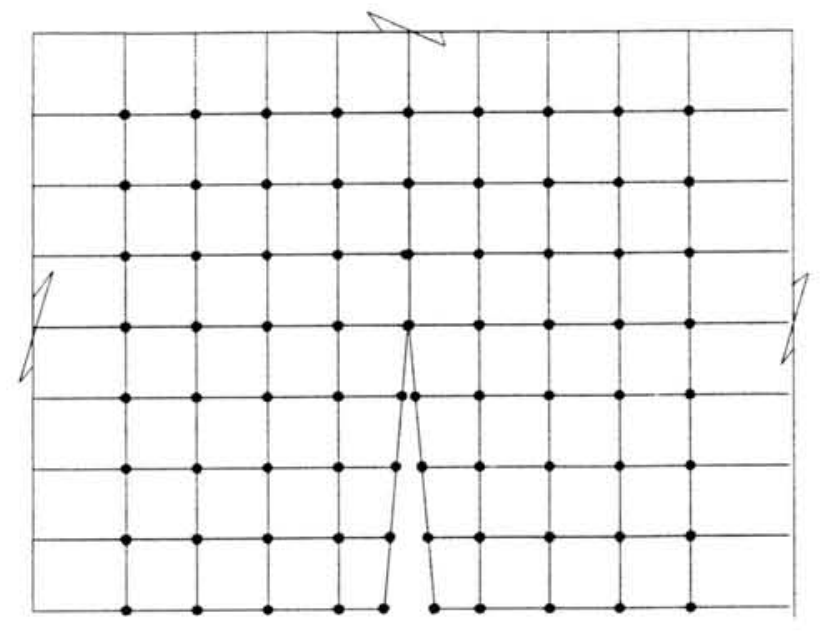

Fig. 3.5---Crack in discrete crack modelling

The discrete cracking criterion can be simply expressed as

$$
\sigma_{1}=\gamma \sigma_{t}^{u}
$$

in which $\gamma$ is a factor to calibrate the model to actual behaviour, $\sigma_{\mathrm{t}}{ }^{\mathrm{u}}$ is the ultimate tensile stress of block units.

\subsection{Elements}

Choice of appropriate finite elements is necessary for successful finite element models. Suitable finite elements should allow the structural behaviour be simulated efficiently and could save the computational requirements. 


\subsubsection{Shell element}

In this analysis, three-dimensional 4-node doubly curved general-purpose isoparametric full-integration shell elements (S4) were used to model the hollow block units and mortar, with 6 degree of freedom at every node: 3 translations, 2 out-of-plane rotations and one extra in-plane rotation. Shell element analysis has the advantage of allowing the face-shells to rotate after web splitting. Furthermore, it reduces the computational requirements as it uses a lower number of state variables at each integration point and fewer integration points than solid elements. As the integration of a shell element is carried over the thickness, the variation of the stresses through the face-shell thickness and the mortar joint width can be expressed with one shell element, which is equivalent to a couple of solid elements through the thickness.

Fig. 3.6 describes the configuration of the shell element with four integration points in the shell surface (full-integration). The number of integration points through the thickness of the shell is chosen to be five, thus when the shell element is used to simulate the faceshell of the block units and mortar, the structural behaviour of both the outside and the inside of the face-shell and mortar can be modelled.

\subsubsection{Solid element}

8-node isoparametric solid elements were used to model bond-beam block units and grout, with 3 degree of freedom at every node: $\mathrm{X}, \mathrm{Y}, \mathrm{Z}$ translations. Fig. 3.7 shows the configuration of the solid element. 


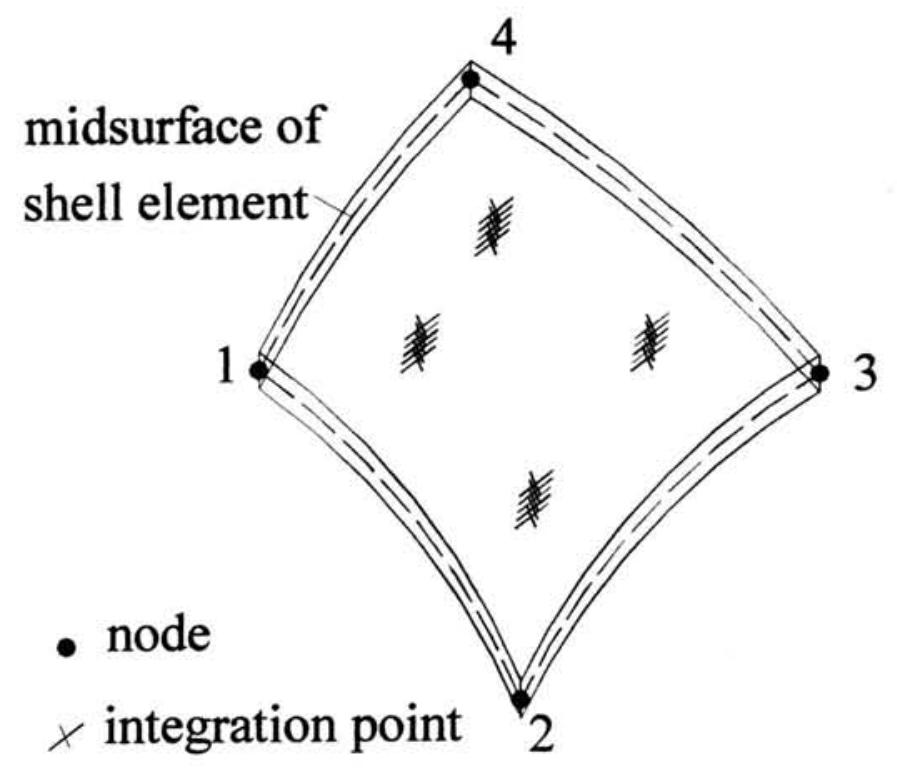

Fig. 3.6---Three-dimensional 4-node doubly curved general-purpose shell element (S4)

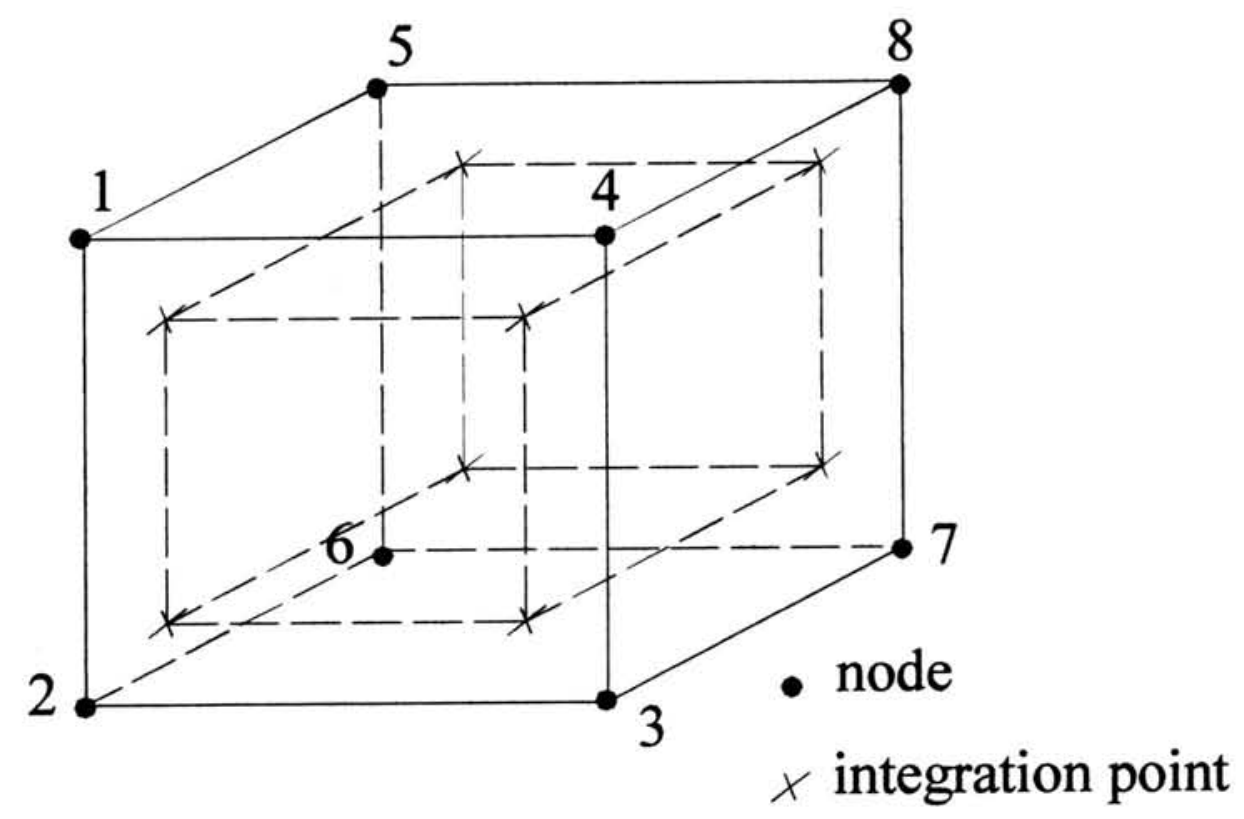

Fig. 3.7---8-node solid element (CPD8) 


\subsubsection{Multiple-point constraint}

The multi-point constraints allow for a transition from shell element modelling to solid element modelling on a shell surface, as shown in Fig. 3.8. This modelling technique was used in the analysis to obtain accurate solutions at shell-solid intersections, where local modelling should use full three-dimensional theory but the other parts of the structure can be modelled as shells. The theory behind the multi-point constraints assumes that the interface between the shell and solid elements is a surface containing the normals to the shell along the line of the intersection of the meshes, so that the lines of nodes on the solid mesh side of the interface in the normal direction to the surface are straight lines.

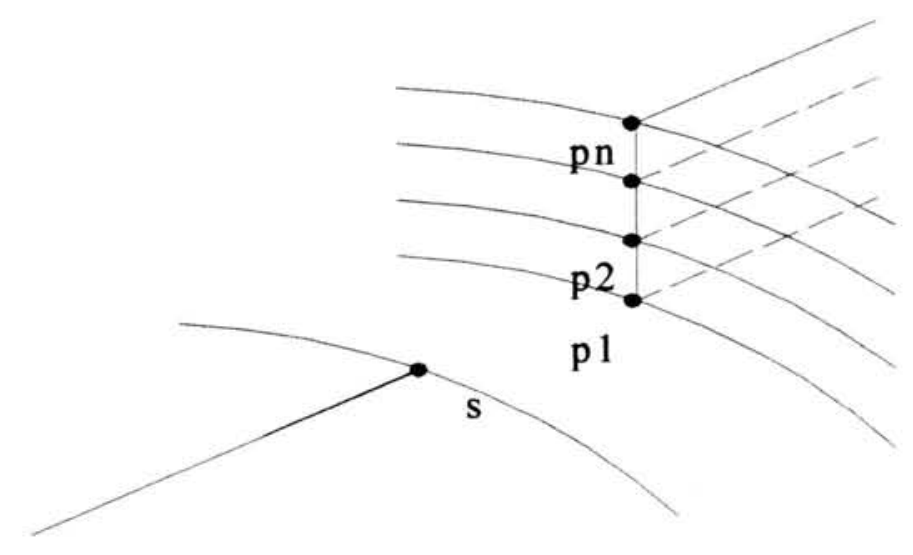

Fig. 3.8---Multiple point constraint between shell and solid element

\subsubsection{Gap element}

Gap elements were used to model the web splitting in the discrete models. Gap elements are defined by specifying two nodes forming the gap and providing geometric data defining the initial state of the gap. Gap elements allow for the nodes to be in contact (gap closed) or separated (gap open) with respect to particular direction and separation 
conditions, and provide the contact forces between two nodes. Fig. 3.9 shows the configuration of the gap element used in this analysis.
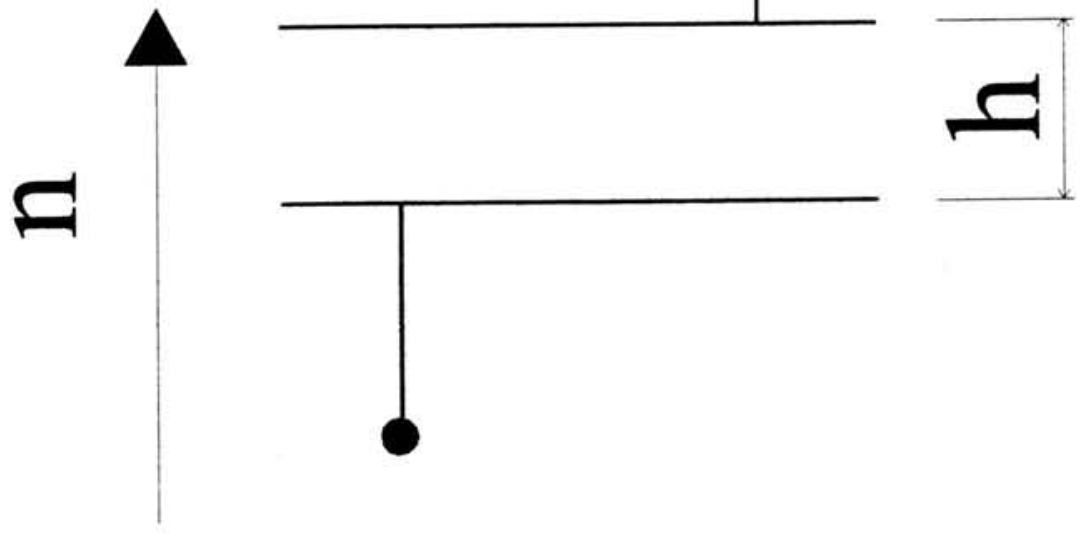

Fig. 3.9---Gap element

The initial separation distance (clearance), $d$, of the gap and the contact direction, $\mathbf{n}$ define the behaviour of the interface being modelled by gap element. The current clearance between two nodes of the gap is defined as

$$
h=d+\mathbf{n} \cdot\left(u^{2}-u^{1}\right)
$$

where $u^{1}$ and $u^{2}$ are the total displacements at the first and the second node forming the gap element.

The mechanical surface interaction model for gap element is shown in Fig. 3.10. Tensile contact pressure up to a value of $\mathrm{T}_{0}$ is allowed to transmit before the nodes separate. 


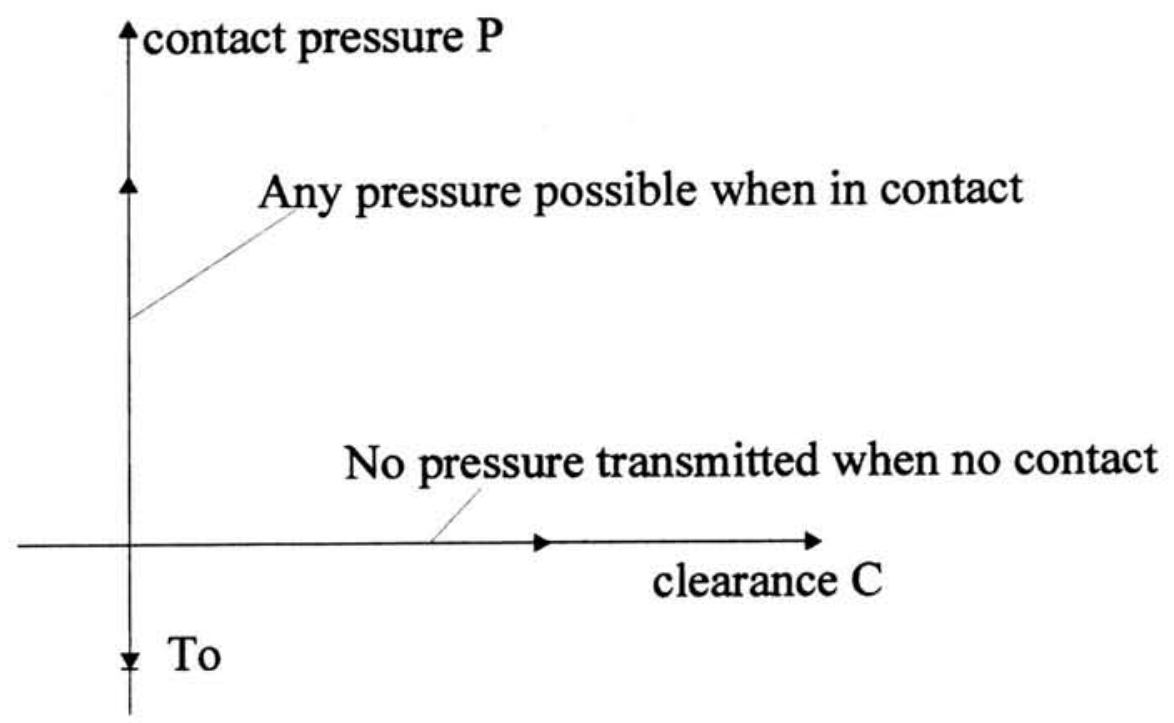

Fig. 3.10---Mechanical interaction model for gap element

\subsection{Numerical Method}

The "Arc-length modified Riks algorithm" is used in the models to overcome the numerical difficulty of passing the limit points during the finite element solution and obtain nonlinear static equilibrium solutions.

The method is incremental (to allow the progressive application of the applied load) combined with iterative (to allow for geometric and material nonlinearity and progressive cracking at a particular load level), based on the Newton-Raphson technique. Elastic behaviour is assumed for the first load increment. In the models, the load is applied incrementally by specifying a set of prescribed displacements on the loading plate. Principal stresses are calculated at every integration point of each element, and if any are tensile, the local behaviour is assumed to be elastic brittle. For other cases, non-linear material behaviour is assigned. 
For each successive load increment, iterations are carried out to allow for geometric and material nonlinearity and progressive cracking. If cracking is detected, the effects of the crack are "smeared" over the full width of the shell element or solid element (for smeared modelling), or gap element is disconnected (for discrete modelling). The iteration continues until the solution converges. The next load increment is then applied and the procedure repeated. Final failure is indicated by the lack of convergence in the calculation. Since the load is produced by an equivalent prescribed displacement, the behaviour of the models can be studied from the first appearance of web cracking almost to final failure under concentric or eccentric compressive load.

\subsection{Summary}

Non-linear material constitutive laws are briefly demonstrated, together with the crack modelling methods, finite elements, and non-linear numerical method. An elasto-plastic model with successive yield surfaces and final failure surface has been used to model the non-linear characteristics of masonry components. Smeared and discrete cracking methods are used to simulate the progressive cracking. Shell elements are used to model the mortar and face-shells for the curvature occurred under compression. Gap elements are used for web splitting in discrete cracking model. To improve the convergence of the model, the "Arc-length modified Riks algorithm" has been used during the finite element solution.

The numerical models will be verified against available experimental results. 


\section{CHAPTER 4}

\section{D NON-LINEAR FINITE ELEMENT MODEL OF FACE-SHELL BEDDED HOLLOW CONCRETE MASONRY PRISMS}

\subsection{Introduction}

3D non-linear elasto-plastic finite element models of hollow concrete masonry prisms were first developed. These models were assessed against experimental results to see if the models were capable of simulating the structural behaviour of the prisms when subjected to concentric and eccentric compression. Three-block-high face-shell bedded stack-bonded prisms as shown in Fig 4.1 were modelled. The hollow block units and mortar were modelled separately. Geometric and material non-linearities as well as damage due to progressive cracking were taken into account in the analyses. Both the smeared and discrete cracking approaches were used to model the progressive cracking and damage. Shell elements and gap elements were used. PATRAN (PDA Engineering 1993) was used for pre- and post-processing for the models, while the numerical computation was performed with ABAQUS (Habbitt et al. 1998).

\subsection{Finite Element Mesh}

Two kinds of models were developed here. In the first model (Model 1), isoparametric shell elements were used to model all the face-shells, webs, and mortar, and only the smeared crack modelling approach was used. The mesh is shown in Fig. 4.2(a). The 
second model (Model 2) was similar with the first one, except that shell elements and gap elements were combined to model web splitting, and the smeared crack modelling was combined with discrete crack modelling: the mesh is shown in Fig. 4.2(b). The cutting planes used to generate these prism meshes are the vertical planes at which the normal stresses are approximately symmetric and shear stresses are zero.

In the models, the actual face-shell and web taper and flare were simplified as depicted in Fig. 4.3. The material (concrete block and mortar) properties used in the models are shown in Fig. 4.4.

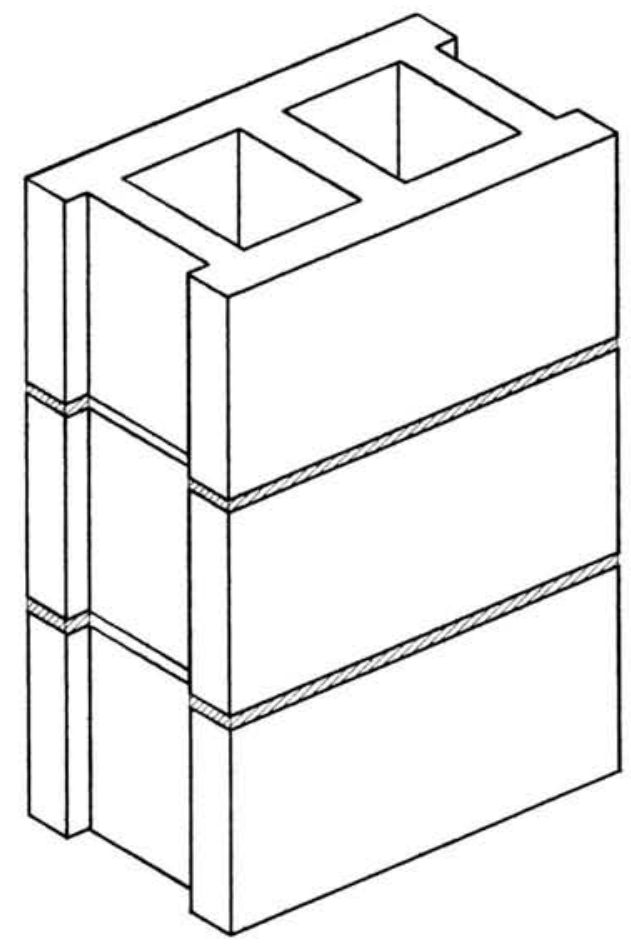

Fig. 4.1---Face-shell bedded stack-bonded hollow concrete masonry prism 


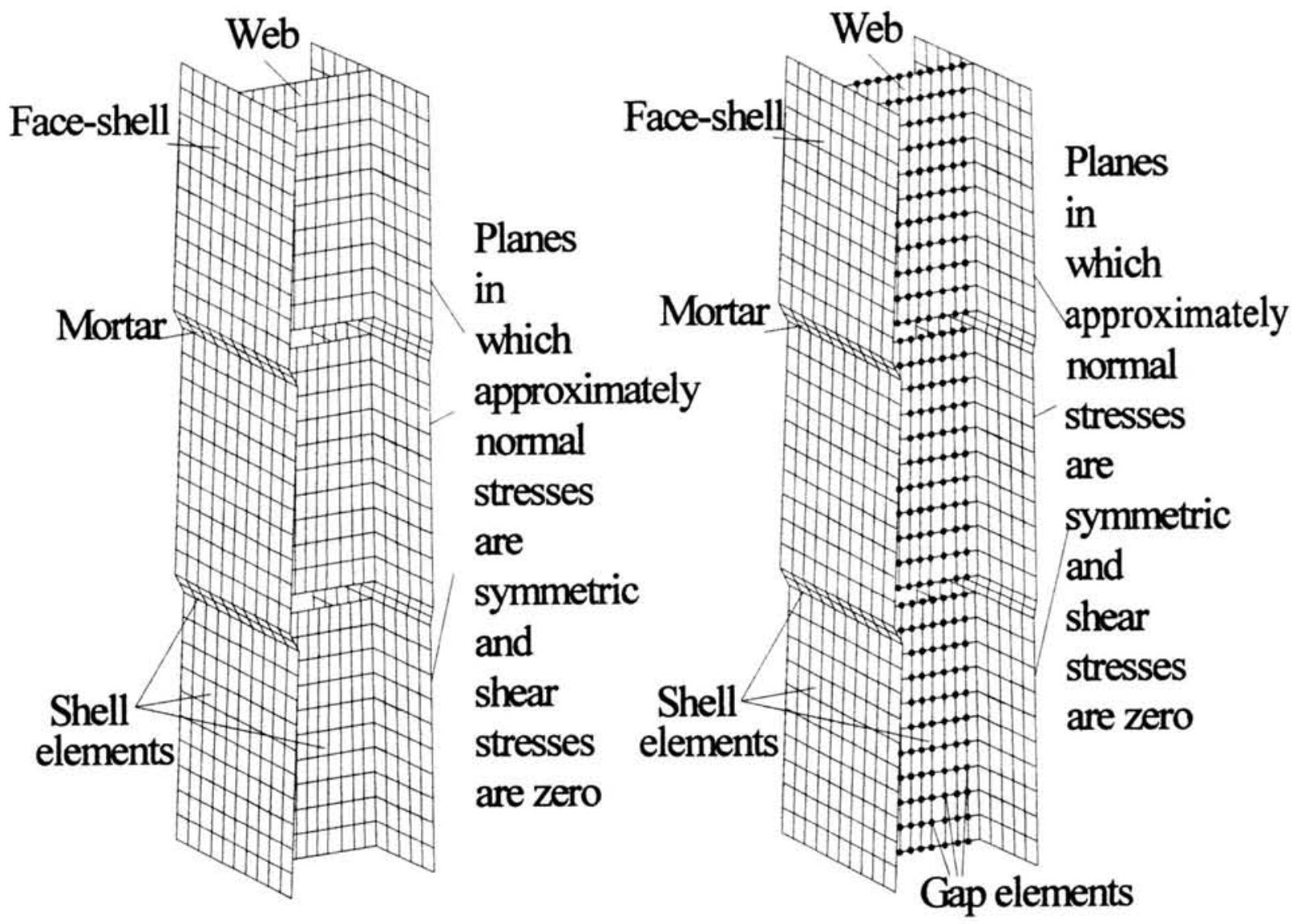

(a)

(b)

Fig. 4.2---Finite element mesh for three-block-high stack-bonded face-shell bedded hollow concrete masonry prisms

(a) smeared model (Model 1) (b) discrete model (Model 2) 


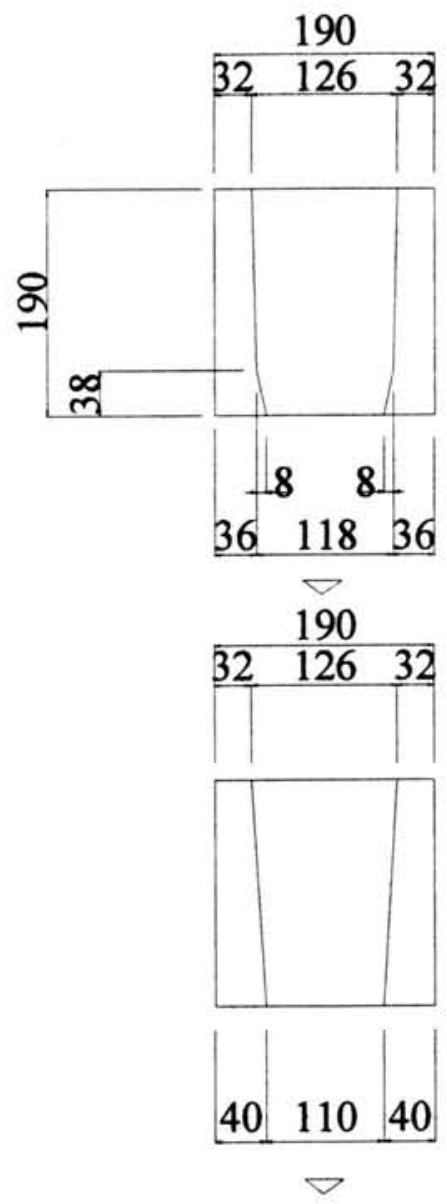

midsurface of shell element

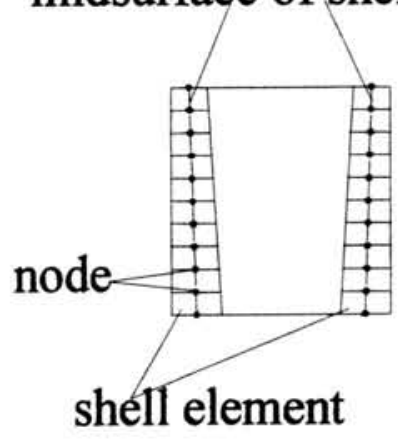

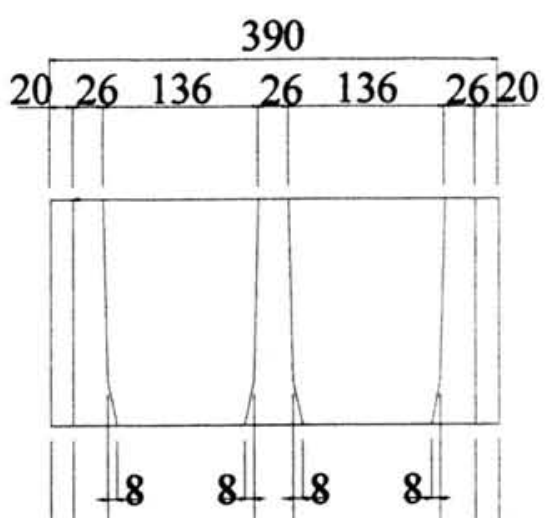
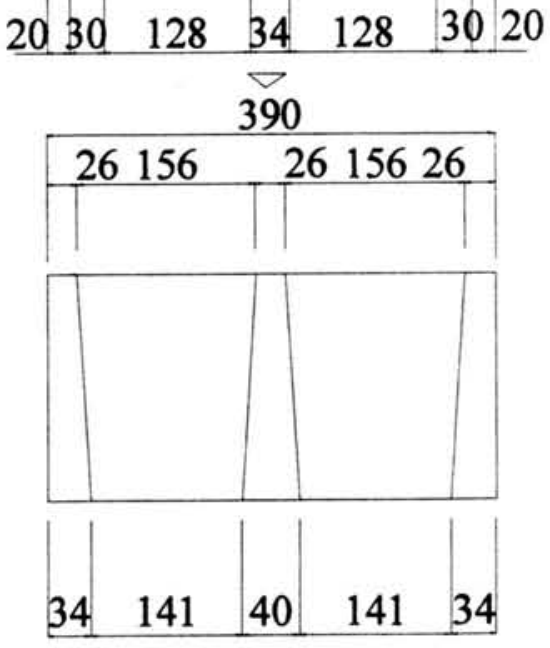

midsurface of shell element

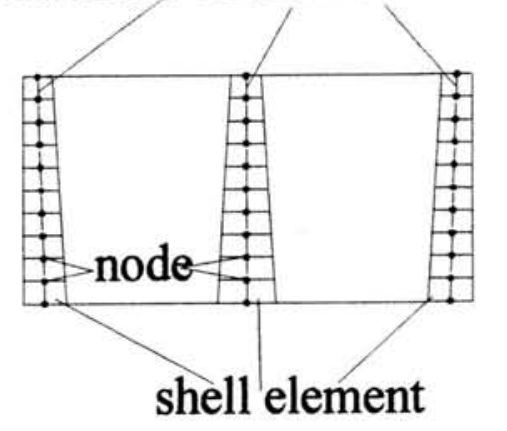

Fig. 4.3---Simplified model of face-shell and web taper and flare 


\section{Uniaxial Stress-Strain Relations}

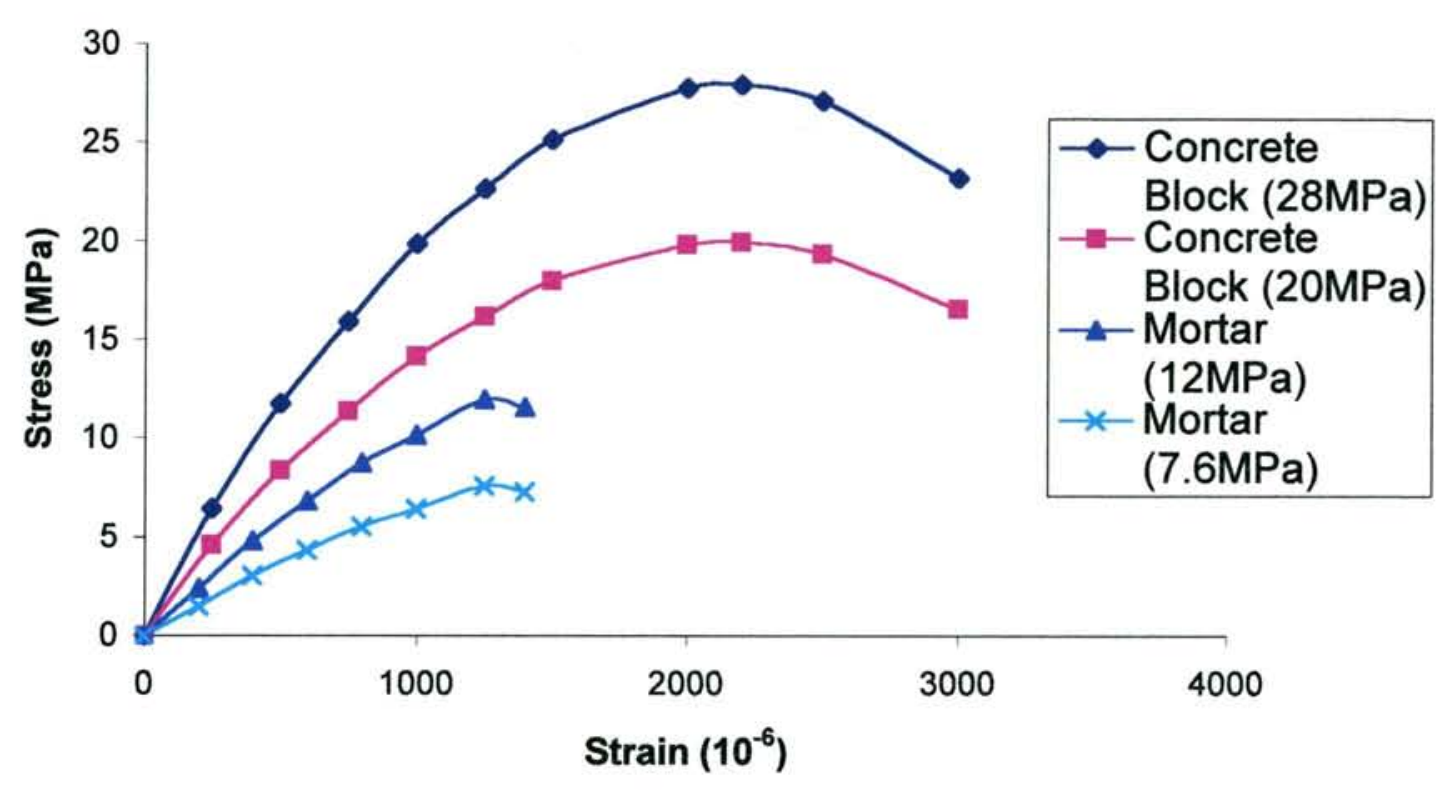

Fig. 4.4---Stress-strain relations in uniaxial compression for concrete block units and mortar (Xie 1998)

\subsection{Results}

A comparison is performed between the experimental behaviour of three-block-high faceshell bedded hollow concrete masonry prisms under concentric and eccentric compressive loading and the results obtained using the models proposed here.

\subsubsection{Failure modes}

Knowledge of failure modes is important to understand the structural behaviour of hollow concrete masonry. The failure modes observed from experiments and predicted from the models are described below. 


\subsubsection{Under concentric compressive load}

Typical comparisons of experimental and predicted failure patterns for a prism under concentric compressive load are shown in Fig.4.5.

The failure mode of the first prism model under concentric compression is as follows: At a load level of approximately $50 \%$ of the failure load, vertical cracks form at the bottom centre region in the web of the upper block where the web thickness is reduced by the web taper. As the load increases, the cracking extends upward, and vertical cracks form at the bottom centre region in the web of the middle block. At a load level of about $70 \%$ of the ultimate load, cracking occurs at the top centre region in the webs of both the middle and lower blocks, and at the same time cracking occurs at the lower part of the junction of the web and face-shells. Final failure occurs by splitting and spalling of the face-shells adjacent to the mortar joint in the region near the webs, and/or crushing of the mortar at the in-side of the face-shells (when mortar is weak compared to the block units).

The failure mode obtained from Model 2 is very similar with that of Model 1, except that no cracking occurs at the junction of the web and face-shells. This may be caused by the effect of the gap elements. Another difference is that with Model 2, the vertical compressive stresses at the out-side of face-shells are a little smaller than with Model 1: this may be due to the larger rotation of face-shells caused by web cracks with Model 2 . 
The horizontal stress distribution in the webs of the prism under concentric compression is shown in Fig. 4.6 for smeared model (Model 1).
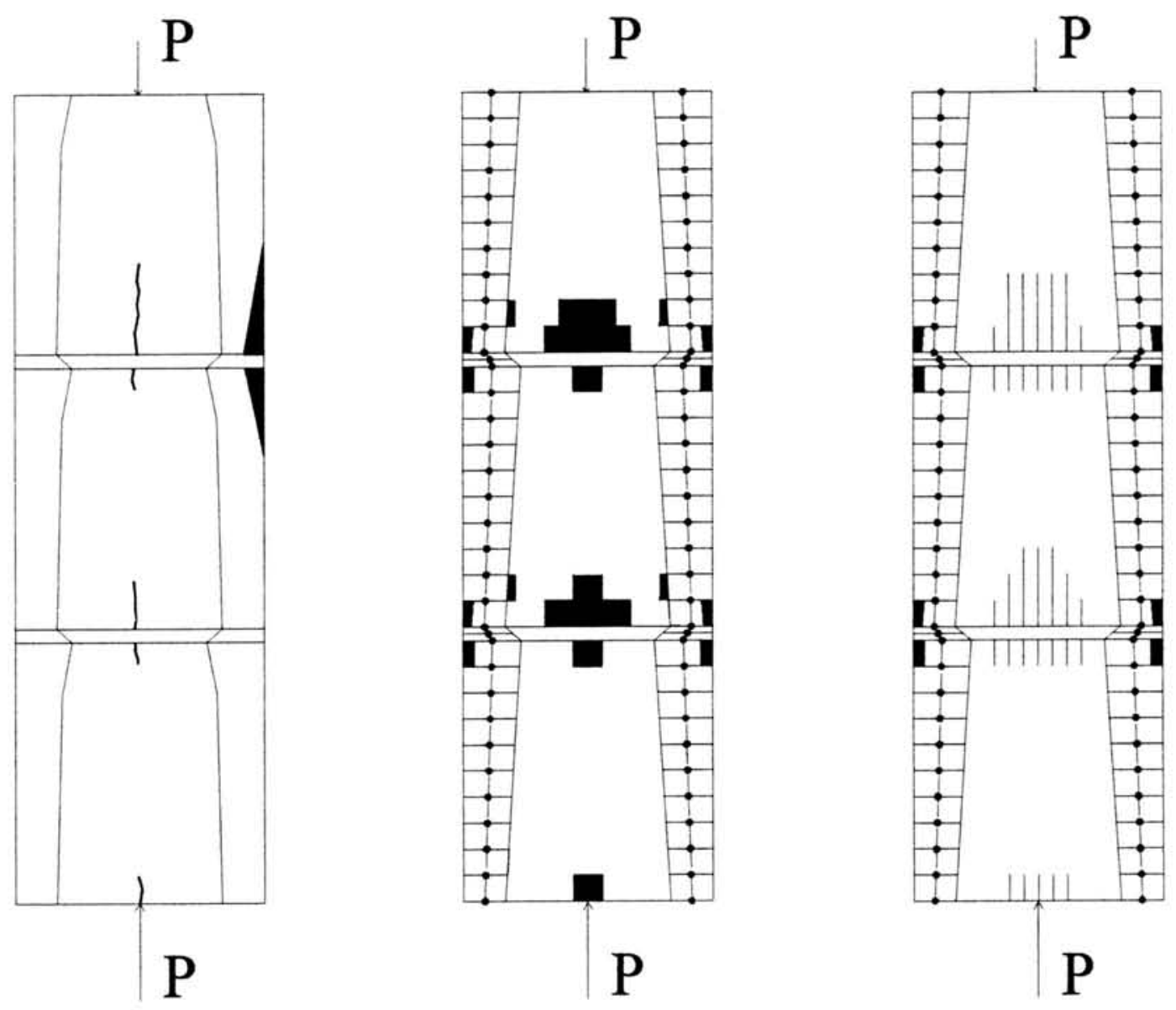

(a)

(b)

(c)

Fig. 4.5----Comparison of failure modes of prisms under concentric compression

(a) Experiment (b) Model 1 (c) Model 2

One thing should be mentioned here. At the bottom of the face-shells adjacent to the mortar joint, the horizontal stresses on the out-side are tensile, although the vertical 
MSC/PATRAN Version 8.0 10-Aug-01 12:31:09

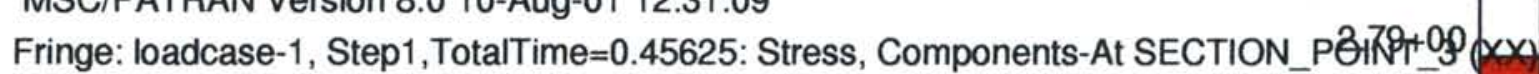

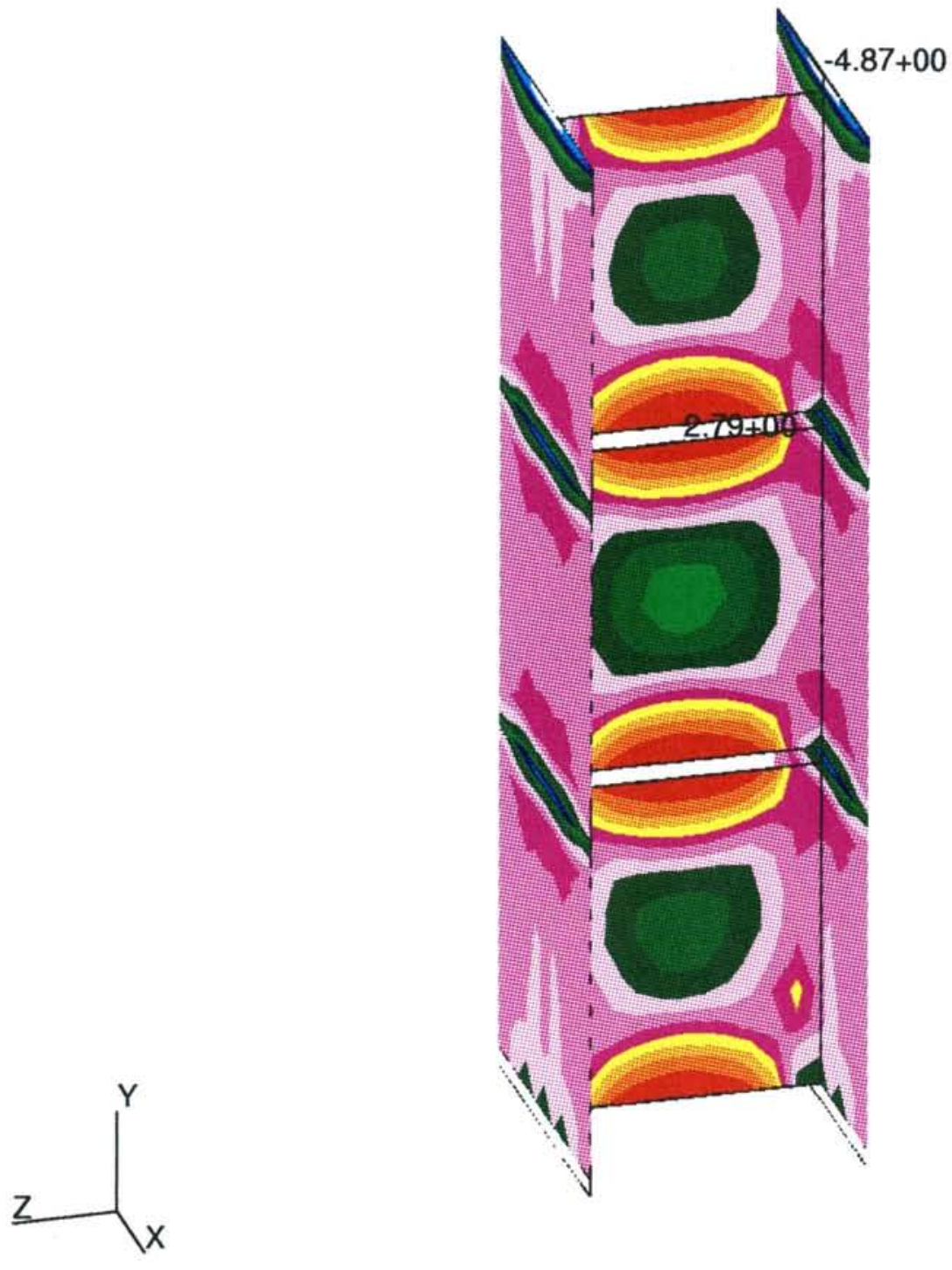

$\begin{array}{r}2.28+00 \\ 1.77+00 \\ 1.26+00 \\ 7.47-01 \\ \hline 2.36-01 \\ -2.74-01 \\ -7.85-01 \\ -1.30+00 \\ -1.81+00 \\ -2.32+00 \\ -2.83+00 \\ -3.34+00 \\ -3.85+00 \\ \hline\end{array}$

default_Fringe :

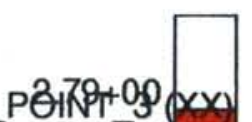

Max 2.79+00@Nd 705

Min-4.87+00@Nd 1386

Fig. 4.6---The horizontal stress distribution in the webs of the prism under concentric compression (smeared model) 
compressive stresses are much smaller than on the in-side of the face-shells, splitting and spalling occurs on the out-side rather than in-side of face-shells. At the top of the faceshells adjacent to the mortar joint, the horizontal stresses on the out-side are tensile, and the vertical compressive stresses are larger than on the in-side of face-shells, undoubtedly splitting and spalling occurs in these regions. The mortar is always in biaxial compression; hence it is not easy for mortar to crush except when it is weak. An example of the stress distributions in the face-shells and mortar around the mortar joint at the ultimate strength of the prism under concentric compression is shown in Fig. 4.7. It can clearly be seen that splitting and spalling of the out-side of the face-shells may occur both above and below the mortar joint.

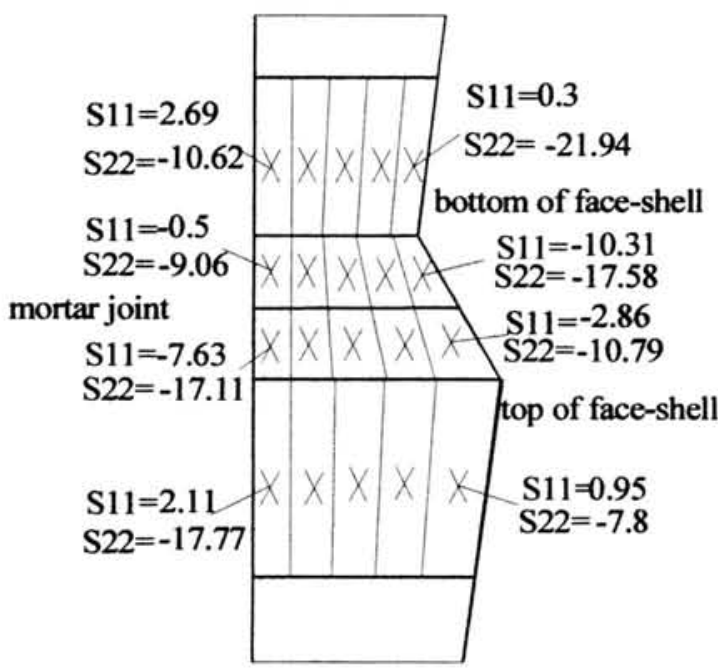

$X$ integration point; S11 horizontal stress; S22 vertical stress

Fig. 4.7---Stresses in the face-shells and mortar around the mortar joint for prism under concentric compression (Model 1) 
The predicted failure patterns compare favourably with the experimental observations (Shrive 1982; Drysdale and Hamid 1979; Becica et al. 1983; Maurenbrecher 1985; Guo 1991; Xie et al. 1992). Some pictures about the failure patterns of hollow concrete masonry prisms under concentric compression are shown in Fig. 4.8.
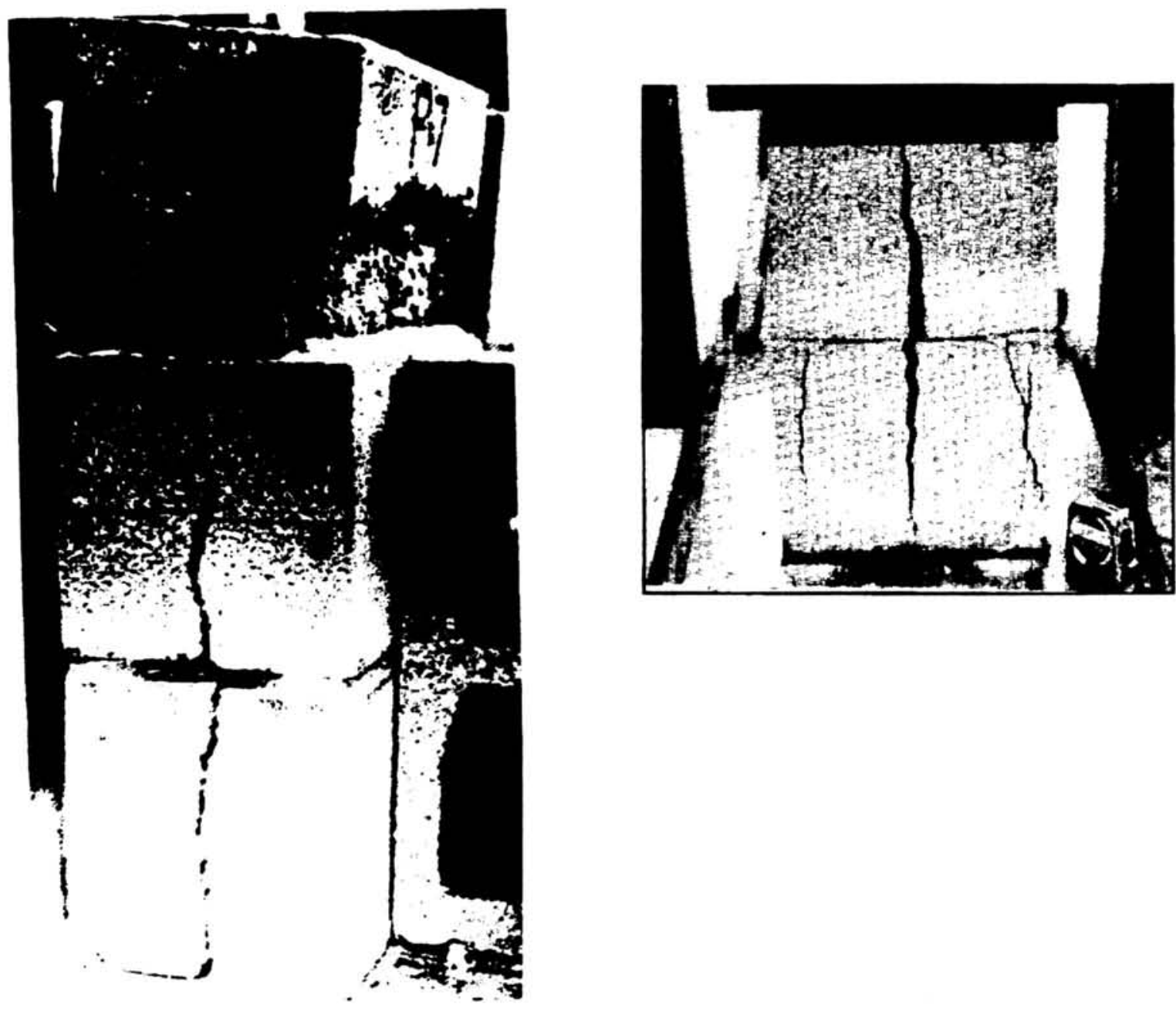

Fig. 4.8---Failure pattern of hollow concrete masonry prism under concentric compression (Shrive 1982; Becica et al. 1983) 


\subsubsection{Under eccentric compressive load (single curvature)}

The predicted failure mode of prism under eccentric compression (single curvature), using Model 1 is as follow:

1. At lower eccentricities (for example $e=t / 6$ ), at a load level of approximately $65 \%$ of the failure load, vertical cracks form at the bottom and near the centre region in the web of the upper block where the web thickness is reduced by the web taper. As the load increases, the cracks extend upward, and other vertical cracks form at the bottom and near the centre region in the web of the middle block. At a load level of about $85 \%$ of the ultimate load, cracks occur at the top and near the centre region in the webs of both the middle and lower blocks, and at the same time cracks develop at the lower part of the junction of the web and the heavily loaded face-shell. Final failure occurs by splitting and spalling of the heavily loaded face-shell adjacent to the mortar joint in the region near the web, and/or crushing of the mortar on the in-side of the heavily loaded face-shell (when the mortar is weak compared to the block units). A typical comparison of experimental and predicted failure patterns for a prism under eccentric compressive load (single curvature with $\mathrm{e}=\mathrm{t} / 6$ ) is shown in Fig. 4.9.

An example of the stresses in the face-shells and mortar around the heavily loaded mortar joint at the ultimate strength of the prism under eccentric compression (single curvature with $\mathrm{e}=\mathrm{t} / 6$ ) is shown in Fig. 4.10 . 


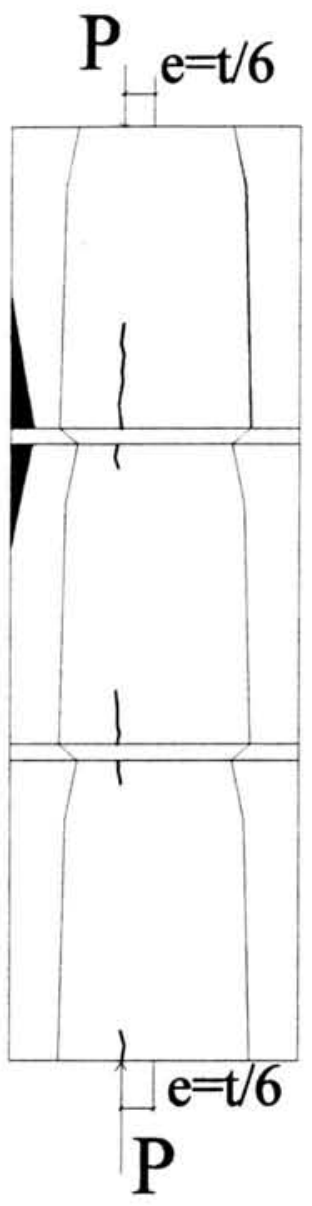

(a)

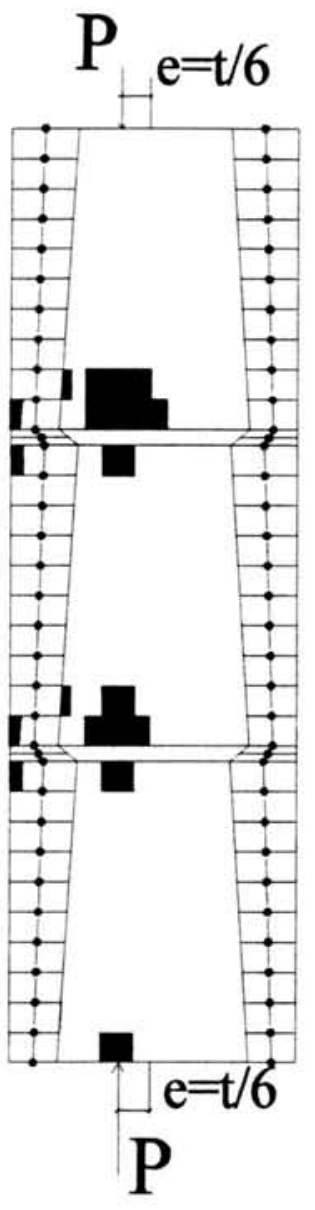

(b)

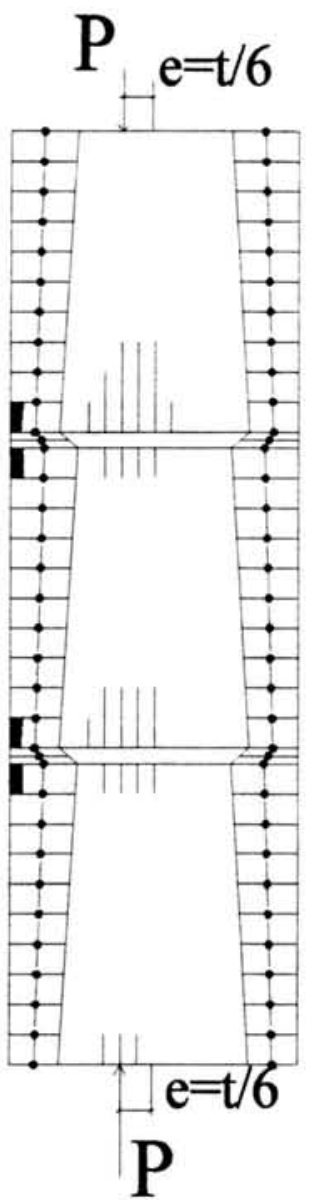

(c)

Fig. 4.9---Comparison of failure modes of hollow concrete masonry prisms under eccentric compression (single curvature with $\mathrm{e}=\mathrm{t} / 6$ )

(a) Experiment (b) Model 1 (c) Model 2

2. At medium eccentricities (for example $e=t / 3$ ), at a load level of approximately $75 \%$ of the failure load, vertical cracks form at the bottom and near the junction of the web and the heavily loaded face-shell in the web of the upper block, rather than near the centre region. As the load increases, vertical cracks form at the bottom and near the junction in 
the web of the middle block. At a load of about $95 \%$ of the ultimate load, cracking occurs at the lower part of the junction of the web and the heavily loaded face-shell. Final failure occurs by splitting and spalling of the heavily loaded face-shell adjacent to the mortar joint, and/or crushing of the mortar on the in-side of the heavily loaded face-shell (when the mortar is weak compared to the block unit). A typical comparison of experimental and predicted failure patterns for a prism under eccentric compressive load (single curvature with $e=t / 3$ ) is shown in Fig.4.11.

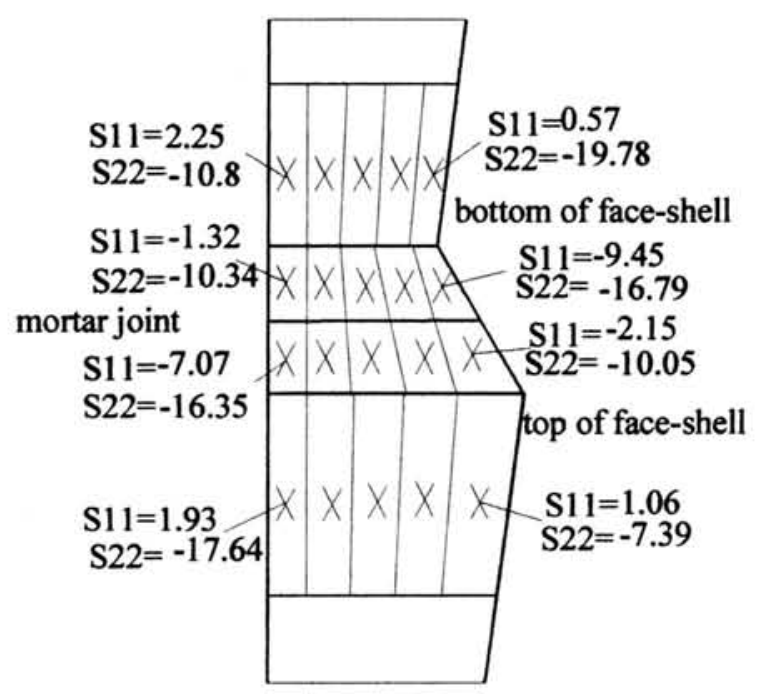

$X$ integration point; S11 horizontal stress; S22 vertical stress

Fig. 4.10---Stresses in the face-shells and mortar around the heavily loaded mortar joint for prisms under eccentric compression (single curvature with $\mathrm{e}=\mathrm{t} / 6$ ) 


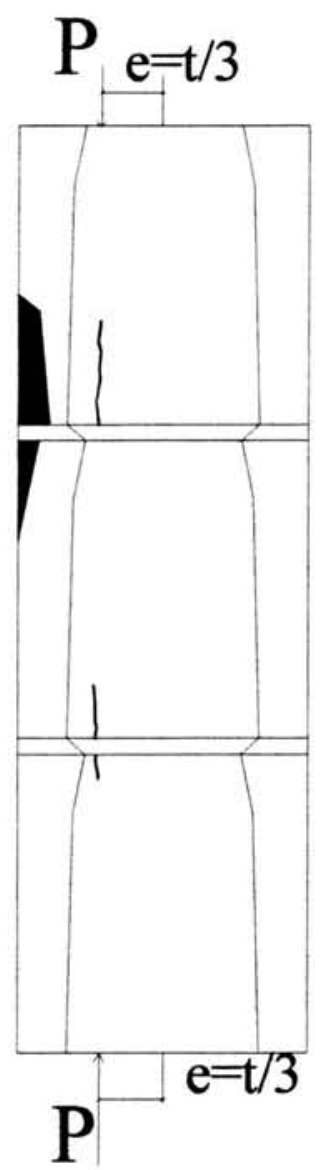

(a)

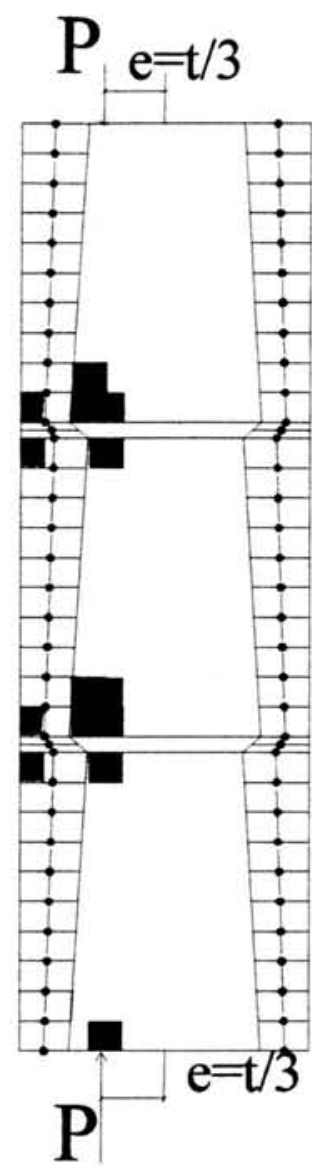

(b)

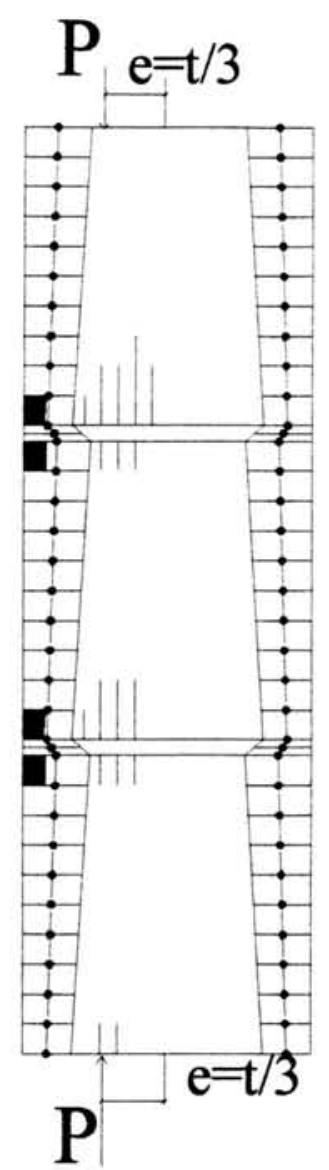

(c)

Fig. 4.11---Comparison of failure modes of prisms under eccentric compression (single curvature with $\mathrm{e}=\mathrm{t} / 3$ ) (a) Experiment (b) Model 1 (c) Model 2

The horizontal stress distribution in the webs of the prism under eccentric compression is shown in Fig. 4.12. An example about the stresses in the face-shells and mortar around the heavily loaded mortar joint with $\mathrm{e}=\mathrm{t} / 3$ is shown in Fig. 4.13 . 
MSC/PATRAN Version 8.0 10-Aug-01 12:30:43

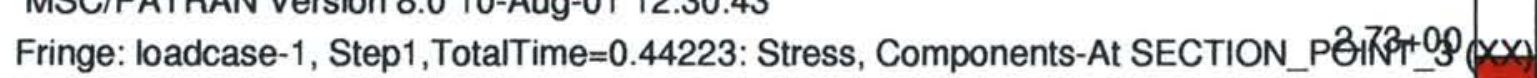
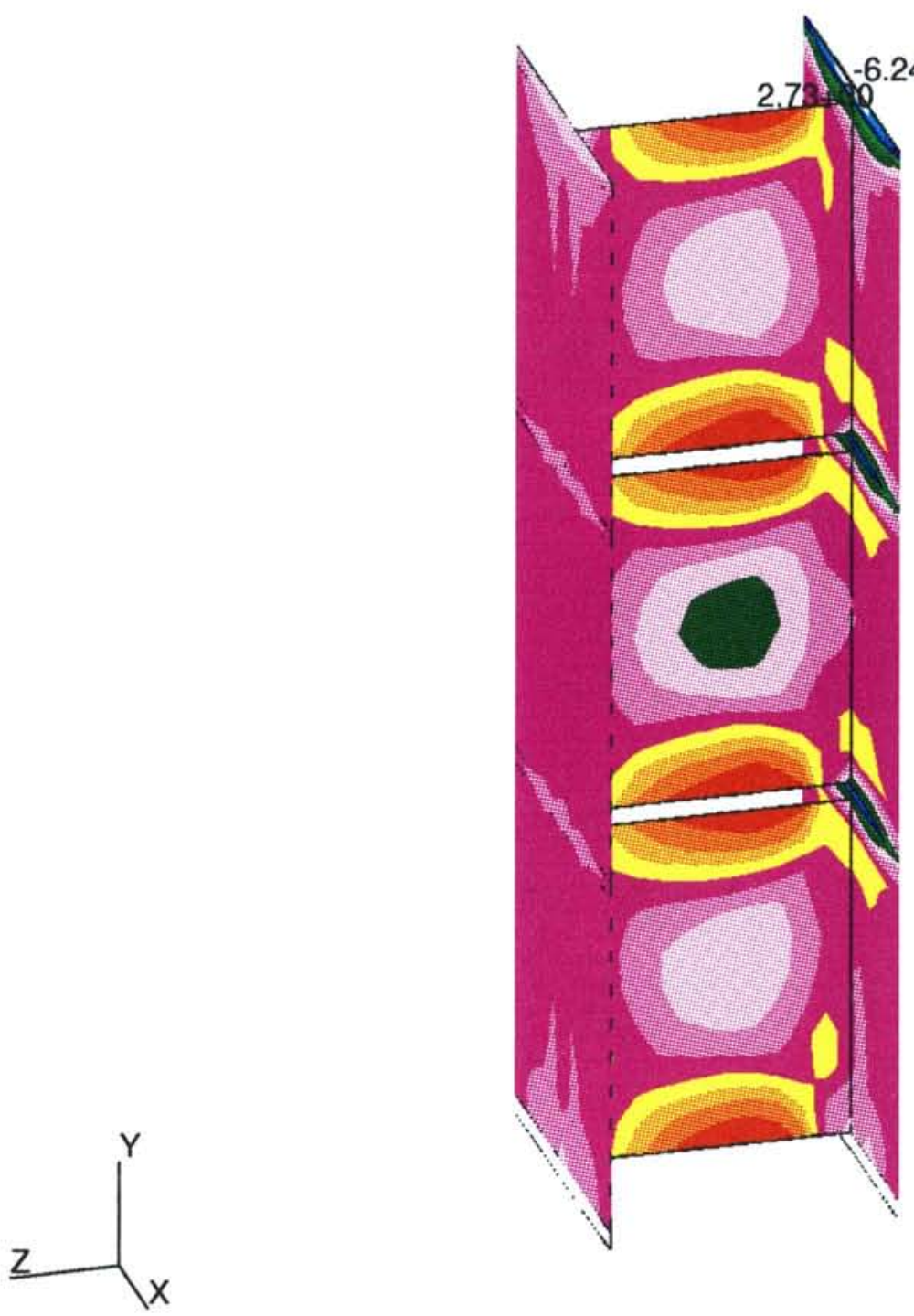

$2.14+00$

$1.54+00$

9.41-01

3.43-01

$-2.55-01$

$-8.53-01$

$-1.45+00$

$-2.05+00$

$-2.65+00$

$-3.25+00$

$-3.84+00$

$-4.44+00$

$-5.04+00$

$-5.64+00$

$-6.24+00$

default Fringe :

$\operatorname{Max} 2.7 \overline{3}+00$ @Nd 1155

Min =6.24+00 @Nd.1386

Fig. 4.12---The horizontal stress distribution in the webs of hollow concrete masonry prism under eccentric compression (single curvature $\mathrm{e}=\mathrm{t} / \mathrm{3}$ ) 


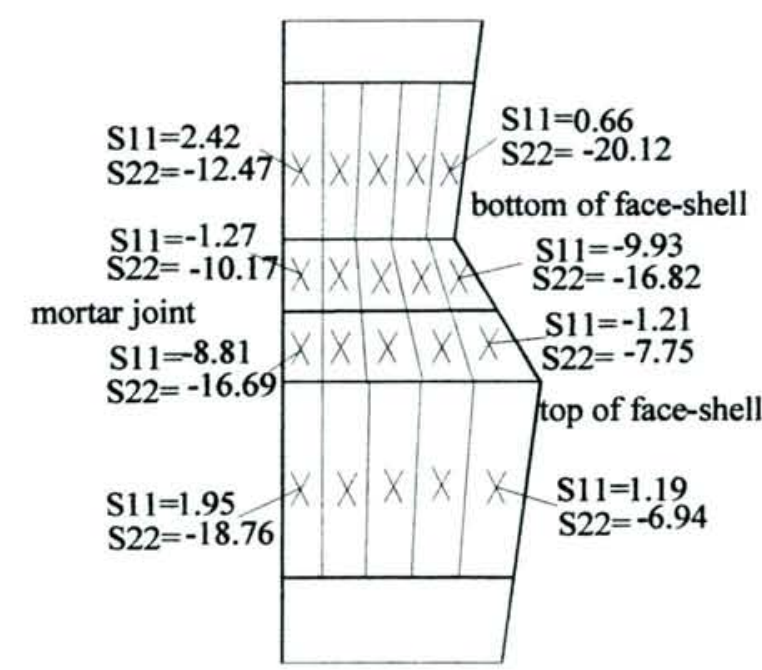

$X$ integration point; S11 horizontal stress; S22 vertical stress

Fig. 4.13---Stresses in the face-shell and mortar around the heavily loaded mortar joint for prisms under eccentric compression (single curvature with $\mathrm{e}=\mathrm{t} / 3$ )

3. At high eccentricities (for example $e=5 \mathrm{t} / 12$ ), at a load level of approximately $85 \%$ of failure load, vertical cracks form at the bottom junction of the web and the heavily loaded face-shell. The failure, finally, occurs at the ultimate capacity by out-side splitting and spalling of the heavily loaded face-shell adjacent to the mortar joint, and/or crushing of the mortar at the in-side of the heavily loaded face-shell (when the mortar is weak compared to the block unit). A typical comparison of experimental and predicted failure patterns is shown in Fig.4.14. 


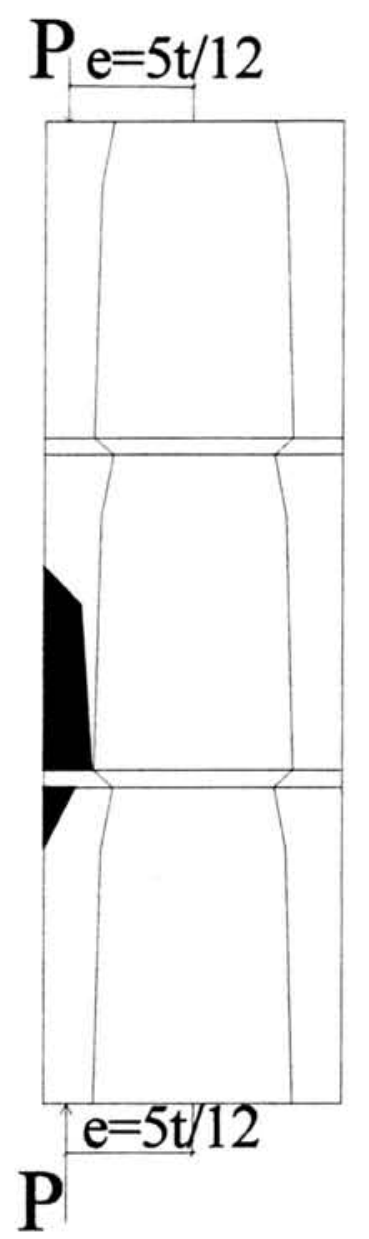

(a)

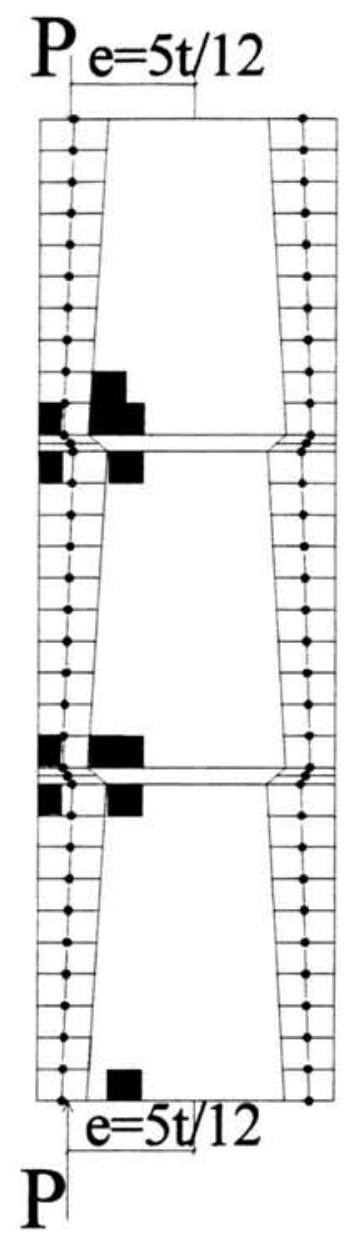

(b)

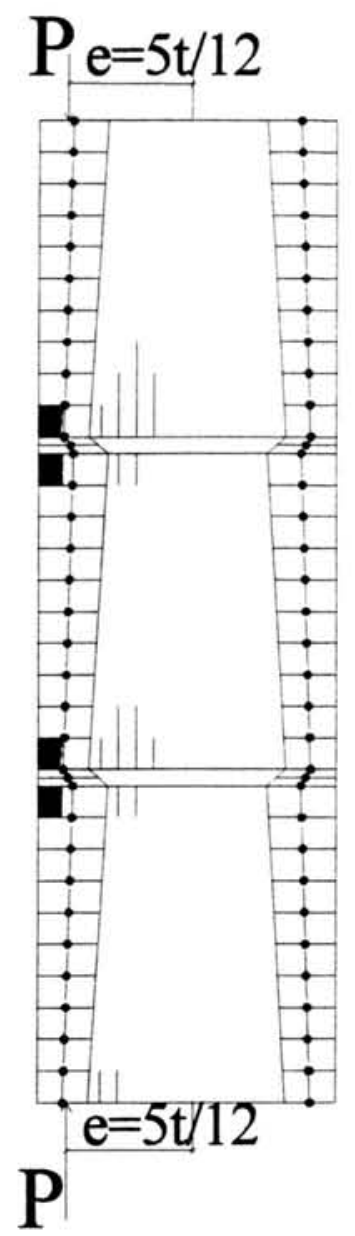

(c)

Fig. 4.14---Comparison of failure modes of prisms under eccentric compression (single curvature with $\mathrm{e}=5 \mathrm{t} / 12$ ) (a) Experiment (b) Model 1 (c) Model 2

An example of the stresses in the face-shells and mortar around the heavily loaded mortar joint with $\mathrm{e}=5 \mathrm{t} / 12$ is shown in Fig. 4.15 .

From Fig. 4.7, 4.10, 4.13, and 4.15, it is well explained that the final failure always occurs with out-side splitting and spalling of face-shells around the mortar joints and/or in-side crushing of mortar. 


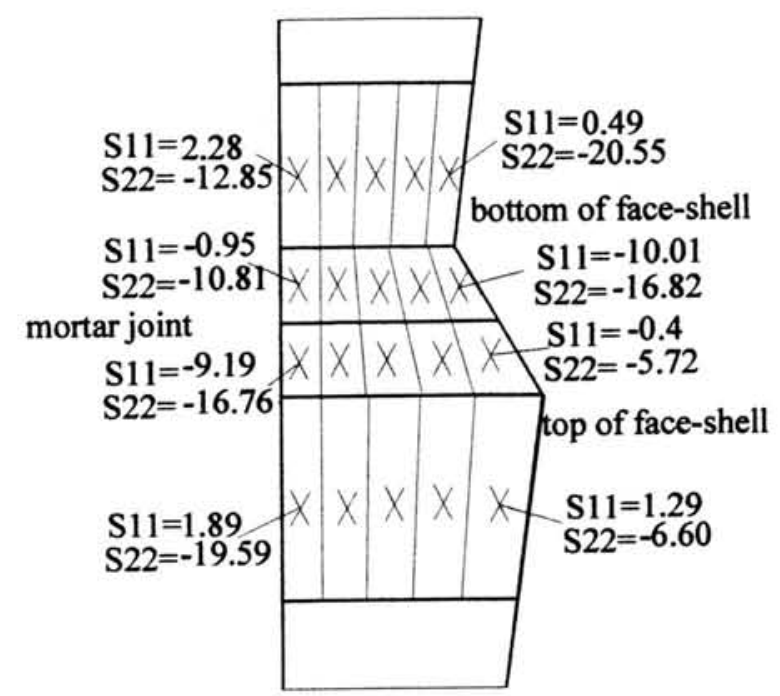

$X$ integration point; $S 11$ horizontal stress; S22 vertical stress

Fig. 4.15---Stresses in the face-shells and mortar around the heavily loaded mortar joint for prisms under eccentric compression (single curvature $e=5 t / 12$ )

The failure modes of prisms under eccentric compression using Model 2 are very similar to those of Model 1, except that no cracking occurs at the junction of the web and faceshells for lower eccentricity with the discrete model (Model 2) in contrast to the smearedonly model (Model 1). This may be caused by the effect of the gap elements. Also, with discrete cracking, the vertical compressive stresses at the out-side of face-shells are a little smaller than with smeared-only model: this may be due to the larger rotation of face-shells with discrete-crack modelling caused by web cracks.

The predicted failure patterns compare favourably with the experimental observations (Becica et al. 1983; Drysdale and Hamid 1983; Maurenbrecher 1983 and 1990; Guo 
1991; Xie et al. 1993 and 1998), except that for prisms under high eccentricities, web cracks were predicted by the models near the face-shells, but were infrequently observed in experiments. Some pictures about the failure patterns of hollow concrete masonry prisms under eccentric compression are shown in Fig. 4.16.
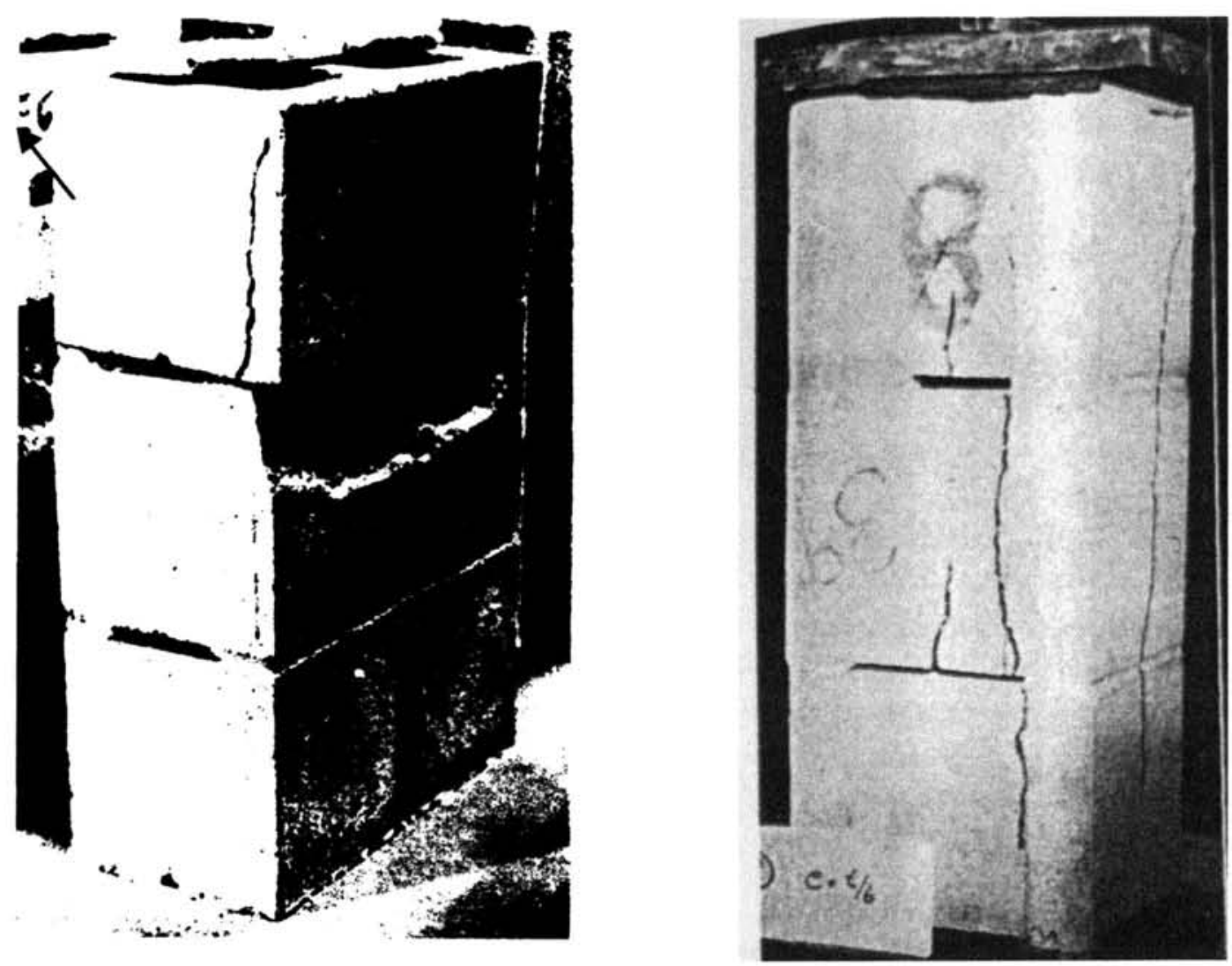

Fig. 4.16---Failure patterns of hollow concrete masonry prisms under eccentric compression (single curvature) (Becica et al. 1983; Drysdale and Hamid 1983) 


\subsubsection{Under eccentric compressive load (double curvature)}

The discrete cracking model would not converge under double curvature loading, so only the smeared cracking model provided results. The predicted failure modes are as follow:

1. At small load inclinations (e.g.: e1 $=-\mathrm{e} 2=\mathrm{t} / 6$ ), at approximately $50 \%$ of the failure load, cracking occurs from the bottom and near the centre of the web of the upper block and develops on an incline upwards. At about $80 \%$ of the failure load, cracking occurs at the top and near the centre of the webs of both the middle and lower blocks, and progresses on an incline downwards with further increases in load, opposite to the web bottom cracks. The final failure occurs with splitting and spalling of the face-shells adjacent to the mortar joint in the region near the web, and/or crushing of the mortar at the in-side of the face-shells when the mortar is weak compared to the block units.

2. At medium load inclinations (for example e1=-e2=t/3), at approximately $50 \%$ of the failure load, cracking occurs in the web of the upper block, from the bottom and near the junction of the web and face-shell, and develops on an incline upwards with increasing load. At about $70 \%$ of the failure load, cracking develops at the top and near the junction in the webs of both the middle and lower blocks, and progresses downwards as the load increases. Finally, when web cracking reaches almost one half of the web height at the junction of the web and face-shell, failure occurs combined with the splitting and spalling of the face-shells adjacent to the mortar joint.

3. At high load inclinations (for example e1=-e $2=5 t / 12$ ), at approximately $55 \%$ of the failure load, cracking occurs from the bottom junction of the web and face-shell, and 
develops upwards as the load increases. At a load of about $70 \%$ of the failure load, cracking occurs at the top junction of the web and the face-shell, and develops downwards as the load increases. Final failure occurs when web cracking reaches about one third of the web height at the junction of the web and face-shell, combined with cracking of the face-shells adjacent to the mortar joint.

Typical comparisons of experimental and predicted failure patterns for a prism under eccentric compressive load (double curvature) are shown in Fig.4.17. The same cracking pattern develops as the eccentricity increases, with cracking moving towards the faceshells. The horizontal stress distribution in the webs of the prism under eccentric compression (double curvature $\mathrm{e}=\mathrm{t} / 3$ ) is shown in Fig. 4.18. The stress distribution in the face-shells and mortar around the mortar joint at the ultimate strength of the prism under eccentric compression (double curvature) is shown in Fig. 4.19.

The predicted failure patterns compare very well with the experimental observations (Maurenbrecher 1990; Xie et al. 1993), except that under medium and high load inclinations face-shell splitting was again predicted by the models but infrequently observed in experiments. Some pictures of actual failure patterns are shown in Fig. 4.20.

\subsubsection{Failure loads}

The failure load ratio (eccentric to concentric compression) from predicted results and experiments are plotted in Fig. 4.21 for single curvature in which equation [4.1] shows the lower bound, and plotted in Fig. 4.22 for double curvature in which equation [4.2] shows the lower bound: 

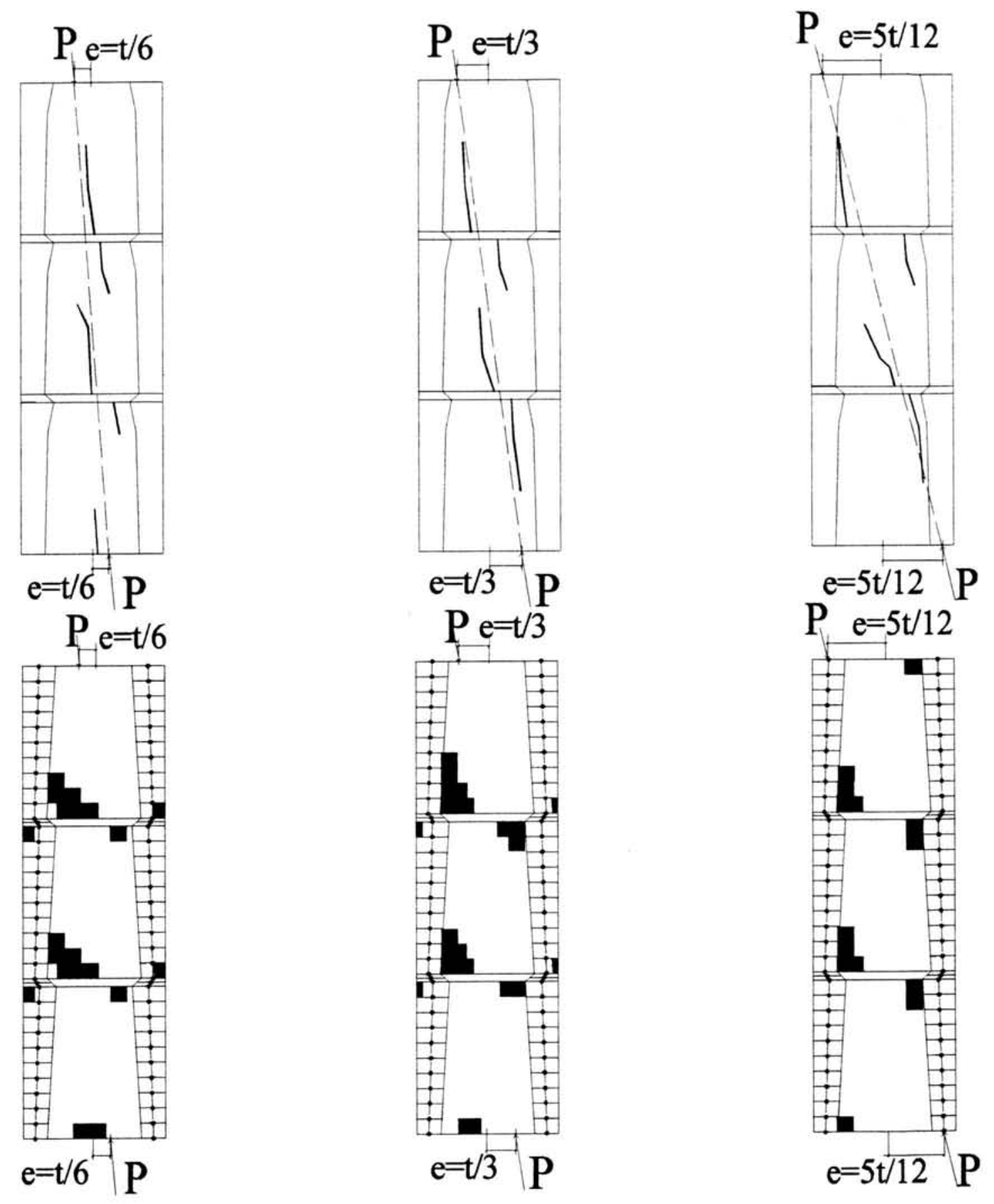

Fig. 4.17---Comparison of failure modes of hollow concrete masonry prisms under eccentric compression (double curvature).

Above are the experimental cracking patterns; below are the predicted cracking patterns. 
MSC/PATRAN Version 8.0 10-Aug-01 12:23:54

Fringe: loadcase-1, Step1, TotalTime $=0.18945$ : Stress, Components-At SECTION_POB

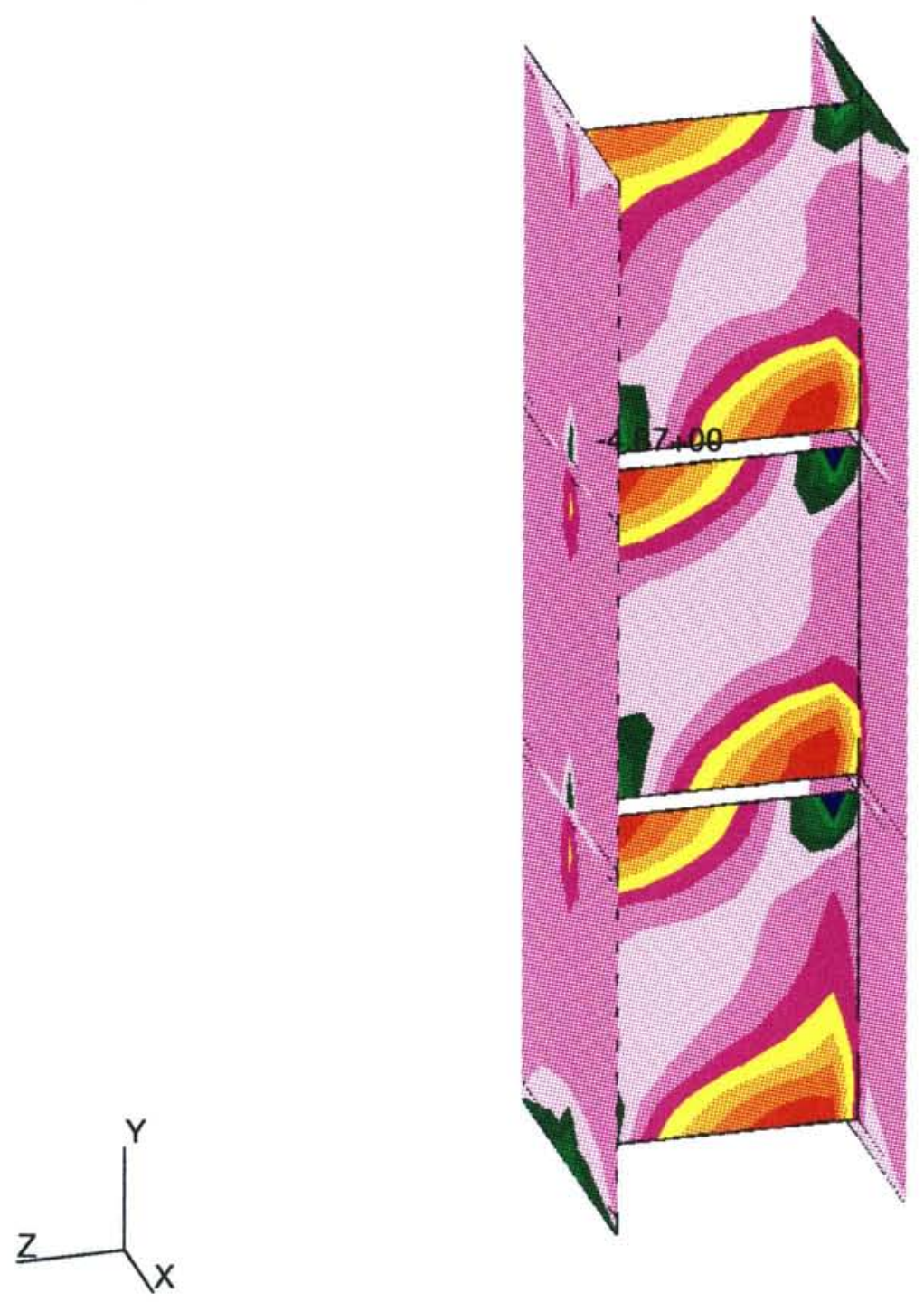

\section{$2.18+00$}

$1.67+00$

$1.17+00$

6.66-01

1.63-01

$-3.40-01$

$-8.43-01$

$-1.35+00$

$-1.85+00$

$-2.35+00$

$-2.86+00$

$-3.36+00$

$-3.86+00$

$-4.36+00$

$-4.87+00$

default_Fringe :

Max 2.68+00@Nd 178

Min-4.87+00@Nd 962

Fig. 4.18---The horizontal stress distribution in the webs of the prism under eccentric compression (double curvature $\mathrm{e}=\mathrm{t} / 3$ ) 


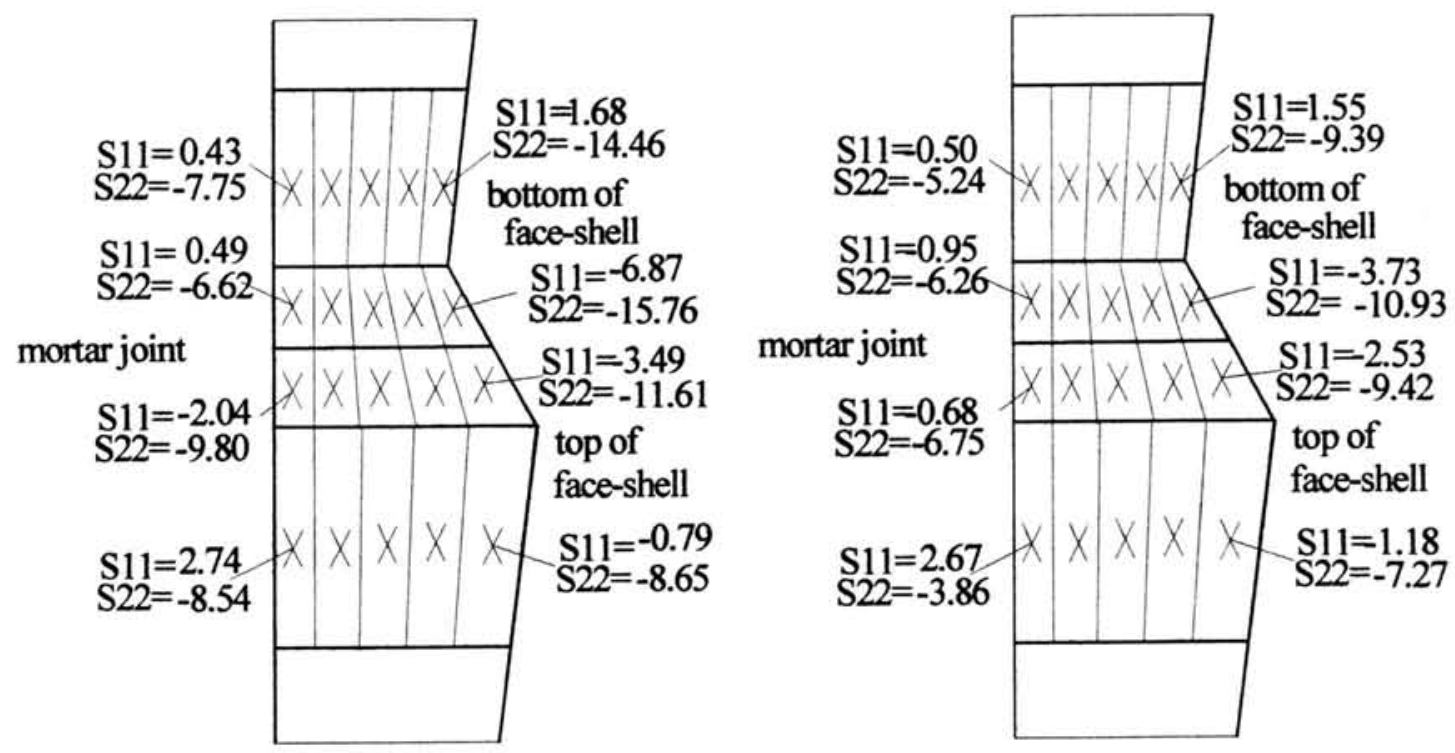

Xintegration point; S11 horizontal stress; S22 vertical stress

(a)

(b)

Fig. 4.19---Stresses in the face-shells and mortar around the mortar joint for prisms under eccentric compression (double curvature) (a) e1=-e $2=t / 6$ (b) $e 1=-e 2=t / 3$

$$
\begin{array}{ll}
P / P_{0}=\frac{1}{1+3(e / t)} & e \leq \frac{5}{12} t \\
P / P_{0}=\frac{1}{1+5(e / t)} & e \leq \frac{5}{12} t
\end{array}
$$

$\mathrm{P}_{0}$ is the ultimate strength of hollow concrete masonry prisms under concentric load, $\mathrm{P}$ is the ultimate strength under eccentric load, $e$ is the out-of-plane eccentricity, and $t$ is the hollow masonry thickness. 

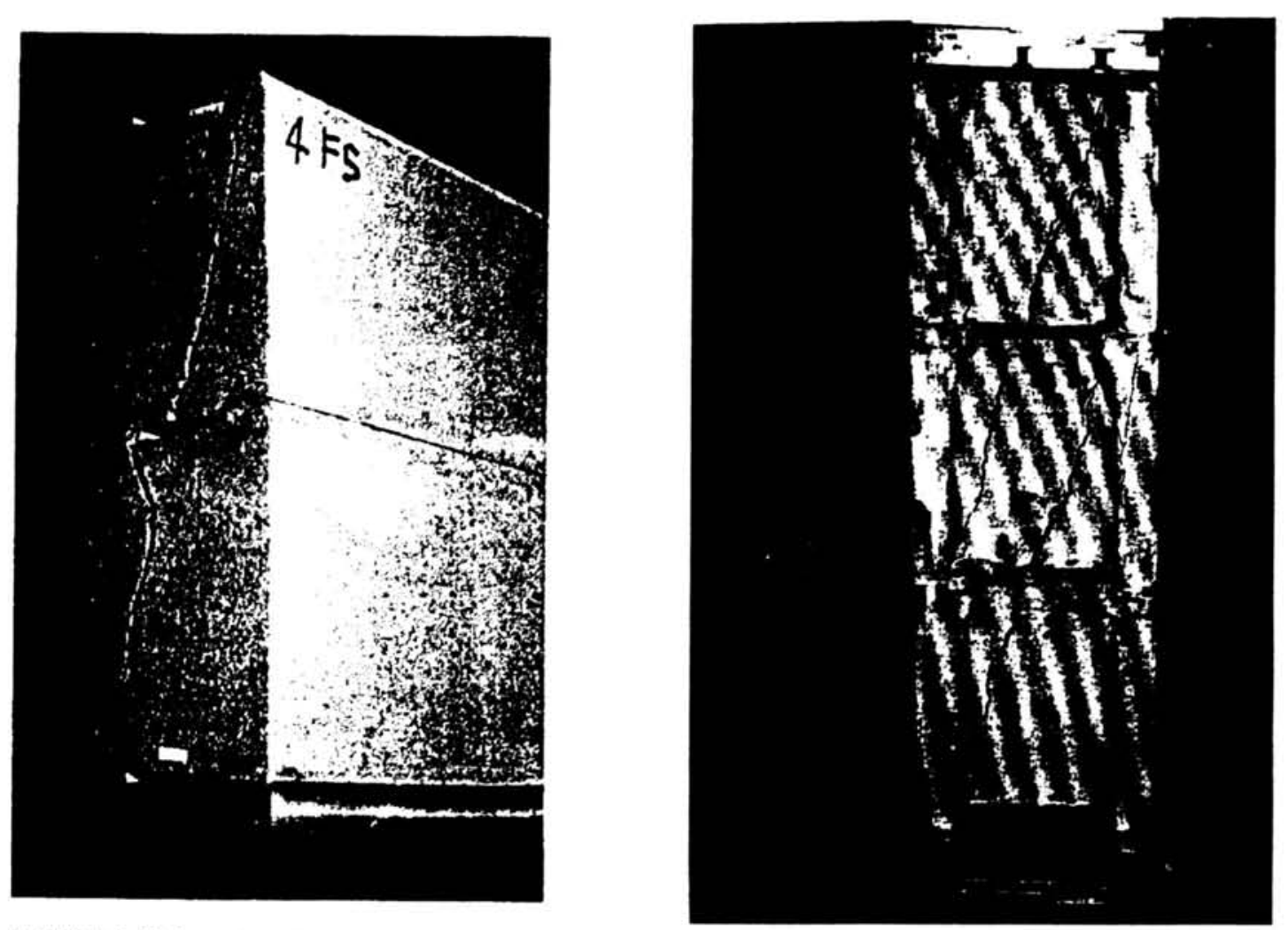

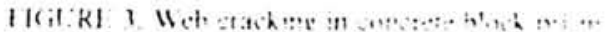

Fig. 4.20---Failure patterns of hollow concrete masonry prisms under eccentric compression (double curvature) (Maurenbrecher 1990; Xie 1998)

There is an excellent agreement between results obtained from the models and experiments at low eccentricities. The predicted results diverge from those from experiments for larger eccentricities, being about $30 \%$ higher at $\mathrm{e}=80 \mathrm{~mm}$. This difference can be attributed to the idealization of the models. In practice, instability develops in prisms loaded under large eccentric compression. However, equations [4.1] and [4.2] give safe results for eccentricity up to $\mathrm{e}=5 \mathrm{t} / 12$. 


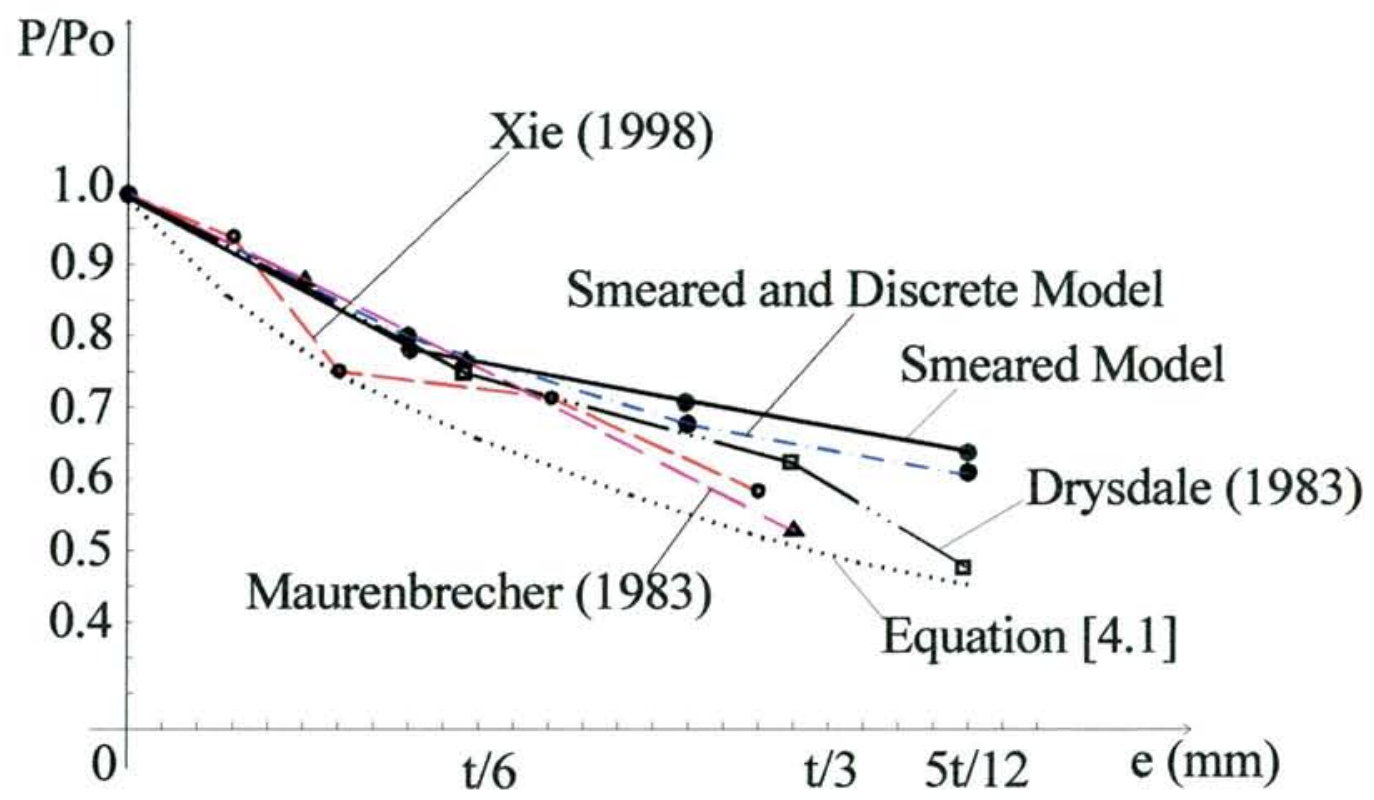

Fig. 4.21---Comparison of failure load ratio (single curvature eccentric compression)

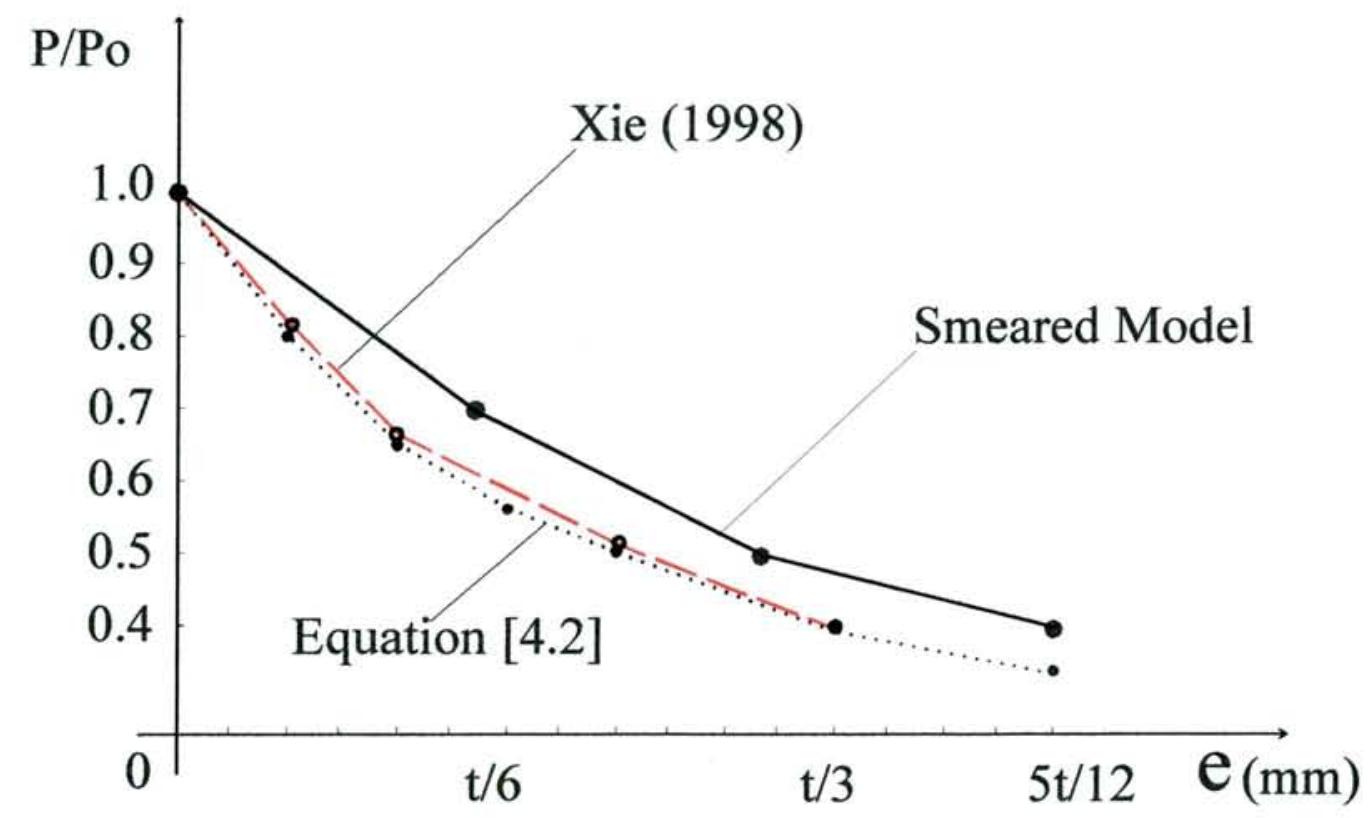

Fig. 4.22---Comparison of failure load ratio (double curvature eccentric compression) 


\subsection{Other Results}

Other results such as load versus vertical deformation (in-side and out-side of face-shell and mortar) for different eccentricities, load versus horizontal deformation (bottom of the web) for different eccentricities, are also predicted by the models and compare very well with the results obtained experimentally (Xie 1998). It is not necessary to report them here, because through the comparison of the results of failure modes and failure loads, the models have been shown to be capable of simulating the structural behaviour of hollow concrete masonry up to the ultimate limit states.

\subsection{Application of Models}

The existence of flare and taper in the hollow blocks has been reported to reduce the ultimate compressive strength of ungrouted hollow block masonry prisms by as much as 38\% (Hamid and Abboud 1986). Based on elastic finite element analysis, Khalil and Shrive also concluded that reducing the face-shell flare and taper of blocks should improve the performance of ungrouted hollow masonry prism (Khalil and Shrive 1987). However, it was reported in another study (Guo 1991) that the geometry of the normal blocks should not significantly influence the ultimate compressive strength of ungrouted hollow block prisms. Therefore, it is very interesting to investigate the influence of the flare and taper of the face-shell in the block using these models. 


\subsubsection{Effect of face-shell flare and taper}

To investigate the influence of the flare and taper of the face-shell in the blocks on the structural behaviour of hollow masonry prisms, models were developed in which the actual face-shell flare and taper were ignored and simplified as depicted in Fig. 4.23. Three-block-high stack-bonded prism models similar with those shown in Fig. 4.3 but without face-shell flare and taper were analyzed to compare with the results obtained from those models shown in Fig. 4.3. The results are as follows:

Under concentric compression, if the face-shell thickness of the model without face-shell flare and taper is $32 \mathrm{~mm}$, the failure load of the model is 1.07 times that of model with face-shell flare and taper, although the failure modes are the same. If face-shell thickness is chosen to be $34 \mathrm{~mm}$, the failure load is 1.11 times that of model with face-shell flare and taper. Under eccentric compression (single curvature and face-shell thickness being $34 \mathrm{~mm}$ ), the failure load of the model without face-shell flare and taper is $1.23,1.10,1.07$ times that of model with face-shell flare and taper for $e=t / 6, e=t / 3$, and $e=5 t / 12$, respectively.

An example of the stresses in the face-shells and mortar around the mortar joint at the ultimate strength of the model without face-shell flare and taper under concentric compression is shown in Fig. 4.24. That under eccentric compression (single curvature with $\mathrm{e}=5 \mathrm{t} / 12$ ) is shown in Fig. 4.25 . 

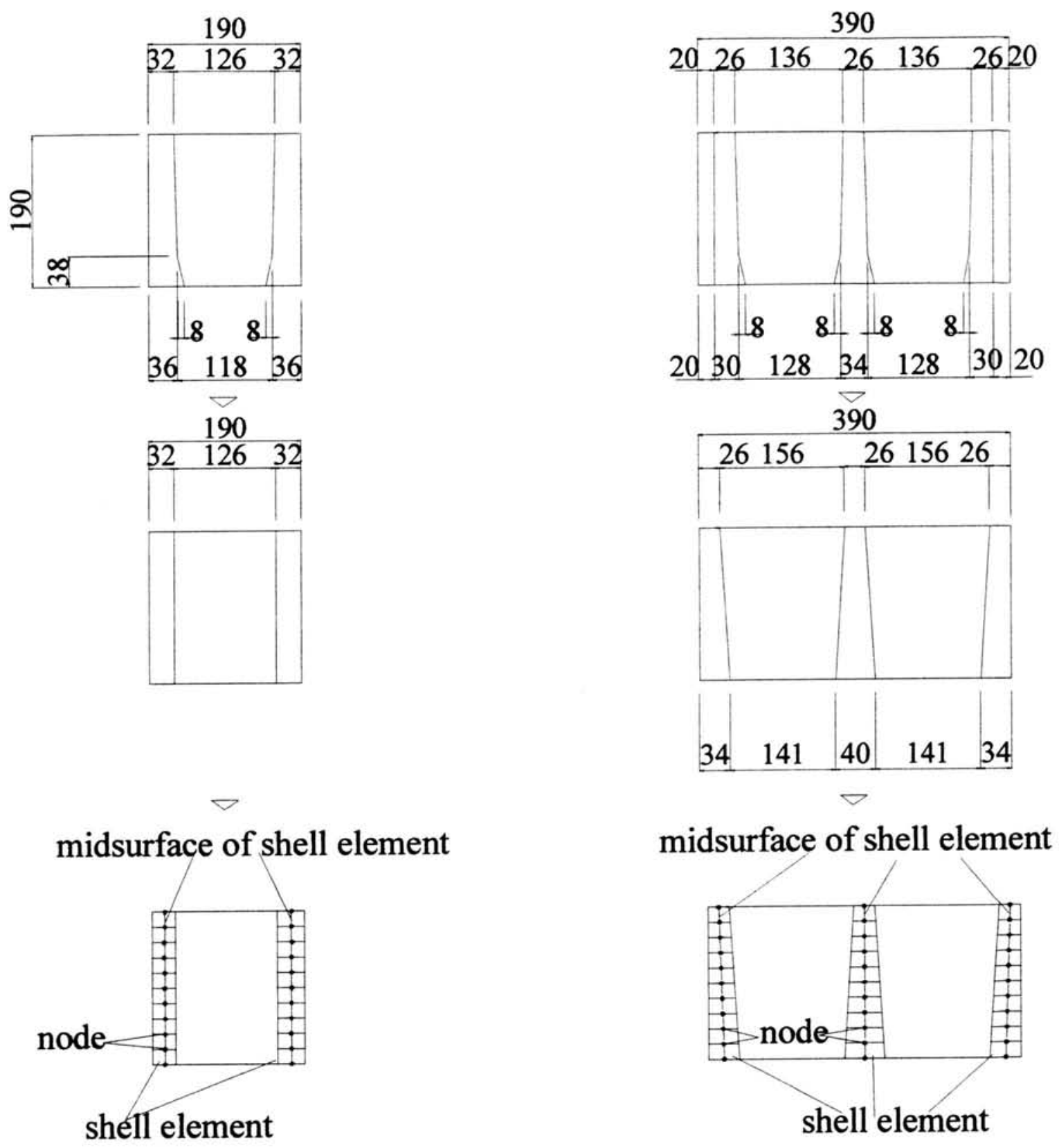

Fig. 4.23---Simplified model without face-shell taper and flare but with web taper and flare 


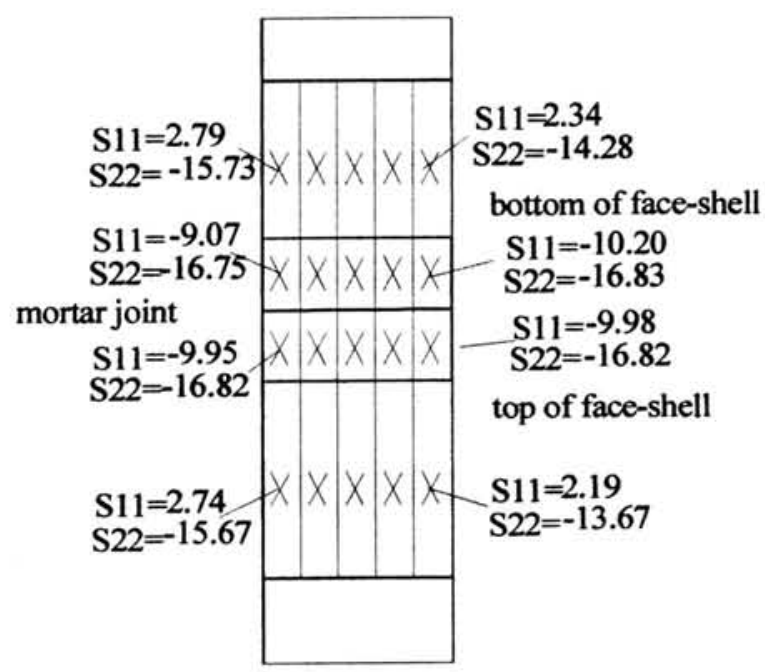

$X$ integration point; S11 horizontal stress; S22 vertical stress

Fig. 4.24---Stresses in the face-shells and mortar around the mortar joint in the model without face-shell flare and taper, under concentric compression

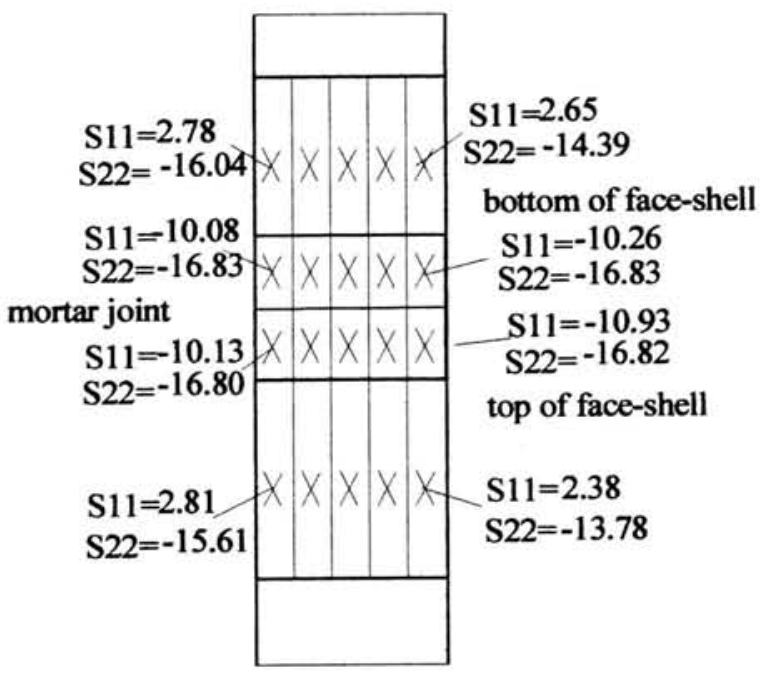

X integration point; S11 horizontal stress; S22 vertical stress

Fig. 4.25---Stresses in the face-shells and mortar around the mortar joint in the model without face-shell flare and taper, under eccentric compression (single curvature with $\mathrm{e}=5 \mathrm{t} / 12$ ) 
As can be seen from Fig. 4.24 and 4.25 , at the ultimate strength, smaller stress gradients exist in the face-shell from out-side to in-side in the models without face-shell taper, compared to the models with face-shell flare and taper (Fig. 4.7, 4.10, 4.13, 4.15).

\subsubsection{Effect of web}

Because cracks usually appear first in the block webs, it is interesting to investigate the effect of the web on the prism's failure mode and ultimate load using these models.

\subsubsection{Effect of web flare and taper}

Three-block-high stack-bonded prism models similar with those shown in Fig. 4.3 but without web flare and taper were used to compare with the results obtained from those models shown in Fig. 4.3.

Under concentric compression, the result showed that the failure load of the model without web flare and taper was almost the same as that of model with web flare and taper. Although the cracking patterns were a little different (web cracking occurred at the top as it occurred at the bottom), the final failure modes were the same: splitting and spalling of the face-shells, and/or mortar crushing.

\subsubsection{Effect of cut web}

Three-block-high stack-bonded prism models similar with those shown in Fig. 4.3 but with webs cut to $1 / 3$ of the web height from both the top and bottom of the centre of the 
webs were used to compare results obtained from the model shown in Fig. 4.3 and from experimental results (Guo 1991, Xie 1998).

Under concentric compression, the predicted results showed that the cutting the web up to $1 / 3$ of the web height had almost no influence on the failure load or the failure mode. The web cracking patterns were only slightly different from those of models without cut webs. The failure loads of the models with cut webs were a little higher. This confirms that the final failure is the result of the stress re-distribution, which occurs after the onset of the cracking of the web, and then causes the out-side splitting/spalling of the face-shell and/or crushing of the mortar (for weak mortar). However, the results also showed that if webs were cut more than $2 / 5$ of the web height from both the top and bottom, the ultimate strength of the prism decreased tremendously. This is because the remaining parts in the middle of the webs are not strong enough to transfer compression, and the prism becomes a mechanism.

Under eccentric compression, the predicted results showed that cutting webs decreased the ultimate capacity significantly, as the cut webs are not able to transfer as much shear force as the uncut webs, especially for double curvature eccentric compression.

Typical comparisons of experimental and predicted failure patterns for a prism with webs cut up to $1 / 3$ of the web height under concentric compressive load are shown in Fig.4.26. The stress distribution in the face-shells and mortar around the mortar joint at the ultimate strength of the prism with cut web under concentric compression is shown in Fig. 4.27. 
The predicted failure patterns and failure loads of prisms with cut webs compare very well with the experimental observation (Guo 1991; Xie 1998).

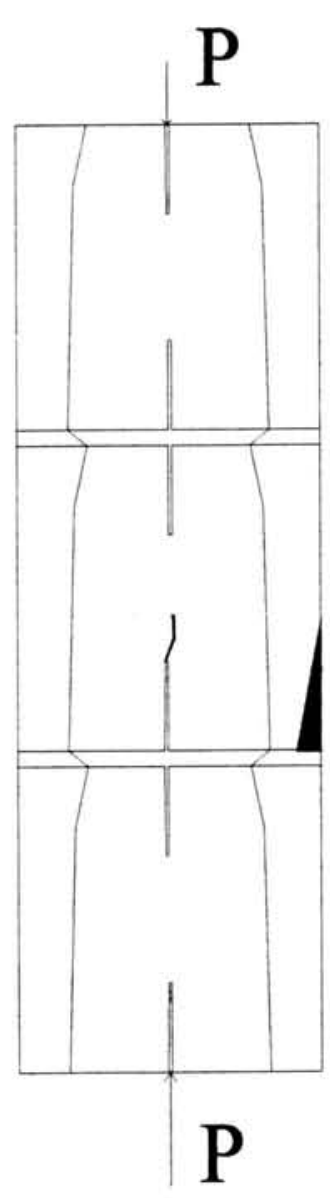

(a)

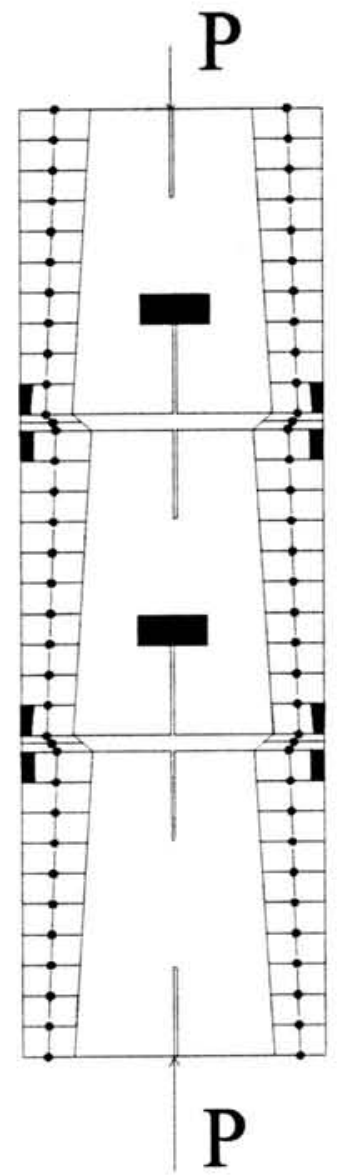

(b)

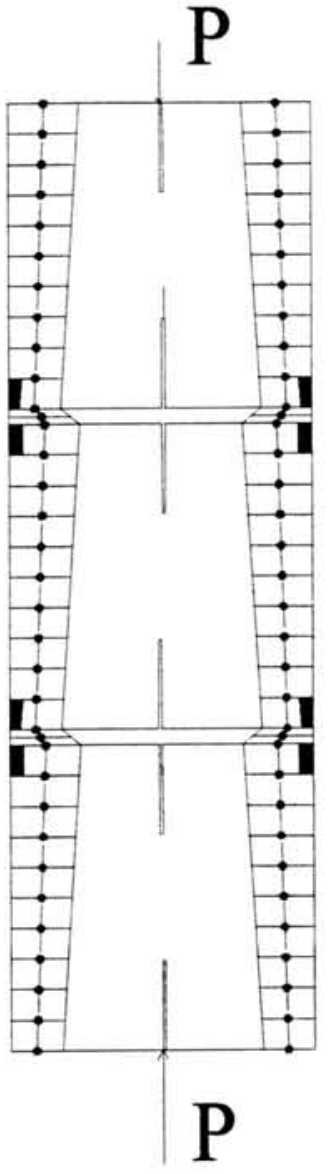

(c)

Fig. 4.26---Comparison of failure modes of prisms with web cut to $1 / 3$ of the web height under concentric compression (a) Experiment (b) Model 1 (c) Model 2 


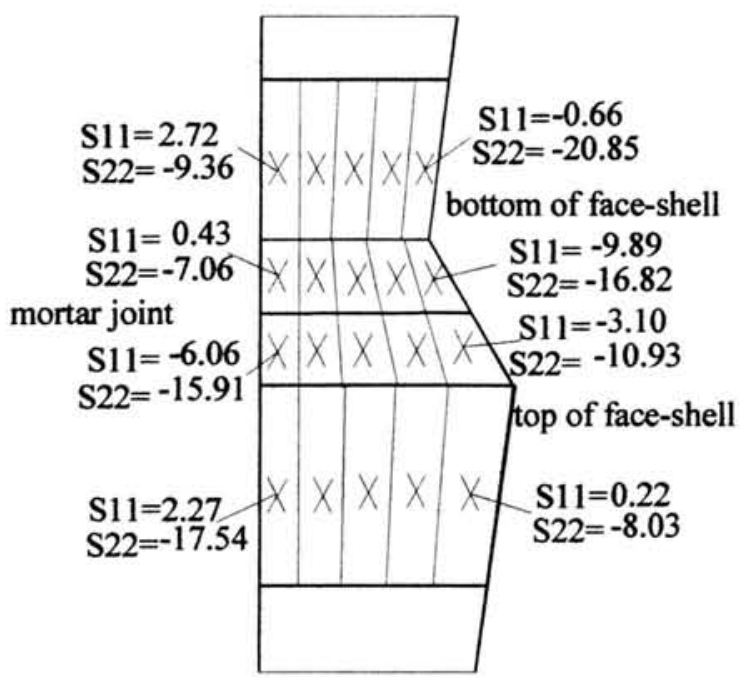

$X$ integration point; $\quad$ S11 horizontal stress; S22 vertical stress

Fig. 4.27---Stresses in the face-shells and mortar around the mortar joint in the model with cut webs, under concentric compression

\subsection{Summary}

3D non-linear elasto-plastic finite element models have been developed and applied to simulate the structural behaviour of hollow concrete masonry prisms under concentric and eccentric compression. Block units and mortar joints were modelled separately. Geometric and material non-linearities were taken into account. Smeared crack modelling and discrete crack modelling approaches were used to model the progressive cracking and damage in the models. Isoparametric shell elements and gap elements were used.

(1). The results of the models were compared with the experimental results. The good agreement confirms that the non-linear behaviour of the hollow masonry prism under 
concentric and eccentric compression can be successfully modelled, although there is some divergence at very high eccentricities. The models are capable of analyzing the structural behaviour of hollow concrete masonry, certainly at low and medium eccentricities.

(2). According to the results of the models, the face-shell flare and taper do have some influence on the ultimate compressive strength of hollow concrete masonry prisms.

(3). According to the results of the models and some other published experimental results, the web flare and taper do not seem to have significant influence on the ultimate compressive strength of hollow concrete masonry prisms.

(4). Cutting the webs up to $1 / 3$ of the web height has almost no influence on the failure load or failure mode when under concentric compression. However, if webs are cut more than $2 / 5$ of the web height from both the top and bottom, the ultimate compressive strength of the prism will be reduced tremendously. Cutting webs decreases the ultimate capacity when subjected to eccentric compression, especially for double curvature eccentric compression.

(5). The model will now be developed further to simulate the structural behaviour of hollow concrete masonry walls subject to concentrated loading. The model will be verified against previous wallette tests (Page and Shrive 1990; Shrive and Sayed-Ahmed 1997). This will demonstrate the validity of the model for both stack and running bond construction. The model will then be used to simulate and analyze the other situations, with critical results verified by further experiments. 


\section{CHAPTER 5}

\section{D NON-LINEAR FINITE ELEMENT MODELS OF HOLLOW CONCRETE MASONRY WALLS SUBJECTED TO CONCENTRATED LOADS}

\subsection{Introduction}

To obtain an increase in the bearing capacity of the walls carrying concentrated loads, industry practice is to grout some of the hollow masonry units or to incorporate a bond beam directly beneath the concentrated loads. Here, for every kind of hollow masonry wall for which experimental results are available (such as plain walls, walls with bond beams, and walls with grouted details), models were developed and the constitutive relations verified. Then the models were used to predict load-carrying capacity and failure mechanism in situations where the wall geometry and loading locations are not described in the literature. In all these wall models, hollow block units, mortar, grout and bond beam block units were modelled separately. Shell elements were used to model the concrete block units and mortar, solid elements were used to model the grout and bond beam block units. Multiple-point constraints were used between the shell and solid elements. After processing the original mesh once, substructuring was used in low stress zones using super elements. Geometric and material non-linearities as well as damage due to progressive cracking were taken into account in the analyses. Both the smeared and discrete cracking approaches were used to model progressive cracking. PATRAN was 
used for pre- and post-processing of the models, while the numerical computation was performed with ABAQUS.

\subsection{Plain Wall Models}

\subsubsection{Geometry}

The plain wall models are shown in Fig. 5.1, 5.2 and 5.3 respectively for the three loading locations modelled: over the central web of a unit; over two end webs and a vertical mortar joint; and over the core. The material properties (compressive strength) used in the models were hollow block units (19MPa) and mortar (7.6MPa), matching the materials used in the experiment (Page and Shrive 1990). The loading plate length modelled was $160 \mathrm{~mm}$. Other loading plate lengths $(80 \mathrm{~mm}, 160 \mathrm{~mm}, 240 \mathrm{~mm}, 320 \mathrm{~mm}$, $480 \mathrm{~mm}, 640 \mathrm{~mm}, 880 \mathrm{~mm}$ ) were also modelled for concentric loading over the central web. The connection detail between face-shells of hollow block units and the loading plate is shown in Fig. 5.4.

\subsubsection{Results}

\subsubsection{Failure modes}

1. Concentrated load over central web:

Under concentric load, when loading plate length is $80 \mathrm{~mm}$ or $160 \mathrm{~mm}$, at about $50 \%$ of the ultimate load, cracking appears in the middle of the top of the central web directly beneath the loading plate. At about $80 \%$ of the ultimate load, cracking appears on the two 
sides of the top of the central web, and also in the face-shells at the edges of the loading plate.

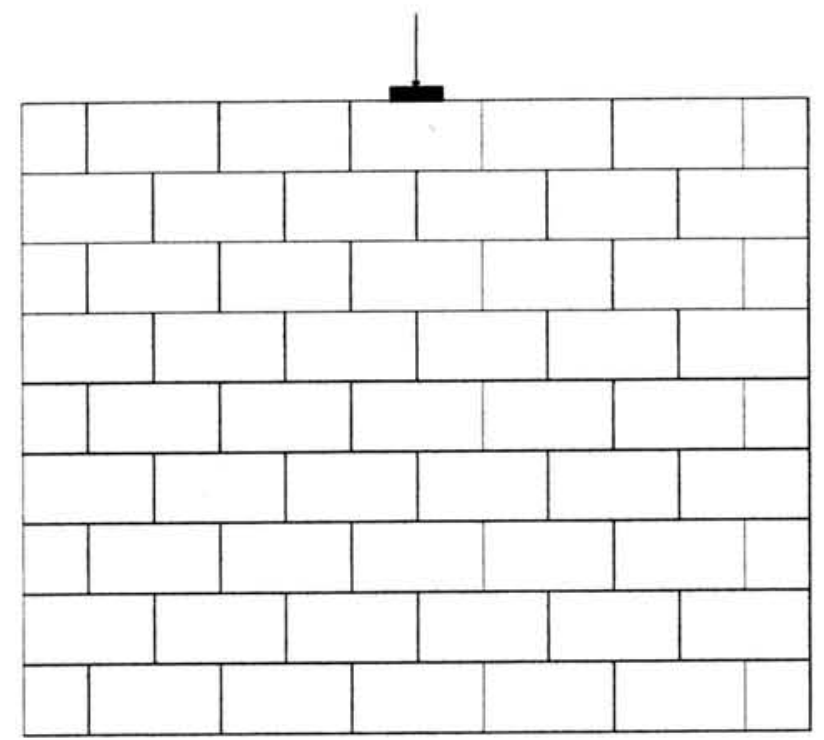

Fig. 5.1---Plain hollow concrete masonry wall model (load over central web)

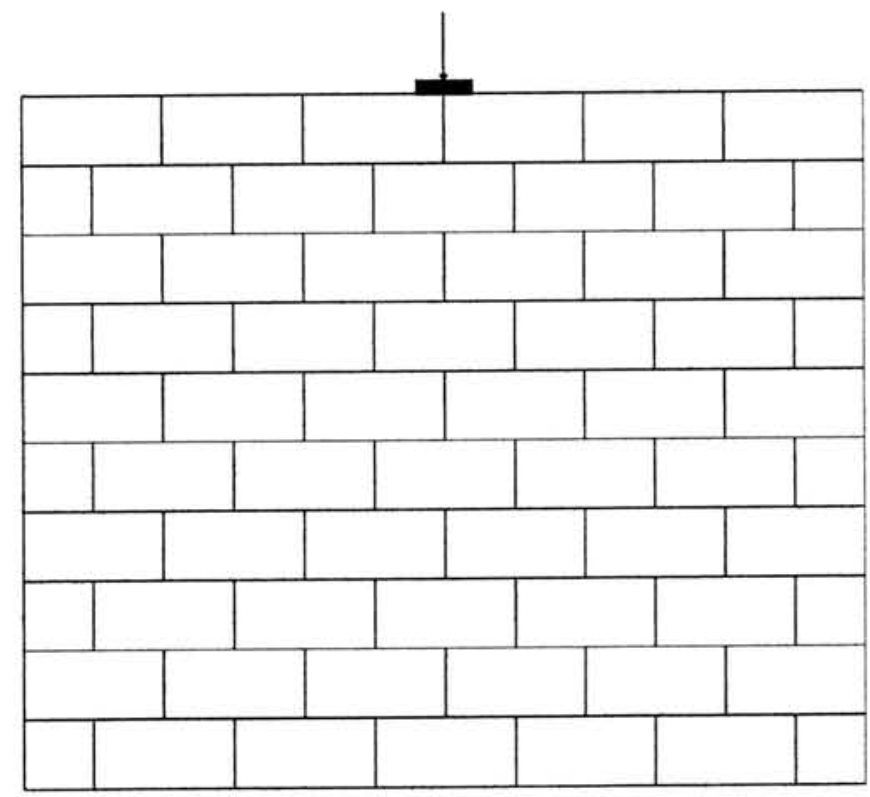

Fig. 5.2---Plain hollow concrete masonry wall model (load over two end webs) 


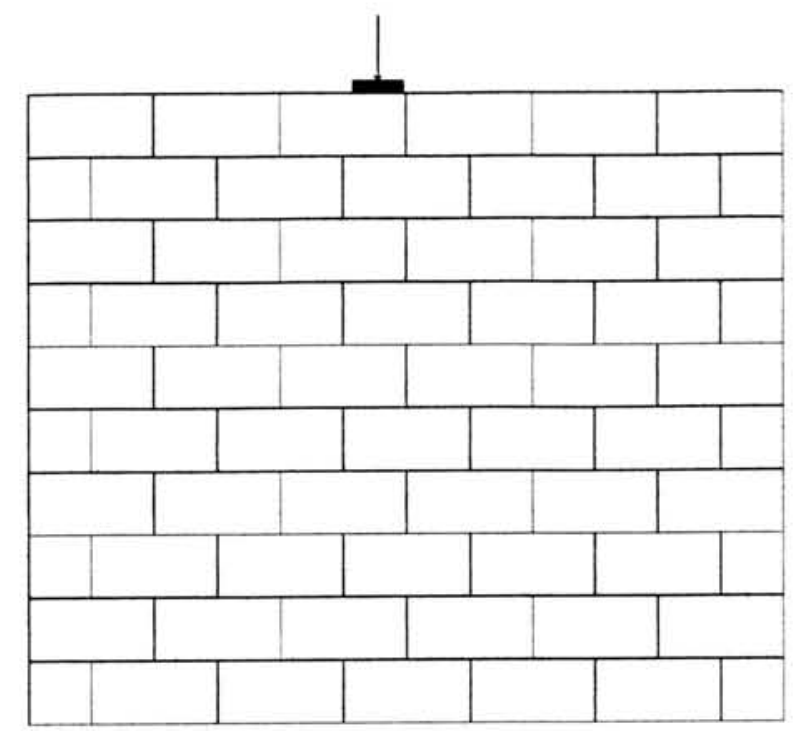

Fig. 5.3---Plain hollow concrete masonry wall model (load over core)

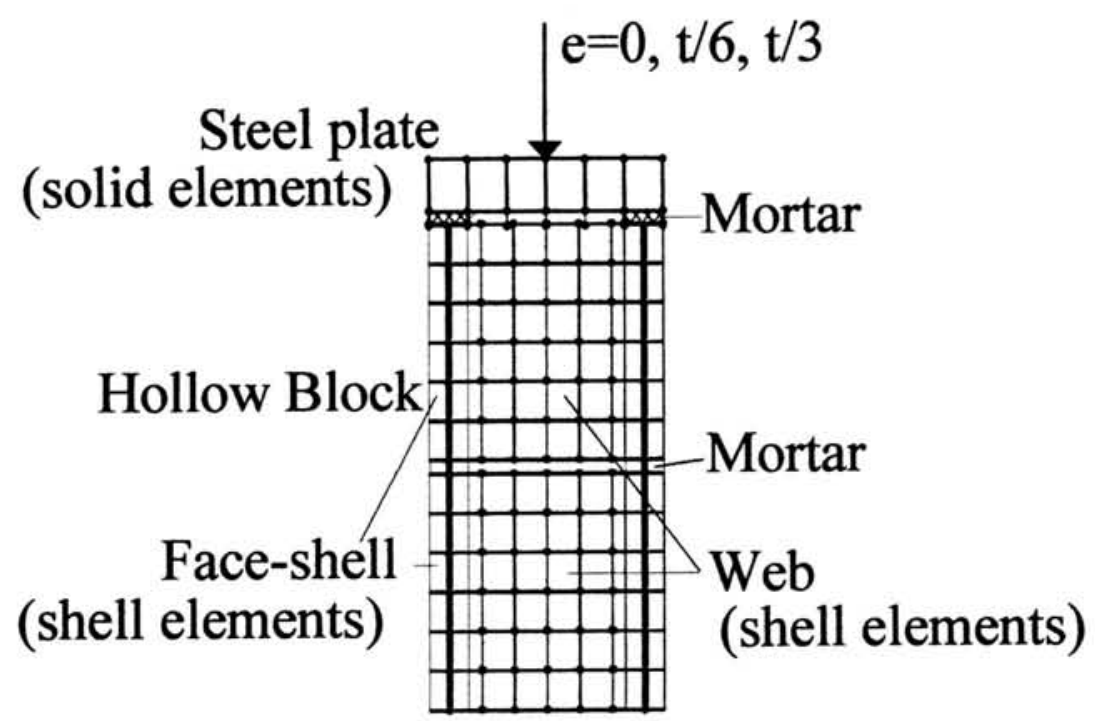

Fig. 5.4---Connection details between hollow block unit and loading plate

At about $90 \%$ of the ultimate load, cracking forms in the middle of the bottom of the central web directly beneath the loading plate. Finally, cracking occurs at the top of the 
two end webs in the second course below the loading plate (running bond), and a vertical crack forms in the face-shells of the unit directly beneath the loading plate and in the mortar one course below in line with the load, similar to a crack that forms in a solid wall loaded in this manner. With increasing loading plate length, the failure modes described above occur again, except that the ultimate capacities are increased. A typical predicted cracking pattern is shown in Fig. 5.5(a).

Under eccentric load, the first cracks still appear at the top of the central web directly beneath the loading plate, but on the lightly loaded side, rather than the middle. As the load increases, cracking develops on the heavily loaded side of the bottom of the central web, and the top of the two end webs in the same unit. And at the same time, a vertical crack develops in the face-shell in line with the load. Final failure occurs with cracking on the lightly loaded side of the top of the two end webs in the second course below the load. As the eccentricity increases, the sequence of cracking and failure is similar except that the top of the central web cracks closer and closer to the lightly loaded face-shell while the bottom of the web cracks closer and closer to the heavily loaded face-shell. A typical predicted cracking pattern is shown in Fig. 5.5(b).

The predicted failure modes compare very well with the available experimental results (Page and Shrive 1990), as depicted in Fig. 5.6(a). The vertical compressive stress distribution of plain wall subjected to concentric concentrated load over central web is shown in Fig. 5.7. The horizontal tensile stress distribution underneath the loading plate is shown in Fig. 5.8. 


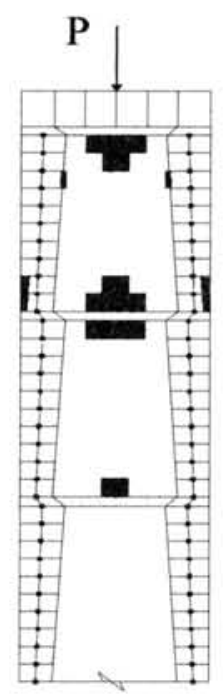

(a)

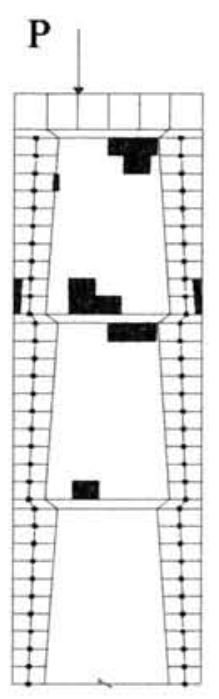

(b)

Fig. 5.5---Cracking pattern of plain hollow masonry walls subjected to concentrated load

(a) concentric concentrated load, (b) eccentric concentrated load

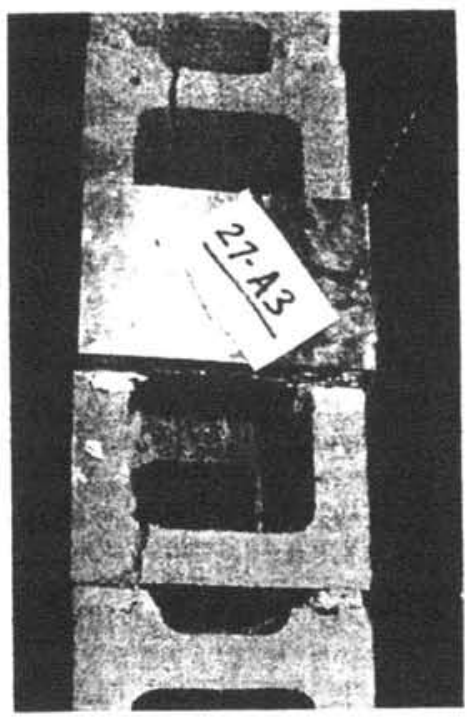

(a)

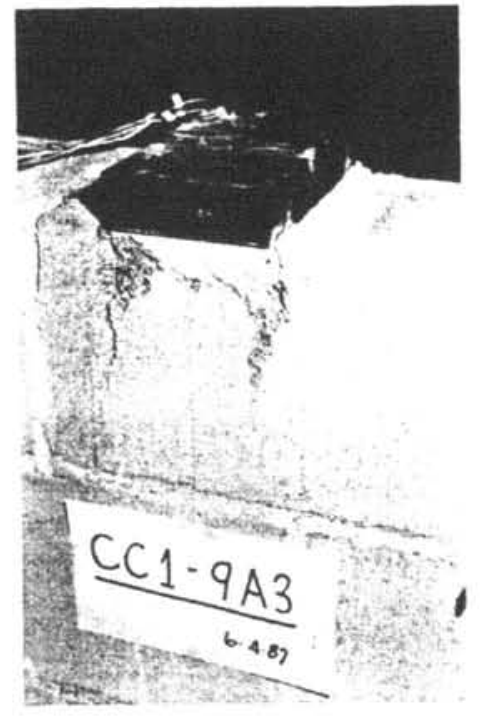

(b)

Fig. 5.6---Failure modes of plain hollow masonry walls subjected to concentrated load (a) load over central web; (b) load over core 


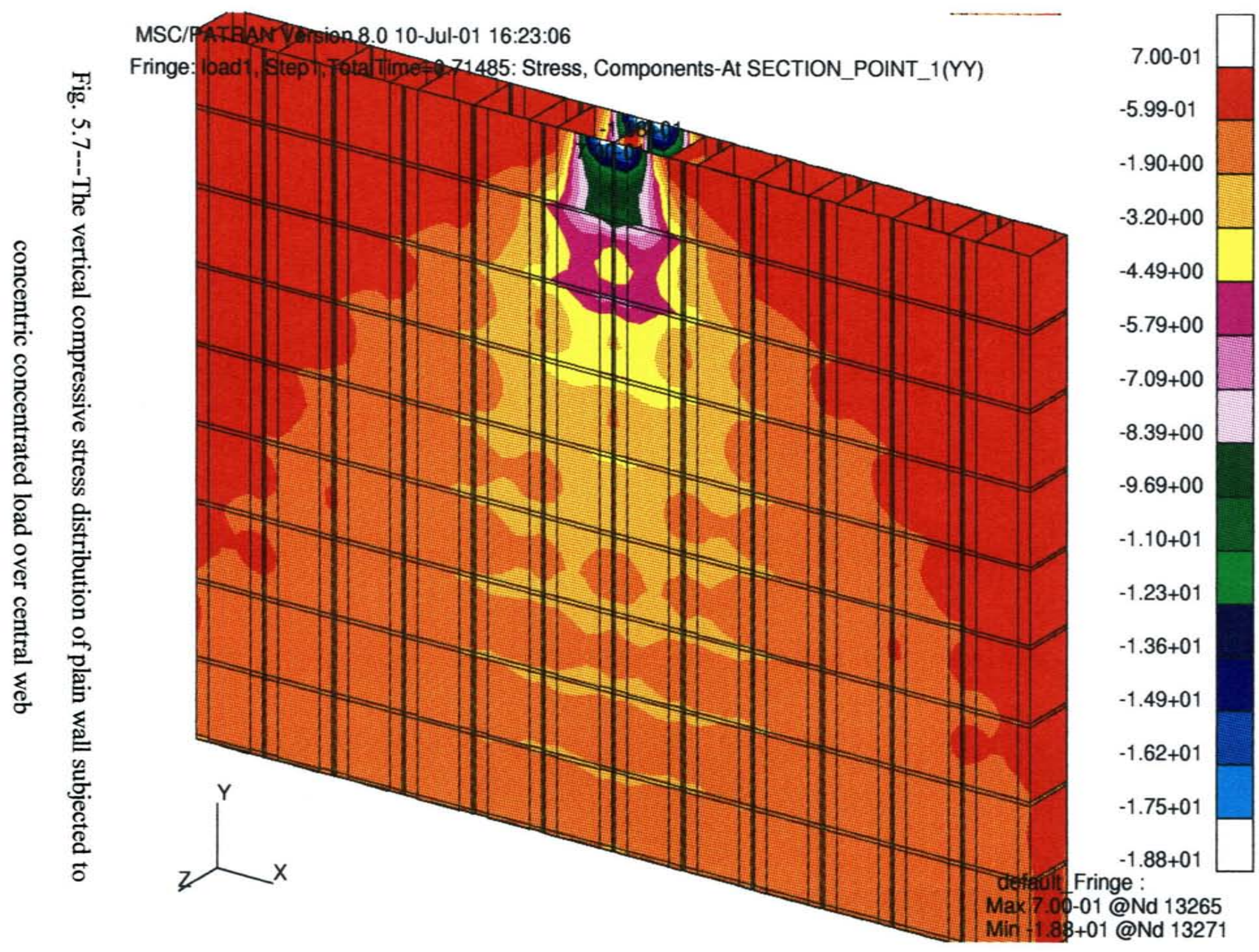




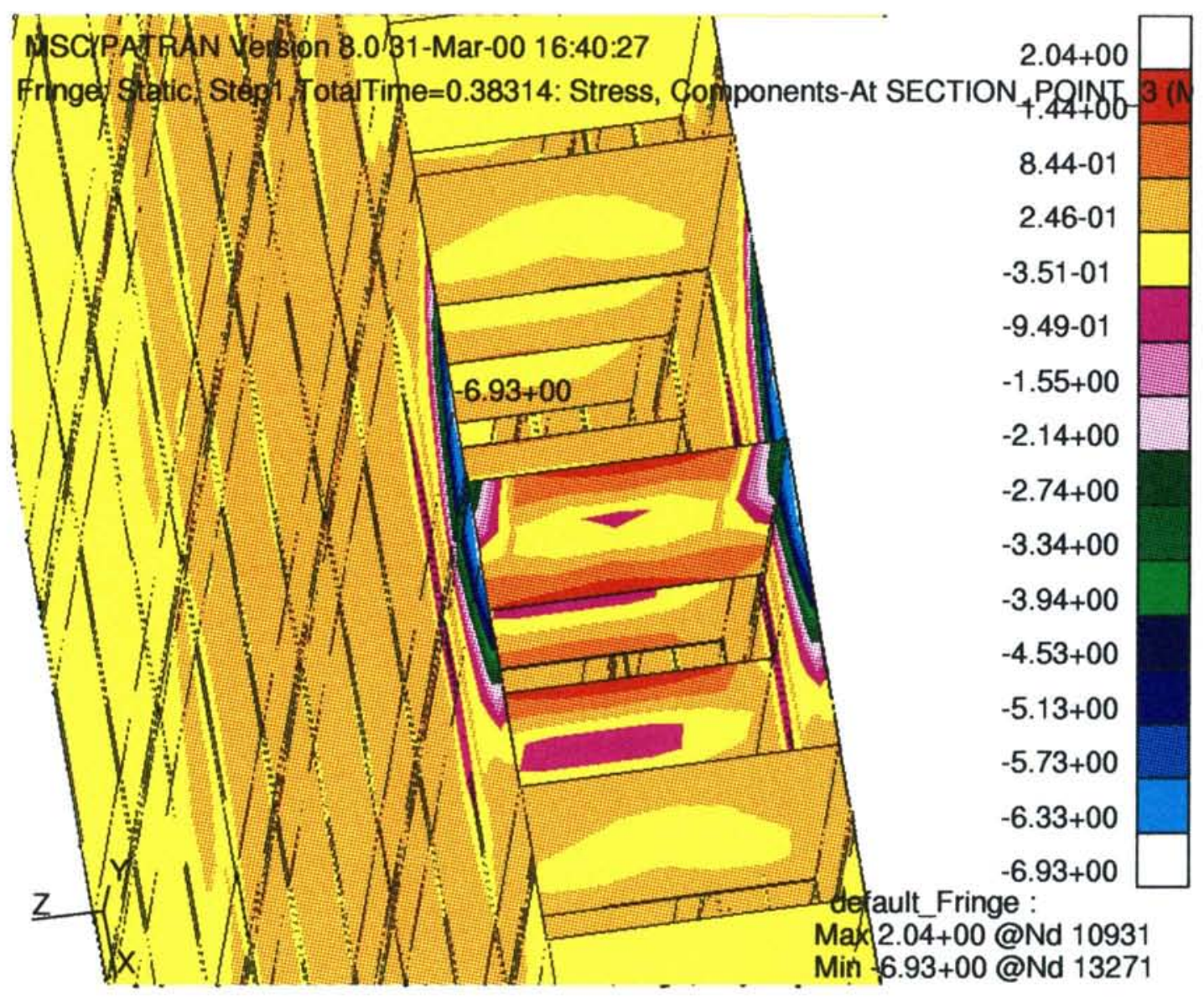

Fig. 5.8---The horizontal tensile stress distribution underneath the loading plate subjected to concentric concentrated load over central web 


\section{Concentrated load over two end webs:}

Under concentric load, at about $55 \%$ of the ultimate load, cracking appears in the middle of the top of the two end webs directly beneath the loading plate. At about $90 \%$ of the ultimate, cracking occurs on the two sides of the top of the two end webs, and also occurs in the face-shells at the edges of the loading plate. At almost the same time cracking occurs in the middle of the bottom of the two end webs. Finally, cracking occurs at the top of the central web one course below (running bond), and a vertical crack forms in the bottom part of the mortar in the course directly beneath the loading plate in line with the load, similar to a crack that forms in a solid wall loaded in this manner.

Under eccentric load, the first cracks still form at the top of the two end webs directly beneath the loading plate, but on the lightly loaded side. As the load increases, cracking appears on the heavily loaded side of the bottom of the two end webs, and a vertical crack forms in the bottom part of the mortar in the course directly beneath the load in line with the load. Final failure occurs when cracks develop on the lightly loaded side of the top of the central web one course below. As the eccentricity is increased, the sequence of cracking and failure is similar except that the top of the two end webs cracks closer and closer to the lightly loaded face-shell while the bottom of the two end webs cracks closer and closer to the heavily loaded face-shell.

The failure modes of hollow concrete masonry wall subjected to concentrated load over two-end webs are almost the same as that with load over the central web, except that when the load is over two-end webs, the wall is stiffer. 


\section{Concentrated load over core:}

Under concentric load, at about $80 \%$ of the ultimate load, mortar connecting the end webs beside the loading plate cracks. Final failure occurs by local splitting of the loaded faceshells directly in line with the edge of the bearing plate, a typical tearing stress failure.

As the eccentricity is increased, final failure occurs by local splitting of the heavily loaded face-shell directly in line with the edge of the bearing plate, and the ultimate load decreases. The predicted result compares very well with the experimental result of Page and Shrive (1990), as shown in Fig. 5.6(b).

\subsubsection{Failure loads}

The failure loads from predicted results and experiments for plain walls subjected to concentrated load are presented in Tables 5.1 and plotted in Fig. 5.9a. There is excellent agreement between the predicted and experimental results, as can be seen. As the eccentricity increases, the models predict a similar failure mechanism but lower and lower failure loads. However, the idealization of the models might overestimate the failure loads of hollow concrete masonry walls subjected to eccentric loads, as instability develops in practice under large eccentric loads.

The strength variation for plain walls subjected to concentrated load with increasing eccentricity is depicted in Fig. 5.9b, in which Equation [4.1] shows the lower bound. 
Table 5.1 Predicted and Experimental Results for Plain Hollow Concrete Masonry Walls Subjected to Concentrated Loads

\begin{tabular}{ccccc}
\hline $\begin{array}{c}\text { Loading } \\
\text { Position }\end{array}$ & $\begin{array}{c}\text { Loading Plate } \\
\text { Length a }(\mathrm{mm})\end{array}$ & $\begin{array}{c}\text { Eccentricities } \\
(\mathrm{mm})\end{array}$ & \multicolumn{2}{c}{ Failure Load $(\mathrm{KN})$} \\
\hline $\begin{array}{c}\text { Load over } \\
\text { central web }\end{array}$ & 80 & $\mathrm{e}=0$ & 179 & \\
& 160 & $\mathrm{e}=0$ & 236 & 251 \\
& 240 & $\mathrm{e}=0$ & 287 & \\
& 320 & $\mathrm{e}=0$ & 349 & \\
& 480 & $\mathrm{e}=0$ & 488 & \\
& 640 & $\mathrm{e}=0$ & 658 & \\
& 880 & $\mathrm{e}=0$ & 862 & \\
& 160 & $\mathrm{e}=31$ & 185 & $171^{*}$ \\
\hline Load over two & 160 & $\mathrm{e}=62$ & 155 & \\
end webs & 160 & $\mathrm{e}=0$ & 221 & $219^{* *}$ \\
& 160 & $\mathrm{e}=31$ & 175 & \\
\hline Load over & 160 & $\mathrm{e}=62$ & 149 & \\
core & 160 & $\mathrm{e}=0$ & 183 & 181 \\
& 160 & $\mathrm{e}=31$ & 156 & \\
\hline
\end{tabular}

Note: Experimental data are from Page and Shrive (1990).

* Eccentricity may be $35 \mathrm{~mm}$.

** From Shrive and Sayed-Ahmed (1997). 


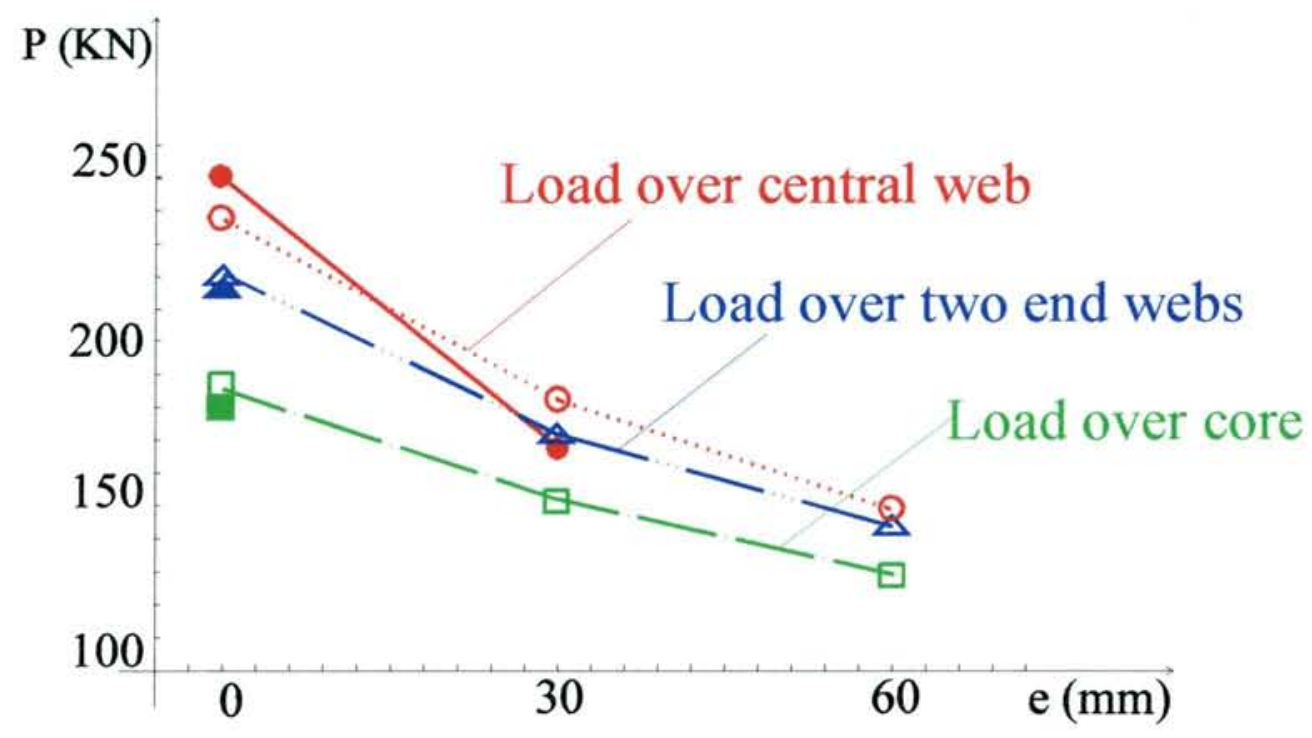

Fig. 5.9a---The failure loads from predicted and experimental results for plain walls (loading plate length $160 \mathrm{~mm}$ ) (solid point: experimental, hollow point: predicted)

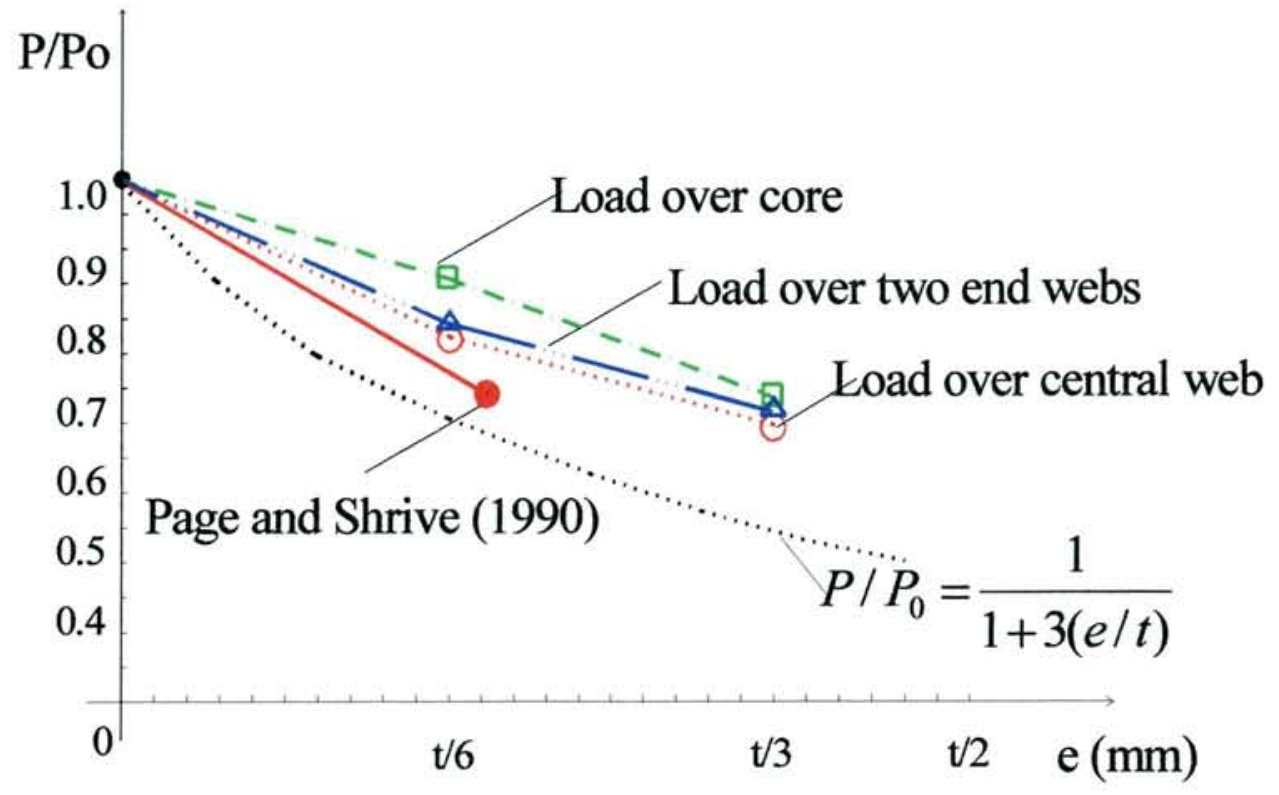

Fig. 5.9b---Ultimate strength variation with increasing eccentricity from predicted and experimental results for plain walls 


\subsubsection{Strength enhancement factor}

Strength enhancement typically occurs in both solid masonry and concrete structures subjected to concentrated load, due to the confining effect of the lightly loaded material adjacent to the concentrated load. For face-shell bedded hollow masonry, the limited experimental results (Page and Shrive 1990) indicate that some enhancement may occur, but it is highly dependent on the local loading detail (loading over web or core) as well as the loaded length ratio.

For face-shell bedded hollow masonry, the strength enhancement factor under a concentrated load is suitably defined as the ratio between the stress directly under the bearing plate based on the hollow masonry face-shell bedded area and the uniaxial strength of plain hollow masonry. According to this definition, strength enhancement was calculated for results from the plain wall model with loading over a central web. Strength enhancement is plotted against the loading plate length in Fig. 5.9c, as Sayed-Ahmed and Shrive (1996) indicated that the governing factor for strength enhancement is the loaded length rather than the ratio of loaded length to wall length in face-shell bedded hollow masonry. Equation [5.1] gives safe estimate for the strength enhancement factor K:

$$
1.0 \leq \mathrm{K}=\frac{80}{\mathrm{a}_{\mathrm{h}}}+0.8 \leq 2.0
$$

where $a_{h}$ is the length (mm) of loading plate on hollow masonry. 


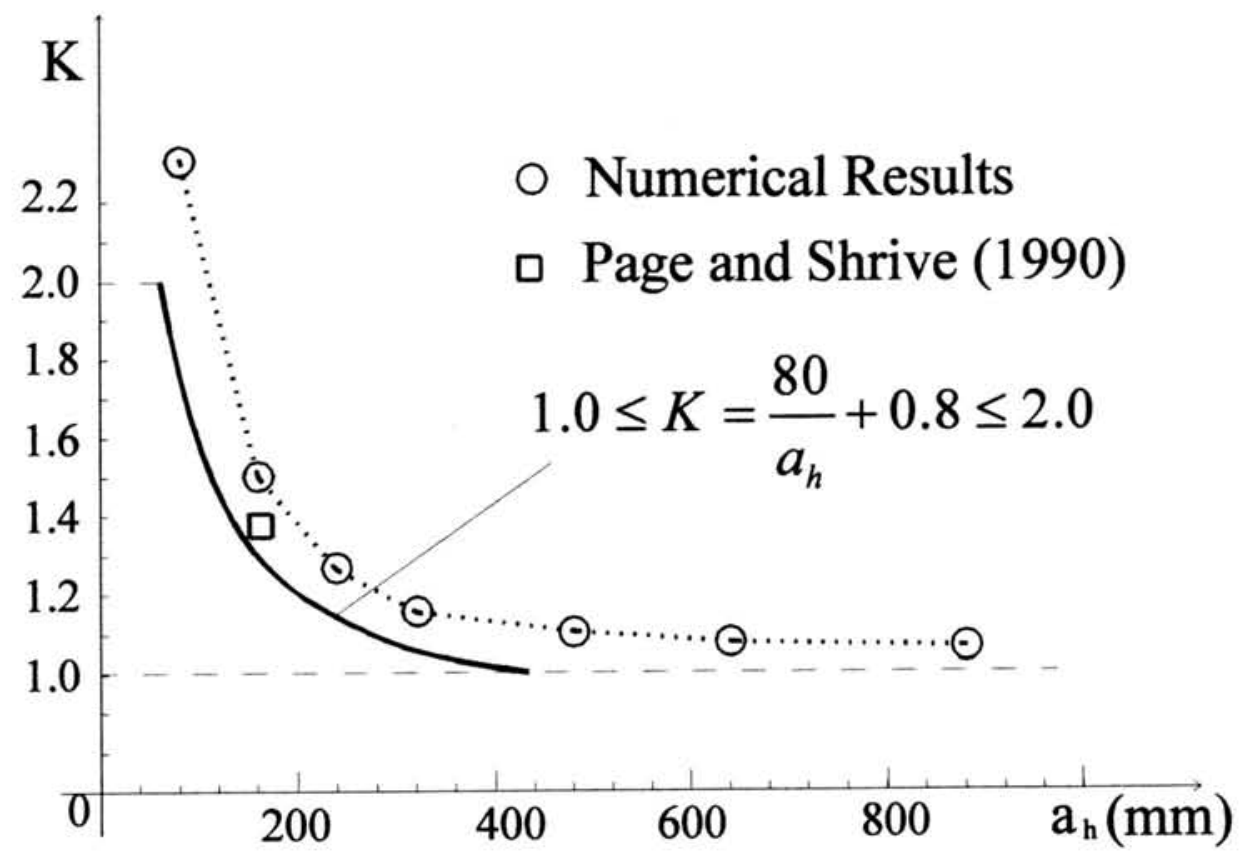

Fig. 5.9c---Strength enhancement factor for plain hollow concrete masonry walls subjected to concentrated loading over central web

\subsection{Walls With Bond Beams}

\subsubsection{Geometry}

Models of walls with one-course and two-course bond beams are shown in Fig. 5.10 and 5.11 respectively. Three loading plate lengths were used: $160 \mathrm{~mm}, 240 \mathrm{~mm}$ and $320 \mathrm{~mm}$. The materials used in the models were: hollow block units (19MPa), mortar (7.6MPa), grout $1(20 \mathrm{MPa})$ and grout $2(50 \mathrm{MPa})$. The details of the model connection between faceshells of hollow block units and bond beam are shown in Fig. 5.12. 


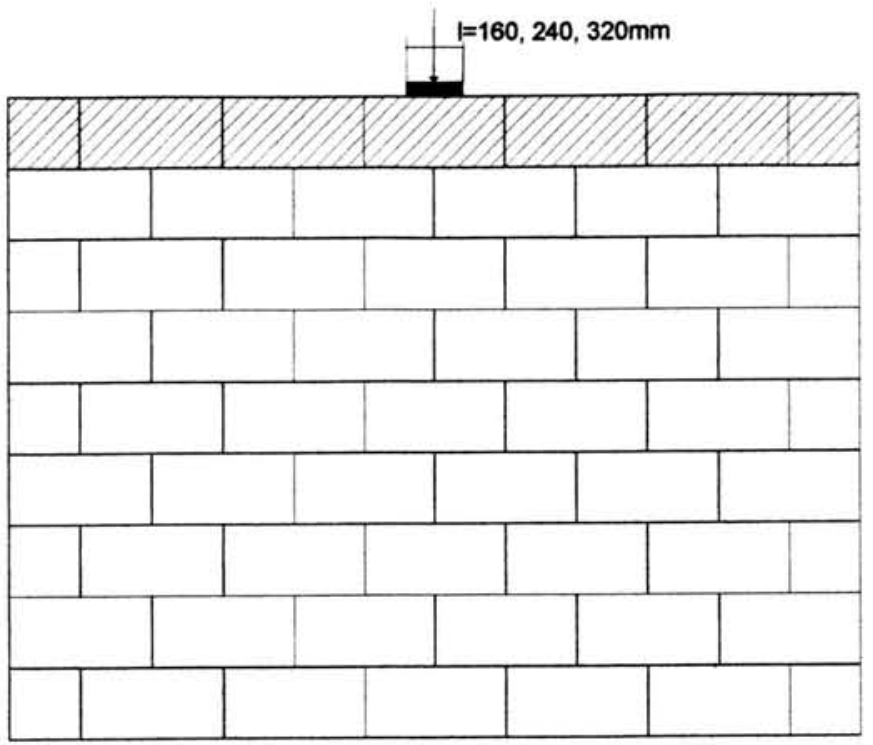

Fig. 5.10---Model of hollow concrete masonry wall with one-course bond beams

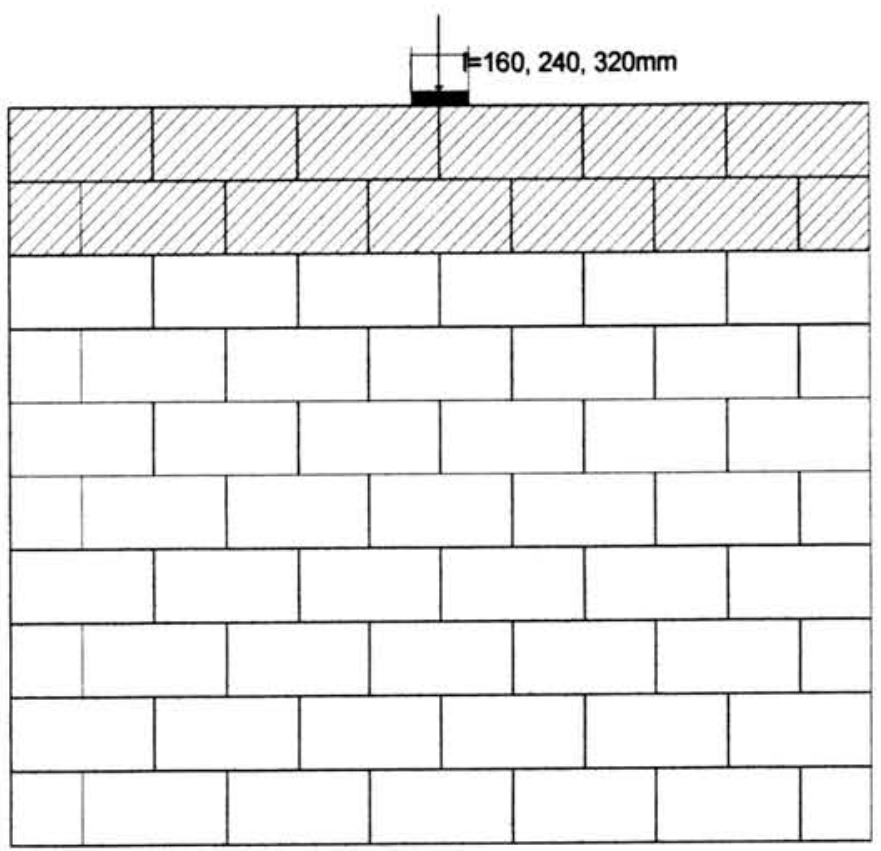

Fig. 5.11---Model of hollow concrete masonry wall with two-course bond beams 


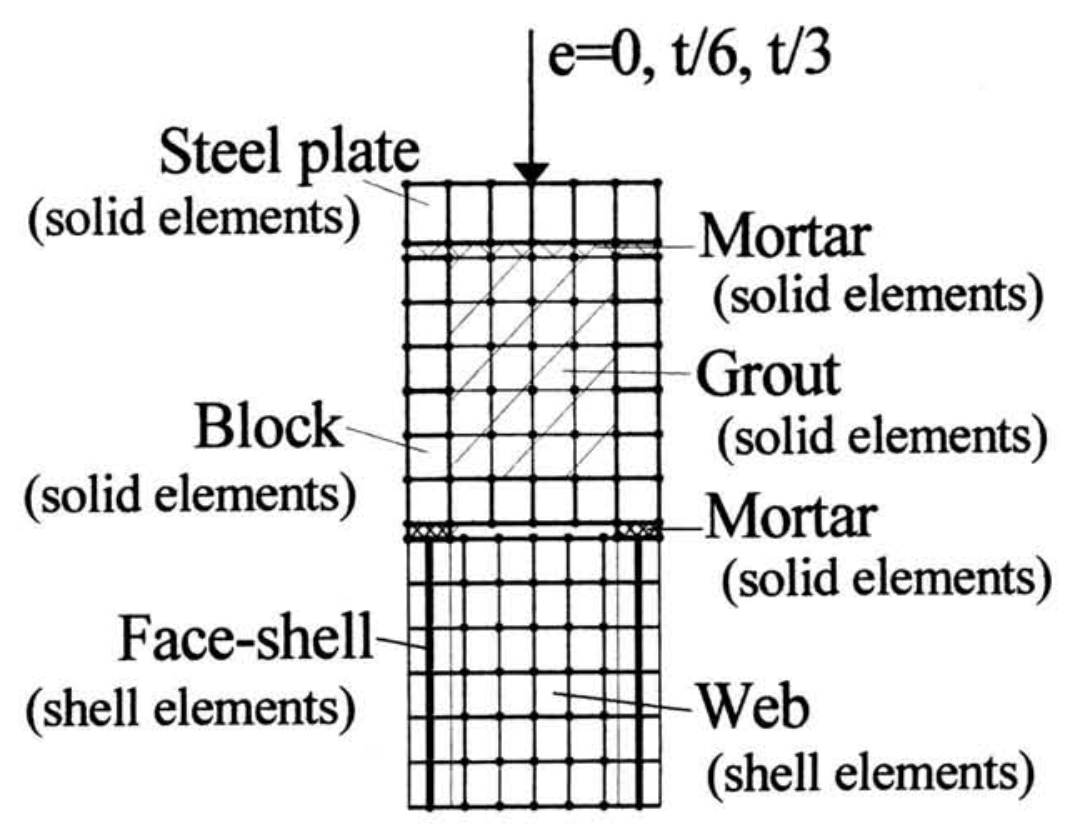

Fig. 5.12---Connection between hollow blocks and grouted bond beam blocks

\subsubsection{Results}

\subsubsection{Failure modes}

The failure modes of walls with one-course bond beams are as follows:

1. Under concentric concentrated load, when the plate length is $160 \mathrm{~mm}$, at about $40 \%$ of the ultimate load, mortar between the bond beam and the face-shells beneath starts to crack. At about $50 \%$ of the ultimate load, cracking occurs in the middle of the bottom of the bond beam directly beneath the loading plate, and webs split in the first hollow course immediately below the bond beam in the region directly beneath the load. At about $60 \%$ of the ultimate, a vertical crack forms in the face-shells in the hollow course in line with the load, similar to a crack that forms in a solid wall loaded in this manner. With 
increasing load, web-splitting progresses along the top of the first hollow course below the bond beam and into the courses beneath, and the surrounding vertical mortar joints also crack due to the combined shear and compressive stress. Final failure occurs when sufficient webs have split, face-shells spalled locally and mortar crushed. When the loading plate length is increased $(240 \mathrm{~mm}, 320 \mathrm{~mm})$, the same cracking sequence occurs but the ultimate loads increases. A typical predicted cracking pattern is shown in Fig. 5.13(a).

2. Under eccentric concentrated load, the first cracks occur at the bottom of the bond beam directly beneath the loading plate, but on the heavily loaded side, rather than the middle. At the same time, cracking appears on the lightly loaded side of the top of the webs in the first hollow course immediately below the bond beam. Also the mortar between the bond beam and the lightly loaded face-shell beneath cracks under combined shear and compression. As the load increases, a vertical crack forms in the face-shells and mortar in line with the load. Final failure occurs when cracking forms at the bottom of the webs in the first hollow course below the bond beam on the heavily loaded side, and at the top of the webs in the second course below the bond beam on the lightly loaded side. As the eccentricity increases, the sequence of cracking and failure is similar except that the predicted ultimate loads are lower and lower, the bottom of the bond beam cracks closer and closer to the heavily loaded face-shell while the top of the webs in the first hollow course immediately below the bond beam crack closer and closer to the lightly loaded face-shell. A typical predicted cracking pattern is shown in Fig. 5.13(b). 
The failure modes of walls with two-course bond beams are similar to those with onecourse bond beams, except that the web splitting progresses wider and deeper, and with higher ultimate capacity. Again the predicted results compare very well with experimental results of (Page and Shrive 1990), as shown in Fig. 5.14. The vertical compressive stress distributions of walls with one-course and two-course bond beams subjected to concentrated load are shown in Fig. 5.15 and 5.16 respectively. The horizontal tensile stress distribution in the hollow block-work underneath the bond beam is shown in Fig.

\subsection{7 .}
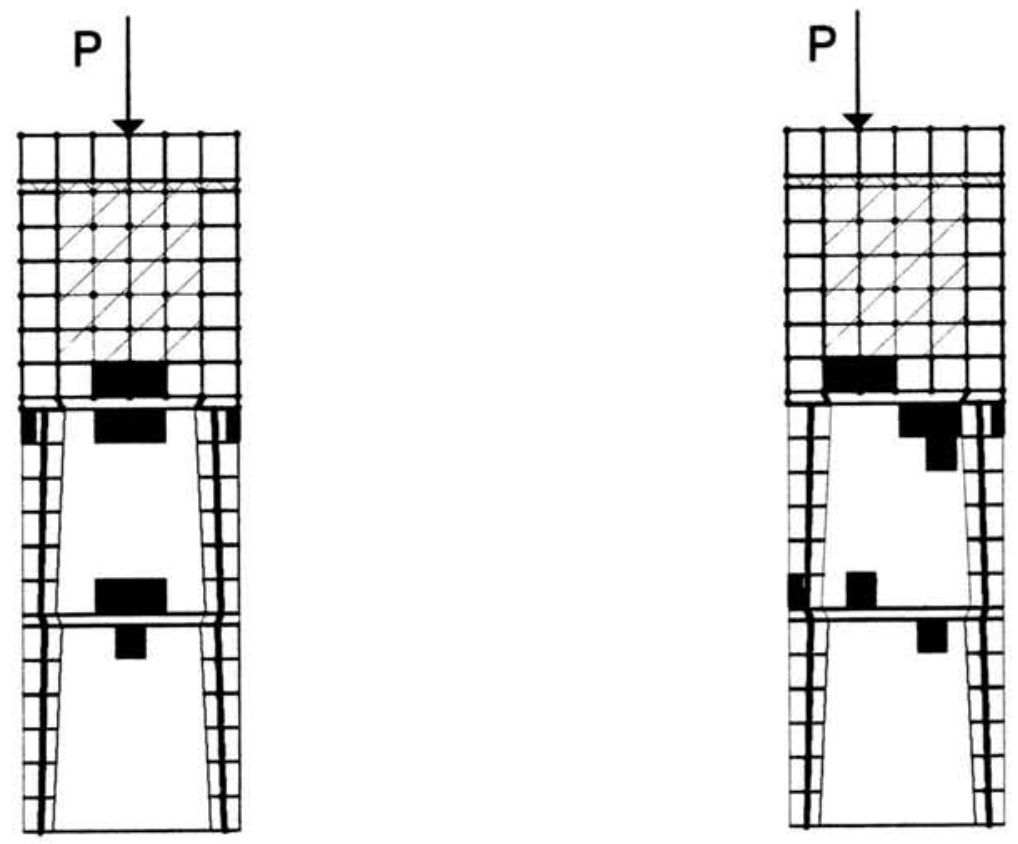

(a)

(b)

Fig. 5.13---Cracking pattern of hollow concrete masonry walls with bond beams (solid black indicates cracking)
(a) concentric concentrated load
(b) eccentric concentrated load 

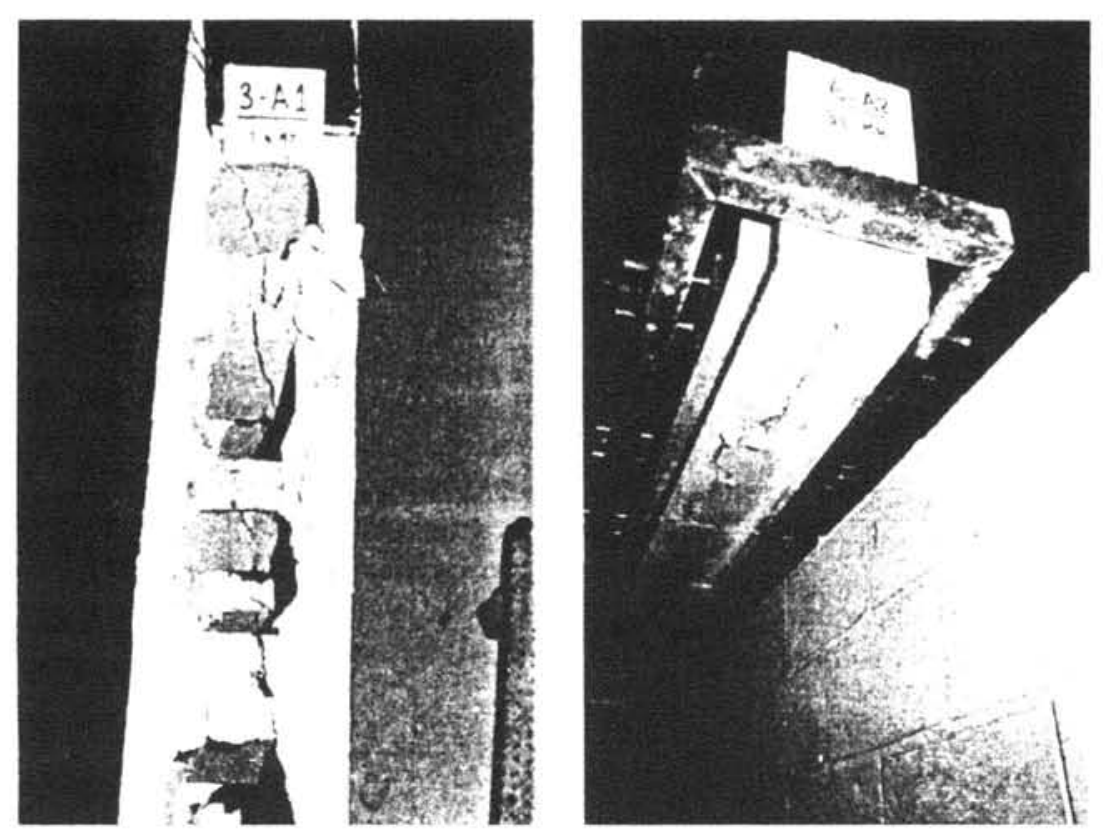

Fig. 5.14---Failure modes of hollow concrete masonry walls with bond beams, subjected to concentrated load

\subsubsection{Failure loads}

The failure loads from predicted and experimental results for walls with one-course and two-course bond beams subjected to concentrated load are given in Tables 5.2 and 5.3, respectively, and plotted in Fig. 5.18a and 5.19a respectively. There is excellent agreement between the predicted results and the available experimental results, as can be seen. As the eccentricity is increased, the models predict a similar failure mechanism but lower failure loads.

The strength variation for hollow concrete masonry walls with bond beams subjected to concentrated load with increasing eccentricity is depicted in Fig. 5.18b and Fig. 5.19b for one-course and two-course bond beams respectively, where Equation [4.1] still shows the lower bound for these results. 


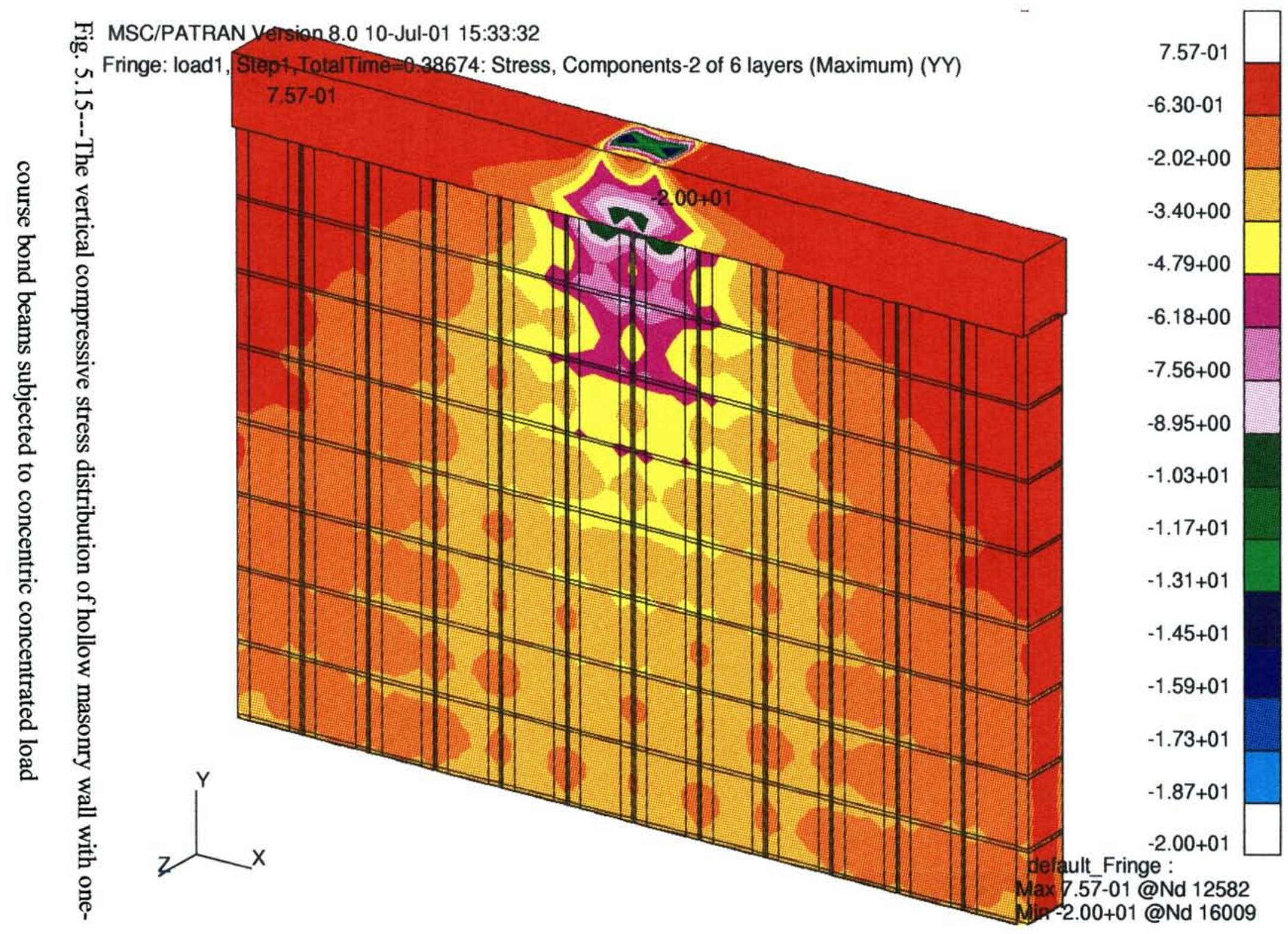




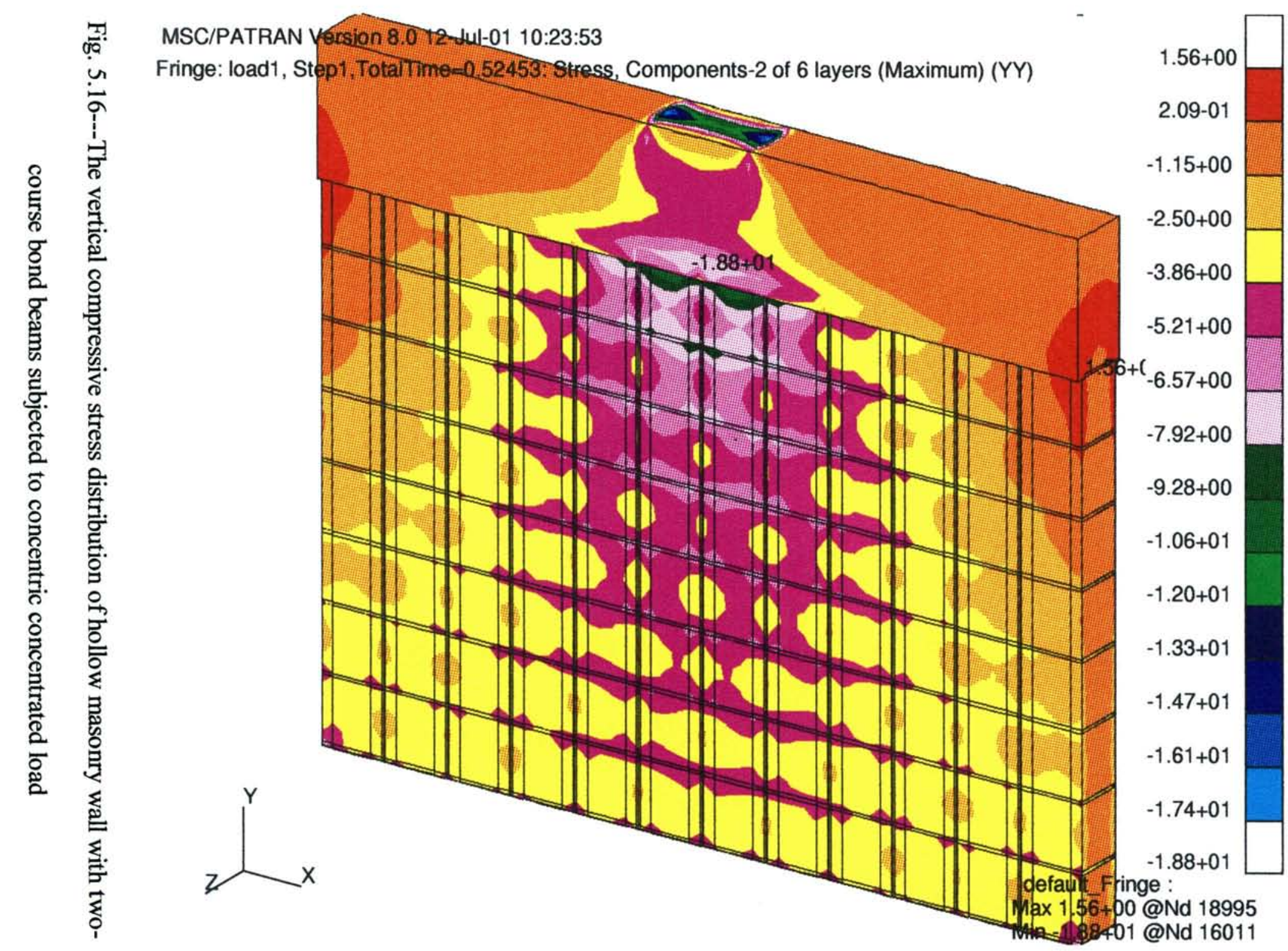




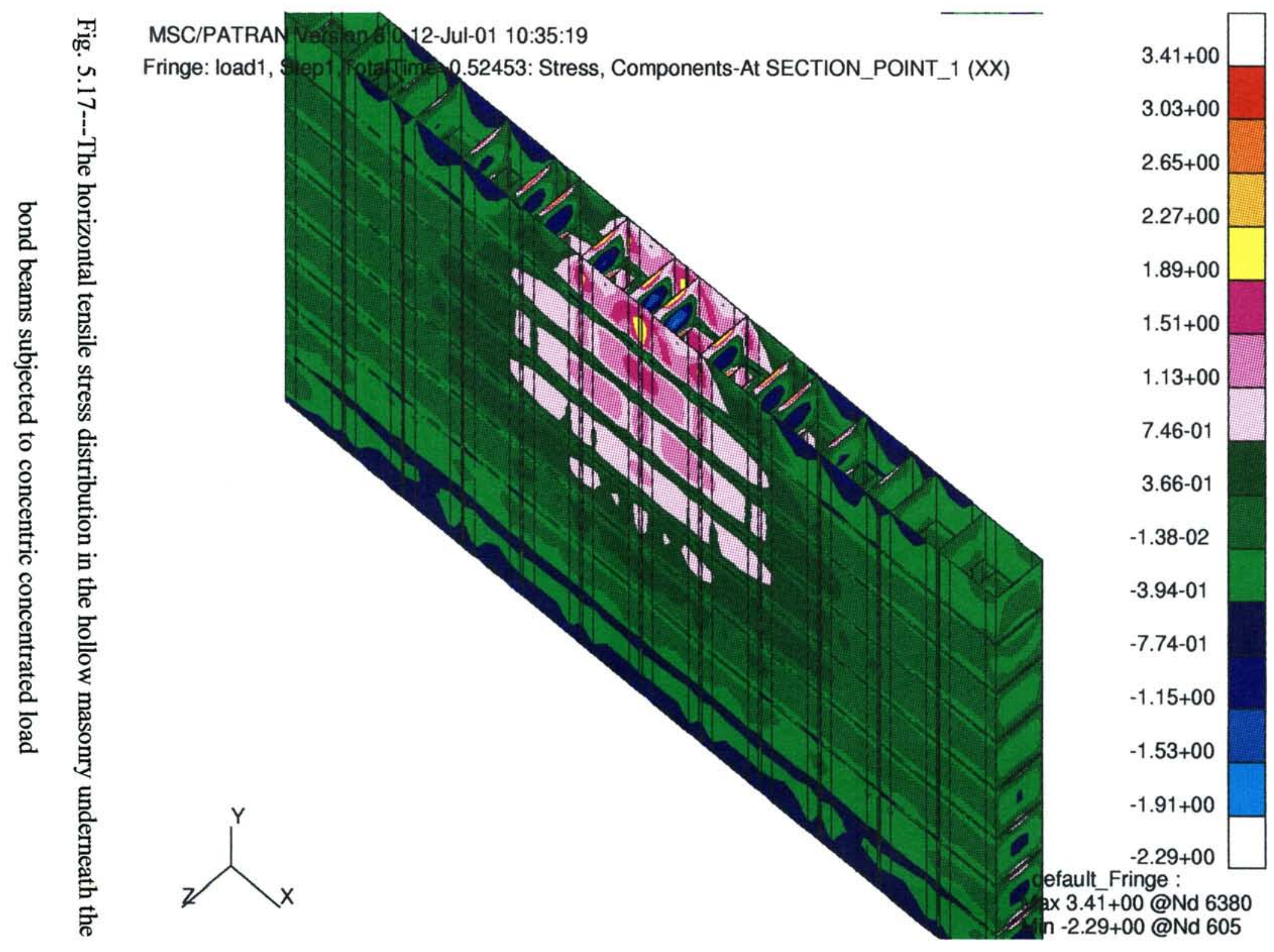


Table 5.2 Predicted and Experimental Results for Hollow Concrete Masonry Walls With One-Course Bond Beams Subjected to Concentrated Loads

\begin{tabular}{cccc}
\hline $\begin{array}{c}\text { Loading Plate } \\
\text { Length }(\mathrm{mm})\end{array}$ & Eccentricities (mm) & \multicolumn{2}{c}{ Failure Load $(\mathrm{KN})$} \\
& & FEM & Experimental \\
\hline 160 & $\mathrm{e}=0$ & 378 & 395 \\
& $\mathrm{e}=31$ & 339 & $313^{*}$ \\
& $\mathrm{e}=62$ & 257 & \\
\hline 240 & $\mathrm{e}=0$ & 426 & \\
& $\mathrm{e}=31$ & 375 & \\
& $\mathrm{e}=62$ & 312 & \\
\hline 320 & $\mathrm{e}=0$ & 517 & \\
& $\mathrm{e}=31$ & 440 & \\
& $\mathrm{e}=62$ & 407 & \\
\hline
\end{tabular}

Note: Experimental data are from Page and Shrive (1990). ${ }^{*}$ Eccentricity is $35 \mathrm{~mm}$.

Table 5.3 Predicted and Experimental Results for Hollow Concrete Masonry Walls With Two-Course Bond Beams Subjected to Concentrated Loads

\begin{tabular}{cccc}
\hline $\begin{array}{c}\text { Loading Plate } \\
\text { Length }(\mathrm{mm})\end{array}$ & Eccentricities $(\mathrm{mm})$ & \multicolumn{2}{c}{ Failure Load $(\mathrm{KN})$} \\
\hline 160 & $\mathrm{e}=0$ & 539 & 520 \\
& $\mathrm{e}=31$ & 491 & $384^{*}$ \\
& $\mathrm{e}=62$ & 406 & \\
240 & $\mathrm{e}=0$ & 588 & 591 \\
& $\mathrm{e}=31$ & 538 & \\
& $\mathrm{e}=62$ & 449 & 660 \\
320 & $\mathrm{e}=0$ & 645 & \\
& $\mathrm{e}=31$ & 556 & \\
& $\mathrm{e}=62$ & 473 & \\
&
\end{tabular}

Note: Experimental data are from Page and Shrive (1990). ${ }^{*}$ Eccentricity is $35 \mathrm{~mm}$. 


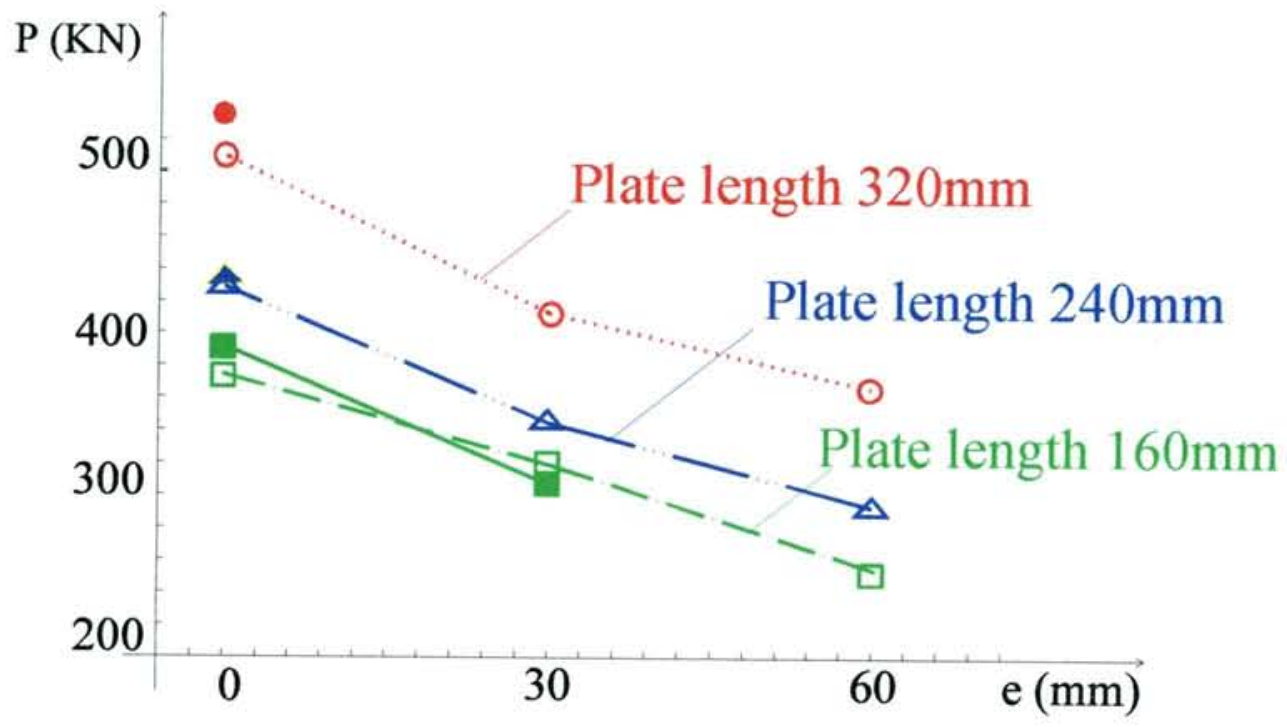

Fig. 5.18a---The failure loads from predicted and experimental results for hollow concrete masonry walls with one-course bond beams (solid point: experimental, hollow point: predicted)

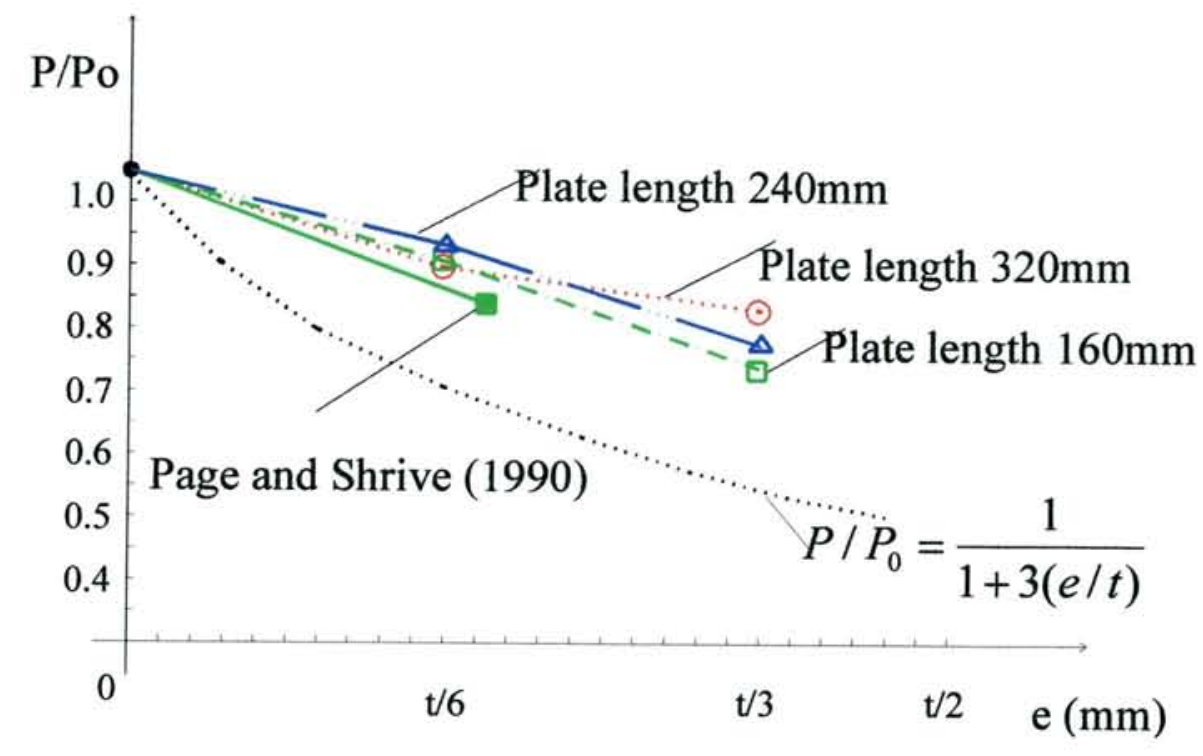

Fig. 5.18b---Ultimate strength variation from predicted and experimental results for walls with one-course bond beams 


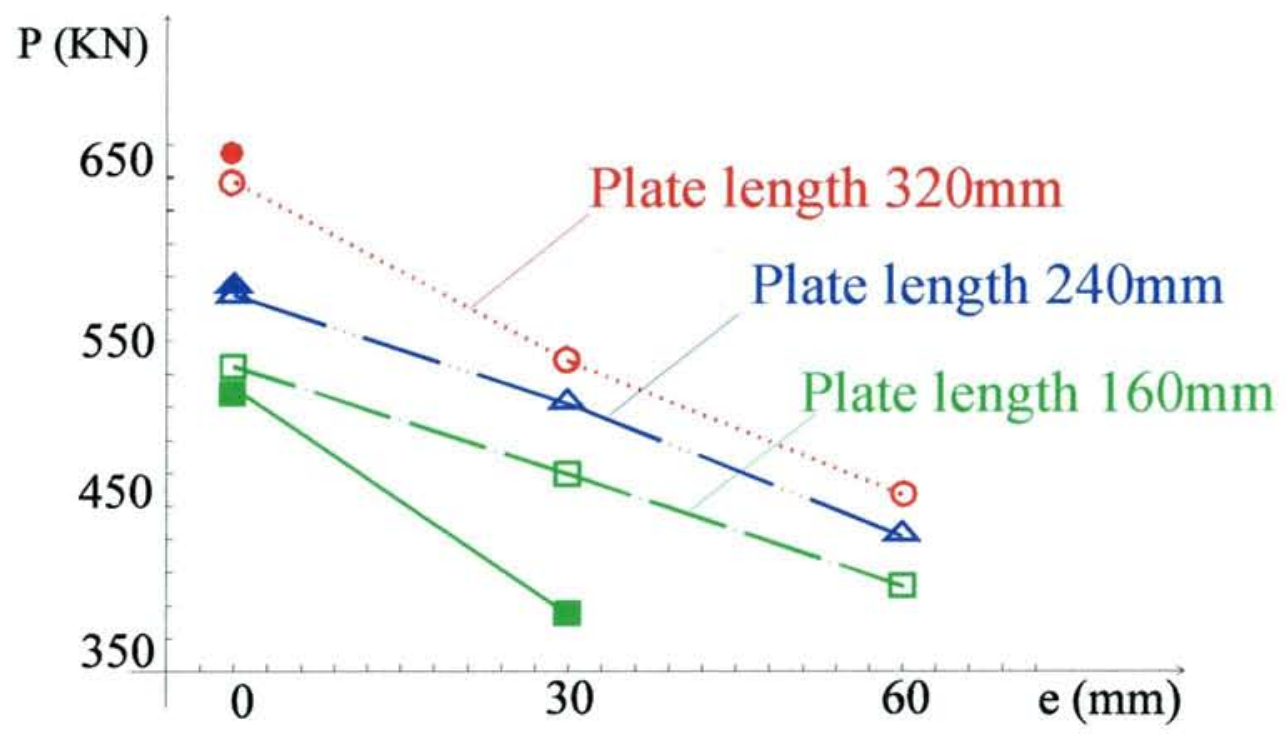

Fig. 5.19a---The failure loads from predicted and experimental results for hollow concrete masonry walls with two-course bond beams (solid point: experimental, hollow point: predicted)

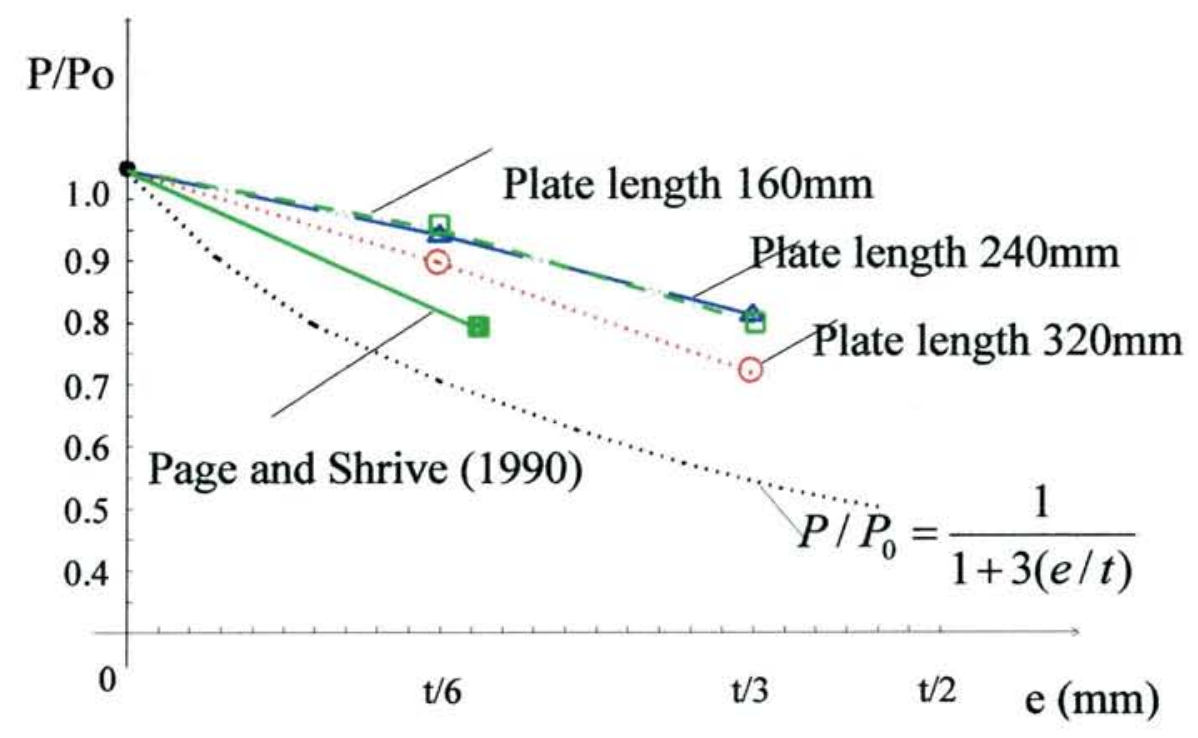

Fig. 5.19b---Ultimate strength variation from predicted and experimental results for walls with two-course bond beams 
An important point to note is that when the grout strength was increased from $20 \mathrm{MPa}$ to $50 \mathrm{MPa}$ in the models of walls with bond beams, the predicted ultimate strength increased less than 5\%. This is in excellent agreement with the results of Page and Shrive (1990) who found very little variation in wall ultimate strength with substantially different grouts. From the sequence of cracking shown by the finite element models, we now recognize that the grout is not involved much in the failure mechanism: its contribution is mainly the distribution of the concentrated load. Hence grout strength will have little influence on overall wall strength if the failure is governed by the hollow masonry beneath the bond beam (which is the case here). If the loading plate is full width (over both grout and face-shells of bond-beam blocks, as in the models and the experiments), the face-shells of the bond-beam blocks help to distribute load as well. Grout strength will not be critical as long as the grout is strong enough to resist local crushing beneath the steel loading plate.

\subsection{Wall Models With One-Course Bond Beams, Subjected to Concentrated Load at Different Locations}

\subsubsection{Geometry}

The wall models with one-course bond beams, subjected to concentrated load at different locations are shown in Fig. 5.20 . Four loading locations $(\mathrm{L}=1200 \mathrm{~mm}, 800 \mathrm{~mm}, 400 \mathrm{~mm}, 0)$ and three out-of-plane eccentricities $(e=0, t / 6, t / 3)$ were examined. The hollow block units, mortar, grout, and bond beam blocks in the walls were modelled separately. The materials (compressive strength) used in the models were: hollow block units (20MPa), 
mortar (7.6MPa), and grout (20MPa). The model connection detail of bond beam and hollow concrete block units beneath is shown in Fig. 5.12.

\subsubsection{Results}

The models for which the experimental data are available (concentrated load at the centre of the wall) were verified first. These models and results were described in the last section. Here we concentrate on the other models. The ultimate loads for the wall models with three out-of-plane eccentricities and four loading locations are summarized in Table 5.4 .
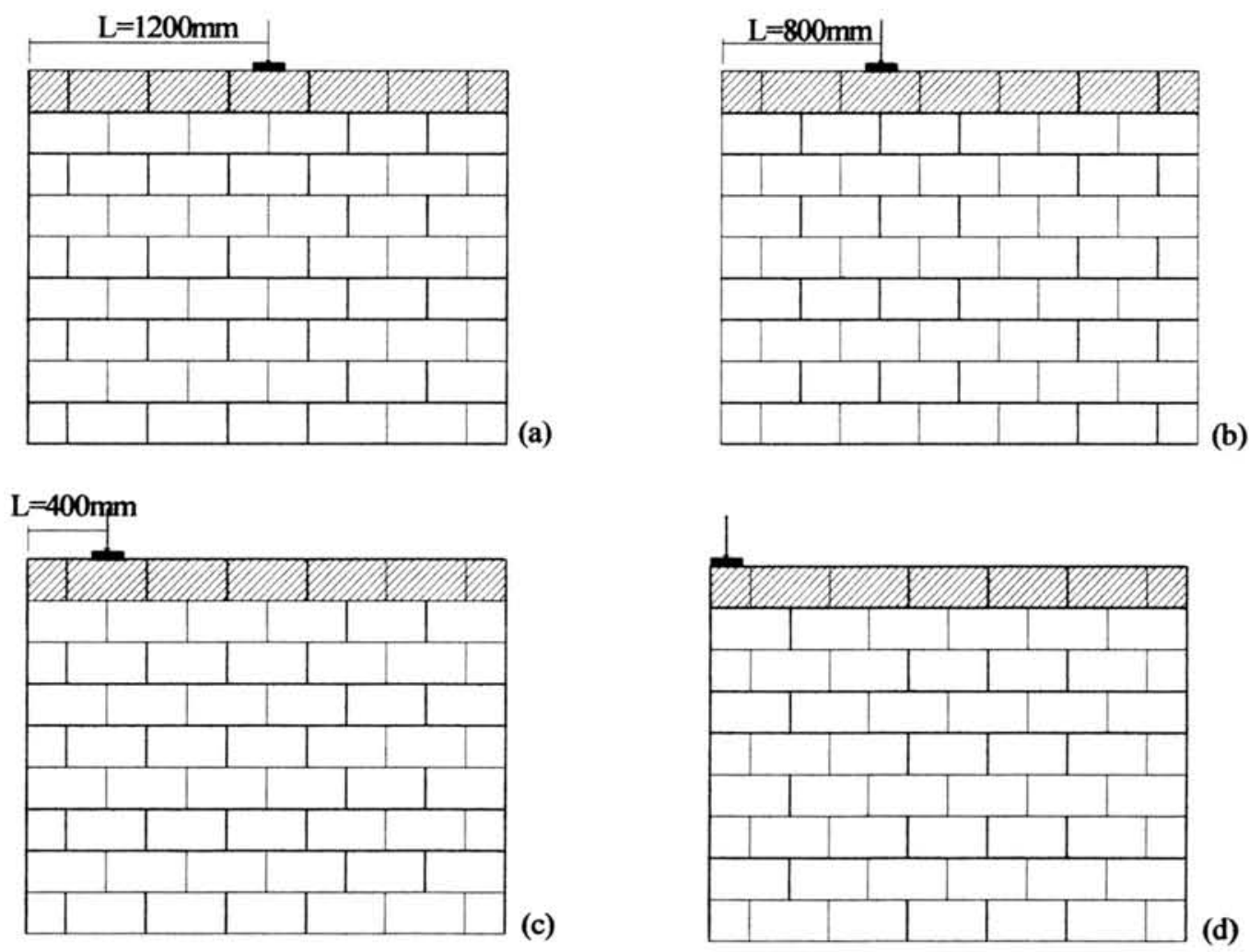

Fig. 5.20---Wall models with one-course bond beams, subjected to concentrated load at different locations (a) $\mathrm{L}=1200 \mathrm{~mm}$ (b) $\mathrm{L}=800 \mathrm{~mm}$ (c) $\mathrm{L}=400 \mathrm{~mm}$ (d) $\mathrm{L}=0$ 
Table 5.4 Capacities of Hollow Masonry Walls With One-course Bond beams, Subjected to Concentrated Loads with Various Loading Locations and Eccentricities

\begin{tabular}{|c|c|c|c|}
\hline $\begin{array}{c}\text { Loading } \\
\text { Location L (mm) }\end{array}$ & Plate Length (mm) & $\begin{array}{c}\text { Out-Of-Plane } \\
\text { Eccentricities (mm) }\end{array}$ & Failure Loads $(\mathrm{KN})$ \\
\hline \multirow[t]{9}{*}{1200} & 320 & $\mathrm{e}=0$ & 517 \\
\hline & & $e=t / 6$ & 440 \\
\hline & & $e=t / 3$ & 407 \\
\hline & 240 & $\mathrm{e}=0$ & 426 \\
\hline & & $e=t / 6$ & 375 \\
\hline & & $e=t / 3$ & 312 \\
\hline & 160 & $\mathrm{e}=0$ & 378 \\
\hline & & $e=t / 6$ & 339 \\
\hline & & $e=t / 3$ & 257 \\
\hline \multirow[t]{9}{*}{800} & 320 & $\mathrm{e}=0$ & 511 \\
\hline & & $e=t / 6$ & 422 \\
\hline & & $e=t / 3$ & 386 \\
\hline & 240 & $\mathrm{e}=0$ & 423 \\
\hline & & $e=t / 6$ & 370 \\
\hline & & $e=t / 3$ & 302 \\
\hline & 160 & $\mathrm{e}=0$ & 375 \\
\hline & & $e=t / 6$ & 330 \\
\hline & & $e=t / 3$ & 252 \\
\hline \multirow[t]{9}{*}{400} & 320 & $\mathrm{e}=0$ & 463 \\
\hline & & $e=t / 6$ & 376 \\
\hline & & $e=t / 3$ & 338 \\
\hline & 240 & $\mathrm{e}=0$ & 395 \\
\hline & & $e=t / 6$ & 325 \\
\hline & & $e=t / 3$ & 265 \\
\hline & 160 & $\mathrm{e}=0$ & 342 \\
\hline & & $e=t / 6$ & 292 \\
\hline & & $\mathrm{e}=\mathrm{t} / 3$ & 216 \\
\hline \multirow[t]{9}{*}{0} & 320 & $\mathrm{e}=0$ & 379 \\
\hline & & $e=t / 6$ & 314 \\
\hline & & $e=t / 3$ & 295 \\
\hline & 240 & $\mathrm{e}=0$ & 309 \\
\hline & & $e=t / 6$ & 264 \\
\hline & & $e=t / 3$ & 226 \\
\hline & 160 & $\mathrm{e}=0$ & 253 \\
\hline & & $e=t / 6$ & 229 \\
\hline & & $e=t / 3$ & 188 \\
\hline
\end{tabular}




\subsubsection{Effects of out-of-plane eccentricities}

The effect of out-of-plane eccentricities on the failure modes of walls with different loading locations $(\mathrm{L}=800 \mathrm{~mm}, 400 \mathrm{~mm}$ or 0$)$ is similar to that with $\mathrm{L}=1200 \mathrm{~mm}$ (described in the last section).

The effect of out-of-plane eccentricities on the ultimate strength of walls for different loading locations is depicted in Fig. 5.21a, b, c, respectively for loading plate lengths of $a=320 \mathrm{~mm}, a=240 \mathrm{~mm}$, and $\mathrm{a}=160 \mathrm{~mm}$, in which Equation [4.1] provides a lower bound for these results.

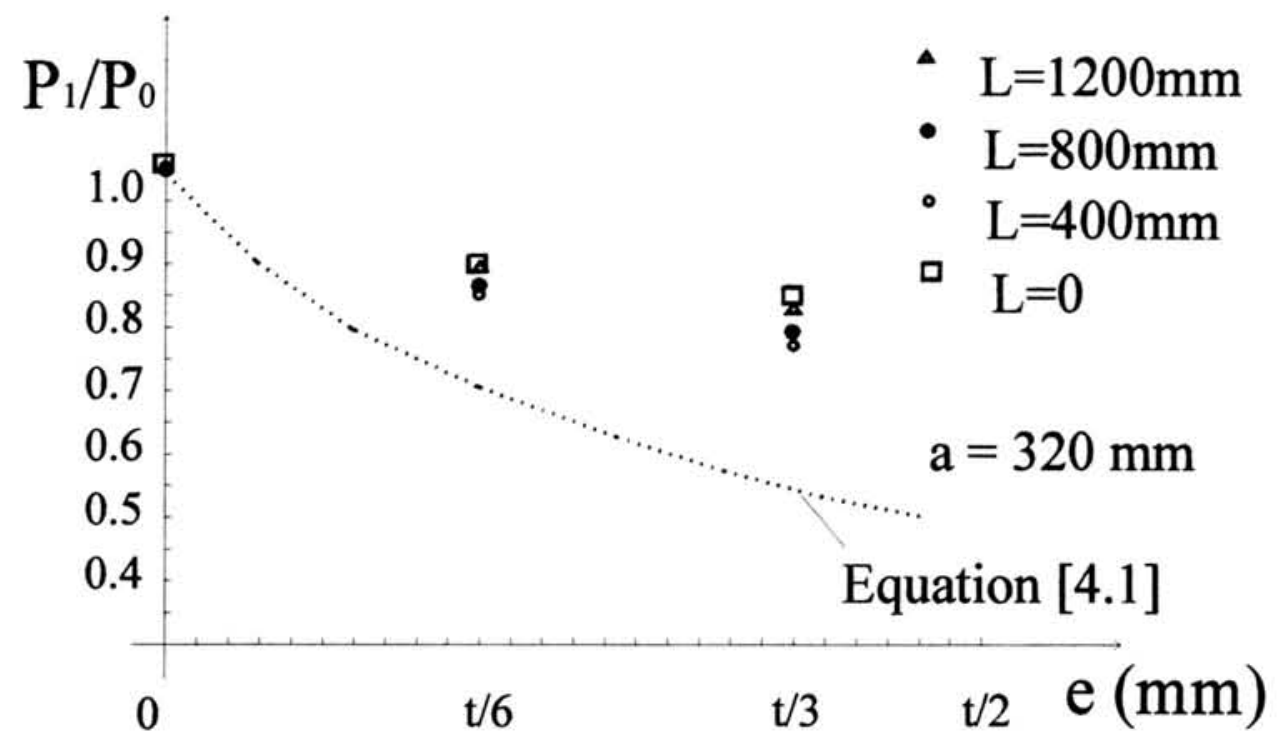

(a) $\mathrm{a}=320 \mathrm{~mm}$ 


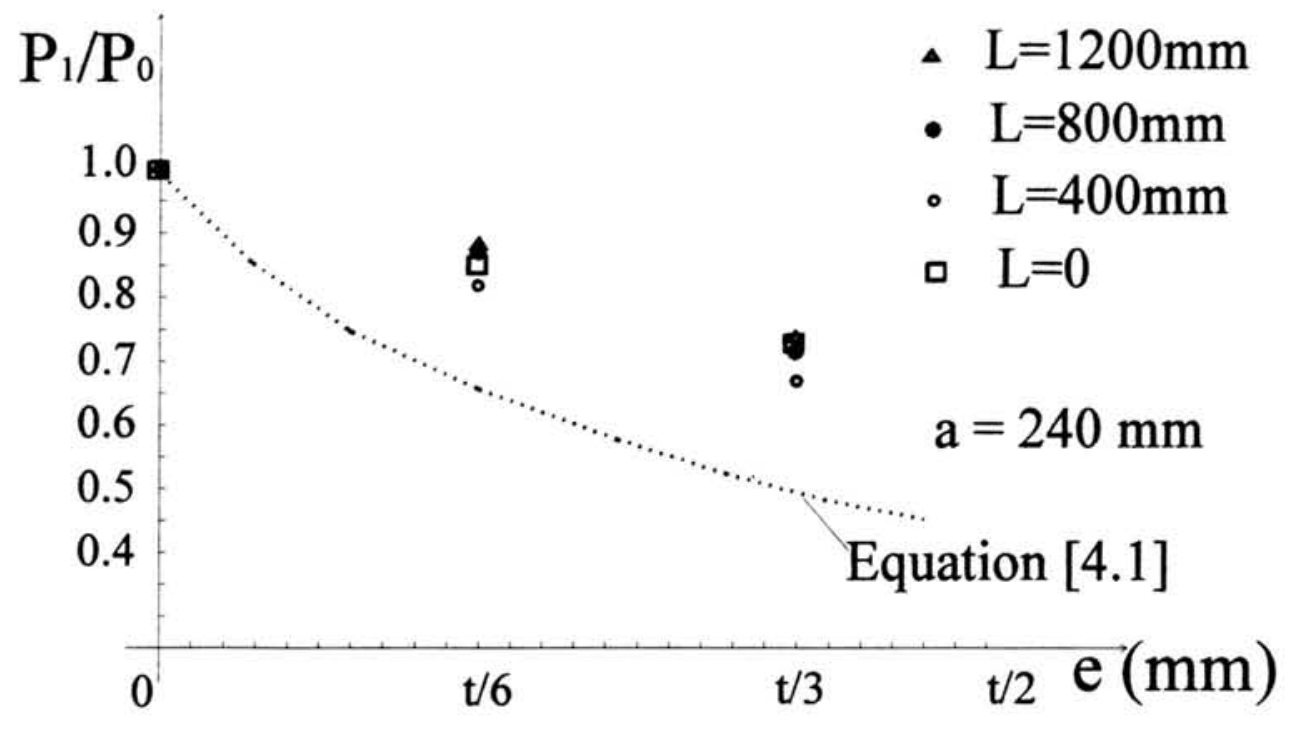

(b) $\mathrm{a}=240 \mathrm{~mm}$

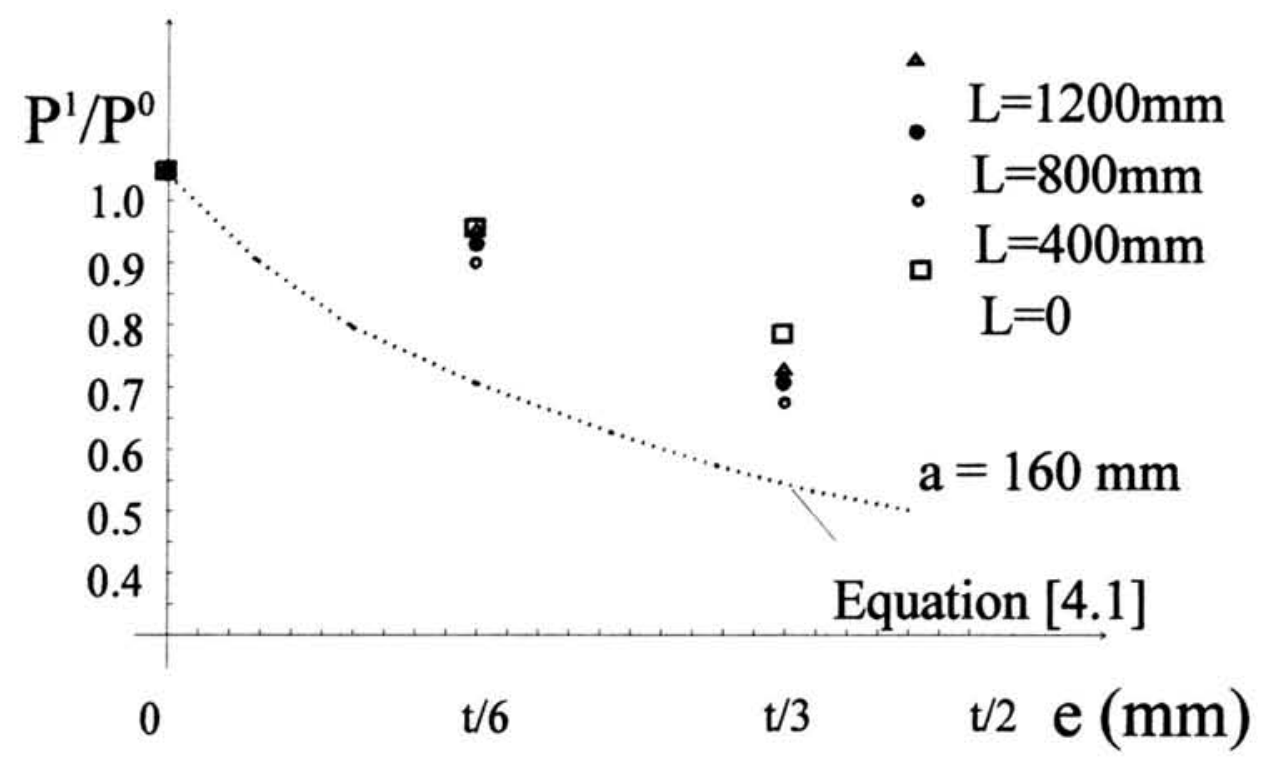

(c) $\mathrm{a}=160 \mathrm{~mm}$

Fig. 5.21---Effect of out-of-plane eccentricities on the strengths for different loading locations and different loading plate lengths

(a) $a=320 \mathrm{~mm}$ (b) $a=240 \mathrm{~mm}$ (c) $a=160 \mathrm{~mm}$ 


\subsubsection{Effects of loading locations}

As can be seen from Table 5.4, the ultimate capacity decreases when the concentrated load is moved toward the end of the wall. This is due to the reduction in confinement by the surrounding, less stressed masonry. When $\mathrm{L}$ is reduced from $1200 \mathrm{~mm}$ to $800 \mathrm{~mm}$, there is almost no decrease in capacity, because the web splitting still occurs in the middle part of the wall. There is no web splitting at the end of the wall. The region of web splitting and face-shell spalling when $\mathrm{L}=800 \mathrm{~mm}$ is almost the same as that with $\mathrm{L}=1200 \mathrm{~mm}$. This means there is still enough confinement for $\mathrm{L}=800 \mathrm{~mm}$. This is in agreement with the results obtained by Sayed-Ahamed and Shrive (1996), which indicated that the strength is virtually the same with the same loading plate size even for two totally different wall sizes. The wall sizes $(3200 * 2400 * 190$ and $1600 * 2400 * 190)$ considered in their analyses are large enough to provide the full confinement to the concentrated load. However, when $\mathrm{L}$ is decreased from $800 \mathrm{~mm}$ to $400 \mathrm{~mm}$, there is a significant decrease in the ultimate capacity. From the results of the model, web splitting progressed to the end of the wall when $\mathrm{L}=400 \mathrm{~mm}$, and the region of web splitting and face-shell spalling was less than that with $\mathrm{L}=800 \mathrm{~mm}$. This means there is not enough surrounding masonry to supply full confinement when $\mathrm{L}=400 \mathrm{~mm}$. However, the failure mechanism remains almost the same as that with $\mathrm{L}=1200 \mathrm{~mm}$ : web splitting followed by face-shell spalling, except that more cracking occurred on the side with more hollow blocks (means more confinement). Typical vertical compressive stress distributions of hollow concrete masonry wall with one-course bond beams subjected to concentrated load with $\mathrm{L}=800 \mathrm{~mm}$ and $\mathrm{L}=400 \mathrm{~mm}$, are shown in Fig. 5.22 and 5.23, respectively. 


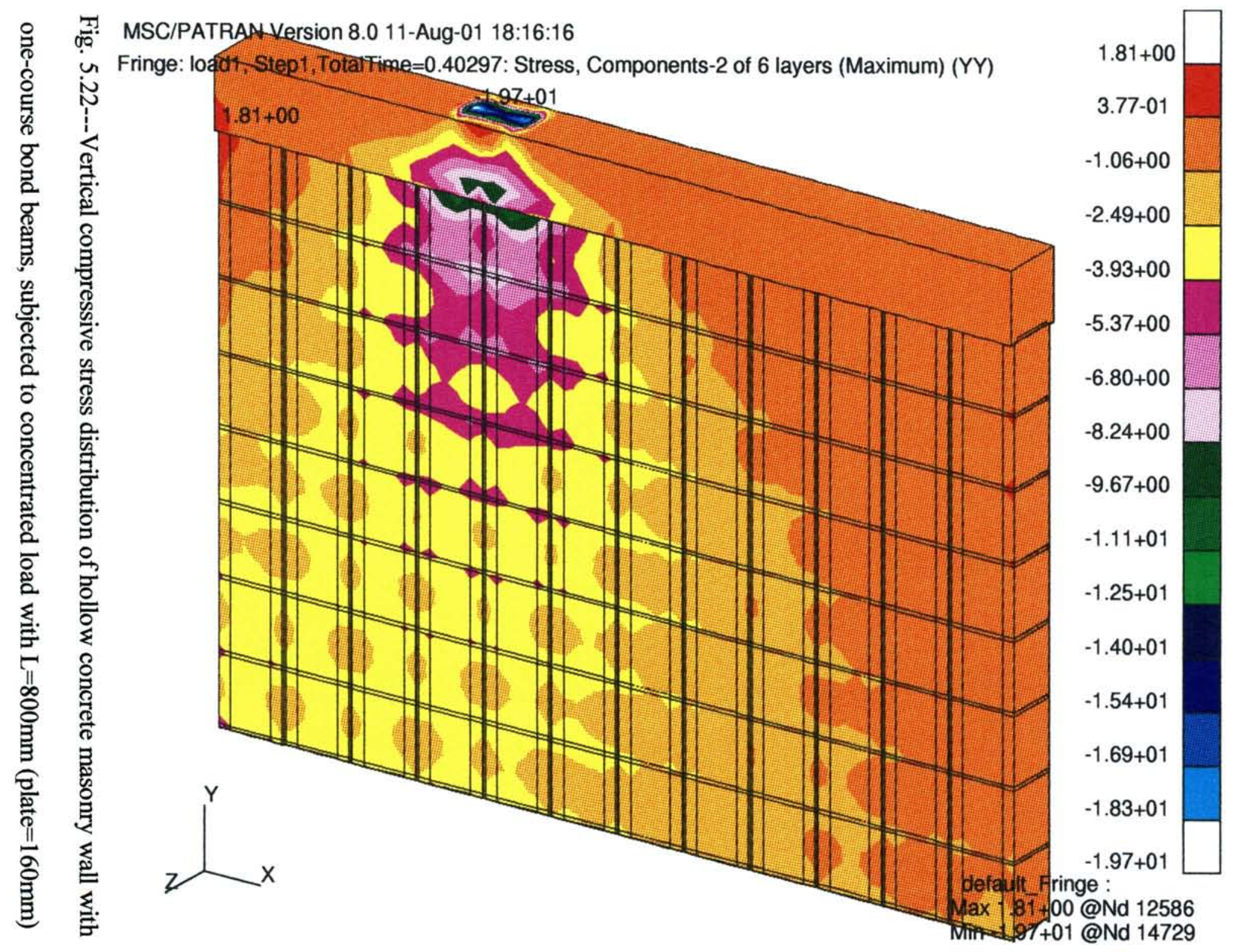




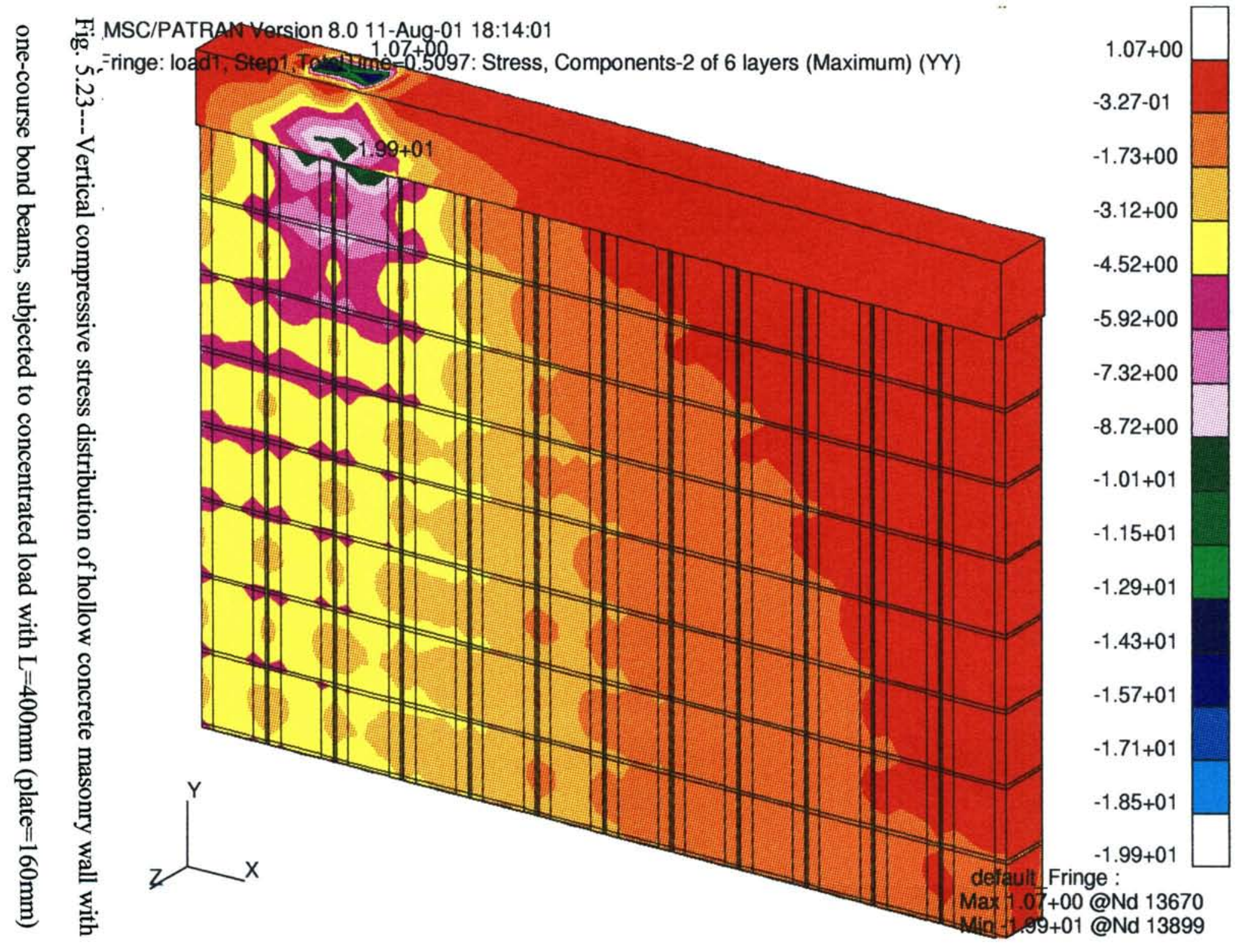


The effect of loading location on the ultimate strength for different out-of-plane eccentricities is depicted in Fig. 5.24a, b, c, respectively for loading plate lengths of $\mathrm{a}=320 \mathrm{~mm}, \mathrm{a}=240 \mathrm{~mm}$, and $\mathrm{a}=160 \mathrm{~mm}$. Equation [5.2] shows the lower bound for these results (wall thickness: $190 \mathrm{~mm}$ ):

$$
\mathrm{P} / \mathrm{P}_{0}^{\prime}=0.6+0.33 \mathrm{~L} \leq 1.0
$$

where $\mathrm{P}_{0}{ }^{\prime}$ is the strength of hollow concrete masonry wall under concentrated load when the load is $1200 \mathrm{~mm}$ from the end of the wall, P is the strength of hollow concrete masonry under concentrated load within $1200 \mathrm{~mm}$ from the end of the wall, L is the distance of the load from the end of the wall (in metre).

Equation [5.2] takes into account the confining effect from the surrounding, less stressed hollow masonry. It could also be used for hollow masonry without bond beam but with grouted details under the concentrated load, as long as the grouted details could transfer the load effectively to the hollow masonry beneath. Hollow masonry with grouted details will be discussed in the following sections. 


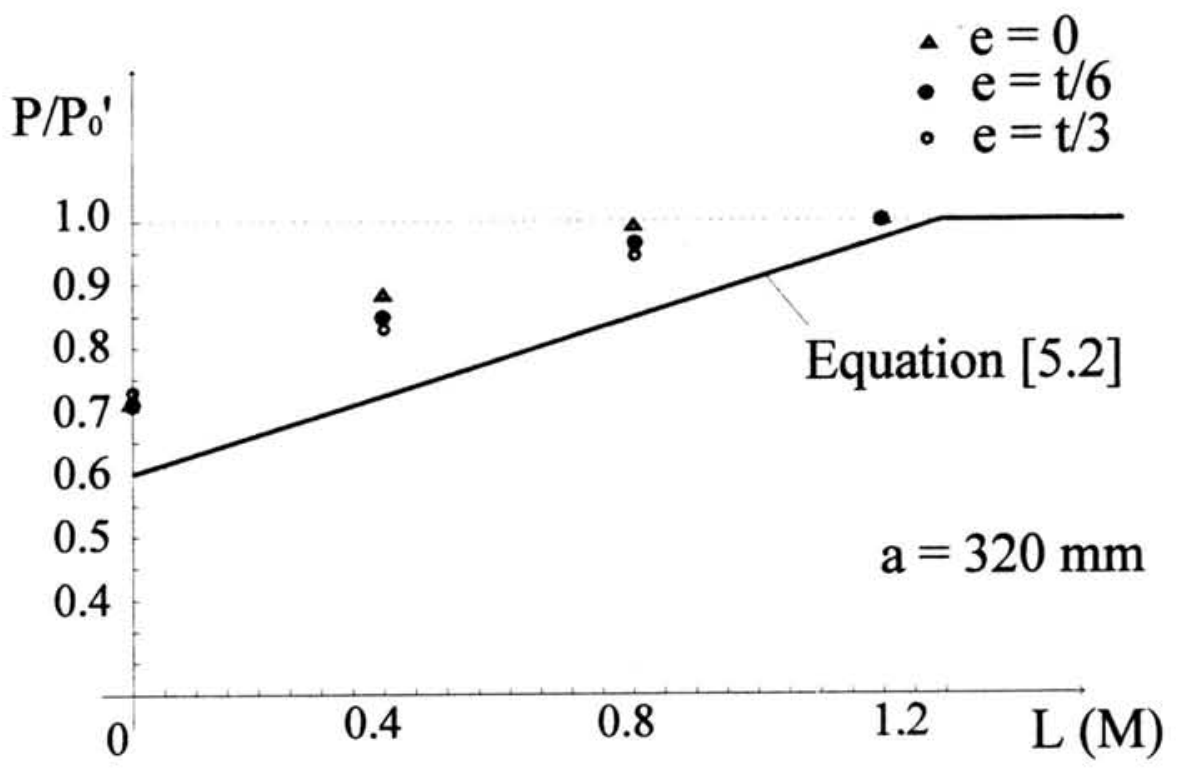

(a) $a=320 \mathrm{~mm}$

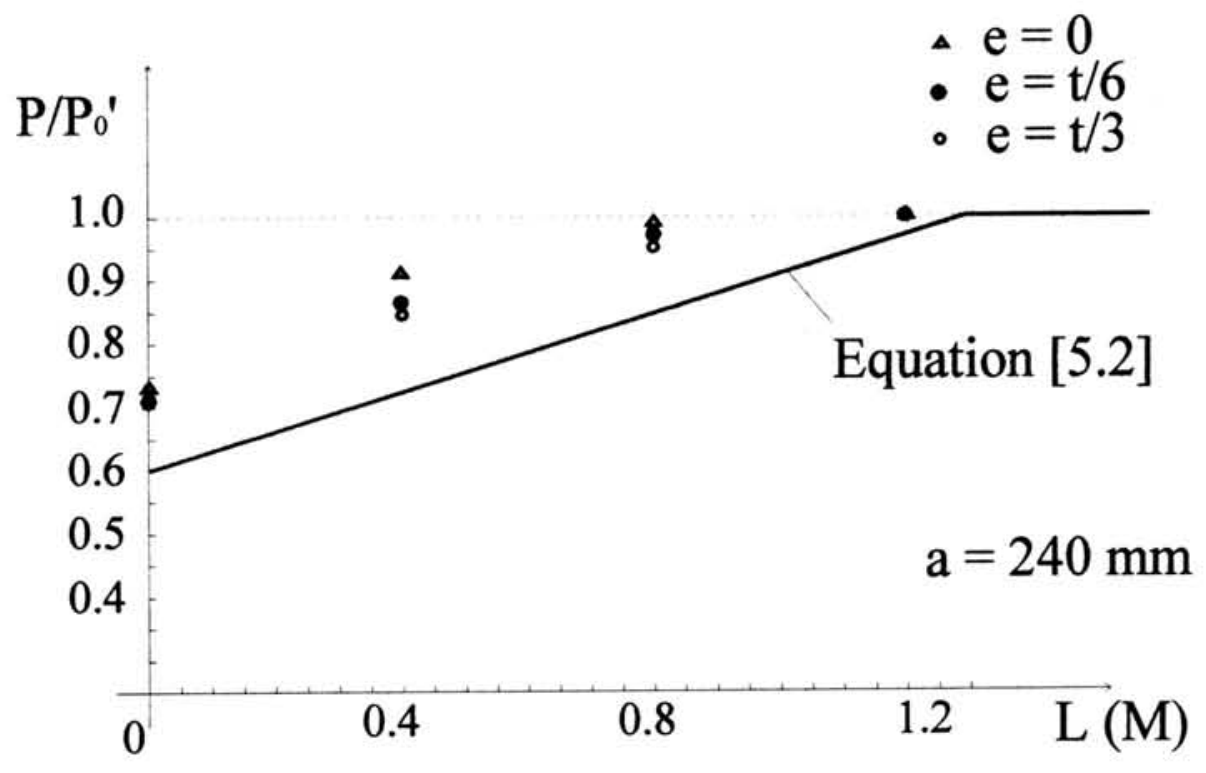

(c) $\mathrm{a}=240 \mathrm{~mm}$ 


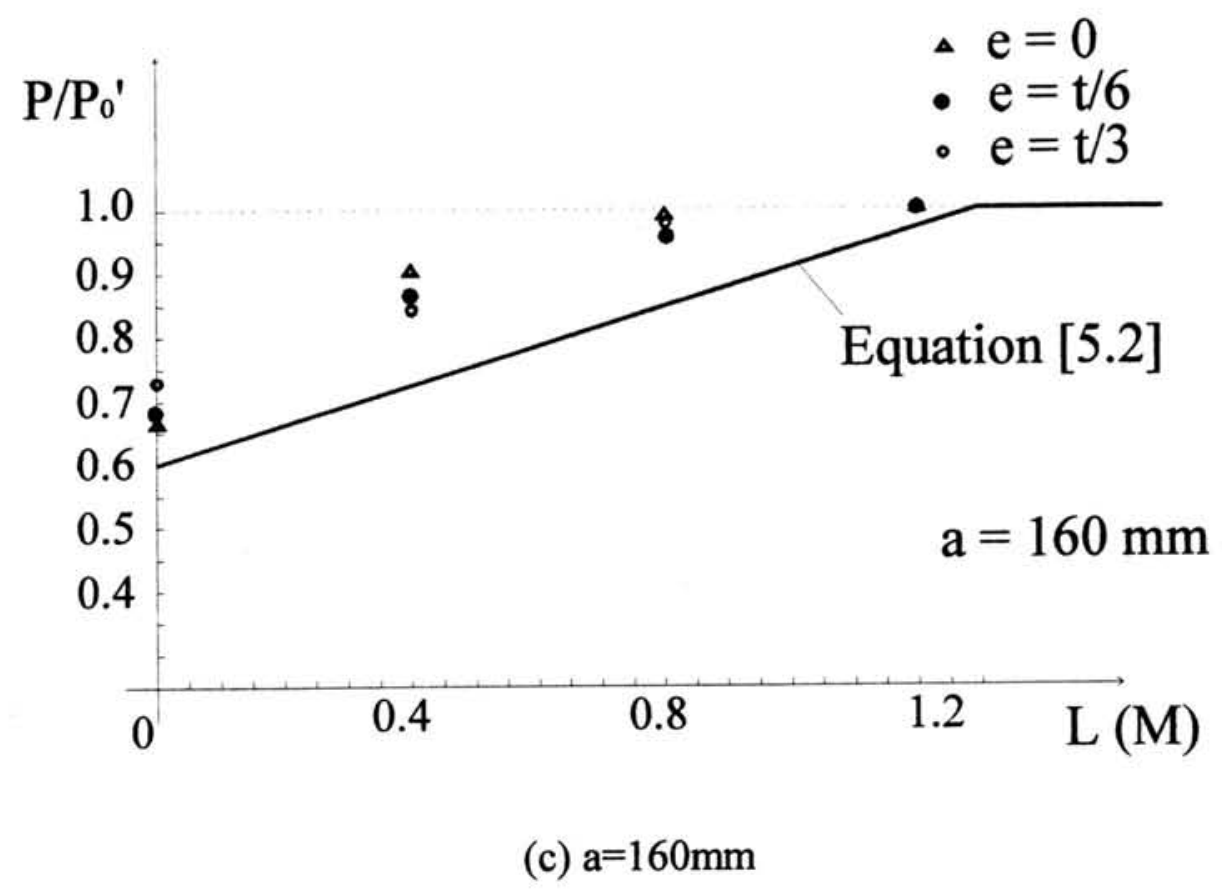

Fig. 5.24---Effect of loading locations on the ultimate strengths for different out-of-plane eccentricities and different loading plate lengths

(a) $a=320 \mathrm{~mm}$ (b) $a=240 \mathrm{~mm}$ (c) $\mathrm{a}=160 \mathrm{~mm}$

\subsubsection{Concentrated load at the end of wall}

The model of the six-block long hollow masonry wall subjected to concentrated load at the end of the wall is shown in Fig. 20d. Both smeared and discrete cracking methods were used for it. Four-block long and five-block long wall models were also analyzed with the discrete cracking method, as shown in Fig. 5.25. The results from the smeared models are presented in Table 5.4. The results from the discrete models are summarized in Table 5.5. Comparison reveals that the ultimate capacities from the smeared and discrete cracking models are almost the same for similar walls. When the wall length is reduced from $2400 \mathrm{~mm}$ to $1600 \mathrm{~mm}$, the ultimate capacities decrease slightly, possibly 
because of lower confinement from the lesser amount of surrounding masonry. Additionally, there is less tensile force between the bond beam and the hollow concrete masonry beneath and less weight balance from the bond beam to resist the uplift moment on the bond beam.

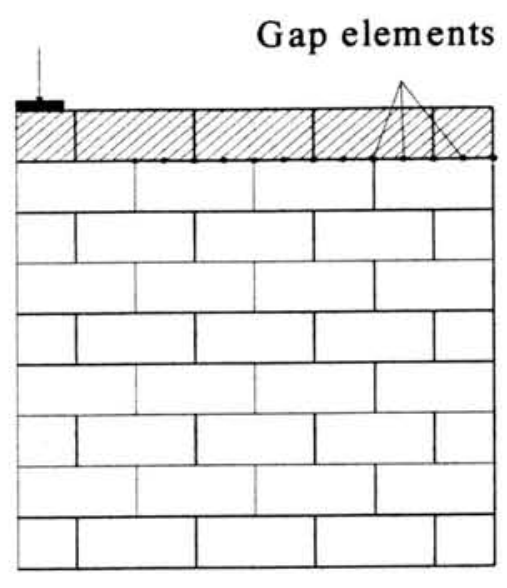

(a)

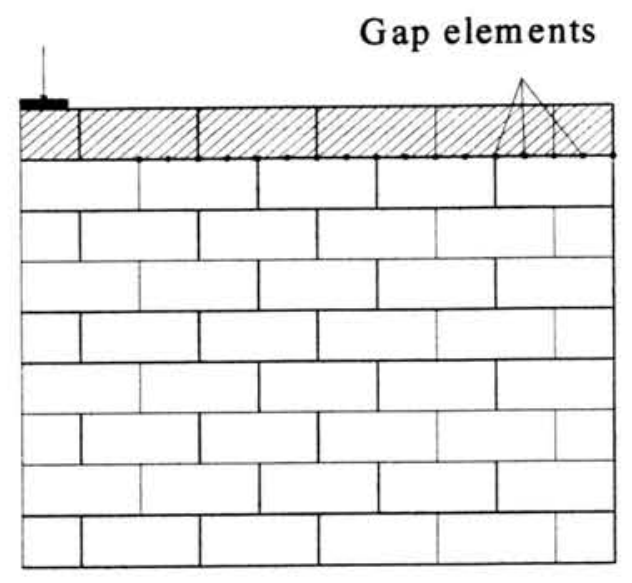

(b)

Fig. 5.25---Discrete models of hollow masonry walls with one-course bond beams, subjected to concentrated load at the end (a) 4-blocks long (b) 5-blocks long

Table 5.5 Results of Hollow Concrete Masonry Walls with One-course Bond Beams and Various Lengths, Subjected to Concentrated Loads at the End

\begin{tabular}{cccc}
\hline Wall Length (mm) & Plate Length $(\mathrm{mm})$ & Failure Loads $(\mathrm{KN})$ & Bond Beam Status \\
\hline 2400 (6 block) & 320 & 326 & not lifted up \\
& 240 & 289 & not lifted up \\
& 160 & 261 & not lifted up \\
\hline 2000 (5 block) & 320 & 316 & tip open \\
& 240 & 277 & tip open \\
& 160 & 255 & tip open \\
\hline 1600 (4 block) & 320 & 309 & lifted up \\
& 240 & 271 & lifted up \\
& 160 & 241 & lifted up \\
\hline
\end{tabular}


The importance of the latter issue is revealed with the discrete cracking method. When the wall is 6-blocks long, the failure mode is the same as predicted by the smeared model (see below). When the wall is 5-blocks long, the failure mode is similar to that of the 6block long wall, except that at about $90 \%$ of the ultimate load, i.e., after web splitting has progressed for some time, a crack opens between the bond beam and the face-shells at the far end of the wall from the concentrated load. This crack does not propagate very far. However, when the wall is 4-blocks long, the failure modes begin as before, but at about $50 \%$ of the ultimate load - at about the same load as web splitting begins beneath the concentrated load - the bond beam separates from the wall. The crack extends quickly towards the loaded end and stops near the loading plate. The shorter the loading plate length, the further the crack extends.

The stress distribution in the 4-block long hollow concrete masonry wall with a onecourse bond beam subjected to concentrated load at the end with the discrete cracking model is shown in Fig. 5.26, for a plate length $160 \mathrm{~mm}$. The predicted results in this case compare well with experimental results (Cormeau and Shrive 1995), as shown in Fig. 5.27 . 


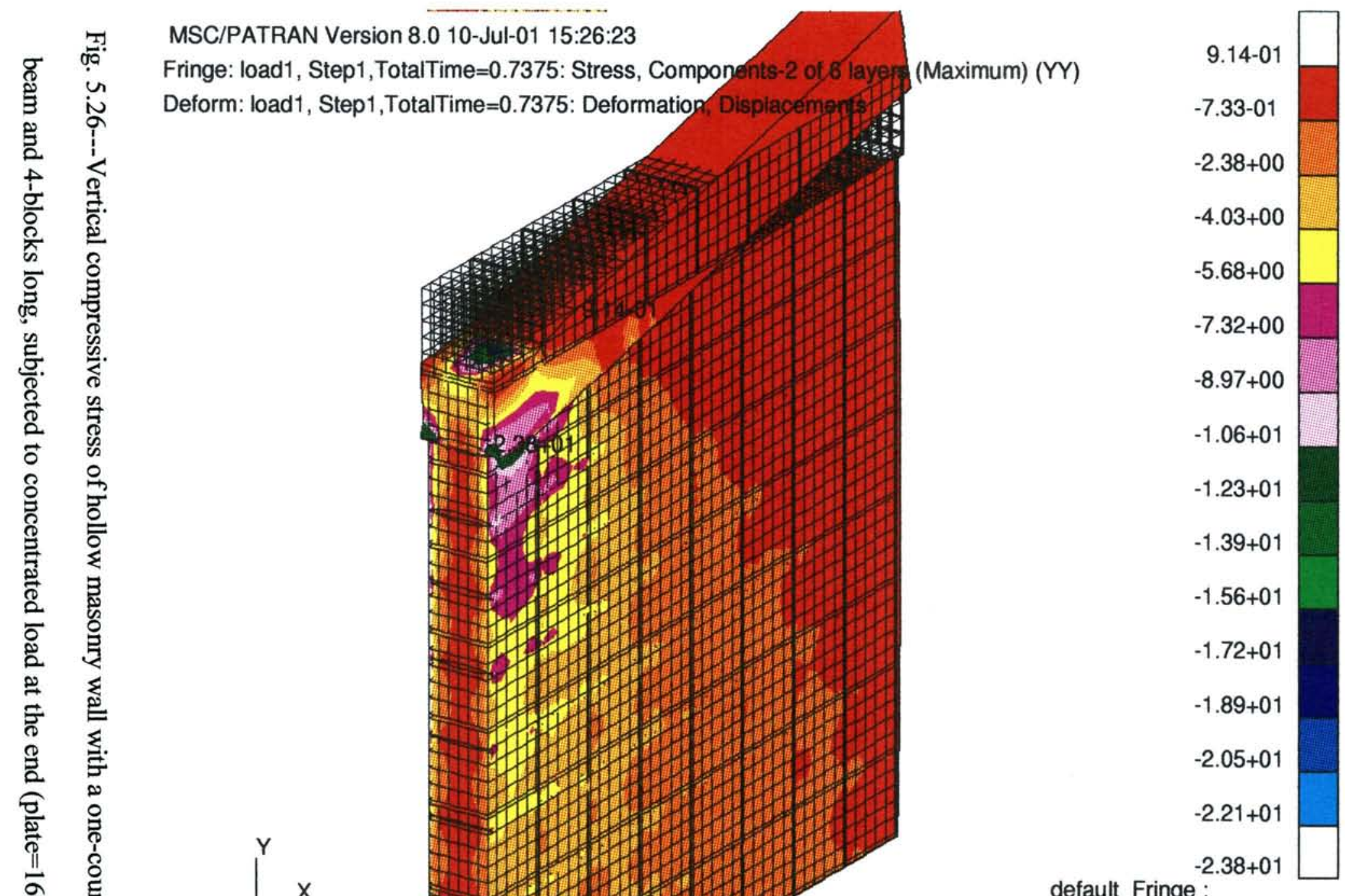

default_Fringe :

Max 9.14-01@Nd 14161

Min-2.38+01@Nd 12586

default_Deformation :

Max4.87-01 @Nd 12659 

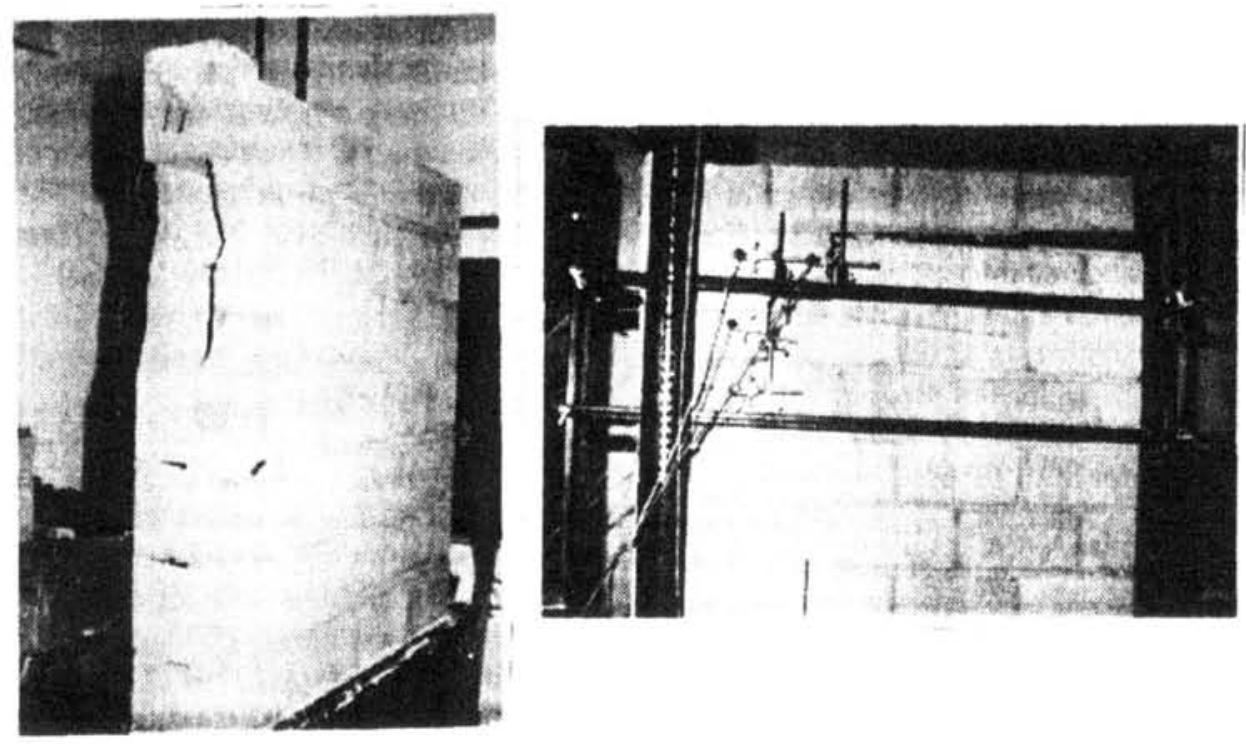

Fig. 5.27---Failure modes of hollow concrete masonry walls with one-course bond beams and 4-blocks long, subjected to concentrated loads at the end

The failure modes predicted by the smeared model when the load is at the end of the wall are similar to those when the load is in the middle of the wall: web splitting followed by face-shell spalling, except that more face-shell cracking occurs in line with the edge of the loading plate. When the loading plate length is increased, the ultimate load increases, and there is a trend that cracking in the face-shells occurs under the loading plate rather than in line with the loading plate edge, as would occur in a solid wall loaded in this manner. As the eccentricity increases, the ultimate load decreases (Fig. 5.21). 


\subsection{Partially Grouted Hollow Concrete Masonry Walls and Walls with Grouted Details}

\subsubsection{Geometry}

The wall models without vertical columns of grout are shown in Fig. 5.28. Six partialgrouting patterns were modelled: three models for load being at the middle of the wall (a pyramid grouting pattern (PGW1), a wedge grouting pattern (PGW2), and a one-block rectangular grouting pattern (PGW3)), and three models for load being at the end of the wall (end pyramid (PGW4), end wedge (PGW5), and end rectangular grouting patterns (PGW6)). When the load was located at the middle of the wall, a loading plate length of $160 \mathrm{~mm}$ was modelled. The out-of-plane eccentricities were $t / 6, t / 3$, and $5 t / 12$ where $t$ is the thickness of the wall $(190 \mathrm{~mm})$. When the load was located at the end of the wall, loading plate lengths of $80 \mathrm{~mm}$ and $160 \mathrm{~mm}$ were studied.

The wall models with vertical grout columns are shown in Fig. 5.29. Four patterns were modelled: two models with one-course bond beams (one with load being at the end of the wall (PGW7), another with load being at the middle of the wall (PGW8)) and two models without bond beam (one with load being at the end of the wall (PGW9), another with load being at the middle of the wall (PGW10)). The loading plate length was $200 \mathrm{~mm}$.

The materials (compressive strength) modelled were: hollow concrete block units (20MPa), mortar (7.6MPa), and grout $(20 \mathrm{MPa})$, matching the materials used in the experiments of Shrive and Sayed-Ahmed (1997). 


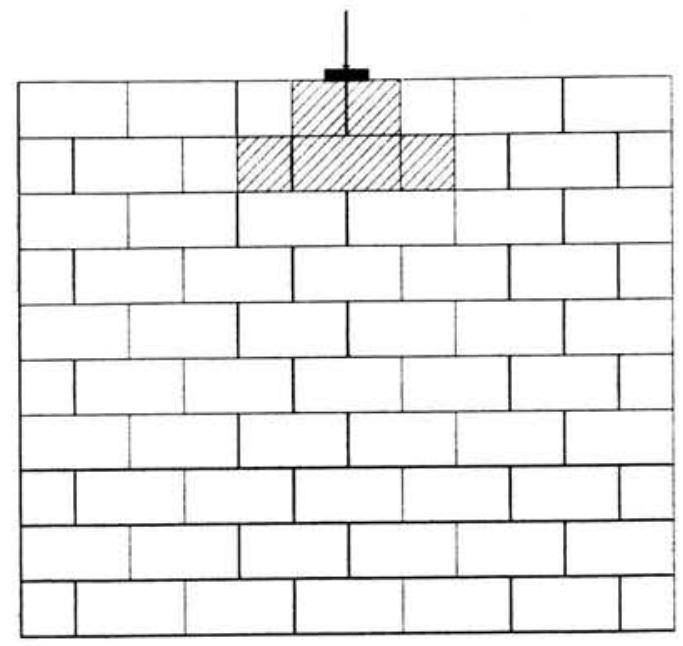

PGW1

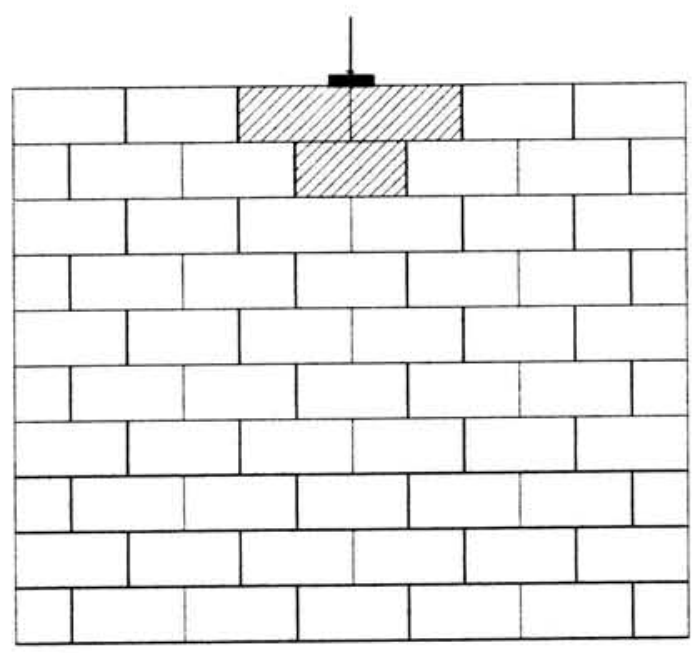

PGW2

Fig. 5.28a---Hollow concrete masonry walls with grouted details

(PGW1, 2) 


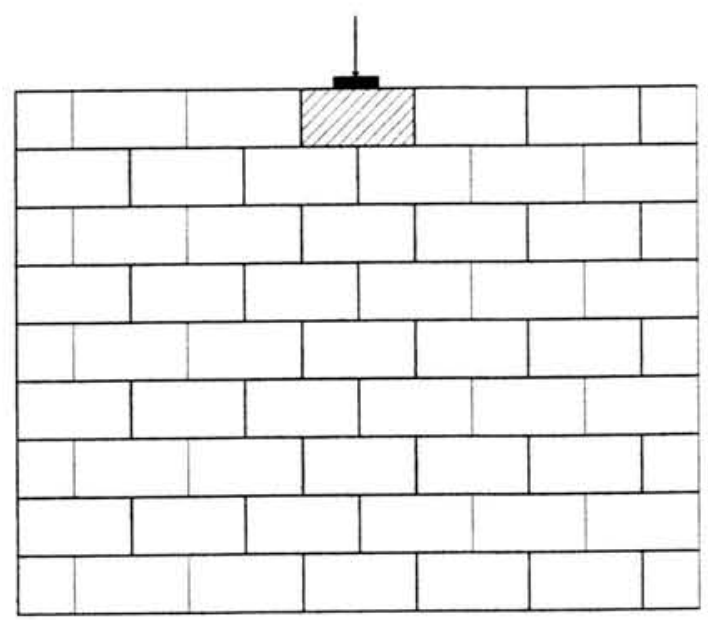

\section{PGW3}

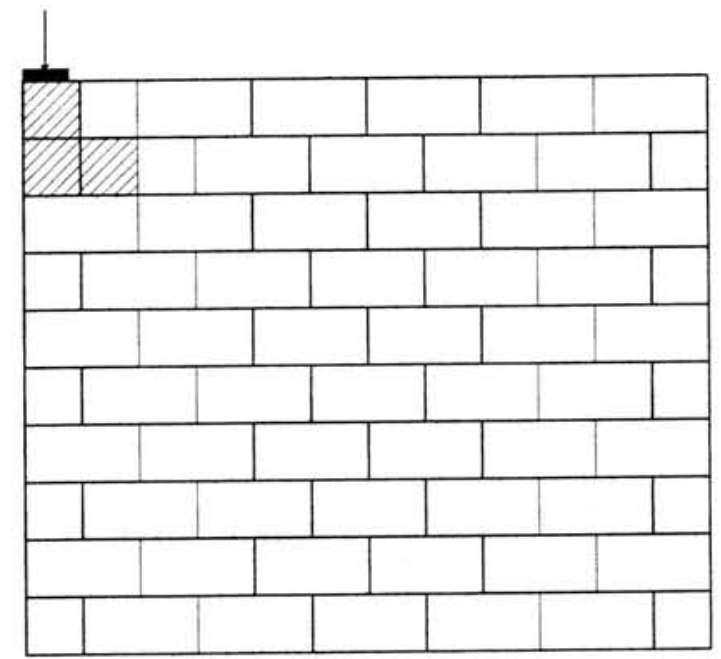

PGW4

Fig. 5.28b---Hollow concrete masonry walls with grouted details

(PGW3, 4) 


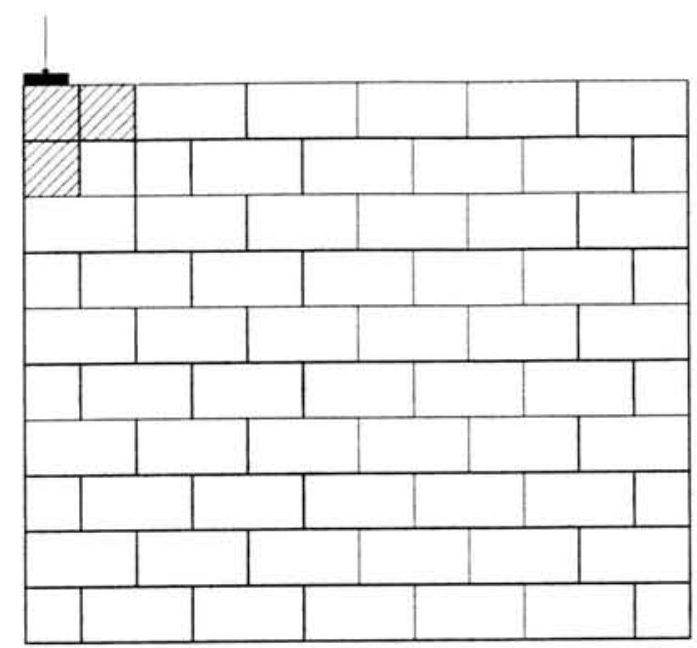

PGW5

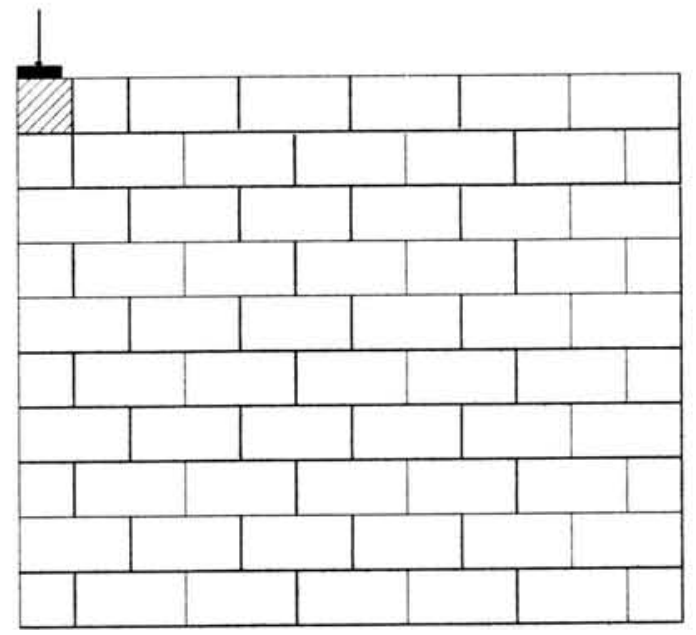

PGW6

Fig. 5.28c---Hollow concrete masonry walls with grouted details (PGW5, 6) 


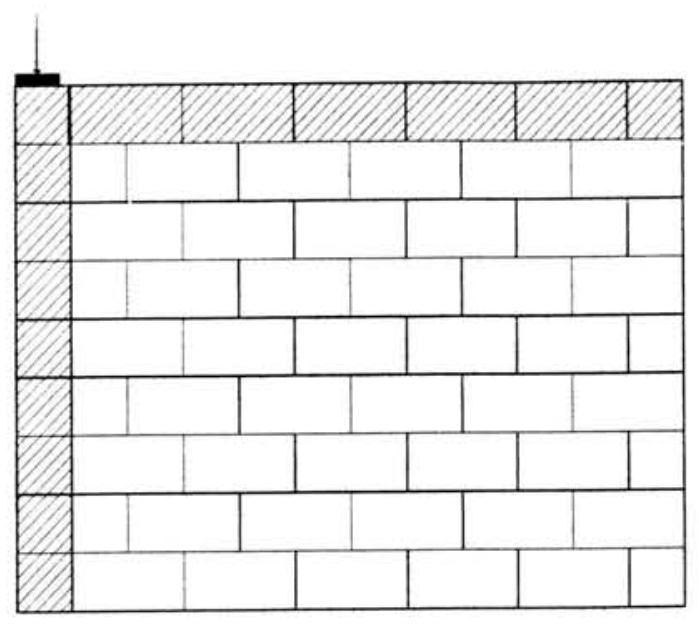

\section{PGW7}

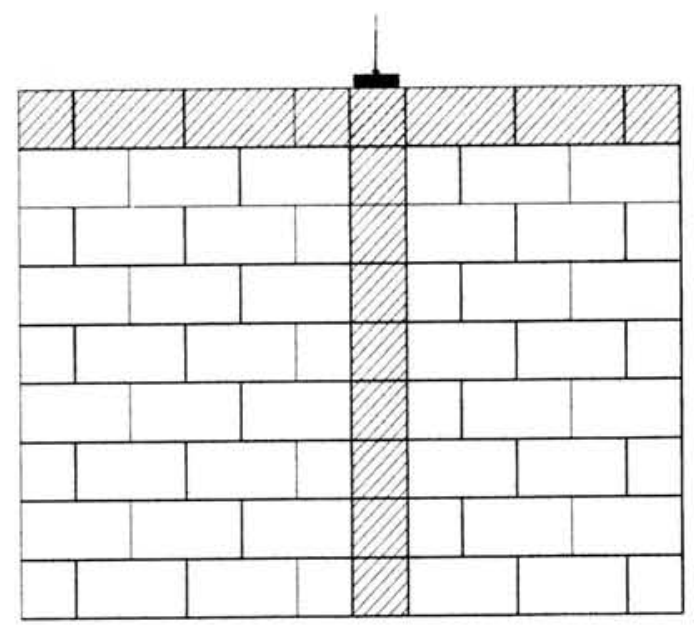

PGW8

Fig. 5.29a---Partially grouted hollow masonry walls with vertical grout column (PGW7, 8) 

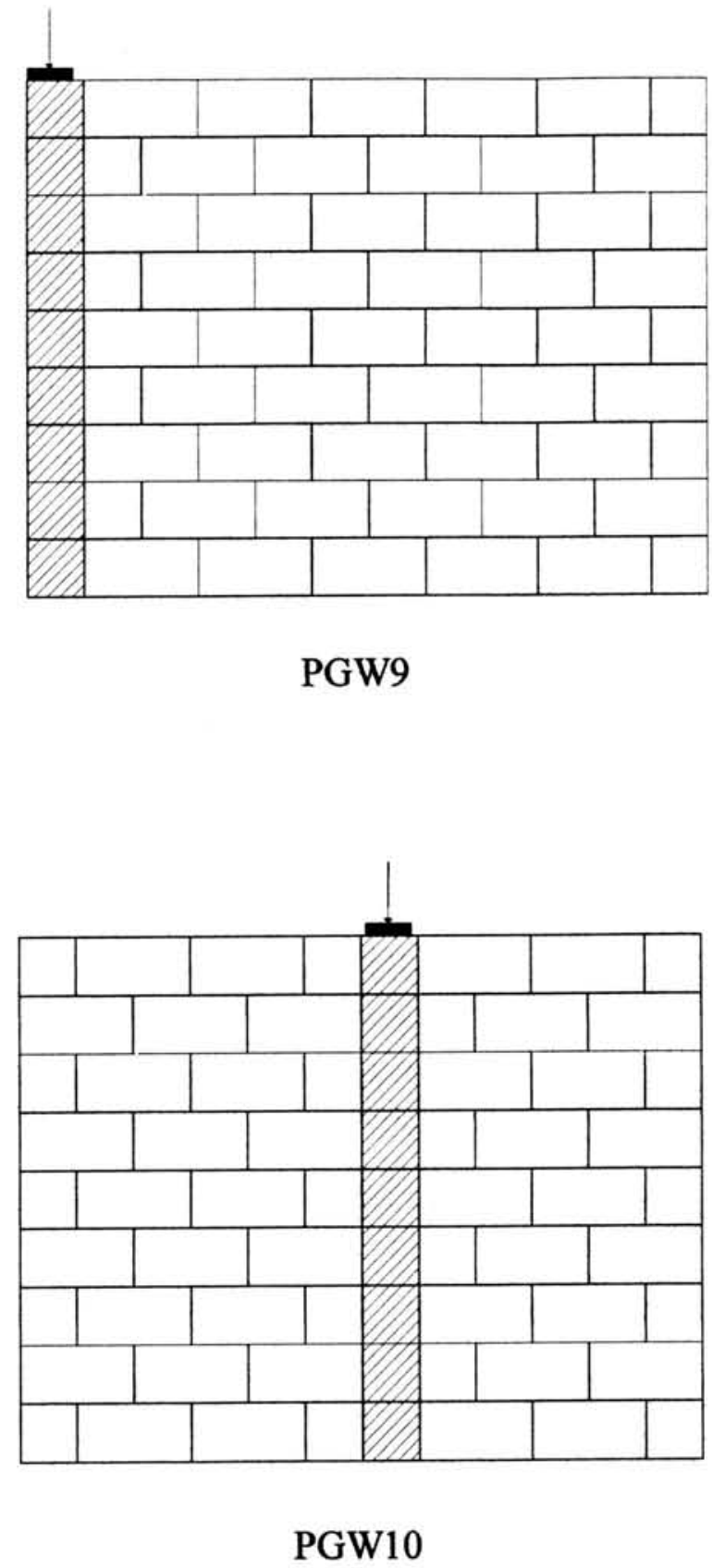

Fig. 5.29b---Partially grouted hollow masonry walls with vertical grout column (PGW9, 10) 


\subsubsection{Verification of models}

The PGW1 and PGW2 models were developed first and compared with the experimental results (Shrive and Sayed-Ahmed 1997). The failure loads from the models and experiments are shown in Table 5.6.

Table 5.6 Comparison of Theoretical and Experimental Strength of Partially Grouted Hollow Masonry Walls Subjected to Concentric Concentrated Loads (PGW1, PGW2)

\begin{tabular}{cccc}
\hline \multirow{2}{*}{ Grout Configuration } & $\begin{array}{c}\text { Eccentricities } \\
(\mathrm{mm})\end{array}$ & Finite Element Model & Experiment \\
\hline Pyramid (PGW1) & $\mathrm{e}=0$ & 495 & 485 \\
Wedged (PGW2) & $\mathrm{e}=0$ & 431 & 449 \\
\hline
\end{tabular}

The failure mode of the model with the pyramid grouting pattern (PGW1) when subjected to concentric load is that at about $40 \%$ of the ultimate load, the mortar between the grouted blocks and the face-shells of hollow blockwork beneath starts to crack. This slight mortar cracking does not seem to affect the loading capacity, and could be invisible to people looking at the wall. At about $50 \%$ of the ultimate load, cracking occurs in the middle of the bottom of the grouted blocks directly beneath the loading plate, and the webs split in the first hollow course immediately below the grouted blocks in the region directly beneath the load. These cracks are not visible from the outside of the wall. At about $60 \%$ of the ultimate load, a vertical crack forms in the mortar in the first hollow block course in line with the load, similar to a crack that forms in a solid wall loaded in this manner. With increasing load, web-splitting progresses along the first hollow course and into the courses beneath, but is limited in the region under the grouted blocks. 
Vertical mortar joints in this region (except the middle vertical one) also crack due to the combined shear and compression stresses. Final failure occurs when sufficient webs split and local face-shells spalled and mortar crushed. The cracking pattern is shown in Fig. 5.30a, and matches that described from the experimental work (Shrive and Sayed-Ahmed 1997).

The failure mode of PGW2 (wedge pattern) predicted by the model is similar to that of PGW1, except that web-splitting and face-shell spalling and/or mortar crushing is more localized beneath the load. The vertical compressive stress distributions of PGW1 and PGW2 are shown in Fig. 5.31, 5.32, respectively. It can be seen that load dispersion by the wedge grout pattern is not as efficient as that of the pyramid pattern. There is excellent agreement between the predicted and experimental results.

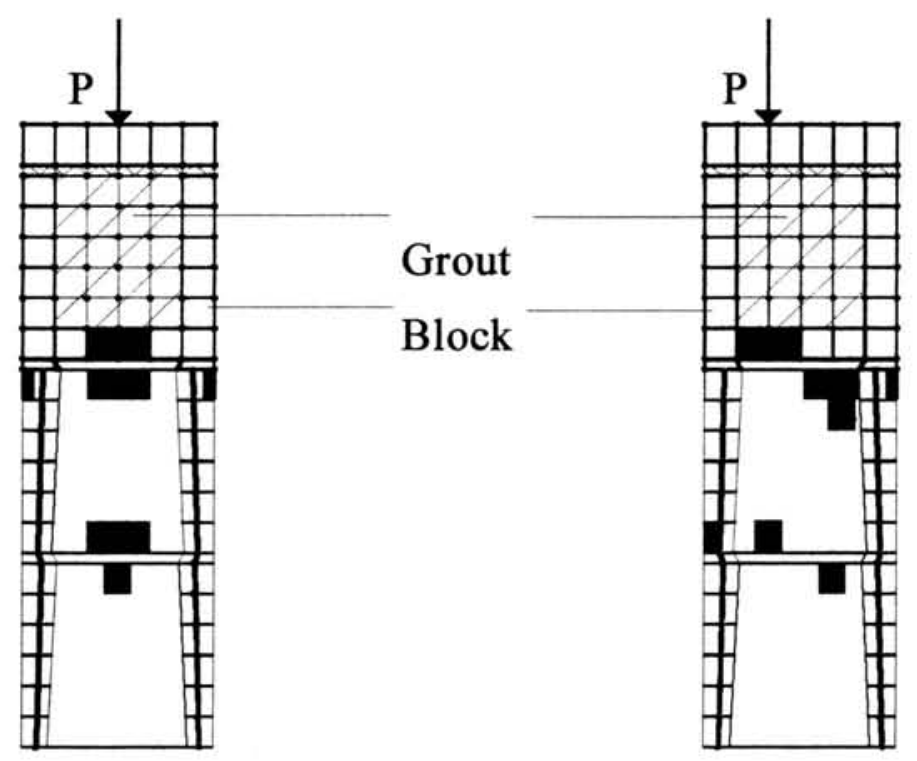

Fig. 5.30---Cracking pattern of hollow masonry walls with grouted details, subjected to concentrated load (Solid black indicates locations of cracks)

$\begin{array}{ll}\text { (a) concentric concentrated load } & \text { (b) eccentric concentrated load }\end{array}$ 


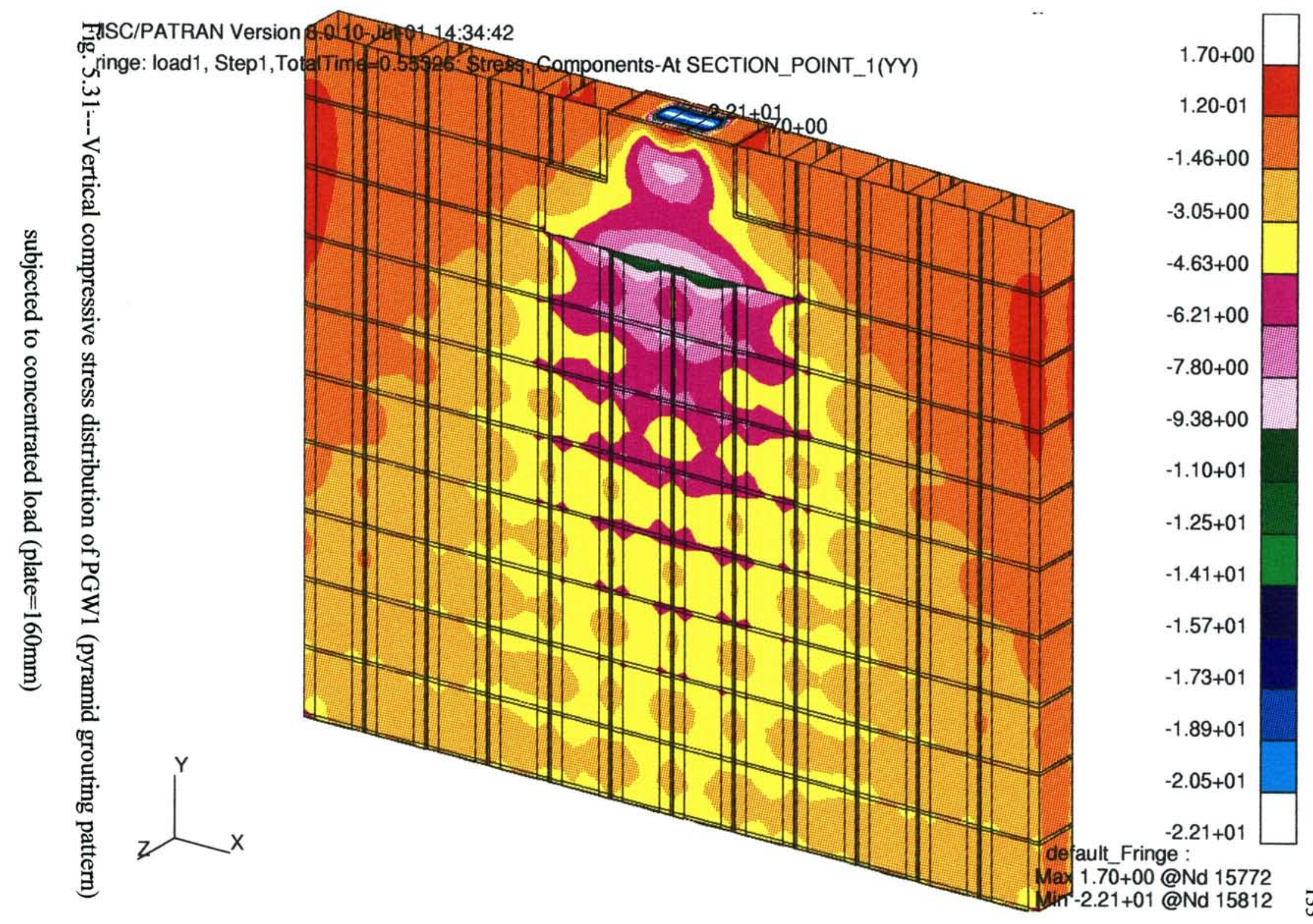



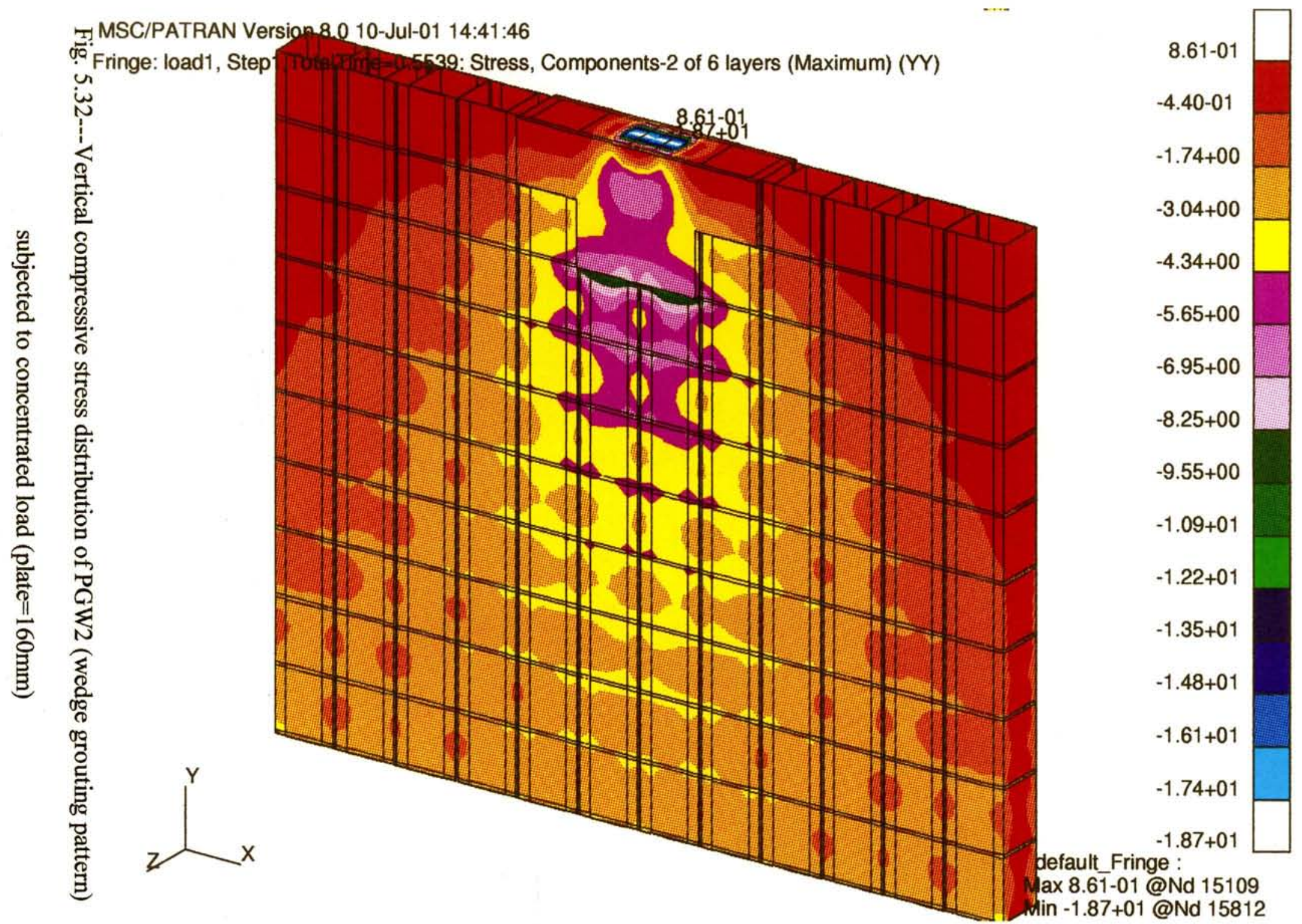

default_Fringe :

ax8.61-01@Nd 15109 din-1.87+01@Nd 15812 


\subsubsection{Application of models}

\subsubsection{Models without vertical grout columns}

Under eccentric load, cracking with the pyramid (PGW1) and wedge grout patterns (PGW2) still occurs at the bottom of the grouted blocks directly beneath the loading plate, but on the heavily loaded side, rather than the middle. And at the same time, cracks appear on the lightly loaded side of the top of the webs in the first hollow course immediately below the grouted blocks, as shown in Fig. 5.30b. Also the mortar between the grouted blocks and the lightly loaded face-shell beneath crack under combined shear and compression. As the load increases, a vertical crack forms in the wall in line with the load. Final failure occurs when cracks form at the bottom of the webs in the first hollow course on the heavily loaded side, and at the top of the webs in the second hollow course on the lightly loaded side.

As the eccentricity is increased, the sequence of cracking and failure is similar, except that the bottom of the grouted blocks cracks closer and closer to the heavily loaded faceshell while the top of the webs in the first hollow course immediately below the grouted blocks cracks closer and closer to the lightly loaded face-shell.

The ultimate loads obtained decrease with increasing eccentricity (Table 5.7). However, the idealization of the models might overestimate the failure loads of hollow concrete masonry walls subjected to eccentric loads, as instability can develop in practice with large eccentric loads. 
Table 5.7 Capacities of Partially Grouted Hollow Concrete Masonry Walls and Walls with Grouted Details Subjected to Concentrated Loads

\begin{tabular}{|c|c|c|c|c|}
\hline $\begin{array}{c}\text { Grout } \\
\text { Configuration }\end{array}$ & $\begin{array}{c}\text { Load Location } \\
\text { Along Wall }\end{array}$ & $\begin{array}{l}\text { Eccentricities } \\
\text { Across Width }\end{array}$ & $\begin{array}{l}\text { Plate Length } \\
(\mathrm{mm})\end{array}$ & $\begin{array}{c}\text { Failure Load } \\
(\mathrm{KN})\end{array}$ \\
\hline \multirow[t]{3}{*}{ PGW1 } & middle & $e=t / 6$ & $a=160$ & 450 \\
\hline & middle & $\mathrm{e}=\mathrm{t} / 3$ & $a=160$ & 383 \\
\hline & middle & $\mathrm{e}=5 \mathrm{t} / 12$ & $a=160$ & 363 \\
\hline \multirow[t]{3}{*}{ PGW2 } & middle & $e=t / 6$ & $a=160$ & 392 \\
\hline & middle & $e=t / 3$ & $a=160$ & 339 \\
\hline & middle & $e=5 t / 12$ & $a=160$ & 318 \\
\hline \multirow[t]{4}{*}{ PGW3 } & middle & $\mathrm{e}=0$ & $a=160$ & 263 \\
\hline & middle & $e-t / 6$ & $a=160$ & 221 \\
\hline & middle & $e=t / 3$ & $a=160$ & 176 \\
\hline & middle & $\mathrm{e}=5 \mathrm{t} / 12$ & $a=160$ & 166 \\
\hline \multirow[t]{5}{*}{ PGW4 } & end & $\mathrm{e}=0$ & $a=80$ & 291 \\
\hline & end & $e=t / 6$ & $a=80$ & 261 \\
\hline & end & $e=t / 3$ & $a=80$ & 217 \\
\hline & end & $e=5 t / 12$ & $a=80$ & 198 \\
\hline & end & $\mathrm{e}=0$ & $a=160$ & 299 \\
\hline \multirow[t]{5}{*}{ PGW5 } & end & $\mathrm{e}=0$ & $a=80$ & 238 \\
\hline & end & $e=t / 6$ & $a=80$ & 212 \\
\hline & end & $e=t / 3$ & $a=80$ & 191 \\
\hline & end & $e=5 t / 12$ & $a=80$ & 168 \\
\hline & end & $\mathrm{e}=0$ & $a=160$ & 281 \\
\hline \multirow[t]{5}{*}{ PGW6 } & end & $\mathrm{e}=0$ & $a=80$ & 155 \\
\hline & end & $e=t / 6$ & $a=80$ & 126 \\
\hline & end & $e=t / 3$ & $a=80$ & 99 \\
\hline & end & $e=5 t / 12$ & $a=80$ & 94 \\
\hline & end & $\mathrm{e}=0$ & $a=160$ & 162 \\
\hline PGW7 & end & $\mathrm{e}=0$ & $a=200$ & 679 \\
\hline PGW8 & middle & $\mathrm{e}=0$ & $a=200$ & 755 \\
\hline PGW9 & end & $e=0$ & $a=200$ & 596 \\
\hline PGW10 & middle & $\mathrm{e}=0$ & $a=200$ & 607 \\
\hline
\end{tabular}




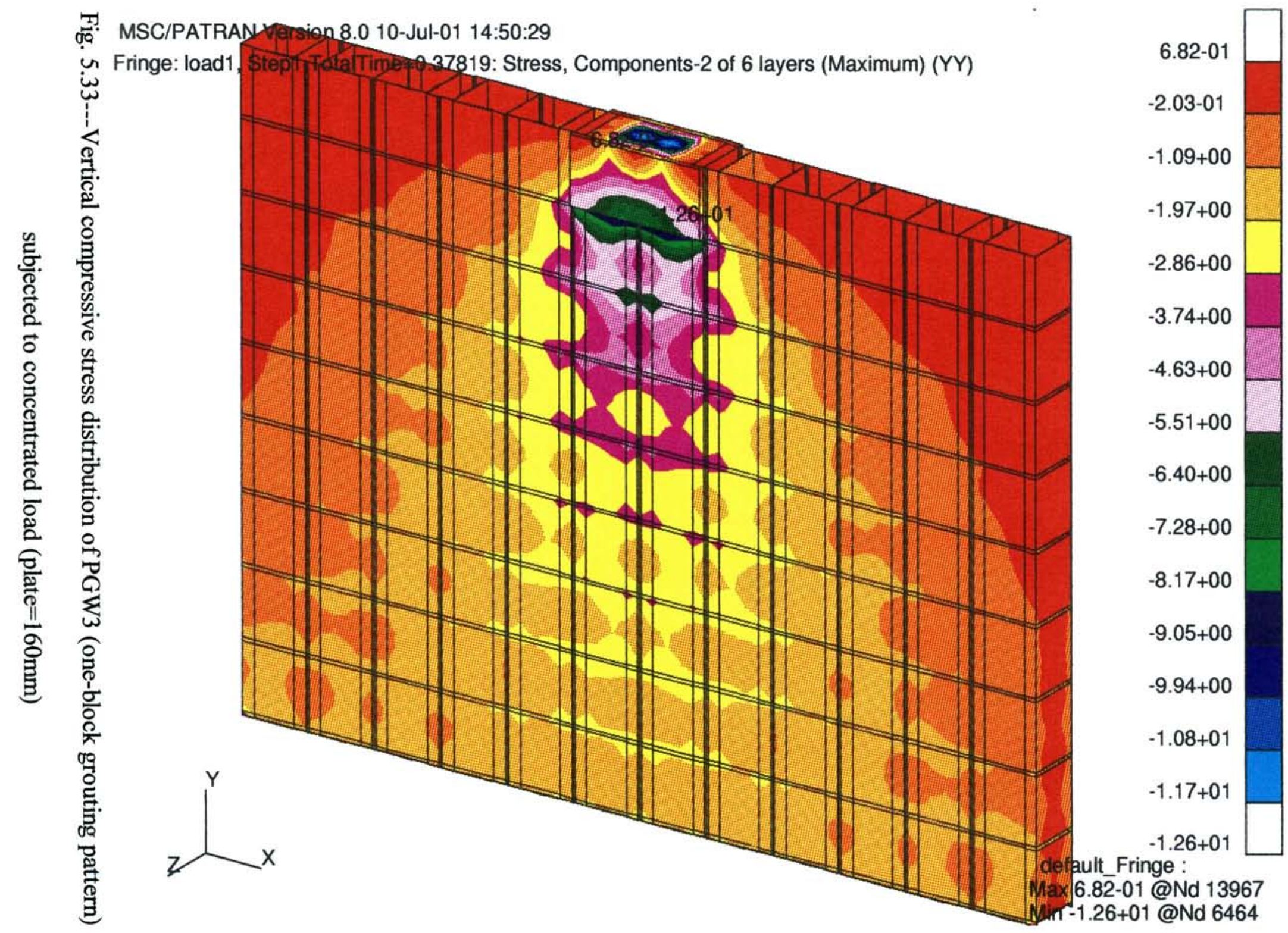


The behaviour of PGW3 is similar to that of PGW1 and PGW2: the bottom of the grouted blocks and the webs beneath split first, followed by face-shell rotation and spalling, and/or mortar crushing. The bearing capacity obtained for PGW3 is much lower than that of PGW1 and PGW2, as filling one block helps spread the concentrated load only a little more than the plain hollow blockwork (Sayed-Ahmed 1996). Similar to PGW1 and PGW2, when the eccentricity increases, the ultimate capacities of PGW3 decrease. The vertical compressive stress distribution of PGW3 is shown in Fig. 5.33. The failure loads of PGW3 are also given in Table 5.7, together with those of PGW4, 5, and 6.

When the concentrated load is applied at the end of the wall, the failure mode is as observed before: the bottom of the grouted blocks and the webs beneath split first, followed by face-shell rotation and spalling, and/or mortar crushing. As can be seen from Table 5.7, when the loading plate length is $80 \mathrm{~mm}$, end pyramid grouting (PGW4) offers the highest capacity, as with loading at the middle of the wall. This is because the pyramid grouting helps spread the concentrated load into the beneath hollow masonry. However, when the plate length is $160 \mathrm{~mm}$, end pyramid grouting does not spread the load as efficiently, as part of the load is spread beyond the grouted core into the adjacent hollow block units, rather than being spread through the grout into the beneath hollow masonry. This also occurs with single block end grouting (PGW6). In contrast, the grouting pattern of PGW5 helps considerably as the grout in the first course spreads the concentrated load into the hollow blocks in the second course. These results imply that 
the grouted region and loading plate should be compatible in size to spread the concentrated load effectively into the hollow blocks beneath the grouted blocks, rather than beside them. For the most common grout detail used in practice ( 2 courses fully grouted under the bearing plate), the capacity would be the same or slightly higher than the pyramid pattern, as the concentrated load would be spread effectively into the hollow blocks beneath, as per the pyramid detail.

The vertical compressive stress distribution of PGW4 with loading plate length $160 \mathrm{~mm}$ is shown in Fig. 5.34. As can be seen, the wide loading plate spreads the concentrated load into the hollow blockwork in the first course beside the grouted blocks. However, when the plate length is $80 \mathrm{~mm}$, the stresses beneath the grouted blocks are almost the same as those with the $160 \mathrm{~mm}$ plate, but the load is not transmitted into the adjacent hollow block in the first course. Hence the small gains from the use of larger plates may not warrant the cost.

\subsubsection{Strength Variation}

When Equation [4.1] is used for hollow concrete masonry walls with grouted details under eccentric concentrated load, the results are shown in Fig. 5.35 and 5.36 for loading in the middle and loading at the end of the wall respectively. Equation [4.1] gives safe results. 

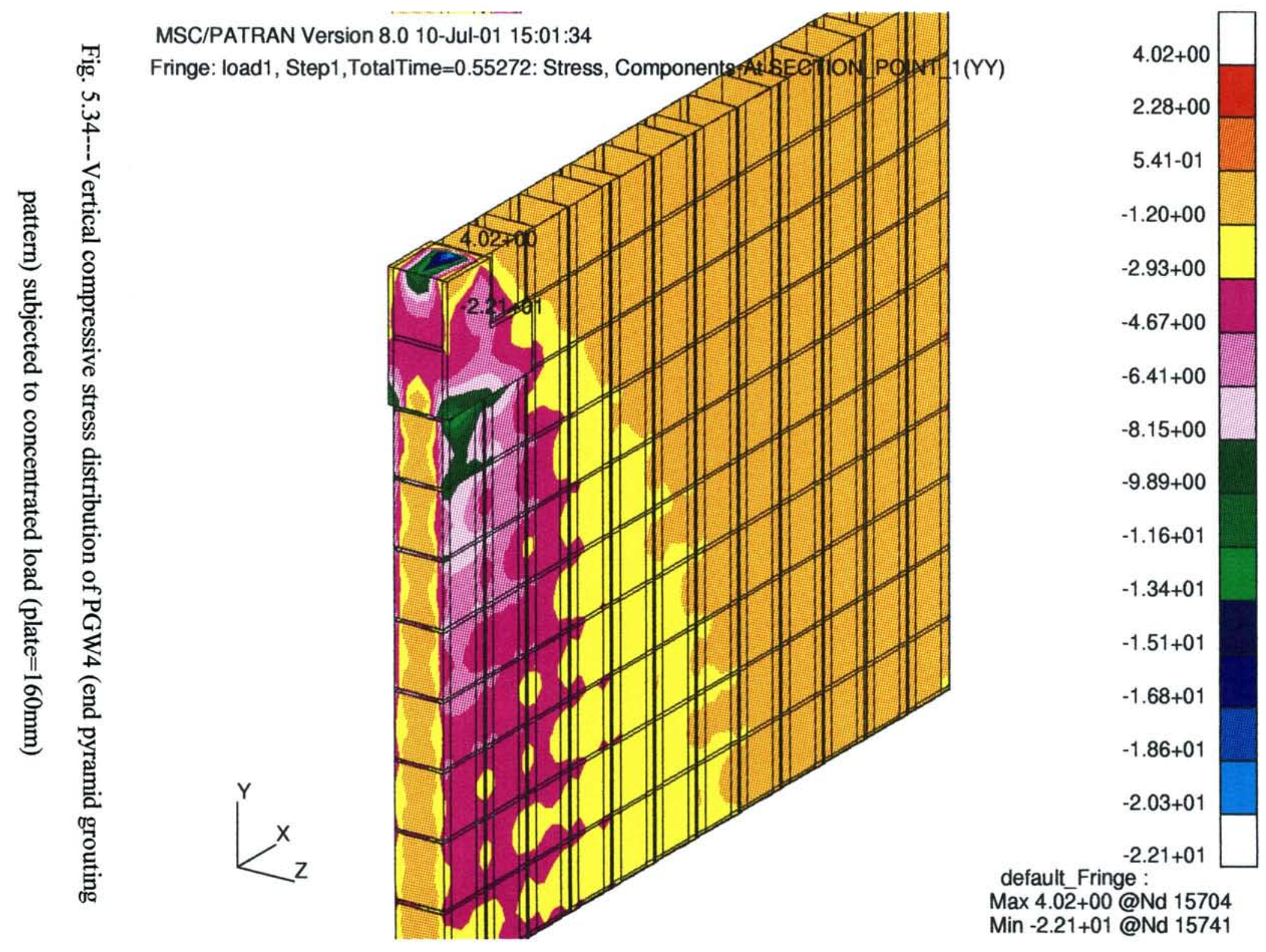

default Fringe :

Max 4.02+00@Nd 15704 Min-2.21+01@Nd 15741 


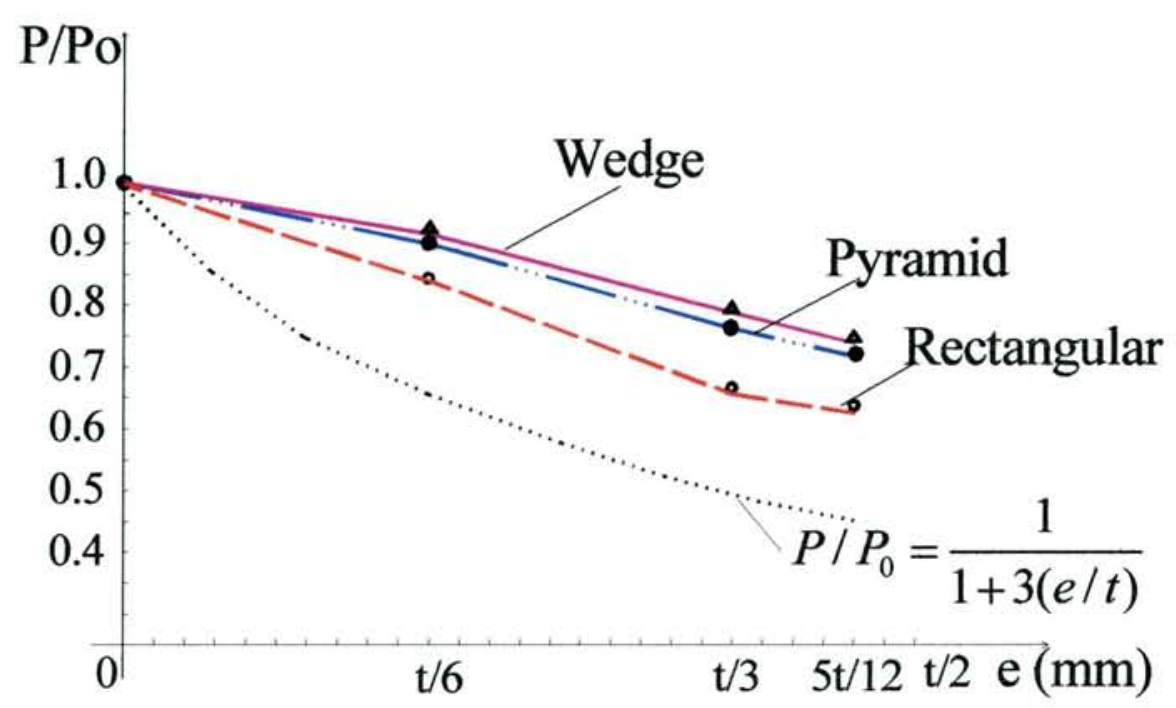

Fig. 5.35---Strength variation for hollow concrete masonry walls with wedge, pyramid and one-block rectangular grouting patterns (PGW1, 2, 3)

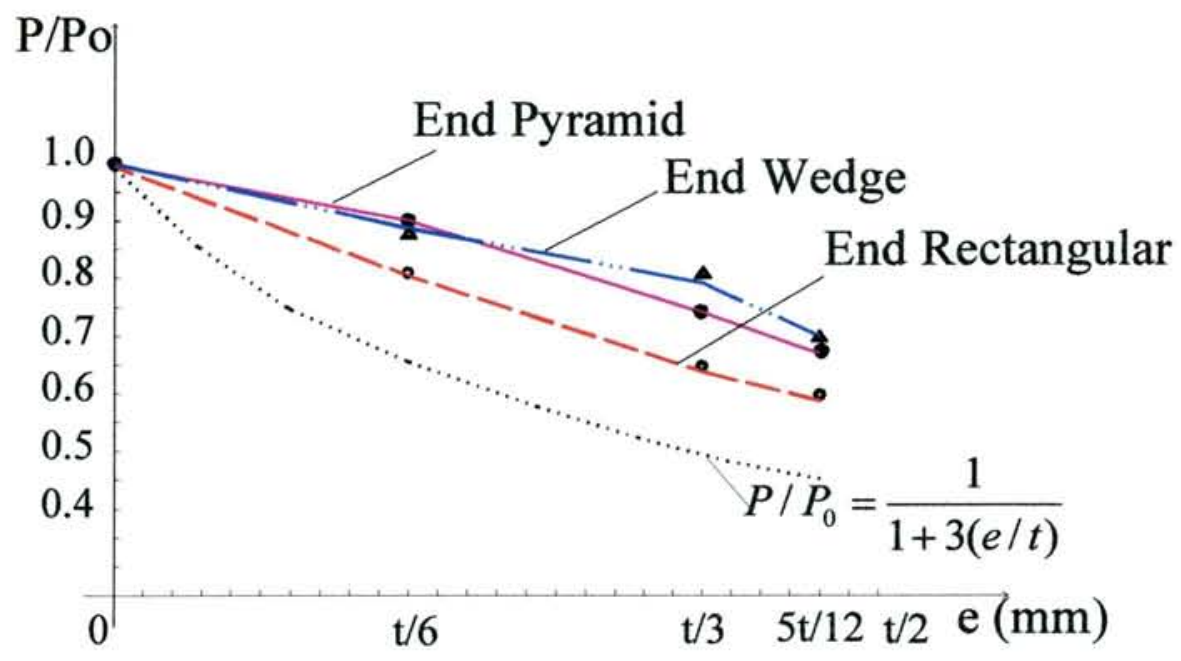

Fig. 5.36---Strength variation for hollow concrete masonry walls with end wedge, end pyramid and end rectangular grouting patterns (PGW4, 5, 6) 


\subsubsection{Models with vertical columns of grout}

Before attempting the analyses of partially grouted walls with vertical columns of grout, a half block column (one-core vertically grouted) without surrounding hollow blockwork was analyzed under concentric load and compared with experimental results in the literature (Khalaf et al. 1993). The materials used matched the materials used in the test. Excellent agreement between the model and experimental results was achieved. The predicted failure mode is that block face-shell and web splitting begins near the mortar joints at $65 \%$ of the ultimate load, followed by grout and mortar crushing. The experimental test result was that some crack propagation was observed in the end of the block at the mid-height of the column and further cracking was observed in the side faceshells at $80-90 \%$ of the ultimate load. The predicted ultimate strength is $581 \mathrm{kN}$, compared with $561 \mathrm{kN}$ from the test.

The predicted failure mode of PGW7 (under concentric concentrated load) is that at about $50 \%$ of the ultimate load, the mortar between the bond beam and the hollow blocks below starts to crack. At about $60 \%$ of the ultimate load, the hollow block face-shells in the corners of the joint of the bond beam and the vertical column start spalling/splitting. As load increases, the webs split in the hollow blocks beside the column. Final failure occurs when the column crushes. The failure mechanism is different from that of walls without a vertical column of grout; that is face-shell spalling first rather than web splitting first. The predicted failure mode of PGW8 is similar to that of PGW7, except that higher ultimate load is obtained, as shown in Table 5.7. 
The predicted failure mode of PGW9 (under concentric concentrated load) is that at about $35 \%$ of the ultimate load, the head joints between the vertical column and the hollow blocks start to crack. At about $50 \%$ of the ultimate load, the face-shells in the hollow blocks connecting to the vertical column start splitting/spalling. As load increases, webs split in the hollow blocks beside the column. Final failure occurs with the vertical column crushing. The predicted failure mode of PGW10 is similar to that of PGW9, except that the grout column has to separate from the hollow concrete masonry on both sides rather than one, and a little higher ultimate load is obtained as given in Table 5.7. The ultimate load of PGW9 and PGW10 are only marginally higher than that of a half block column, very little load is dispersed into the hollow masonry surrounding the column of grout.

\subsection{Dispersion of Concentric Concentrated Load}

To obtain an estimate of the angle of load dispersion $\theta$ through bond beams and grouted details, the procedure shown schematically in Fig. 5.37 was adopted. For every masonry type, loading location and loading plate size, the angle of concentric concentrated load dispersion required to produce an average stress intensity at the top of the first hollow masonry course equal to the uniaxial wall strength $\left(f_{m}{ }^{\prime}\right)$ was calculated. The uniaxial wall strength $\mathrm{f}_{\mathrm{m}}$ ' was 13.7MPa for the materials (block units and mortar) used in the models.

The values of $\theta$ obtained are summarized in Table 5.8. It can be seen that for walls with one-course bond beams, the dispersion angle is larger than that with two-course bond beams. As the location of load application moves towards the end of the wall, the dispersion angle decreases. Also, as the loading plate length increases, the angle 
decreases. These results can be explained by consideration of the failure mechanism: failure occurs by progressive splitting of the webs in the hollow courses immediately below the bond beam or grouted blocks in the region beneath the concentrated load, causing horizontal dilation and face-shell rotation, leading to face-shell spalling and/or mortar crushing. When a concentrated load is applied, the load disperses and local web splitting is resisted by a number of cross-webs. The greater the number of participating webs, the greater the load dispersion. In the plain wall case, only a small number of webs are mobilized to resist splitting and load dispersion is negligible as can be seen from Fig. 5.7. In the case of walls with bond beams, as the loading plate length increases, the number of webs available to resist transverse splitting also increases, but with a decreasing effect. High vertical compressive stresses remain more localized beneath the concentrated load, and hence there is a limit to the dispersion and the associated web splitting and horizontal dilation. A similar result was observed in walls with two-course bond beams. As the load moves towards the end of the wall, the number of webs available to resist transverse splitting decreases and hence the dispersion angle decreases.

In the case of partial grouting patterns, the pyramid grouting pattern offers the largest angle, while grouting only the block immediately below the load offers much smaller dispersion.

The dispersion angles calculated are significantly less than the $45^{\circ}$ accepted by most codes of practice (such as the MSJC). However, these angles are confirmed by the vertical compressive stress figures from the non-linear finite element models, and experimentally by the readings obtained from the vertical strain gauges in the hollow 
course immediately below the bond beam (Page and Shrive 1990). An angle of $22^{\circ}$ or slope (vertical to horizontal) of $2.5: 1$ is a reasonable choice for a safe estimate of dispersion for all the wall types but the wedge and one-block grouting patterns which should be avoided in practice.
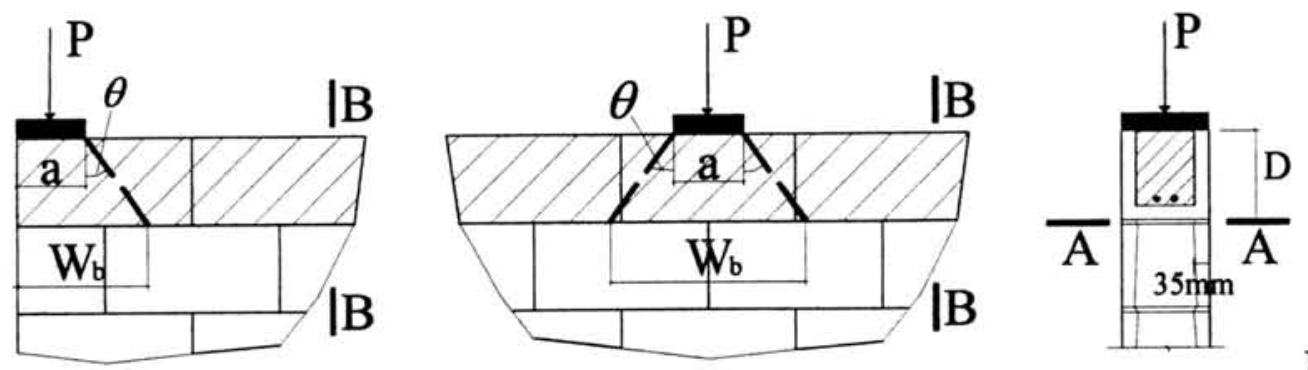

$\underline{B-B}$
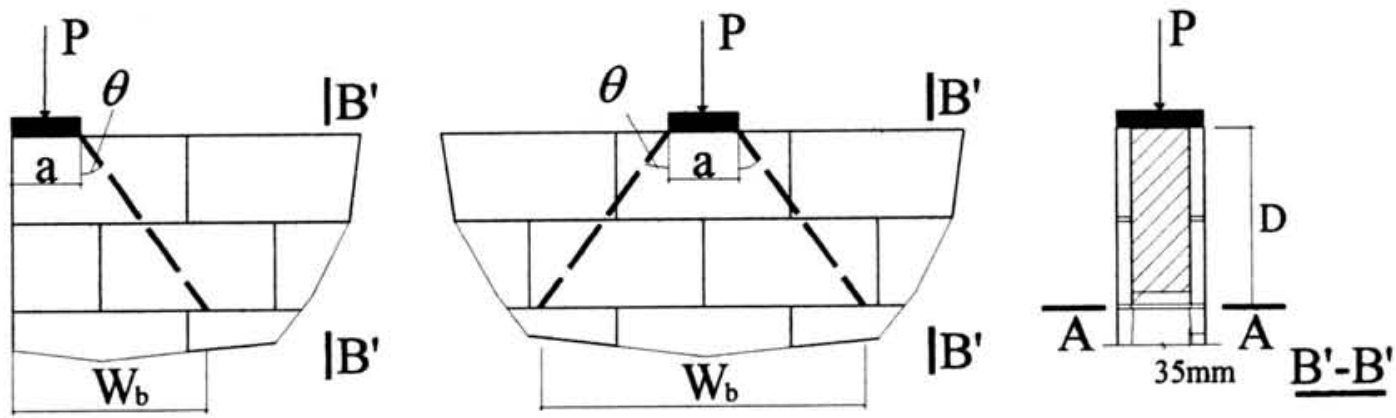

Stress at A-A:

End loading

$$
\begin{aligned}
& \frac{P \times 10^{3}}{70 \times W_{b}}=f_{m}^{\prime} \\
& \theta=\tan ^{-1}\left(\frac{W_{b}-a}{D}\right)
\end{aligned}
$$

Middle loading

$$
\begin{aligned}
& \frac{P \times 10^{3}}{70 \times W_{b}}=f_{m}^{\prime} \\
& \theta=\tan ^{-1}\left(\frac{W_{b}-a}{2 D}\right)
\end{aligned}
$$

Fig. 5.37---Concentric concentrated load dispersion 
Table 5.8 Dispersion of Concentric Concentrated Load Through Bond-beams or Grouted Hollow Blocks

\begin{tabular}{ccccccc}
\hline Wall Type & $\begin{array}{c}\text { Load Location } \\
\text { Along Wall L } \\
(\mathrm{mm})\end{array}$ & $\mathrm{D}(\mathrm{mm})$ & $\begin{array}{c}\text { Plate } \\
\text { Length a } \\
(\mathrm{mm})\end{array}$ & $\begin{array}{c}\text { Failure Load } \\
\mathrm{P}_{\mathrm{u}}(\mathrm{KN})\end{array}$ & $\mathrm{W}_{\mathrm{b}}(\mathrm{mm})$ & $\theta^{\circ}$ \\
\hline One-course & 1200 & 200 & 160 & 378 & 394 & 30 \\
bond beam & 1200 & 200 & 240 & 426 & 444 & 27 \\
& 1200 & 200 & 320 & 517 & 539 & 29 \\
\cline { 2 - 7 } & 800 & 200 & 160 & 375 & 391 & 30 \\
& 800 & 200 & 240 & 423 & 441 & 27 \\
& 800 & 200 & 320 & 511 & 532 & 28 \\
\hline & 400 & 200 & 160 & 342 & 357 & 26 \\
& 400 & 200 & 240 & 395 & 412 & 23 \\
& 400 & 200 & 320 & 463 & 483 & 22 \\
\hline Two-course & 0 & 200 & 160 & 253 & 264 & 27 \\
bond beam & 1200 & 400 & 160 & 539 & 562 & 27 \\
& 1200 & 400 & 240 & 588 & 613 & 25 \\
\hline Pyramid & 1200 & 400 & 320 & 645 & 672 & 24 \\
\hline grouting & 1200 & 400 & 160 & 495 & 516 & 24 \\
\hline Wedge & 0 & 400 & 80 & 291 & 303 & 29 \\
\hline grouting & 1200 & 400 & 160 & 431 & 449 & 20 \\
\hline One-block & 1200 & 400 & 80 & 238 & 248 & 22 \\
grouting & 0 & 200 & 160 & 263 & 274 & 16 \\
\hline & 200 & 80 & 155 & 161 & 22 \\
\hline
\end{tabular}

\subsection{Summary}

3D non-linear finite element models have been developed and applied to the analysis of the structural behaviour of hollow concrete masonry walls subjected to concentric and 
eccentric concentrated load. Plain walls, walls with bond beams, and with grouted details were examined. Hollow concrete block units, mortar, grout, and bond beam blocks were modelled separately. Geometric and material non-linearities were taken into account. Both smeared and discrete crack modelling approaches were used to model the progressive cracking and damage. Shell elements were used to model the hollow concrete block units and mortar, solid elements were used to model the grout and bond beam blocks, and gap elements were used to model the joint between bond beam and the hollow masonry beneath. Where possible, results of the models were compared with results observed in the small number of available experiments. The good agreement confirms that the non-linear behaviour of hollow concrete masonry walls subjected to concentrated load can be successfully modelled.

\subsubsection{Plain walls}

The failure mechanism is by progressive web splitting of the hollow concrete block units in the region beneath the loading plate, followed by spalling of face-shells and/or crushing of mortar. When the eccentricity is increased, the models predict basically the same failure mechanism, but with lower failure loads.

Equation [4.1] can be used to assess the effect of eccentricity on the ultimate strength.

\subsubsection{Walls with bond beams}

The failure mechanism under concentric concentrated load is by progressive web splitting of the hollow concrete units in the region under the bond beam beneath the load, followed 
by spalling of face-shells and/or crushing of mortar. The grout does not help much in resisting cracking in hollow concrete masonry walls with bond beams, so grout strength only influences the ultimate capacity marginally. If local crushing beneath the steel loading plate is avoided, with increasing eccentricity, the models predict basically the same failure mechanism, but with lower failure loads.

When the concentrated load is moved from the middle to the end of the hollow concrete masonry wall, the failure mechanism does not change. However, the ultimate strength decreases due to the lower confining effect from the adjacent hollow masonry. When the load is at one end of the wall, the bond beam will lift off at the other end if the wall is only 4-blocks long: there is insufficient tensile strength and weight to resist the uplift moment. However, if the wall is 6-blocks long, the bond beam will not lift off.

When the out-of-plane eccentricity increases, the ultimate capacities decrease for all load cases. Equation [4.1] appears to give a safe estimate of the capacity for walls under eccentric loading, and equation [5.2] appears to give a safe estimate of the ultimate capacity for walls with the load approaching the end of the wall. A dispersion angle of $22^{\circ}$ or slope (vertical to horizontal) of 2.5:1 appears to give a safe estimate of dispersion through bond beams.

\subsubsection{Partially grouted walls and walls with grouted details}

For hollow concrete masonry walls with grouted details beneath the concentrated load, the failure mechanism when the load is at the end of the wall is the same as when the load is applied in the middle of the wall: bottom of grouted blocks and webs beneath split first, 
followed by face-shell rotation and spalling, and/or mortar crushing. Filling only the block immediately beneath the load provides much lower bearing capacity than the pyramid or wedge grouting patterns: the pyramid grouting pattern is better than wedged one. To spread the concentrated load effectively, the grouting patterns should have a grouting length compatible with the load dispersion from the loading plate, and be deep enough (at least two courses deep) to distribute the load evenly to the underlying hollow masonry. When the out-of-plane eccentricity increases, the ultimate capacities decrease for all load cases but Equation [4.1] continues to give a safe estimate of the strength. A dispersion angle of $22^{\circ}$ or slope (vertical to horizontal) of $2.5: 1$ can also be used to give a safe estimate of dispersion through grouted details but the wedge and one-block grouting patterns.

For partially grouted hollow concrete masonry walls with vertical columns of grout, the failure mechanism when the load is applied over an end column is similar to that when the load is applied over a middle column in the wall: vertical columns of grout separate from the surrounding hollow masonry, then crush. The failure mechanism is different from that of plain hollow masonry. Very little load is dispersed into the hollow masonry surrounding the column of grout when no bond beam exists under the concentrated load; only the column of grout resists the concentrated load. These newly predicted modes of failure need to be verified. 


\section{CHAPTER 6}

\section{EXPERIMENTS OF PARTIALLY GROUTED HOLLOW CONCRETE MASONRY SUBJECTED TO CONCENTRATED LOADS}

\subsection{Introduction}

Despite of the wide use of hollow concrete masonry walls, only the finite element modelling just described has been performed to assess the structural behaviour of partially grouted walls subjected to concentrated load. The non-linear models showed when a concentrated load is applied over a grouted core, the failure mechanism is different to the failure mechanism of walls without vertical columns of grout.

Partial grouting implies that not all the cores in the hollow masonry are grouted and reinforced. Typical construction of partially grouted hollow concrete masonry wall is shown in Fig. 6.1. The bond beam normally provided through good practice at each floor and roof level to tie the structural elements together into an integral whole is easily seen. When vertical cores in the masonry are grouted to increase flexural capacity, but not reinforced, bond beams are normally made by grouting lintel block units and reinforced with $2 \# 10$ rebars placed horizontally at the bottom of the lintel units. When there is vertical reinforcement, one rebar is normally placed vertically in a core which is subsequently grouted to connect the blockwork and the steel: knock-out blocks are then used for the bond beam instead of lintel blocks to simplify vertical grouting. In many 
instances, it is not necessary to reinforce and grout every core to achieve the necessary flexural strength. The result is partial grouting.

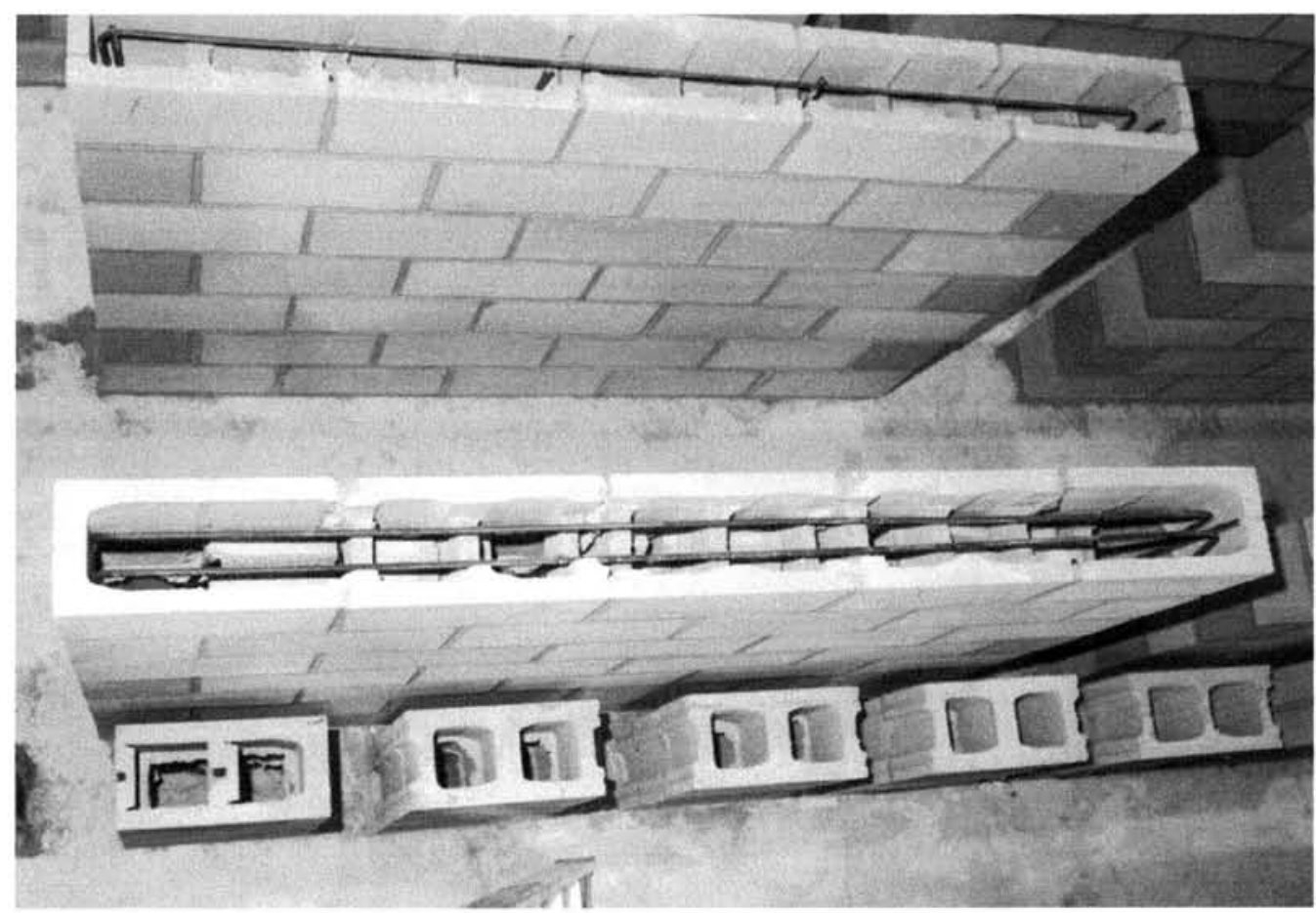

Fig. 6.1---Typical construction of partially grouted hollow concrete masonry walls (with bond beams and vertical grouting every three cores)

Since the finite element models indicate a change in failure mode from plain hollow masonry, an experimental study was performed to assess the theoretical predictions. The experiments were designed to investigate the behaviour of face-shell bedded hollow concrete masonry wallettes with bond beams and vertical columns of grout, subjected to in-plane concentrated loads applied at different locations along a wall.

The testing programme and mechanisms of failure are described, together with strength variation with increasing eccentricity, and dispersion of the concentrated load through the 
bond beam. General implications for the design of partially grouted hollow concrete masonry subjected to concentrated loads are discussed.

\subsection{Experimental Programme}

All masonry was constructed using standard hollow concrete units [nominal dimensions $400 \mathrm{~mm}$ long $\times 200 \mathrm{~mm}$ high $\times 200 \mathrm{~mm}$ thick] in running bond using face-shell mortar bedding and ready-mix Type S mortar. An experienced group of masons, using normal construction procedures, built all masonry in the laboratory. One-course bond beams were incorporated in the tops of the wallettes, using units with "knock-out" webs. All bond beams were reinforced with two $10 \mathrm{~mm}$ diameter mild-steel deformed bars hooked at each end to insure adequate anchorage. All vertical columns of grout were reinforced with one $10 \mathrm{~mm}$ diameter rebar. Grout was obtained commercially, with a maximum aggregate size of $10 \mathrm{~mm}$ in combination with Type 10 Portland cement. Samples of masonry were taken at regular intervals throughout construction. The compressive strength of the units, prisms and grouts are presented in Table 6.1.

\subsubsection{Sample test}

Units and hollow prisms were tested in face-shell bedding using plywood strips as capping. Compressive strengths were calculated using a nominal face-shell bedded area of $27300 \mathrm{~mm}^{2}$ for units and hollow prisms. Hollow prisms, grouted prisms and grouts were tested at 28 days. 
Table 6.1 Compressive strengths of hollow concrete block units, together with 28-day strengths of grout cylinders and masonry prisms

\begin{tabular}{cccc}
\hline & Dimensions (mm) & No. in sample $\begin{array}{c}\text { Strength (MPa) (Mean } \\
\pm \text { Std. Dev.) }\end{array}$ \\
\hline Standard block units & $400 * 200 * 200$ (nominal) & 8 & $18.7 \pm 1.95$ \\
"Knock-out" block units & $400 * 200 * 200$ (nominal) & 6 & $16.7 \pm 1.07$ \\
$\begin{array}{c}\text { Hollow prisms built with } \\
\text { standard units }\end{array}$ & $400 * 600 * 200$ (3 block high) & 5 & $15.1 \pm 0.61$ \\
$\begin{array}{c}\text { Hollow prisms built with } \\
\text { "knock-out" units }\end{array}$ & $400 * 600 * 200$ (3 block high) & 5 & $11.6 \pm 1.23$ \\
$\begin{array}{c}\text { Grout (fog-room) } \\
\text { Grout (air-cured) }\end{array}$ & $150 * 300$ (cylinders) & 6 & $32.4 \pm 1.09$ \\
$\begin{array}{c}\text { Grouted prisms built } \\
\text { with standard units }\end{array}$ & $400 * 600 * 200$ (3 block high) & 3 & $13.8 \pm 0.53$ \\
$\begin{array}{c}\text { Grouted prisms built } \\
\text { with "knock-out" units }\end{array}$ & $400 * 600 * 200$ (3 block high) & 3 & $13.1 \pm 1.24$ \\
\hline
\end{tabular}

\subsubsection{Hollow block units test}

Standard hollow block units (Fig. 6.2) and units with "knock-out" webs (Fig. 6.3) were tested respectively to compare their failure modes and compressive strengths. The test set-up is shown in Fig. 6.4. The results are as follows:

For standard hollow block units, at about $80 \%$ of the compressive ultimate capacity, vertical cracks form in the top and bottom of the webs. With increasing load, the faceshells start to split and failure occurs. The failure mode is shown in Fig. 6.5.

For units with "knock-out" webs, failure is abrupt with a sudden web-splitting and breaking, and face-shell spalling at almost the same time. Fig. 6.6 shows the failure mode for units with "knock-out" webs. 

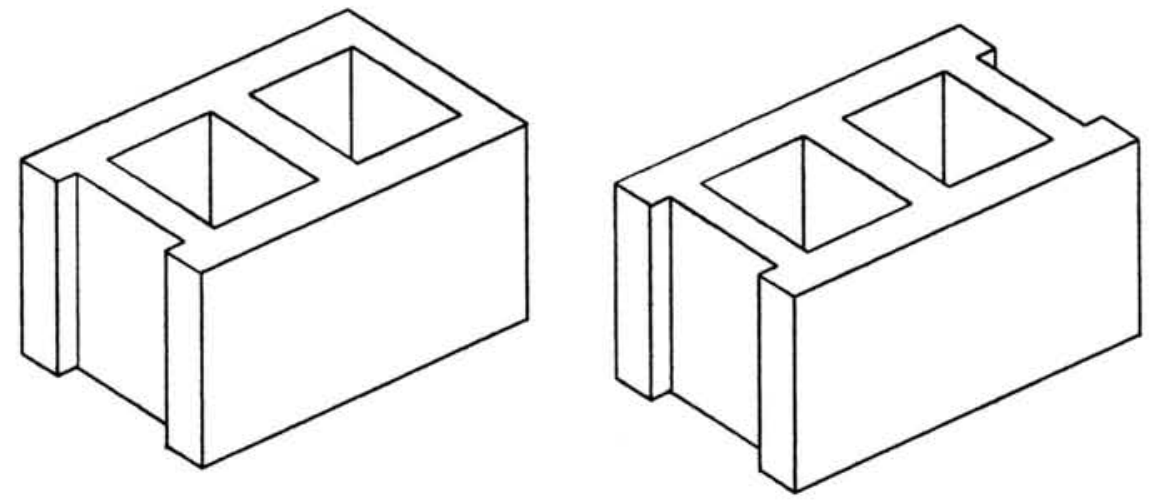

Fig. 6.2---Standard hollow block units
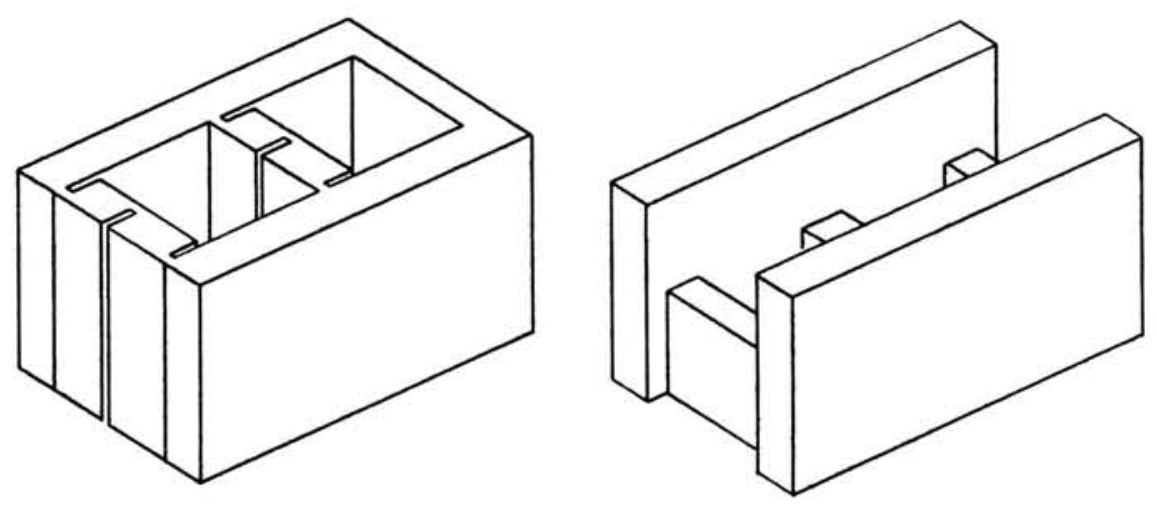

Fig. 6.3---Block units with "knock-out" webs 


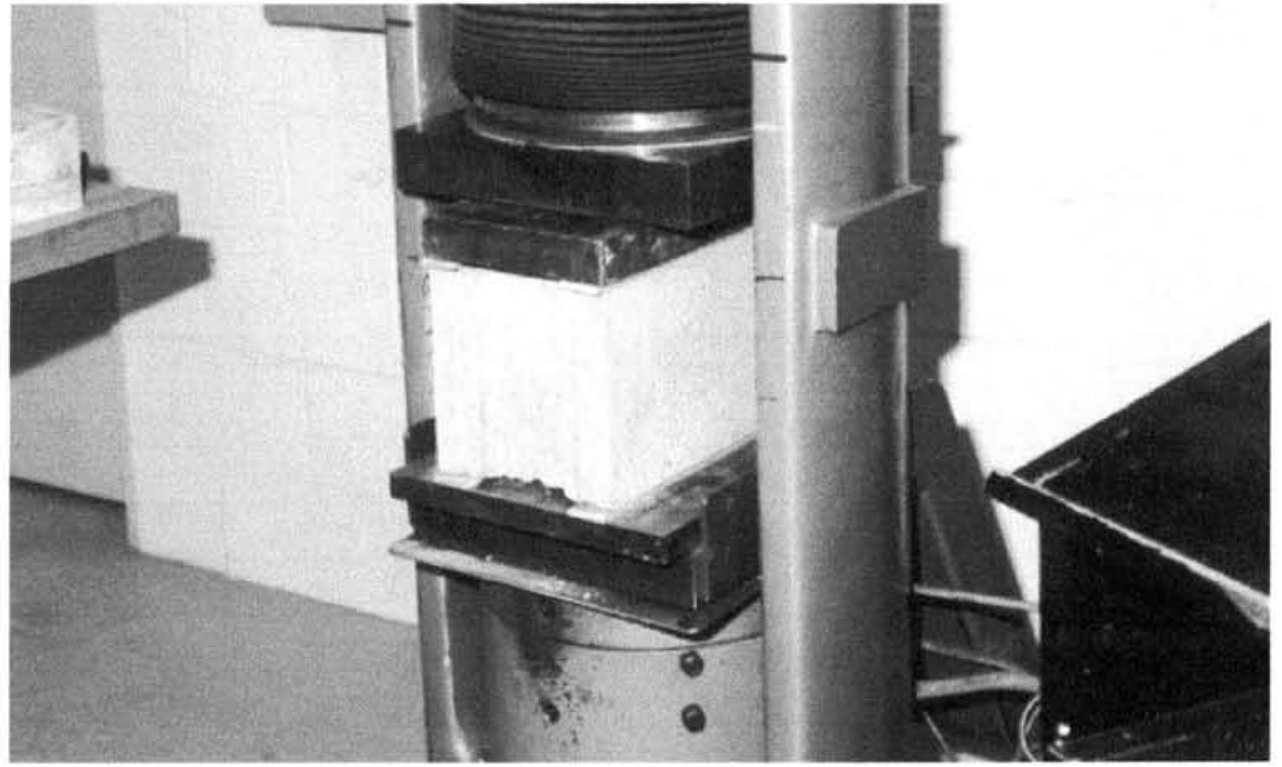

Fig. 6.4---Test set-up for hollow block units

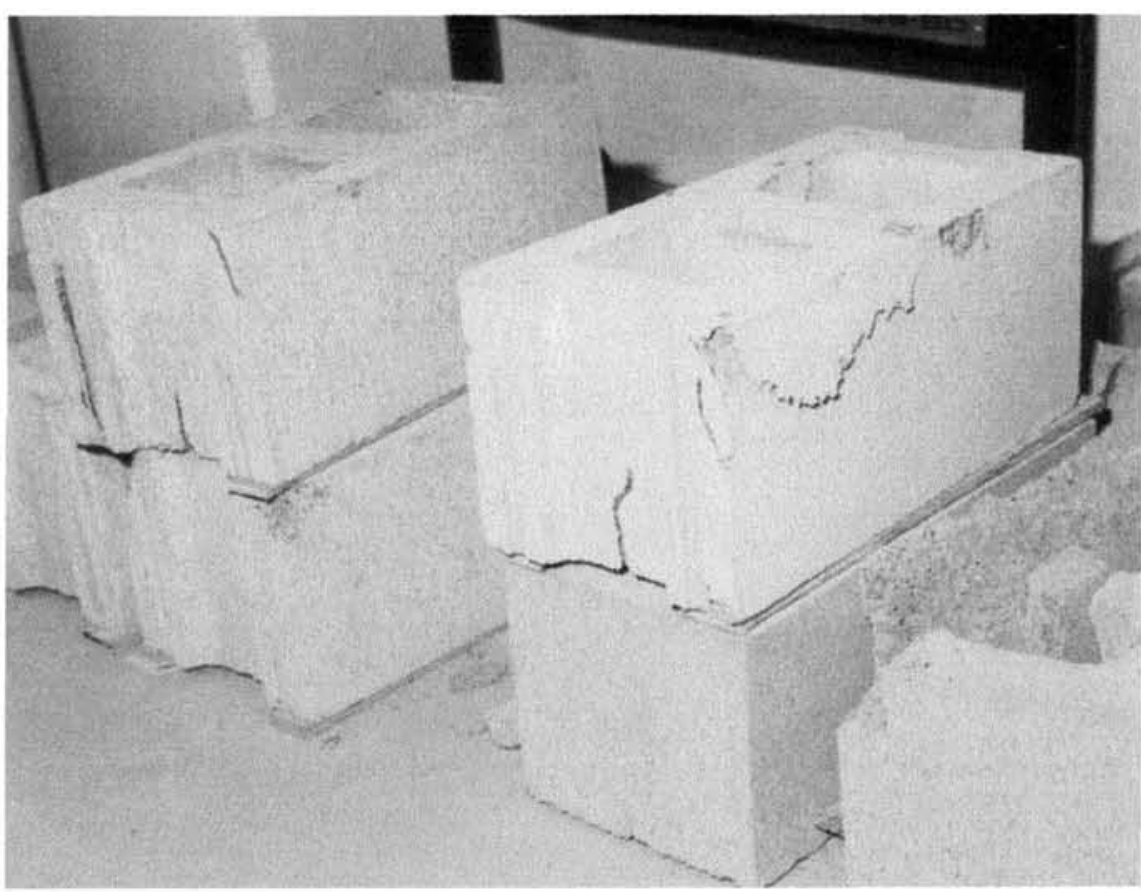

Fig. 6.5---Failure mode of standard hollow block units 


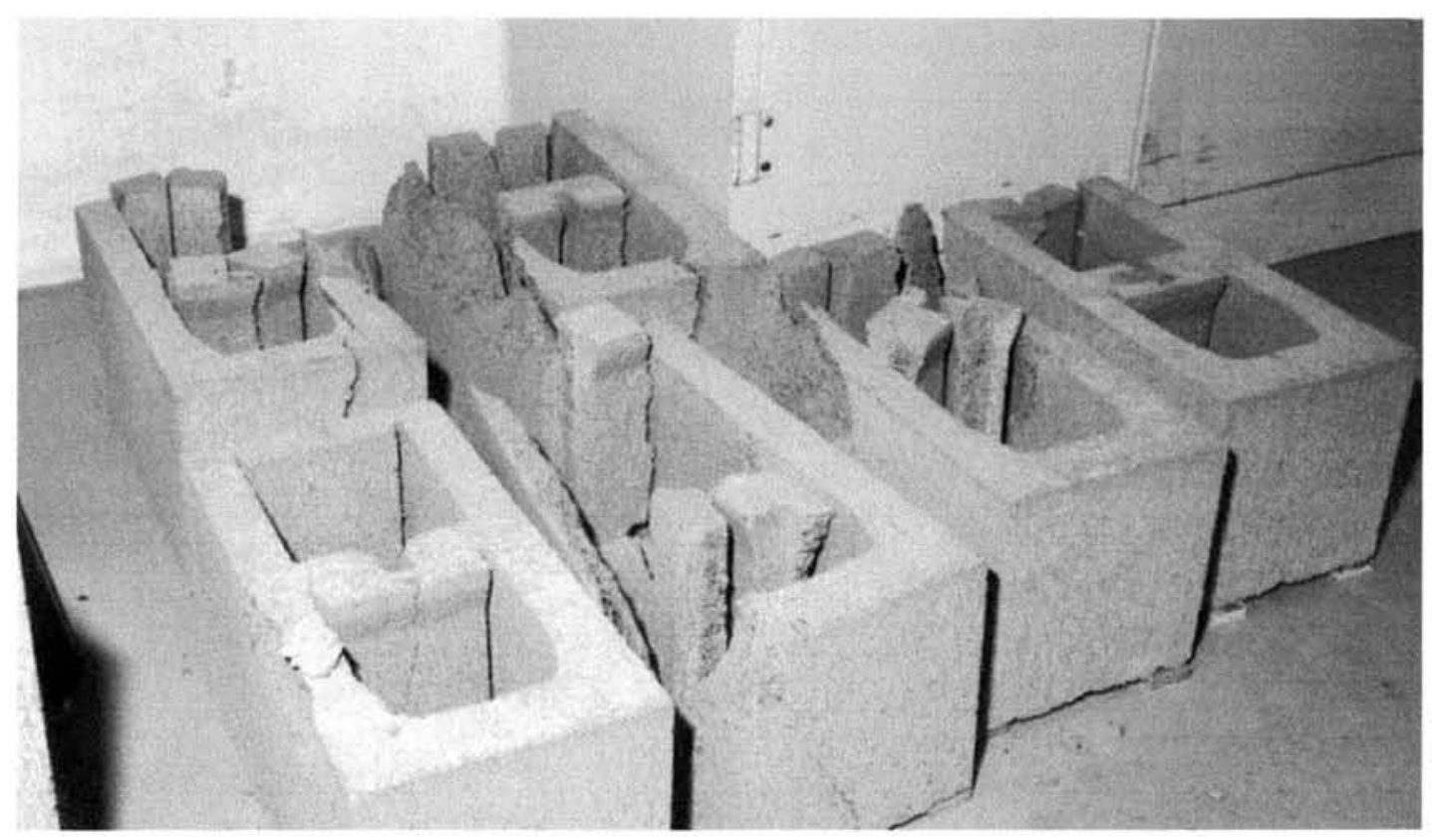

Fig. 6.6---Failure mode of hollow block units with "knock-out" webs

The compressive strengths of the units are given in Table 6.1. The strength of units with "knock-out" webs is about $10 \%$ lower than that of the standard units. The existing weak webs decrease the compressive strength of units with "knock-out" webs. However, the decrease is typically offset by the end constraint of the steel loading platen. The influence of the weak web will be seen in the hollow prism tests, where the constraint of end loading platen is reduced because the prism is three-blocks high.

\subsubsection{Prism test}

Hollow concrete prisms built of standard hollow block units (Fig. 6.7) and of units with "knock-out" webs (Fig. 6.8) were tested respectively to compare their failure modes and compressive strengths. The test set-up for prisms is shown in Fig. 6.9. 


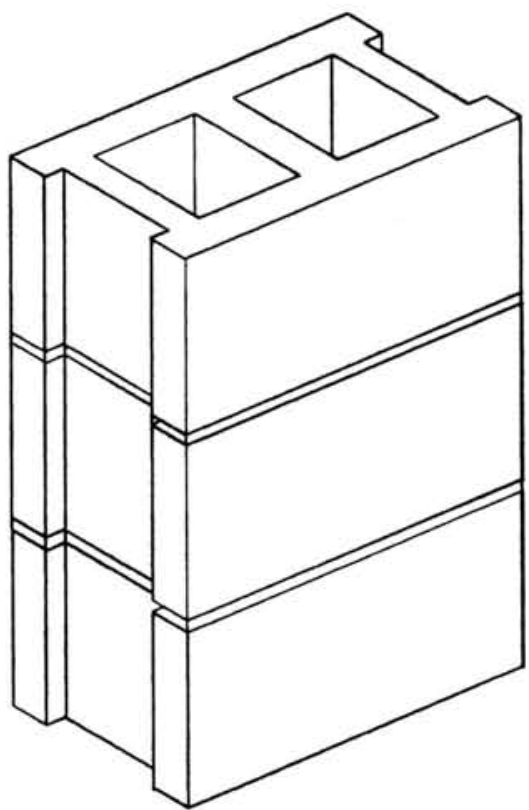

(a)

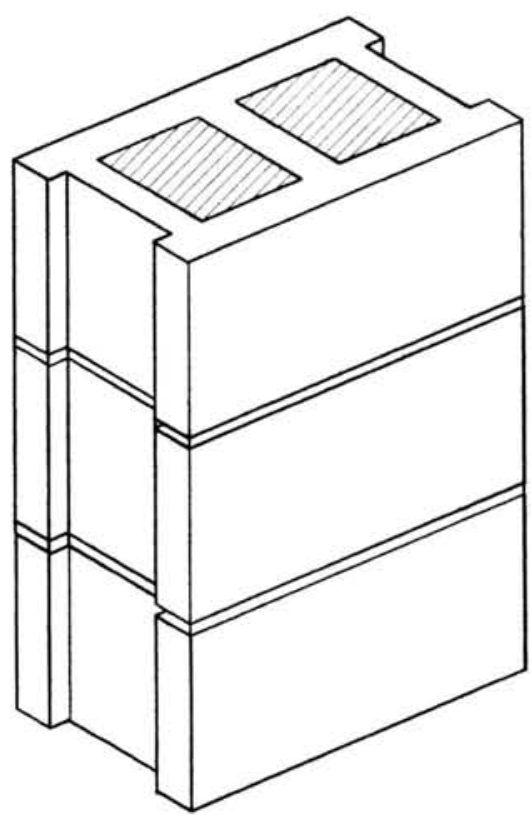

(b)

Fig. 6.7---Prisms built of standard units (a) hollow, (b) grouted

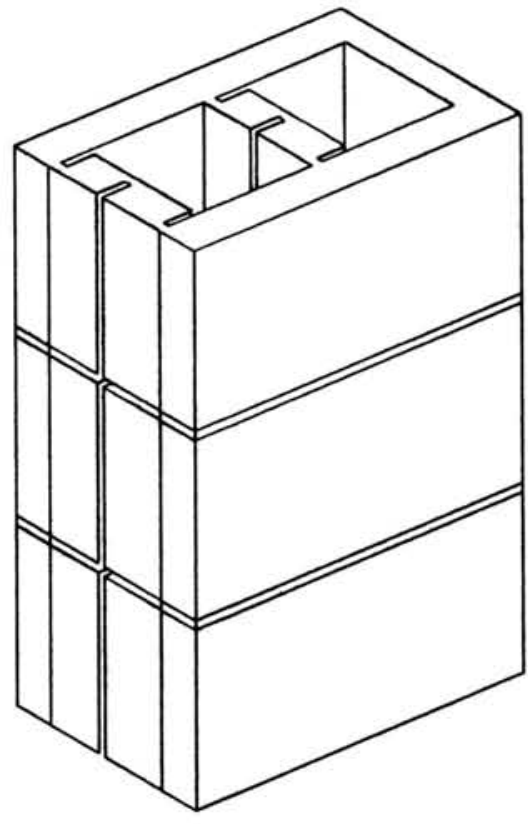

(a)

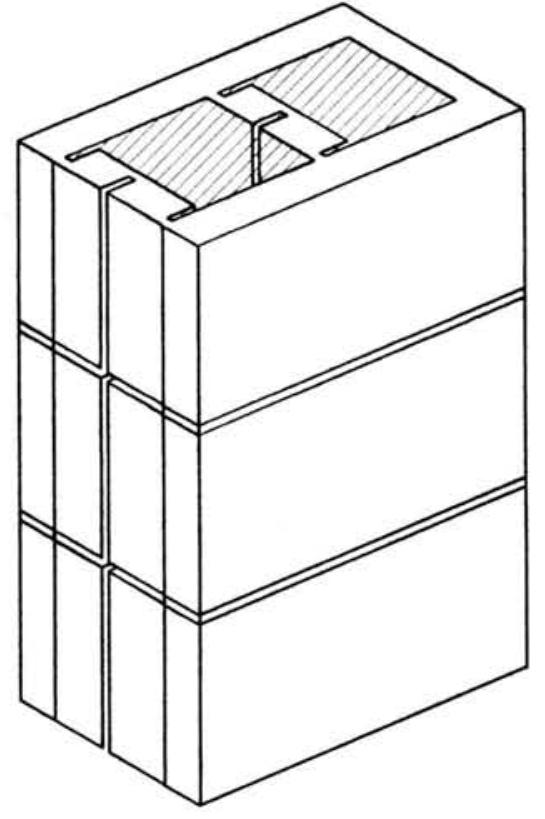

(b)

Fig. 6.8---Prisms built of units with "knock-out" webs (a) hollow, (b) grouted 


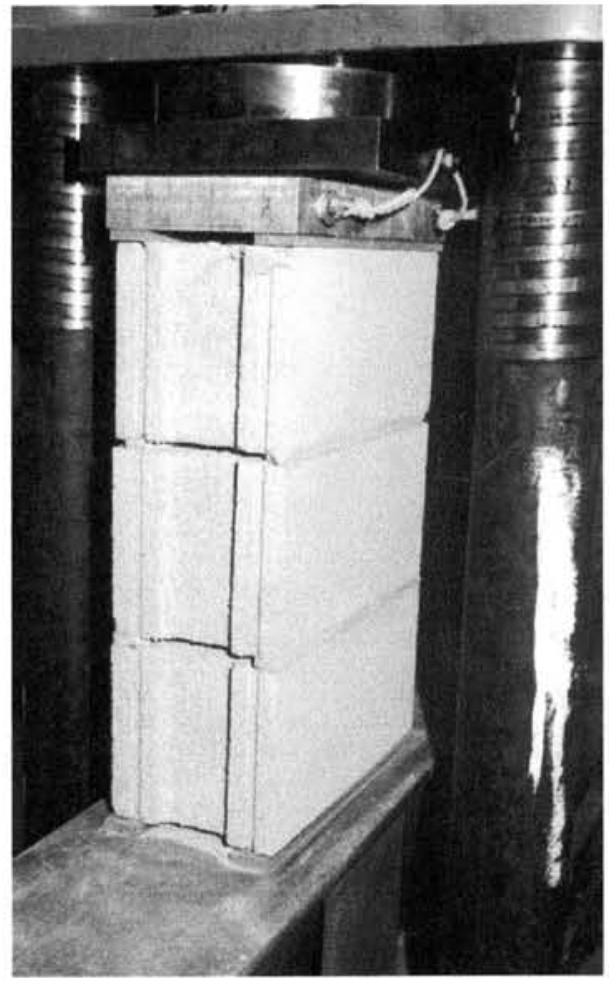

Fig. 6.9---Test set-up for prisms

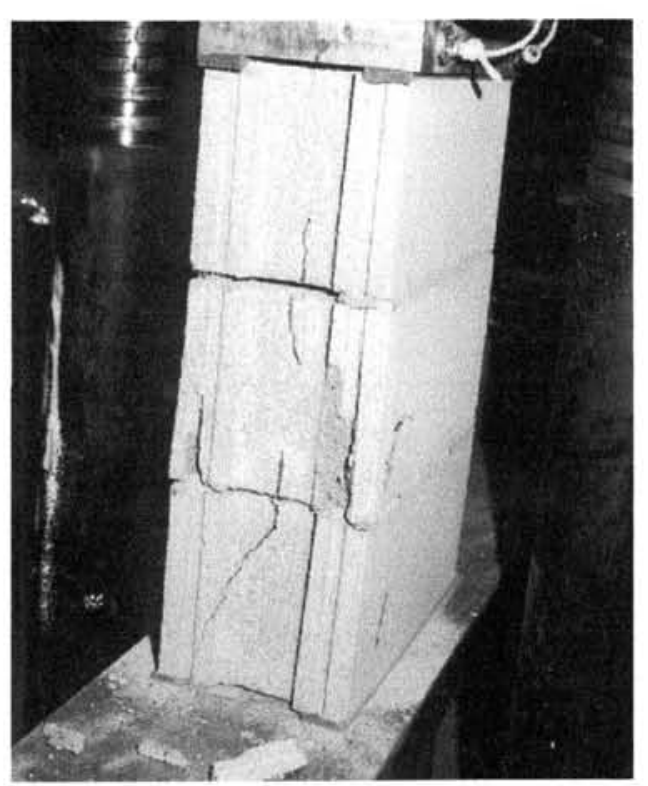

Fig. 6.10---Failure mode of hollow prism with standard units

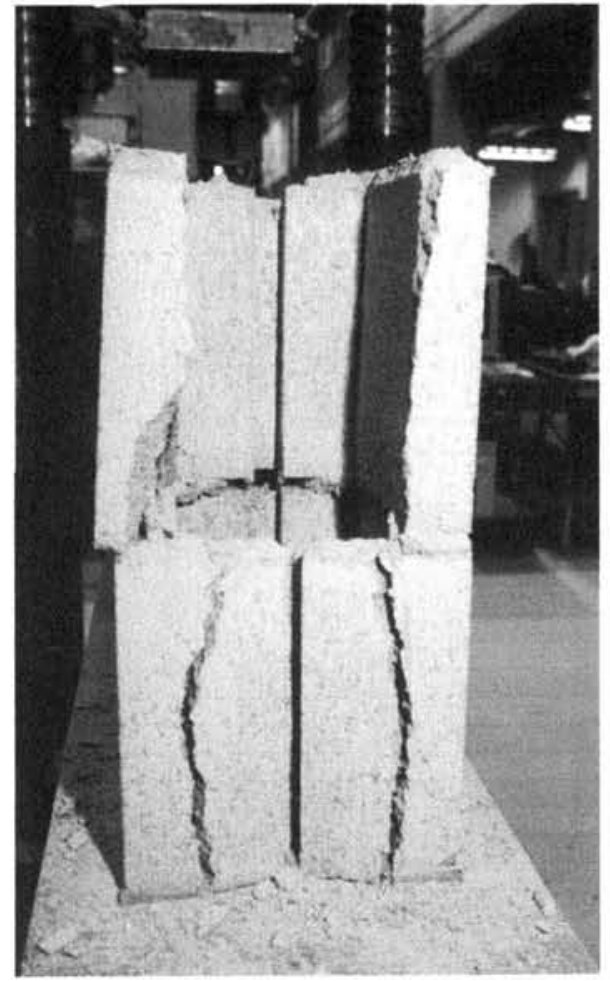

Fig. 6.11---Failure mode of hollow prism with "knock-out" webs

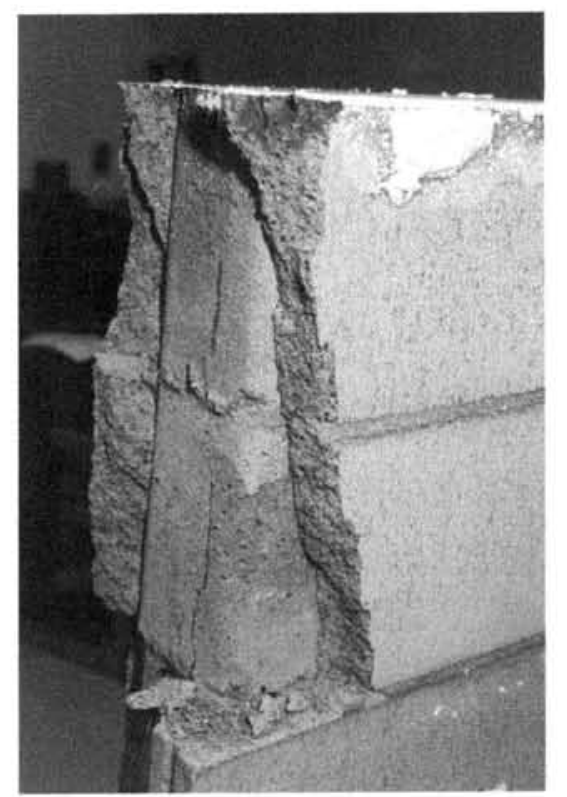

Fig. 6.12---Failure mode of grouted prism 
The failure modes of hollow prisms built of standard hollow block units are as follows: at a load level of approximately $50 \%$ of the prism ultimate capacity, vertical cracks form in the webs. These cracks normally commenced at the bottom centre of the webs of the units where the web thickness is reduced by the web taper. Final failure occurs at a higher load by crushing of the mortar joint on the inside of the face-shell, and/or a local spalling of the outside of the unit face-shell adjacent to the mortar joint. The failure modes are shown in Fig. 6.10 and are consistent with the results obtained from the non-linear finite element models described in Chapter 4.

The failure modes of hollow prisms built of units with "knock-out" webs are very abrupt: sudden web breaking with the face-shell spalling unstably, as shown in Fig. 6.11.

For grouted prisms, the failure mode of the prisms built of standard units is the same as that built of units with "knock-out" webs: tensile splitting first in the hollow blocks, followed by vertical cracking in the grout like that of a normal concrete specimen in a compression test. The failure mode of grouted prisms is shown in Fig. 6.12.

The compressive strengths of the prisms are also given in Table 6.1. The strength of hollow prisms with "knock-out" webs is about $26 \%$ lower than that of prisms built of standard units. This is due to the influence of the weak web, and the constraint of the loading platen not being significant here. However, "knock-out" webs seem not to affect the compressive strengths of grouted prisms.

The compressive strength of a grouted prism is lower than those of both an ungrouted prism and the grout. 


\subsubsection{Wallette test}

The five-unit wide by seven-course high wallettes were considered large enough to be representative of hollow concrete masonry wall behaviour. The wallettes were constructed in one group and air cured in the laboratory for at least 28 days before testing. Three series of tests were performed. The first series (Series 1) was aimed at investigating the failure mechanisms and strength of hollow masonry walls with concentrated load applied on the bond beam above the hollow blocks, and consisted of 11 wallette tests (Fig. 6.13). The second test series (Series 2) consisted of 24 wallette tests, with the concentrated load being applied above the end columns of grout (Fig. 6.14). The third test series (Series 3 ) consisted of 8 wallette tests, with the concentrated load being applied above the middle columns of grout (Fig. 6.15).

The wallettes were tested in a testing machine equipped with a sliding steel beam bed, which allowed the specimen to be mounted accurately on a thin layer of plaster on the bed while clear of the machine. The concentrated loads were applied through $40 \mathrm{~mm}$ thick steel plates. Plates 160 and $240 \mathrm{~mm}$ long were used for Series 1, as used by Page and Shrive (1990) for comparison. Plates 80, 160 and $240 \mathrm{~mm}$ long were used for Series 2, and the $160 \mathrm{~mm}$ long plate was used for Series 3 . The load was applied to the loading plate through a spherically mounted loading platen and a $25 \mathrm{~mm}$ wide steel strip to ensure accurate location of the load in relation to the wall thickness (Fig. 6.16). Load was applied either concentrically ( $\mathrm{e}=0$ ) or eccentrically $(\mathrm{e}=32 \mathrm{~mm}$ and $64 \mathrm{~mm}$ from the wall centre-line, corresponding to eccentricities of approximately one-sixth and one-third of the wall thickness). These eccentricities were chosen to investigate the significance of 
load eccentricity, incurred, for example, by a beam spanning at right angles to the wall. For the wallettes loaded on their ends, it was necessary to balance the sliding bed with weights. All wallettes were loaded monotonically to failure.

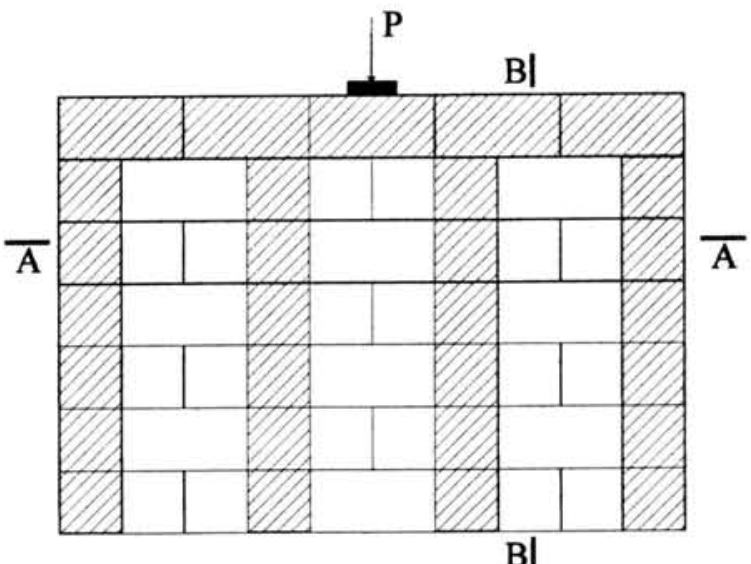

B|

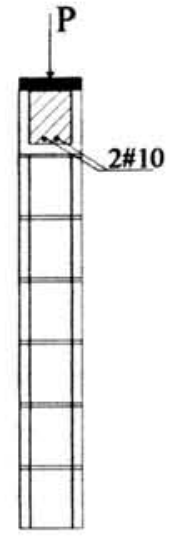

$\underline{B-B}$

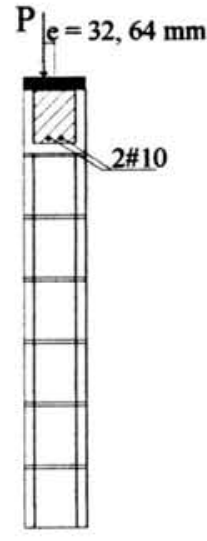

$\underline{B-B}$

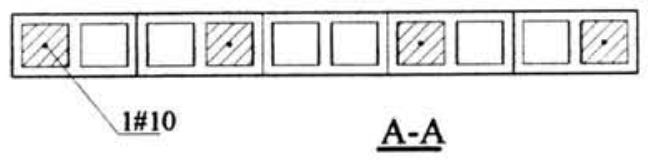

Fig. 6.13---Series 1, load on the bond beam above hollow blocks

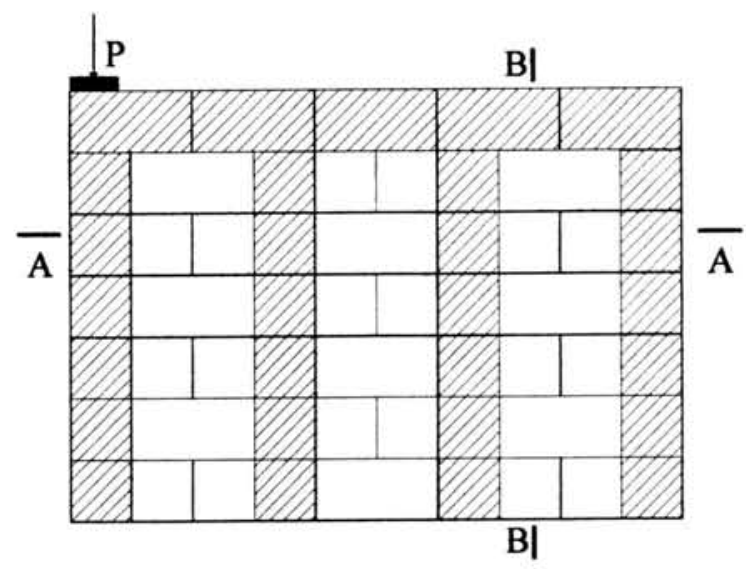

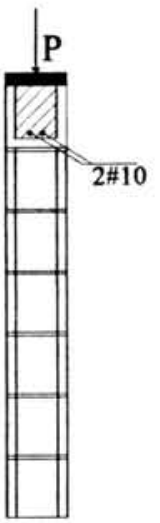

B-B

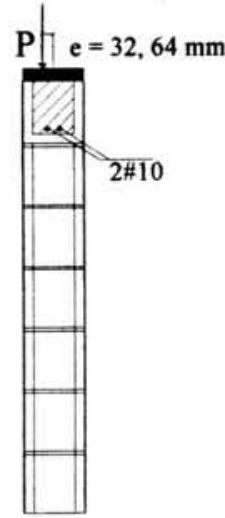

B-B

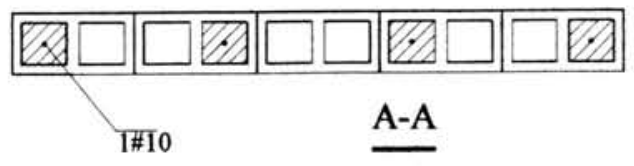

Fig. 6.14---Series 2, load above the end column of grout 

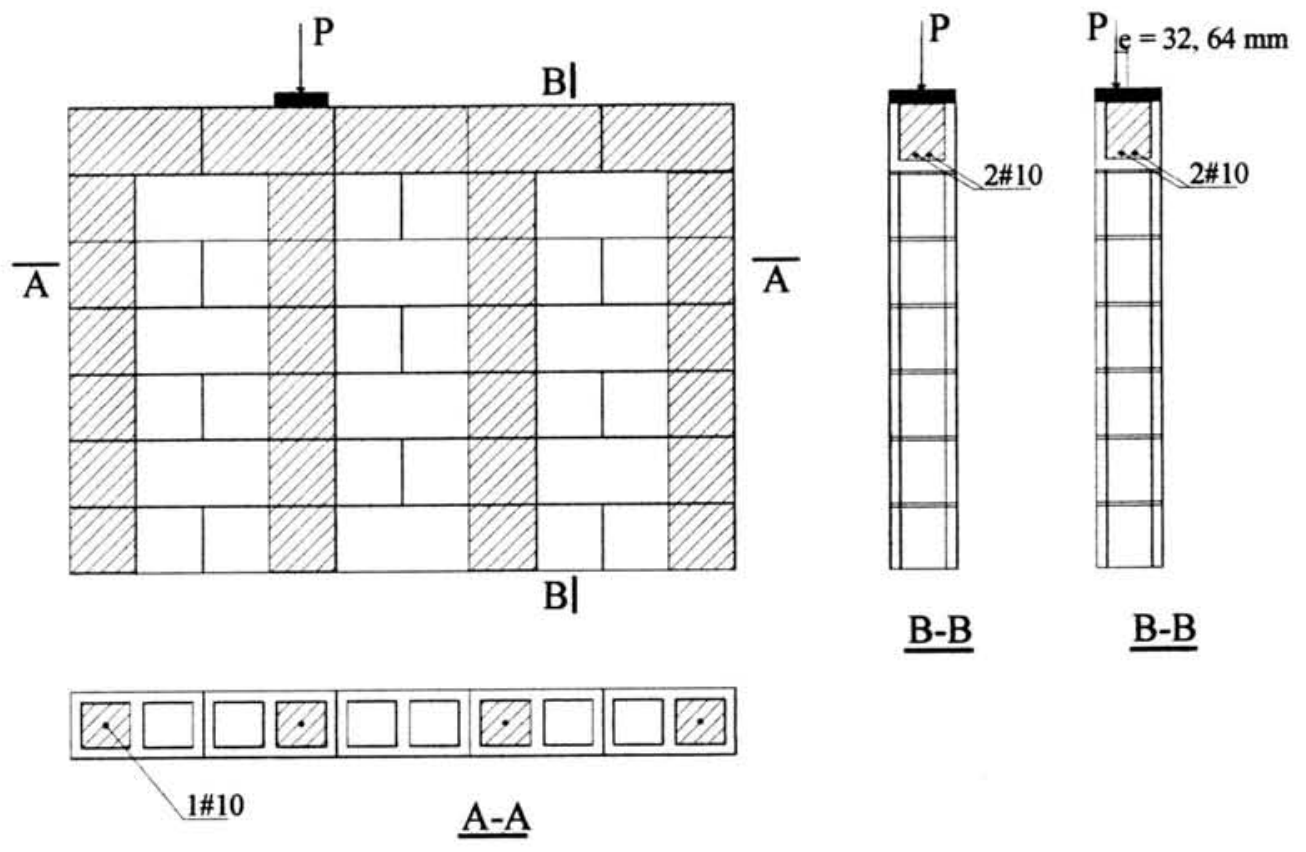

Fig. 6.15---Series 3, load above the middle column of grout
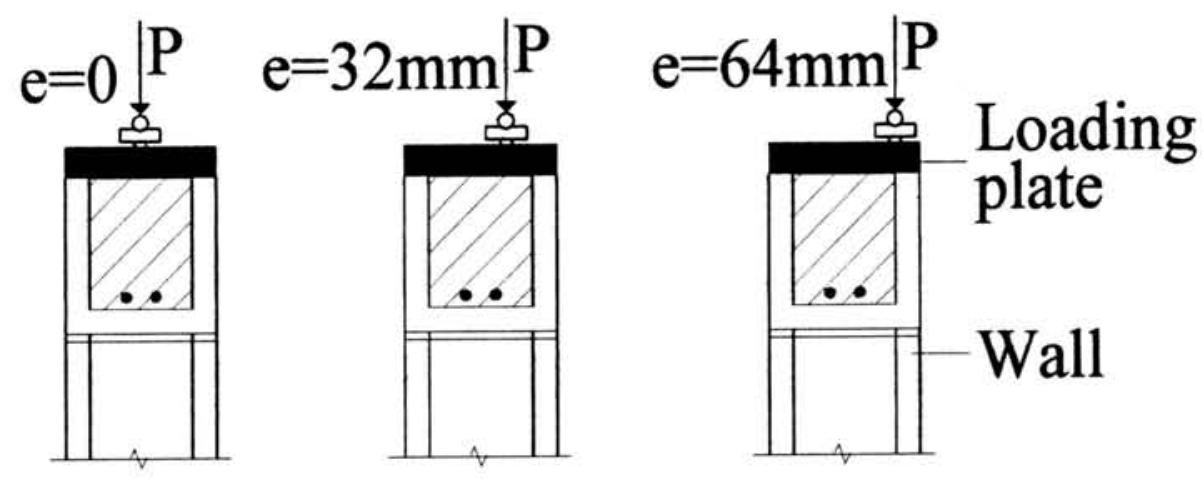

Fig. 6.16----Concentric and eccentric loading 
An overall view of the tests is shown in Fig. $6.17 \mathrm{a}$ and b. A summary of the wallette tests and results is given in Table 6.2. External surface deformations were monitored using linear potentiometer displacement transducers (LPDTs). Progressive web splitting or horizontal dilation was monitored by measuring the lateral displacement at the critical points of the wall in the through-thickness direction by mounting LPDTs normal to the wall on each side of the specimen supported by an independent steel frame. Vertical cracking was measured by LPDTs mounted on the specimen on a $500 \mathrm{~mm}$ horizontal gauge length. Vertical displacement was measured by LPDTs mounted on the specimen from the top to the bottom. Typical LPDTs arrangements are shown in Fig. 6.18, 19, and 20 for test Series 1, 2, and 3 respectively. The output from the instrumentation was fed directly into a data acquisition system, allowing displacements to be plotted during the test. Progressive vertical and web cracking was readily observed.

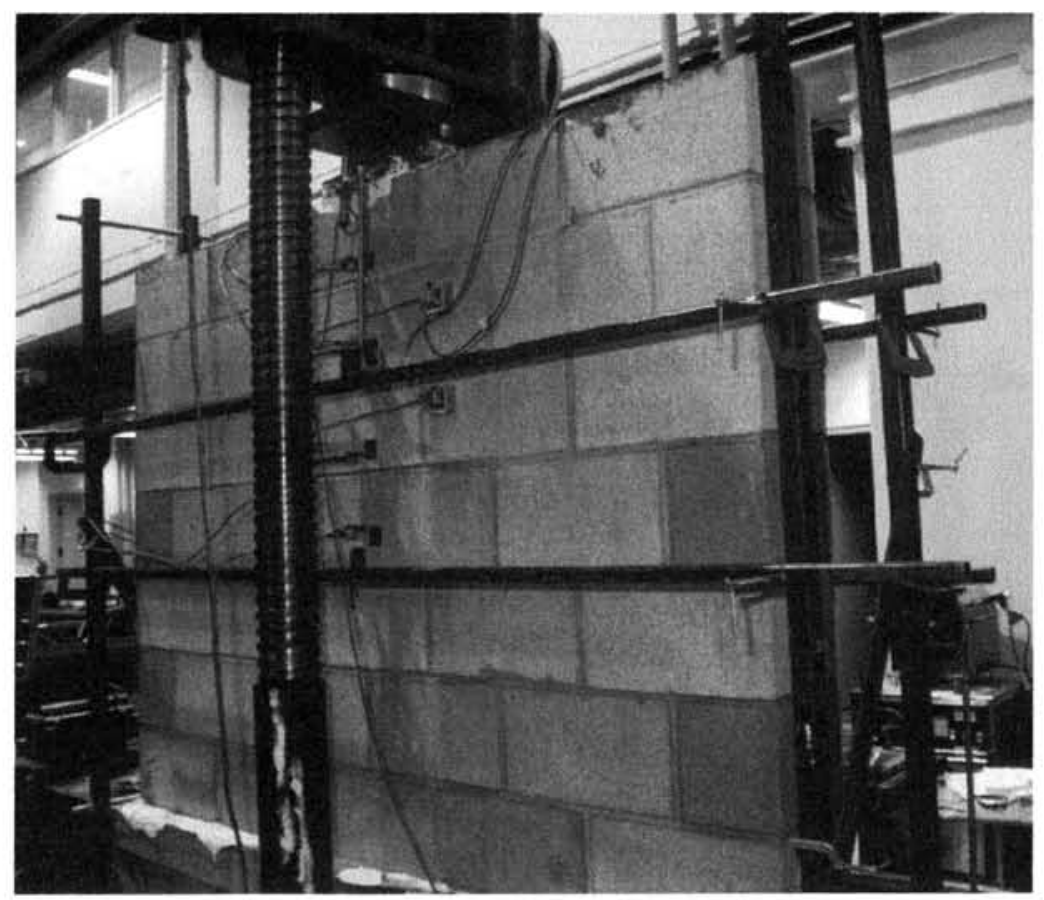

Fig. 6.17a---Test set-up for wallettes loaded in the middle 


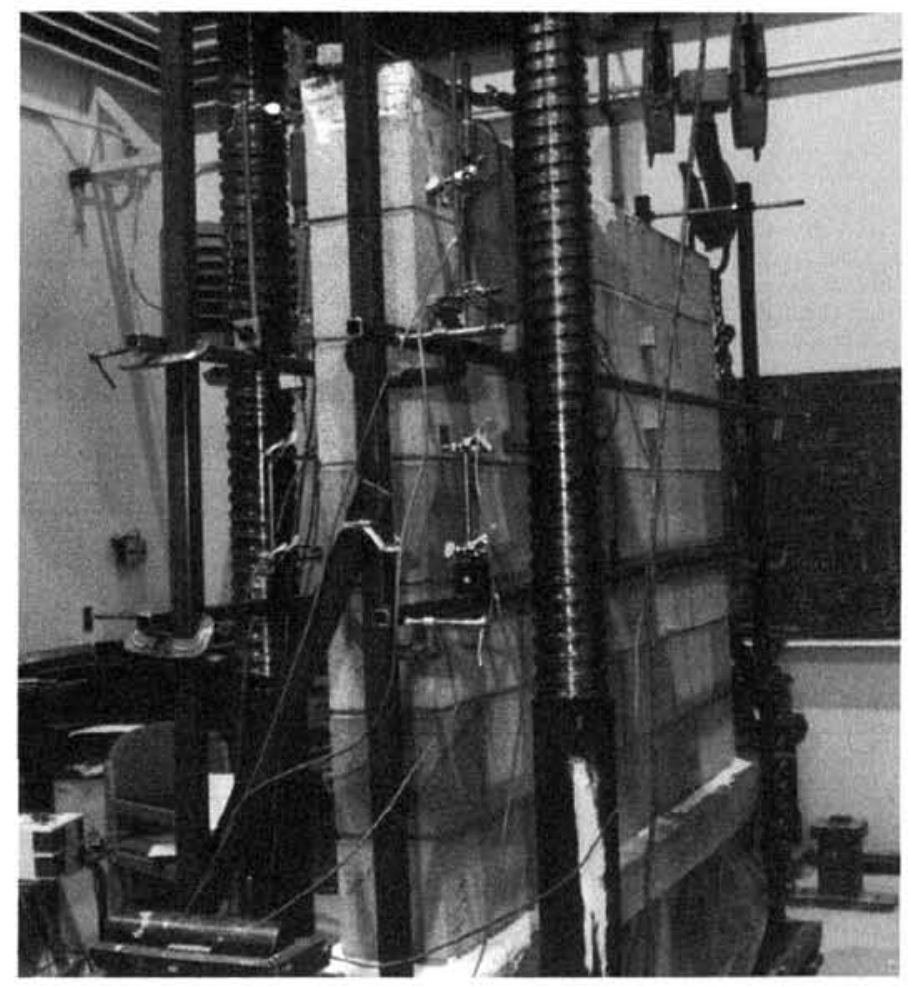

Fig. 6.17b---Test set-up for wallettes loaded at the end

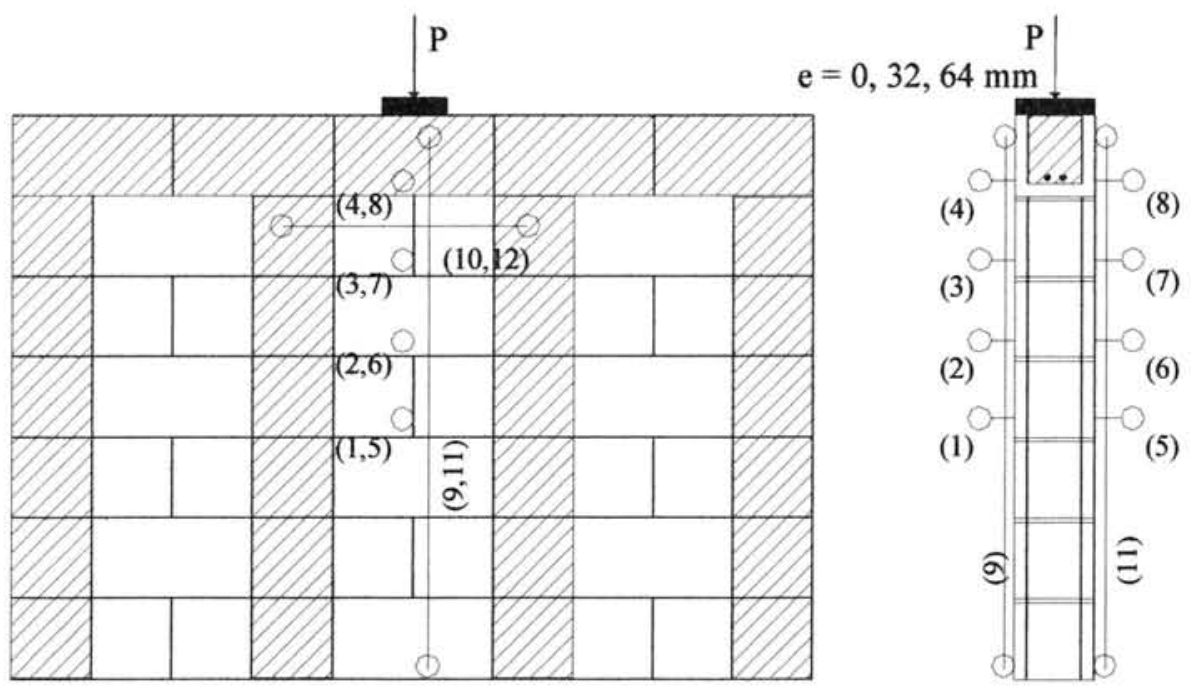

Fig. 6.18---LPDTs arrangement for Series 1 test 


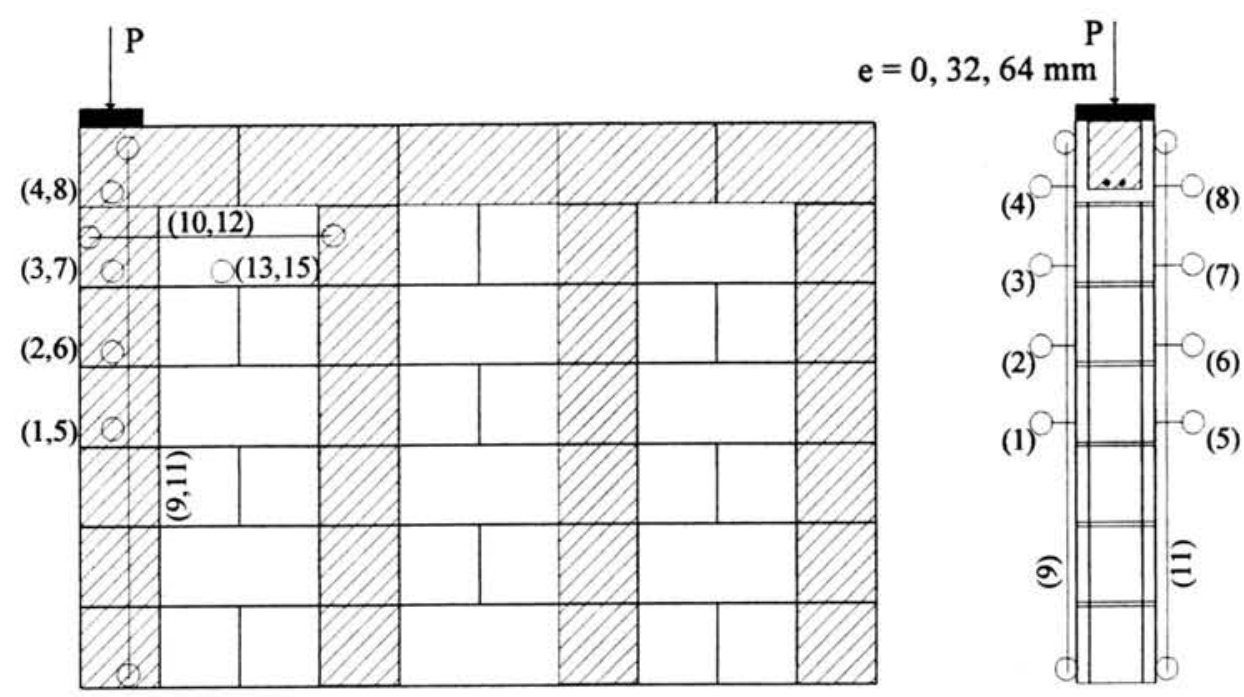

Fig. 6.19---LPDTs arrangement for Series 2 test

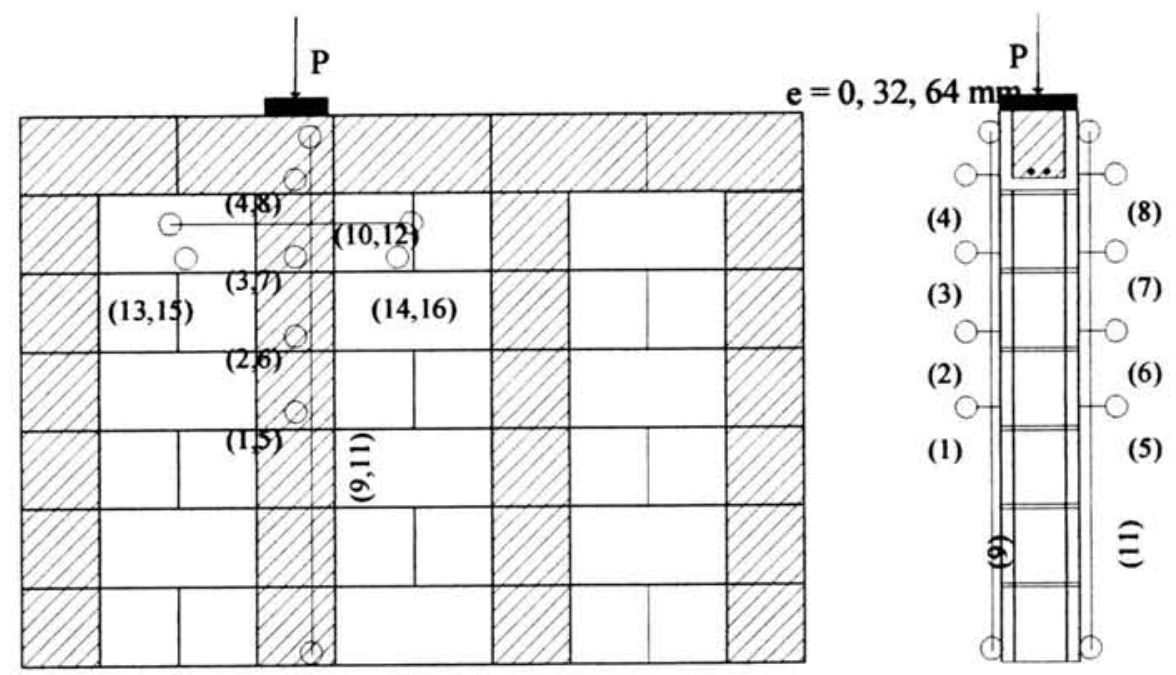

Fig. 6.20---LPDTs arrangement for Series 3 test 
Table 6.2 Summary of wallette test series and results

\begin{tabular}{|c|c|c|c|c|c|c|c|c|}
\hline $\begin{array}{l}\text { Wall } \\
\text { type }\end{array}$ & Series & Loading location & $\begin{array}{l}\text { Loading } \\
\text { plate } \\
\text { length } \\
(\mathrm{mm})\end{array}$ & $\underset{(\mathrm{mm})}{\mathrm{e}}$ & $\begin{array}{l}\text { No. } \\
\text { of test }\end{array}$ & $\begin{array}{c}\text { Average } \\
\text { ultimate } \\
\text { capacity } \\
(\mathrm{KN})\end{array}$ & $\begin{array}{l}\text { Coeff. of } \\
\text { vari. }\end{array}$ & $\begin{array}{l}\begin{array}{c}\text { Results } \\
\text { from }\end{array} \\
\text { literature* } \\
(\mathrm{KN})\end{array}$ \\
\hline $\mathrm{C} 160 \mathrm{M}$ & 1 & middle bond beam & 160 & 0 & 3 & 496 & $8.30 \%$ & 395 \\
\hline $1 \mathrm{E} 160 \mathrm{M}$ & 1 & middle bond beam & 160 & 32 & 3 & 343 & $10.80 \%$ & $313^{* *}$ \\
\hline $2 \mathrm{E} 160 \mathrm{M}$ & 1 & middle bond beam & 160 & 64 & 2 & 248 & $10.10 \%$ & \\
\hline $\mathrm{C} 240 \mathrm{M}$ & 1 & middle bond beam & 240 & 0 & 3 & 549 & $10.40 \%$ & 436 \\
\hline $\mathrm{C} 160 \mathrm{E}$ & 2 & end column & 160 & 0 & 3 & 606 & $4.95 \%$ & \\
\hline $1 \mathrm{E} 160 \mathrm{E}$ & 2 & end column & 160 & 32 & 3 & 425 & $5.65 \%$ & \\
\hline $2 \mathrm{E} 160 \mathrm{E}$ & 2 & end column & 160 & 64 & 3 & 243 & $4.94 \%$ & \\
\hline $\mathrm{C} 240 \mathrm{E}$ & 2 & end column & 240 & 0 & 3 & 634 & $9.31 \%$ & \\
\hline 1E240E & 2 & end column & 240 & 32 & 3 & 435 & $7.82 \%$ & \\
\hline $2 \mathrm{E} 240 \mathrm{E}$ & 2 & end column & 240 & 64 & 3 & 305 & $17.70 \%$ & \\
\hline C80E & 2 & end column & 80 & 0 & 3 & 352 & $13.35 \%$ & \\
\hline $1 \mathrm{E} 80 \mathrm{E}$ & 2 & end column & 80 & 32 & 3 & 263 & $10.65 \%$ & \\
\hline $\mathrm{C} 160 \mathrm{C}$ & 3 & middle column & 160 & 0 & 3 & 765 & $5.09 \%$ & \\
\hline $1 \mathrm{E} 160 \mathrm{C}$ & 3 & middle column & 160 & 32 & 3 & 555 & $13.33 \%$ & \\
\hline $2 \mathrm{E} 160 \mathrm{C}$ & 3 & middle column & 160 & 64 & 2 & 245 & $14.28 \%$ & \\
\hline
\end{tabular}

Note: *From Page and Shrive (1990). There were no vertical columns of grout in the wall, and the two-block-high prism strength was $16.8 \mathrm{Mpa}$. ${ }^{* *}$ Eccentricity $\mathrm{e}=35 \mathrm{~mm}$. 


\subsection{Wallette Test Results and Discussions}

\subsubsection{Failure modes}

\subsubsection{Concentrated loads on bond beams (Series 1)}

When concentrated load is applied on the bond beam above the hollow block units, the failure characteristics of wallettes with vertical columns of grout are similar to those without vertical grout columns.

Under concentric loading, at about $55 \%$ of the corresponding ultimate strength, the webs split in the region directly beneath the concentrated load in the underside of the bond beam and in the hollow course immediately below (Fig. 6.21a). At about the same time, or sometimes just before, a vertical crack formed normal to the plane of the wall in line with the load (Fig. 6.21b). The stiffness of the wall started to decrease (Fig. 6.21c) when vertical cracking and web cracking developed. With increasing load, web-splitting progressed into the courses beneath, the vertical crack widened, and cracking developed in the face-shells beside the vertical columns of grout. In the final stages, the cracks in the webs became very large, producing buckling instability local to the loading plate: the vertical crack did not appear to affect final failure. Typical examples of web splitting and vertical cracking are shown in Fig. 6.22 and Fig. 6.23, respectively.

Under eccentric loading with small eccentricity $(e=32 \mathrm{~mm})$, the sequence above was repeated, except that web cracking and vertical cracking occurred at about $75 \%$ of the ultimate load (Fig. 6.24a and Fig. 6.24b). The vertical deformation of the heavily loaded side was greater than that of the lightly loaded side (Fig. 6.24c), whereas the vertical cracking was about the same on each side (Fig. 6.24b). Web cracking started in the 
hollow course immediately beneath the bond beam and progressed only into the course below. Final failure occurred when the web cracking produced instability and the faceshell of the bond beam spalled away and separated from the grout on the heavily loaded side. A typical example of the failure mode under eccentric load with small eccentricity is shown in Fig. 6.25.

At larger eccentricity $(\mathrm{e}=64 \mathrm{~mm})$, there was no web cracking in the hollow block units (Fig. 6.26a), and only a thin vertical crack developed in line with the load (Fig. 6.26b). The vertical deformation of the heavily loaded side was greater than that of the lightly loaded side (Fig. 6.26c). Final failure was caused by spalling of the face-shell of the bond beam on the heavily loaded side, separating from the grout. A typical example of the failure mode under eccentric load with large eccentricity is shown in Fig. 6.27.

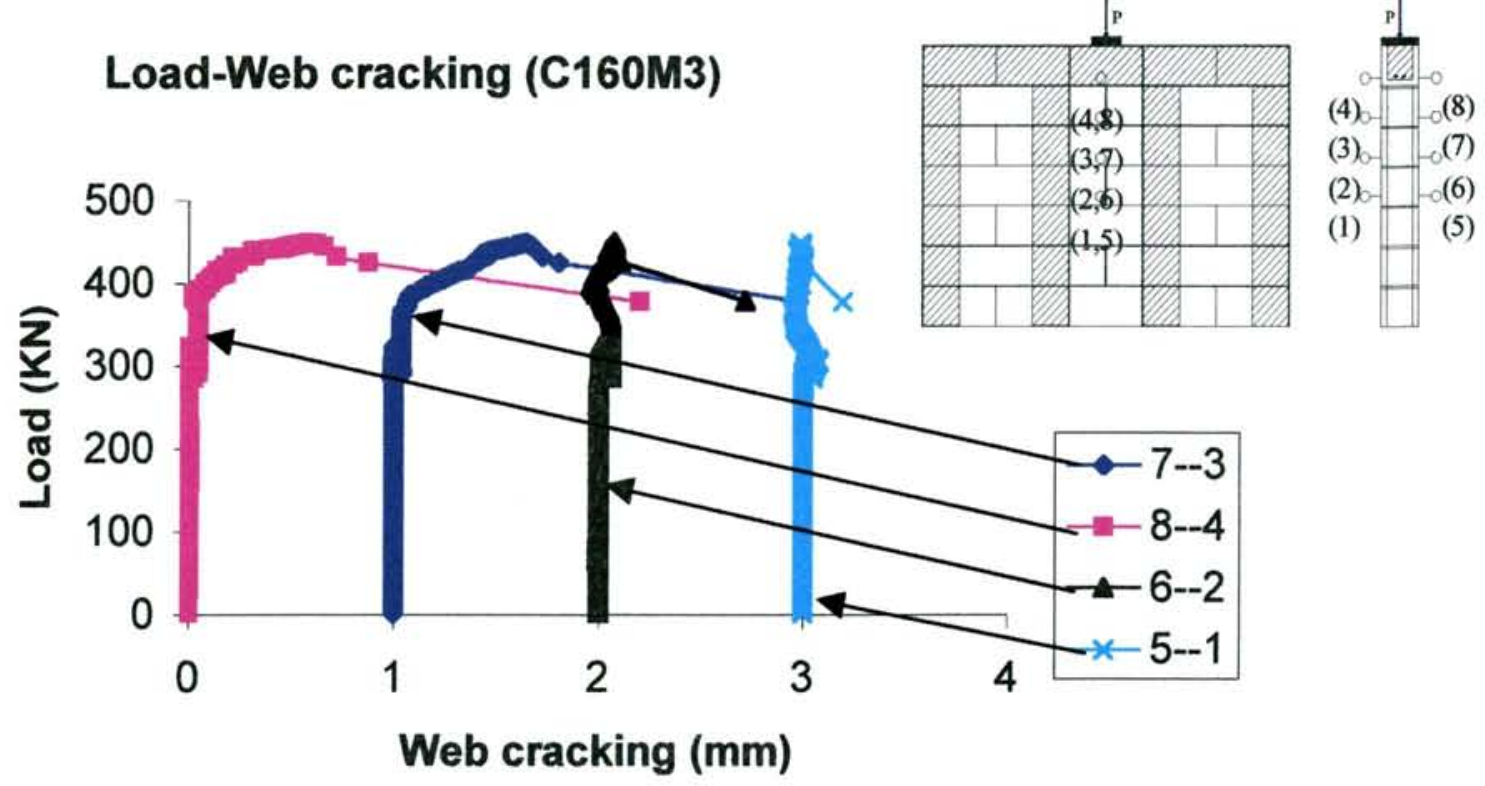

Fig. 6.21a---Load versus web cracking for $\mathrm{C} 160 \mathrm{M}$ 

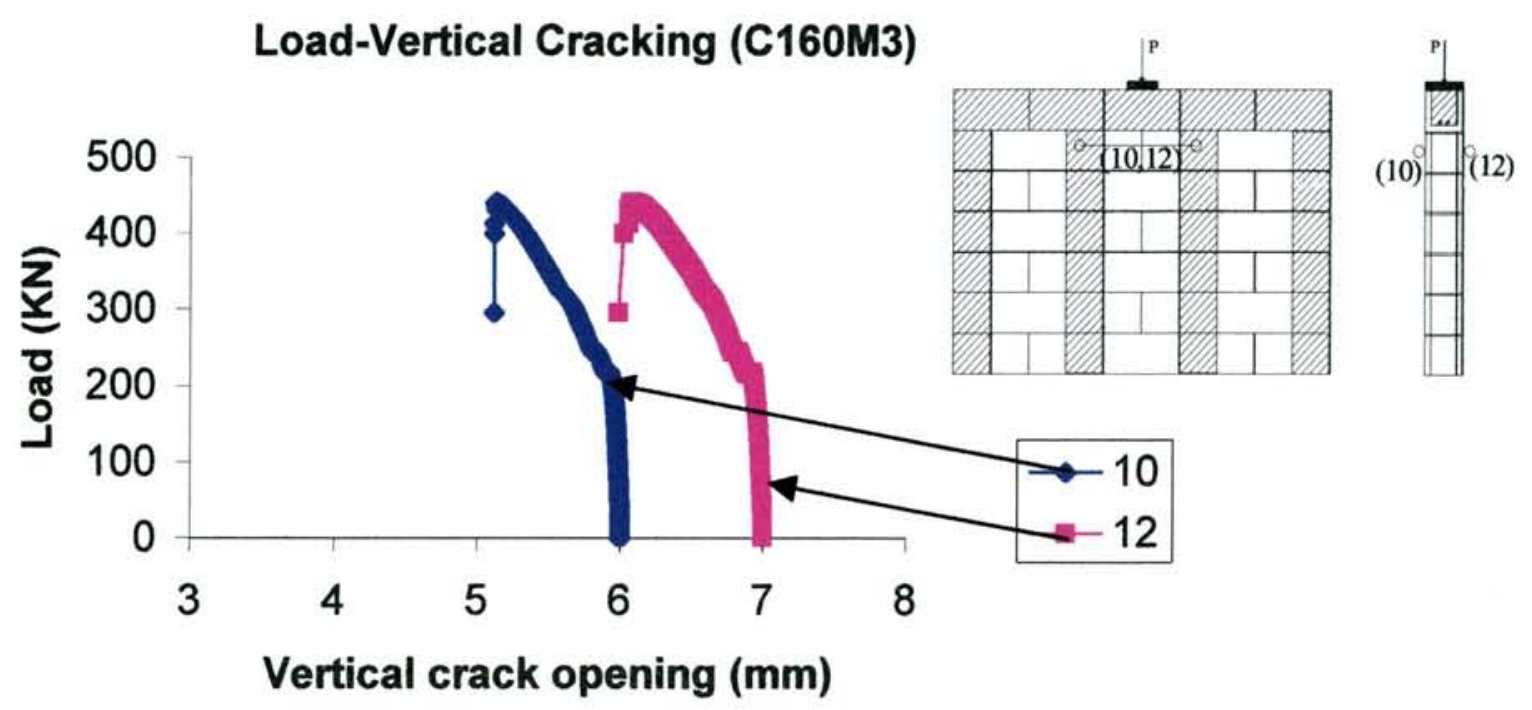

Fig. 6.21b---Load versus vertical cracking for C160M

\section{Load-Vertical Displacement (C160M3)}

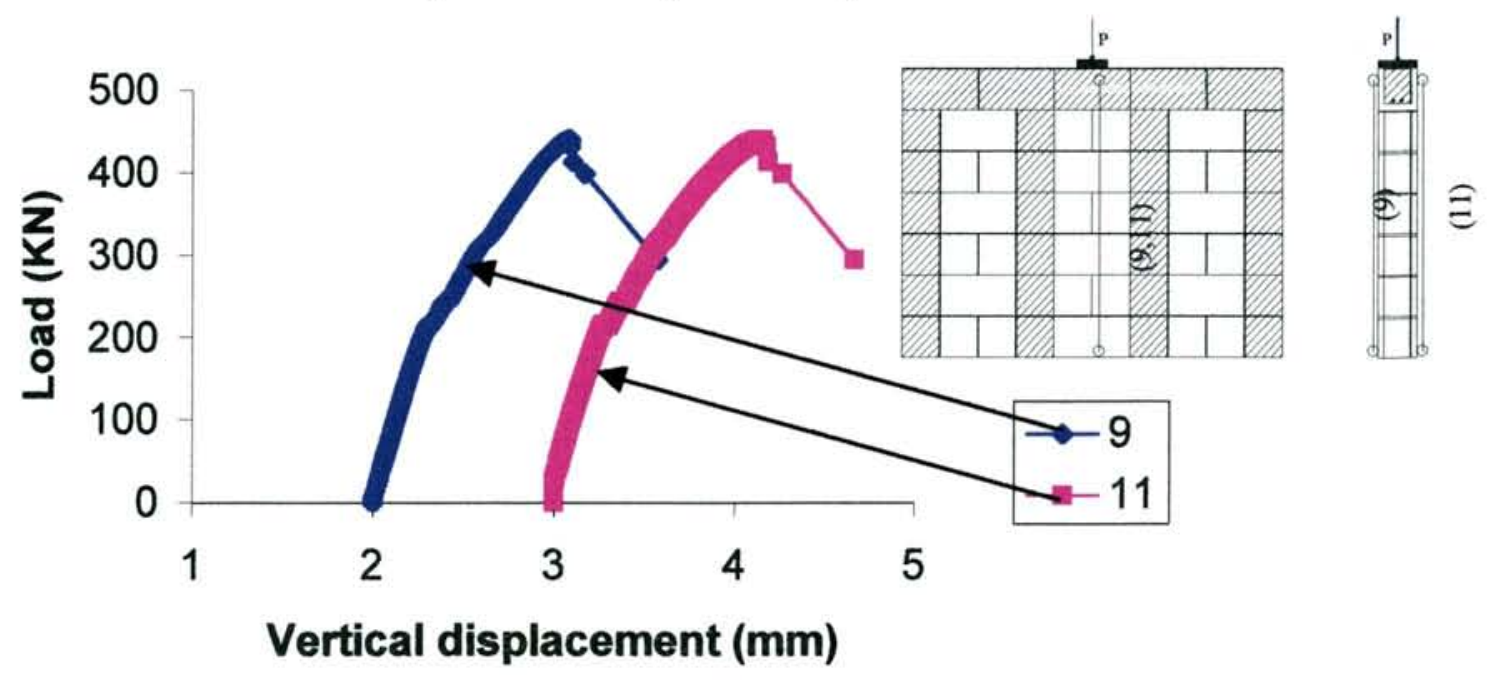

Fig. 6.21c---Load versus vertical displacement for C160M 

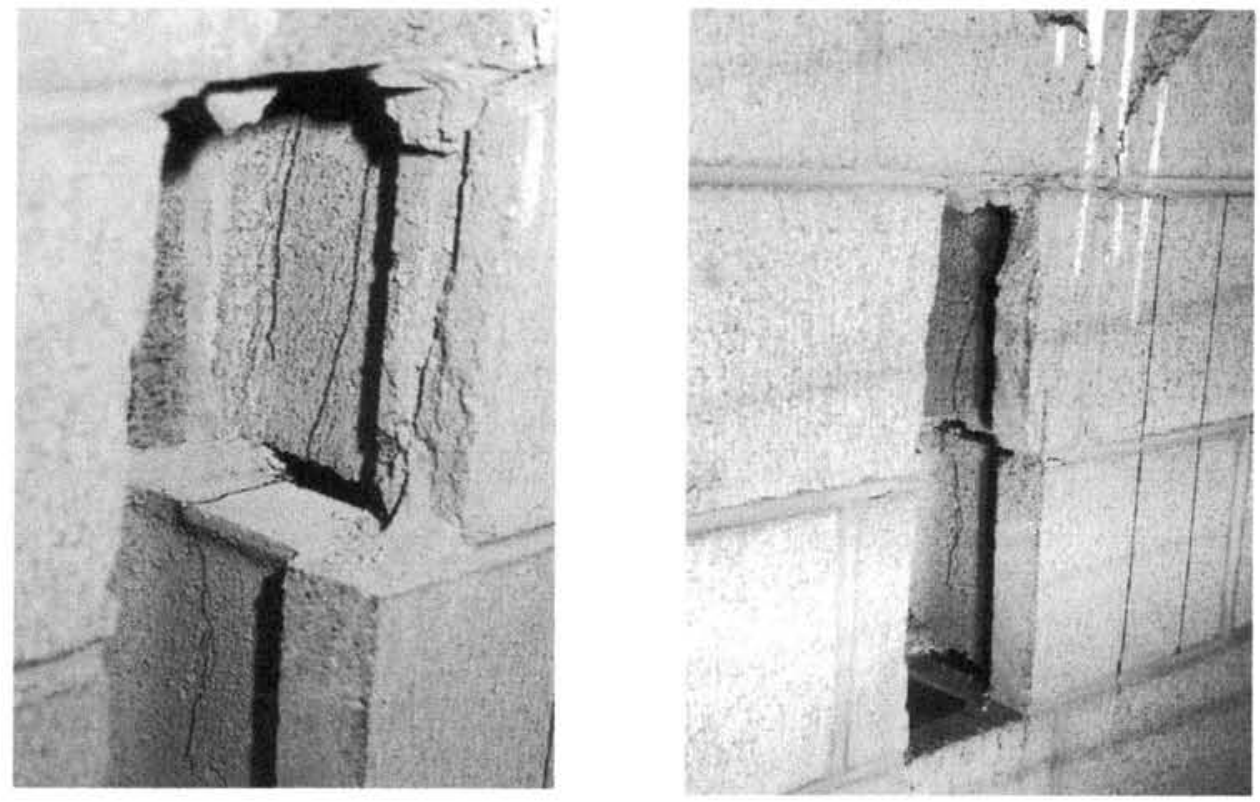

Fig. 6.22a---Typical web-splitting occurred in the hollow blocks beneath the bond beam: concentric loading (seen after cutting the face-shells)
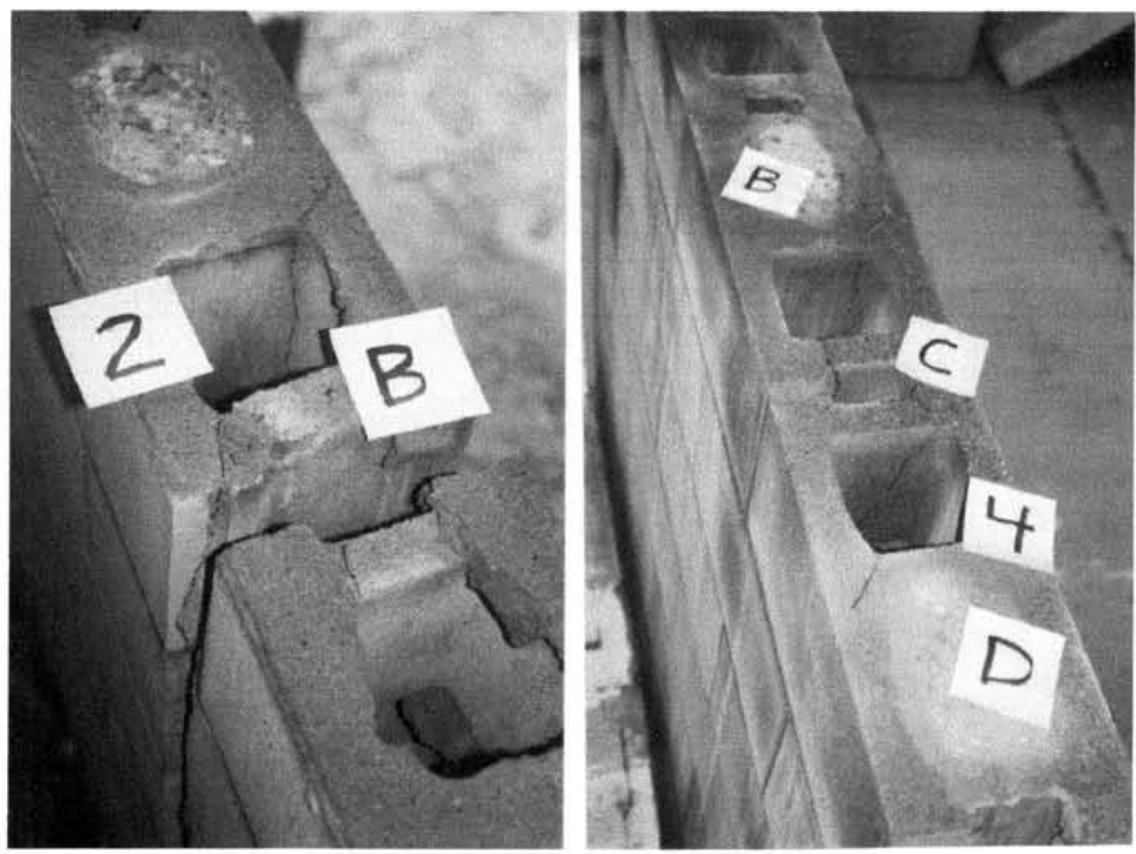

Fig. 6.22b---Typical web-splitting occurred in the hollow blocks beneath the bond beam: concentric loading (seen after removing the bond beam) 


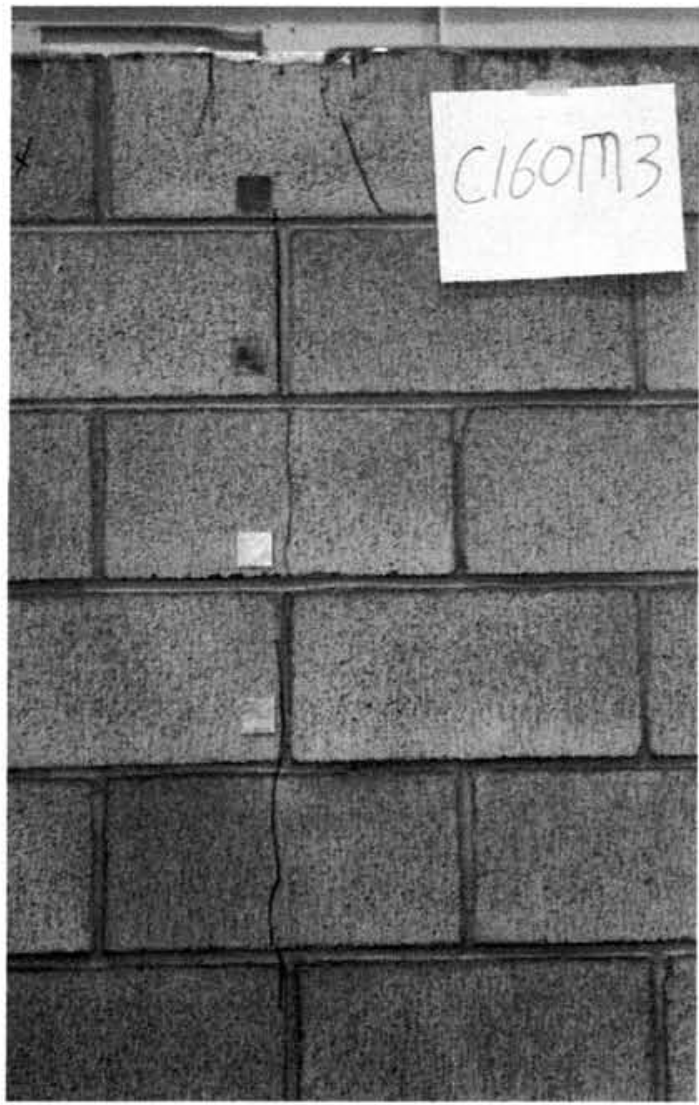

(a)

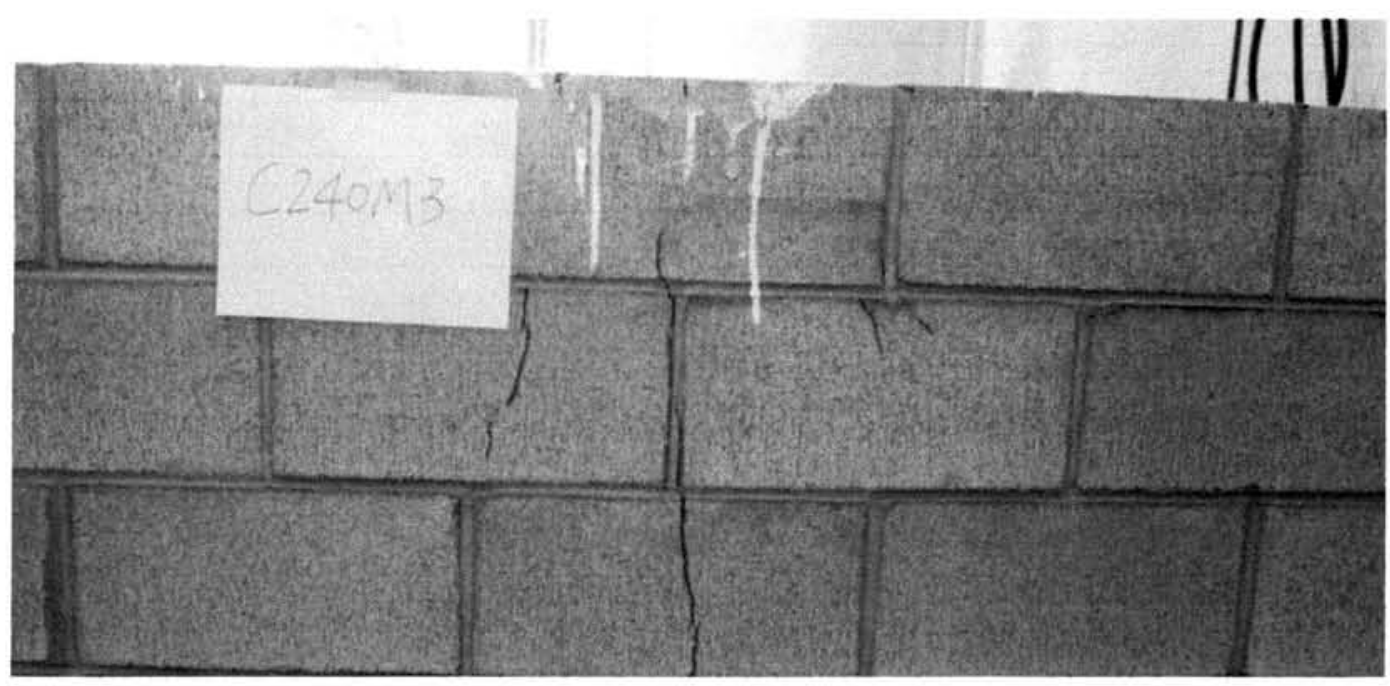

(b)

Fig. 6.23---Vertical cracking normal to the wall plane: concentric loading (a) loading plate length $160 \mathrm{~mm}$, (b) loading plate length $240 \mathrm{~mm}$ 


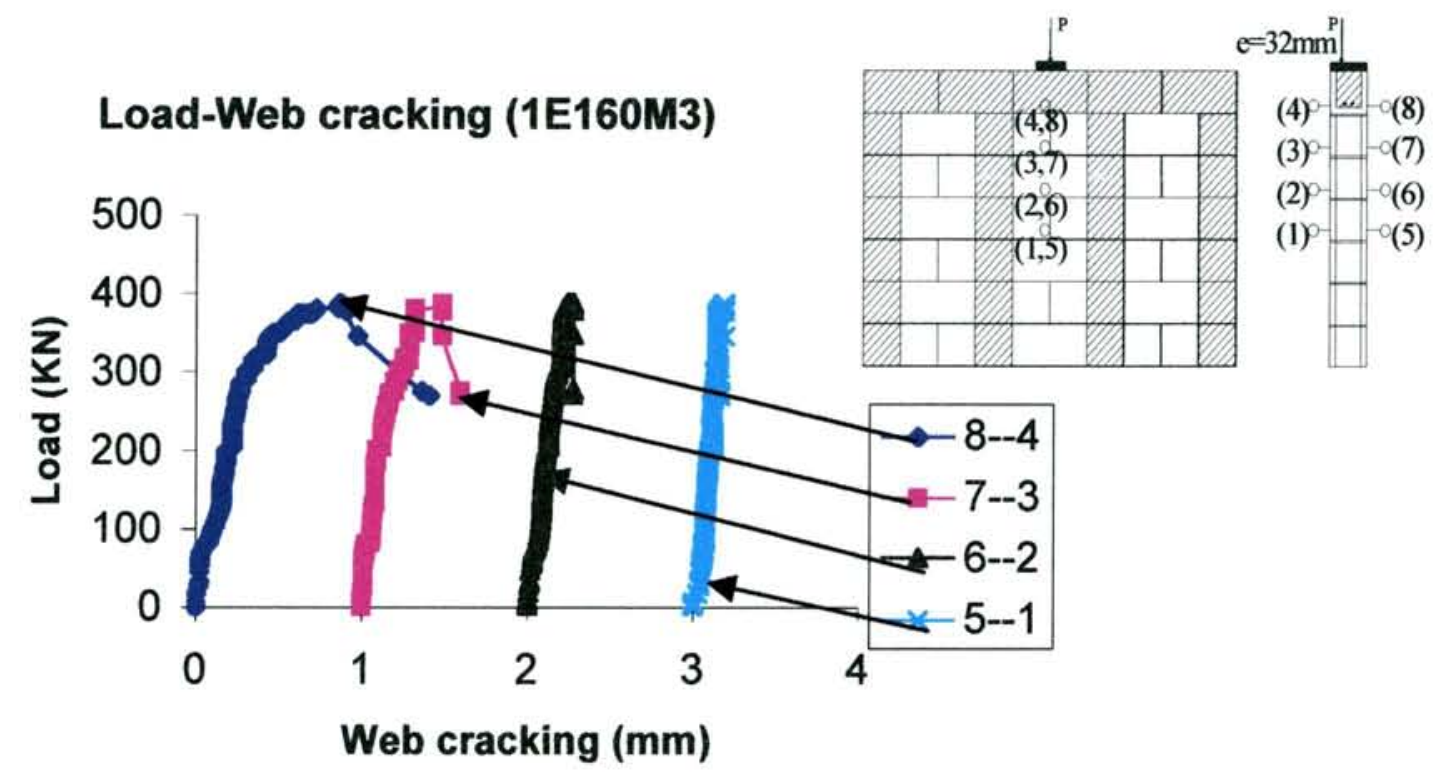

Fig. 6.24a---Load versus web cracking for $1 \mathrm{E} 160 \mathrm{M}$

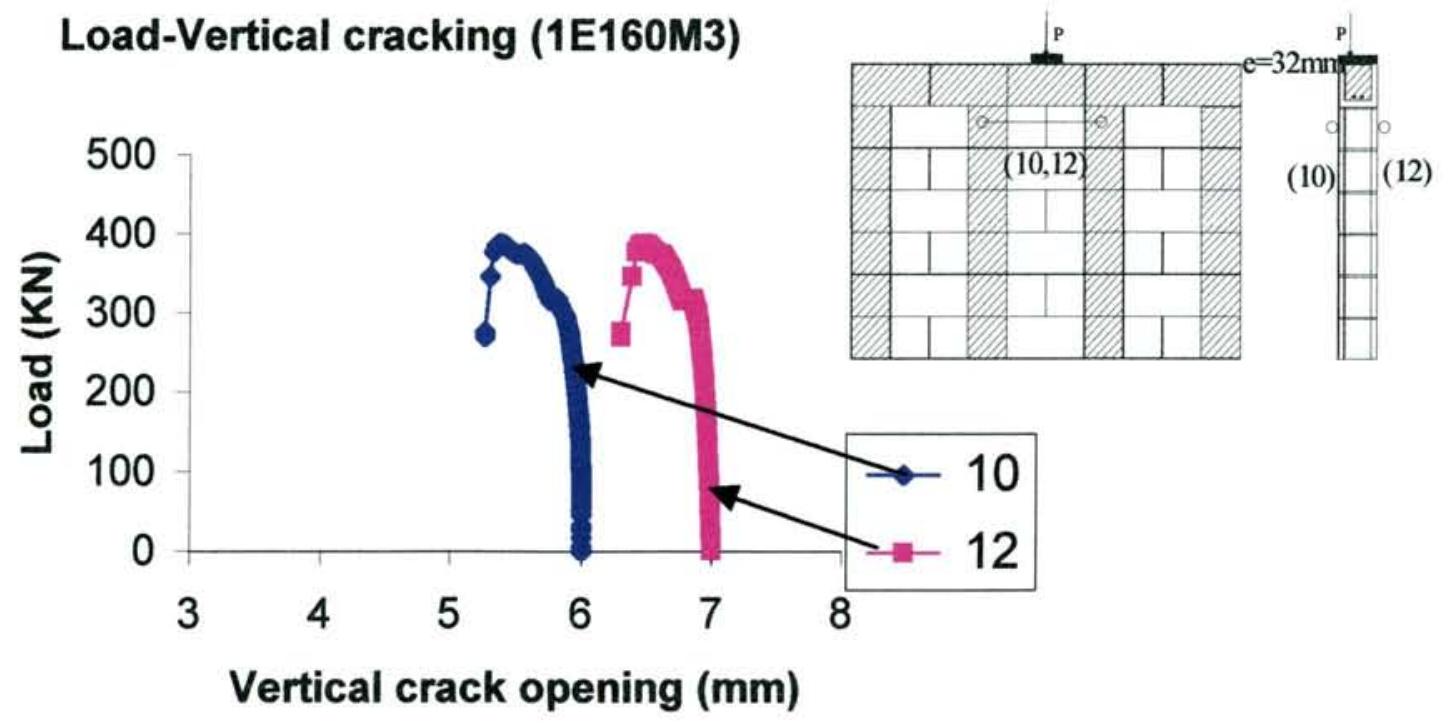

Fig. 6.24b---Load versus vertical cracking for 1E160M 


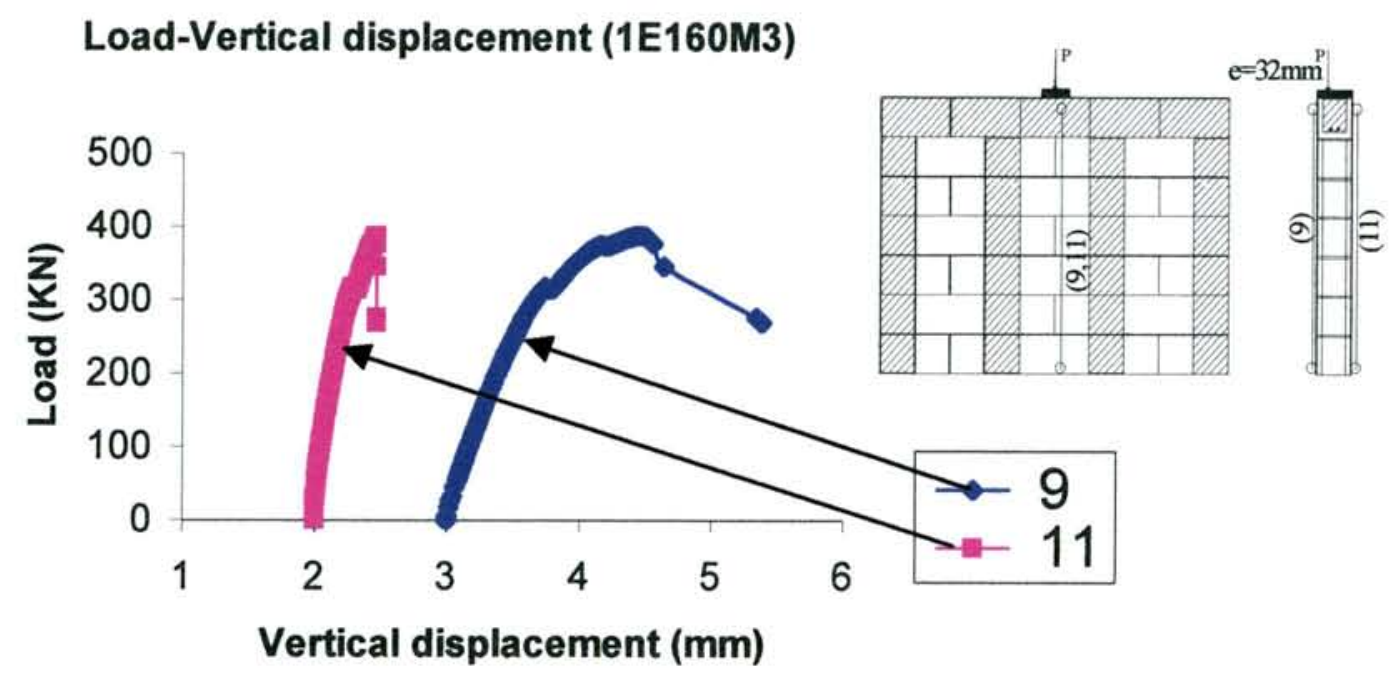

Fig. 6.24c---Load versus vertical displacement for 1E160M

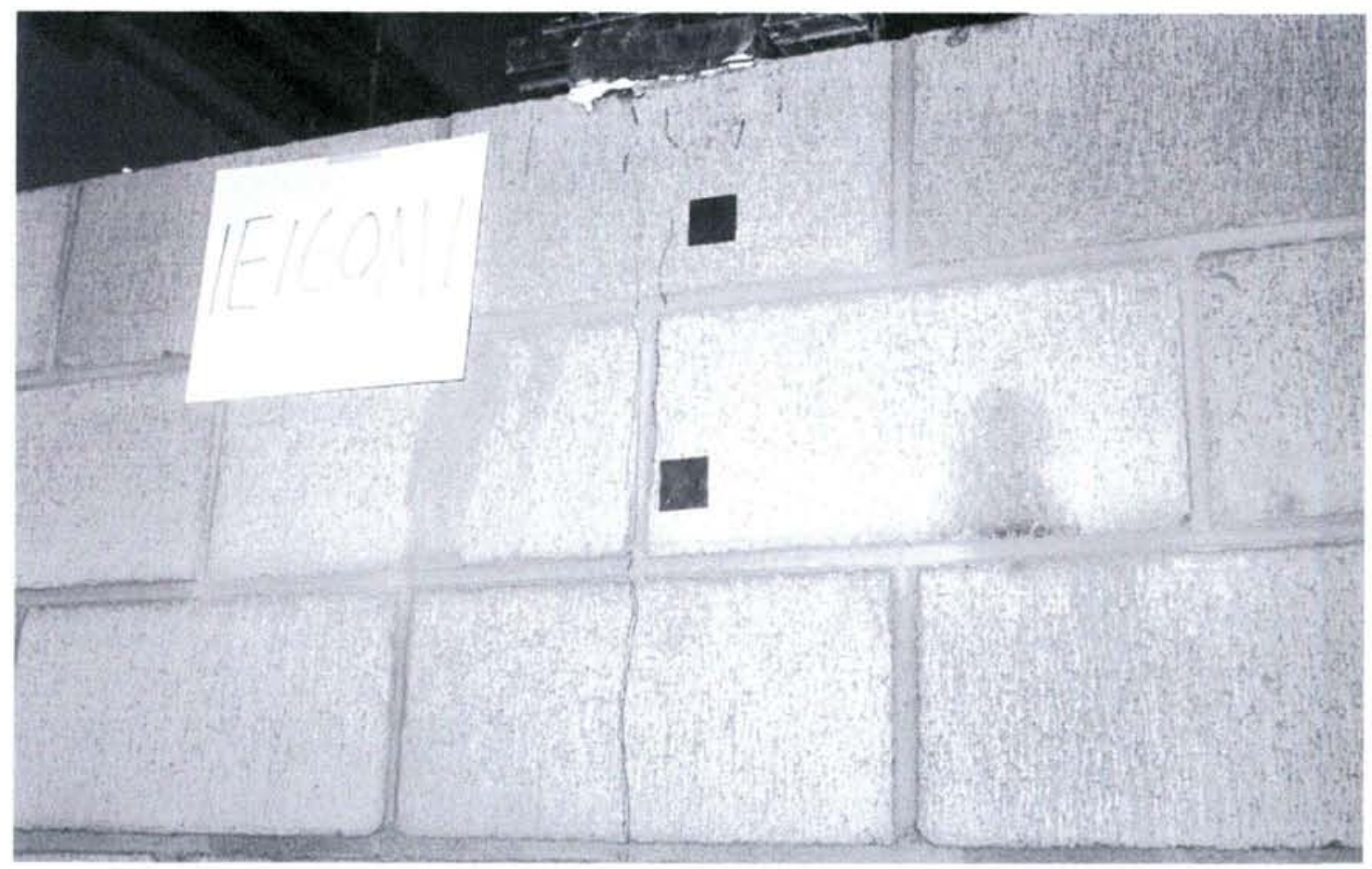

Fig. 6.25---Typical failure mode of wallette under eccentric concentrated load $(\mathrm{e}=32 \mathrm{~mm})$ 


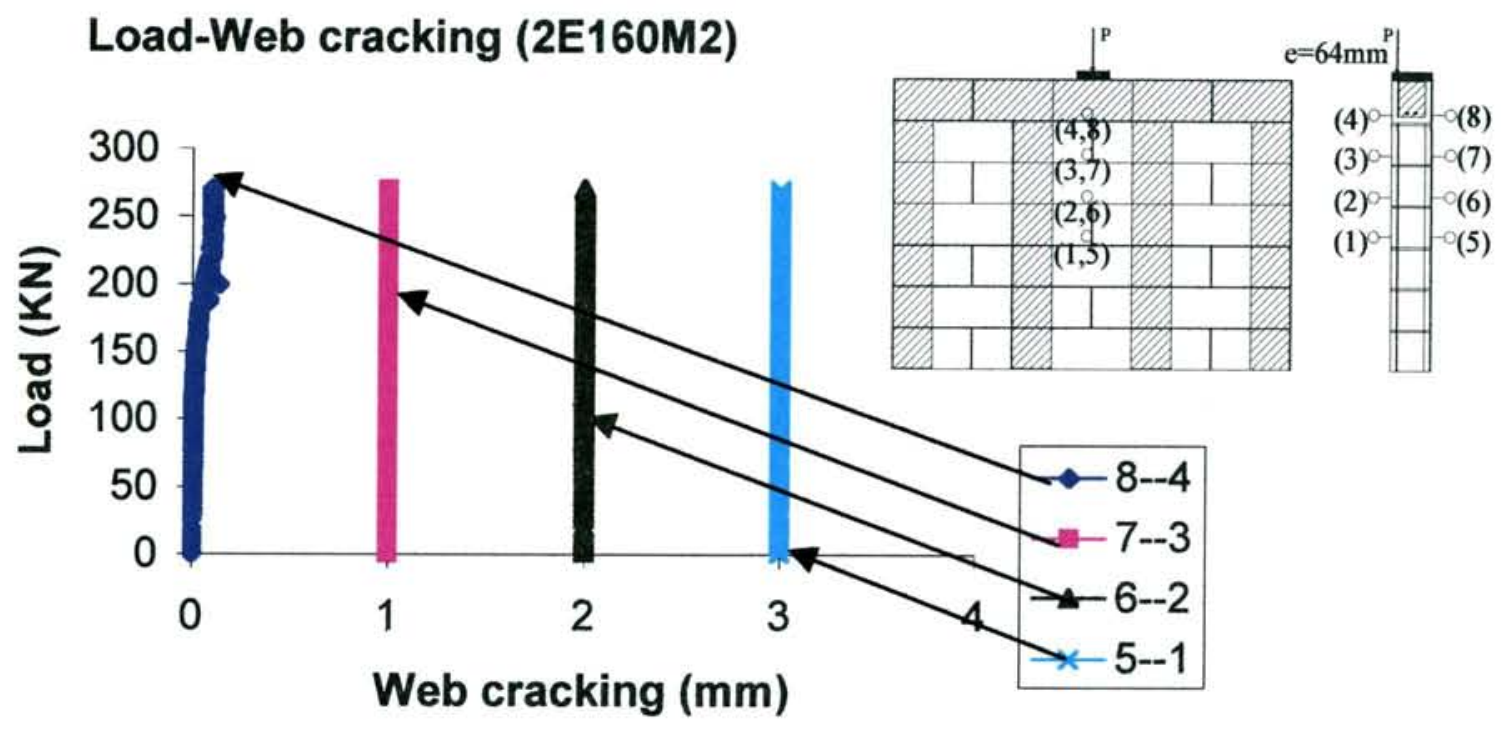

Fig. 6.26a---Load versus web cracking for 2E160M

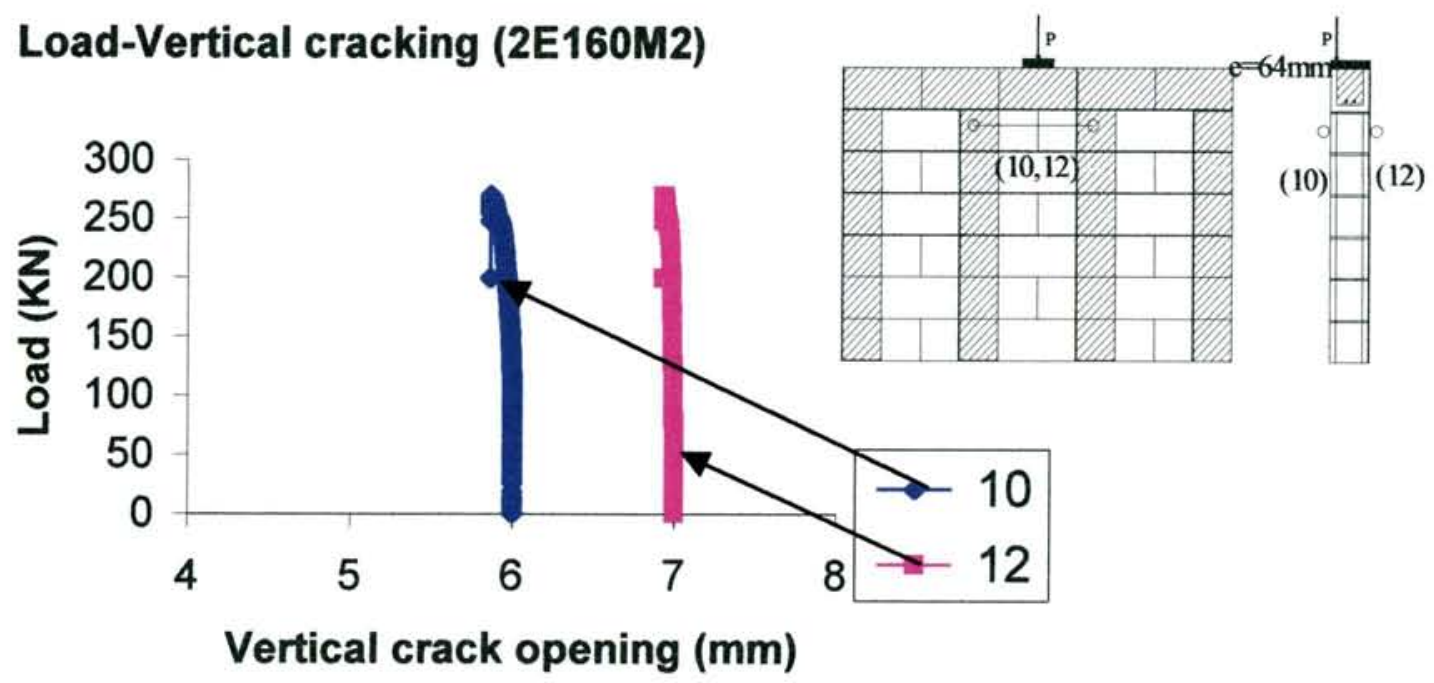

Fig. 6.26b---Load versus vertical cracking for 2E160M 


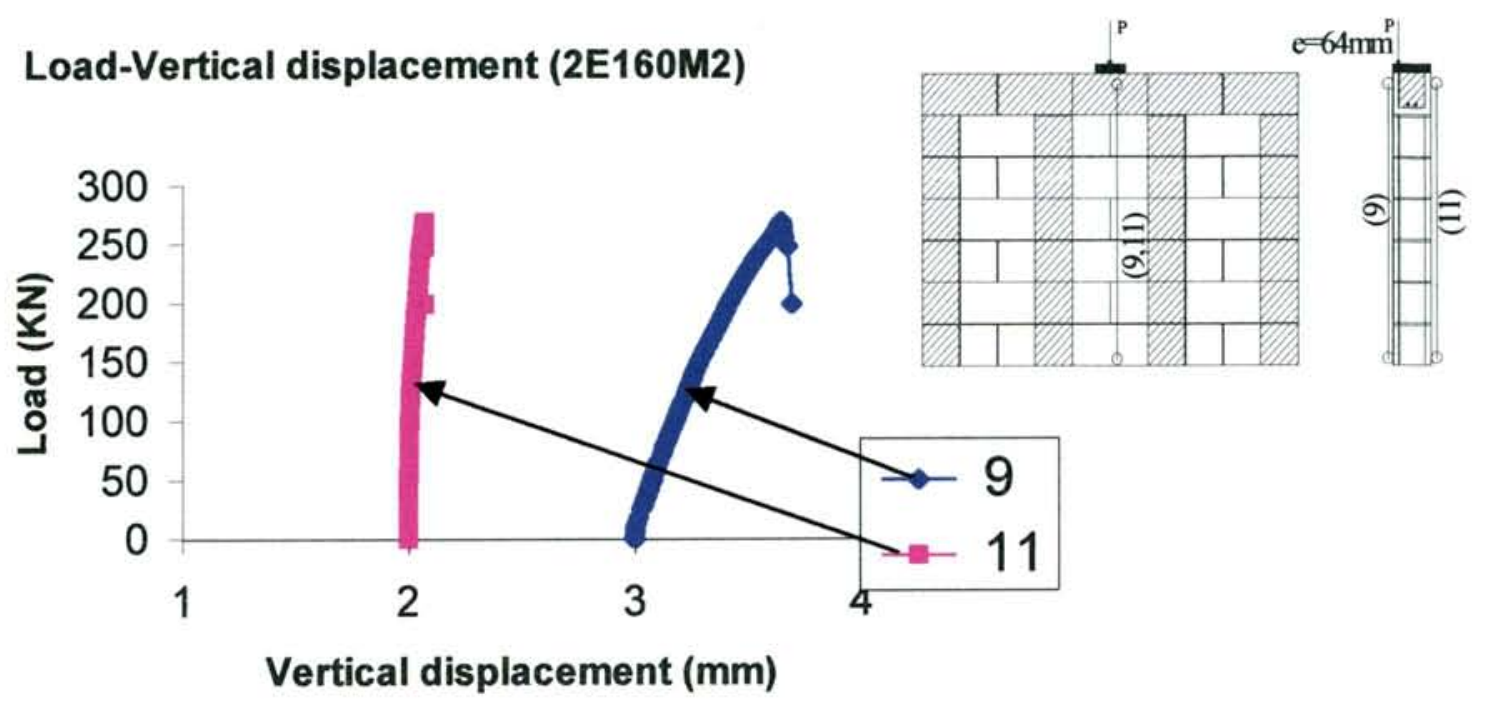

Fig. 6.26c---Load versus vertical displacement for 2E160M

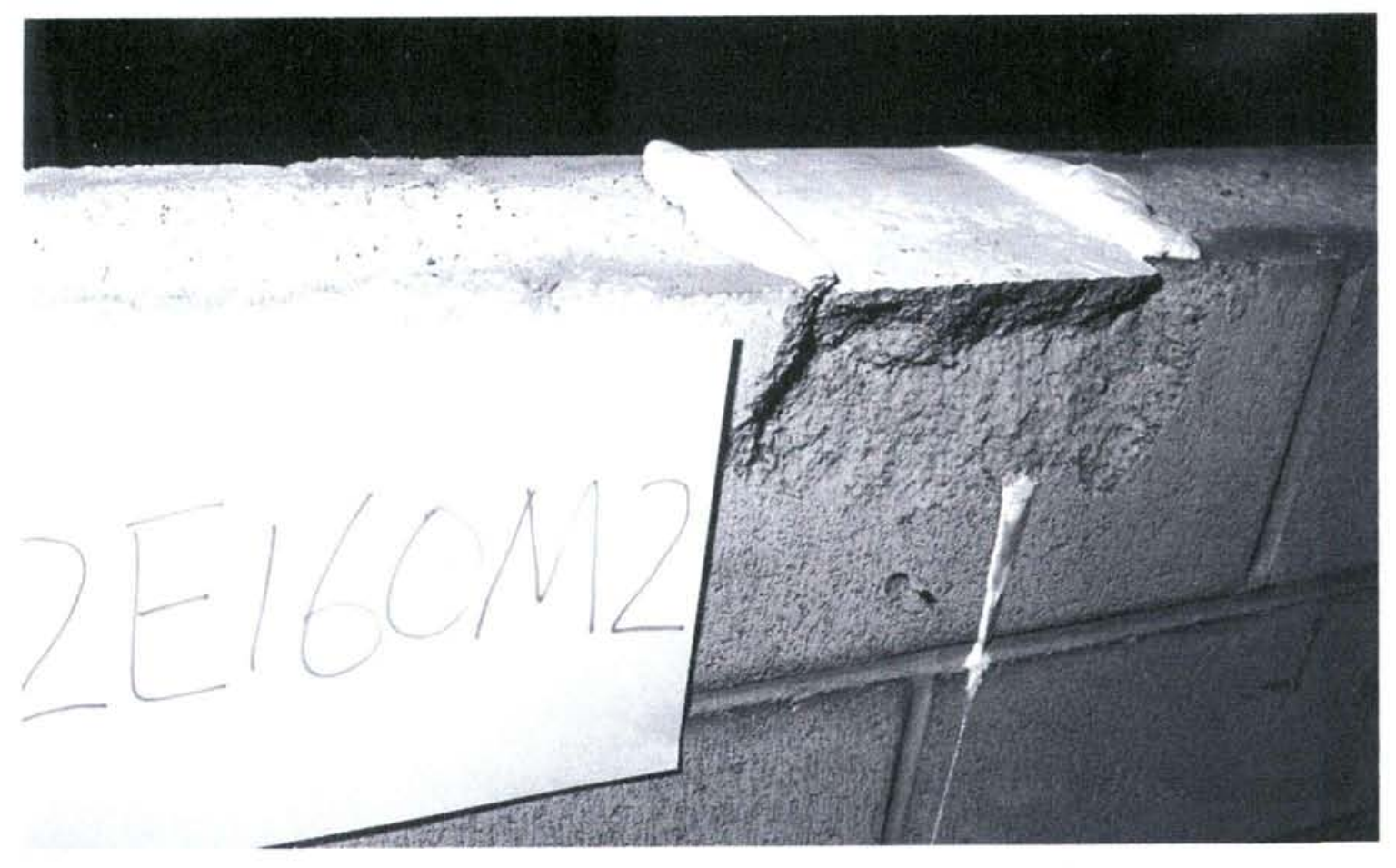

Fig. 6.27---Typical failure mode of wallette under eccentric concentrated load $(\mathrm{e}=64 \mathrm{~mm})$ 


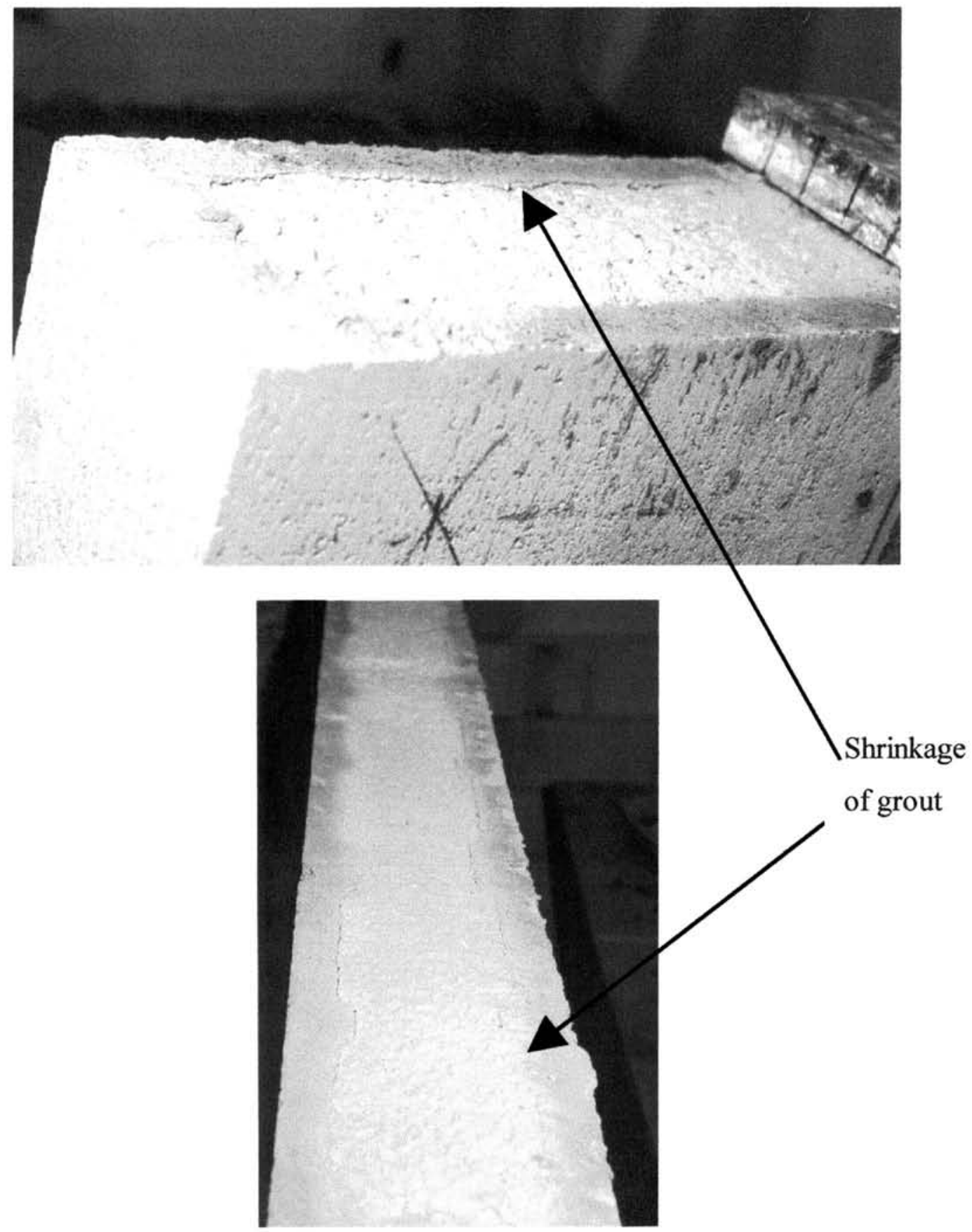

Fig. 6.28---Shrinkage of grout in the bond beam

Local face-shell spalling under large eccentricity is thought to be initiated by the shrinkage of the grout, which resulted in shrinkage cracks forming between the grout and the bond beam face-shells, as shown in Fig. 6.28. 
When the concentrated load is applied completely on the grout in a block cell, the shrinkage crack may reduce the effectiveness of load transfer from the grout to the blocks. Further research needs to be done about the detrimental effect of grout shrinkage.

\subsubsection{Concentrated loads on end columns (Series 2)}

Under concentric loading, when the loading plate length was $240 \mathrm{~mm}$, at about $50 \%$ of the ultimate capacity, vertical cracking formed in the vertical mortar head joints between the adjacent hollow block unit and the vertical column of grout (Fig. 6.29a), and the stiffness of the wall started to decrease (Fig. 6.29b). As load was increased, the vertical cracking extended quickly downwards, and the face-shells of hollow unit started spalling in the corners where the bond beam and the vertical column joined. Web cracking occurred also in the hollow block immediately below the bond beam at about $75 \%$ of the ultimate load (Fig. 6.29c). There was considerable horizontal dilation of the column at final failure (Fig. 6.29d) when the column crushed. With a $160 \mathrm{~mm}$ long loading plate, the same sequence was observed (Fig. 6.30a and b). However, when the loading plate was $80 \mathrm{~mm}$, the wall behaved almost linearly to final failure (Fig. 6.31a). No obvious web cracking or vertical cracking were observed (Fig. $6.31 \mathrm{~b}$ and c). Final failure occurred by local column crushing accompanied by large horizontal dilation (Fig. 6.31d), with end of the column splitting apart from the main part of the column and wallette. A $80 \mathrm{~mm}$ long plate is too small to spread the concentrated load out of the column. Typical examples of vertical cracking, face-shell spalling, web splitting, and local splitting are shown in Fig. 6.32, Fig. 6.33 and Fig. 6.34 . 
Load-Vertical cracking (C240E3)

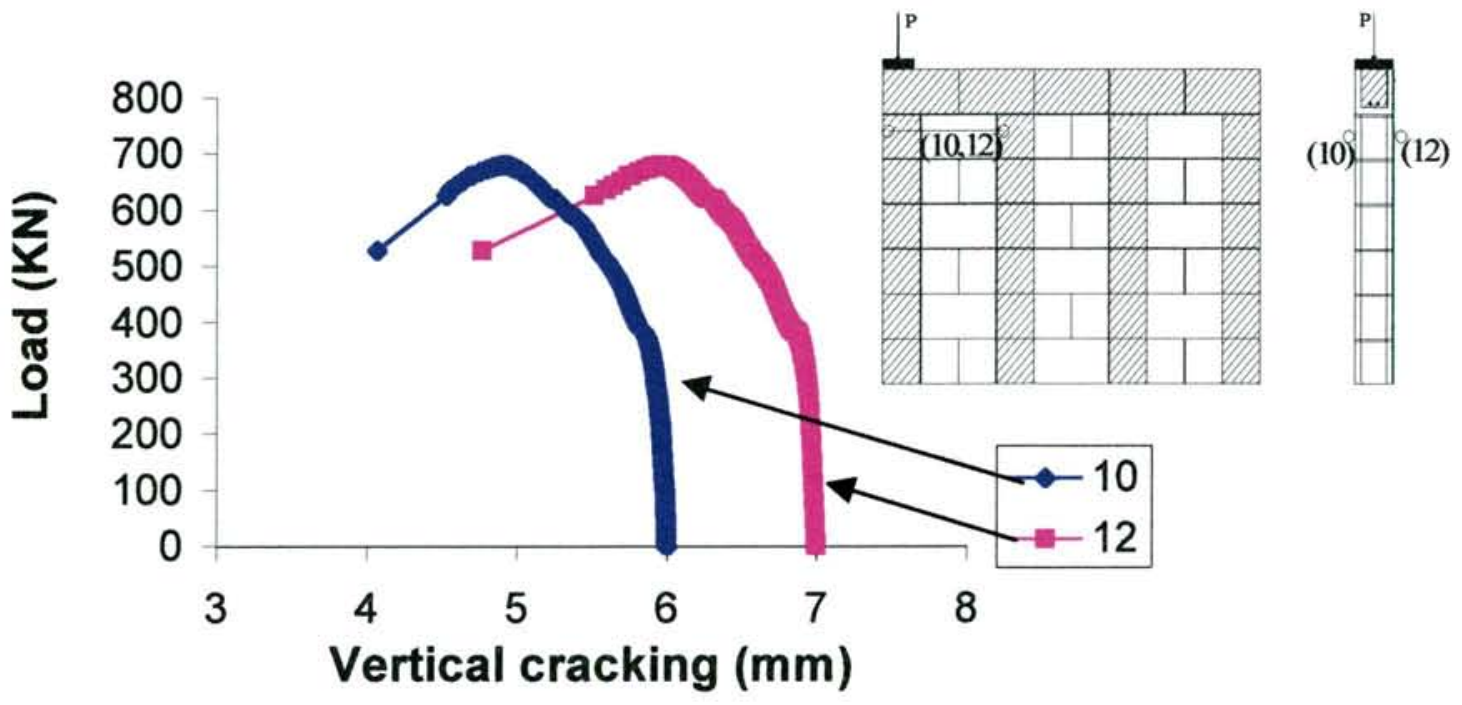

Fig. 6.29a---Load versus vertical cracking for C240E

\section{Load-Vertical displacement (C240E3)}

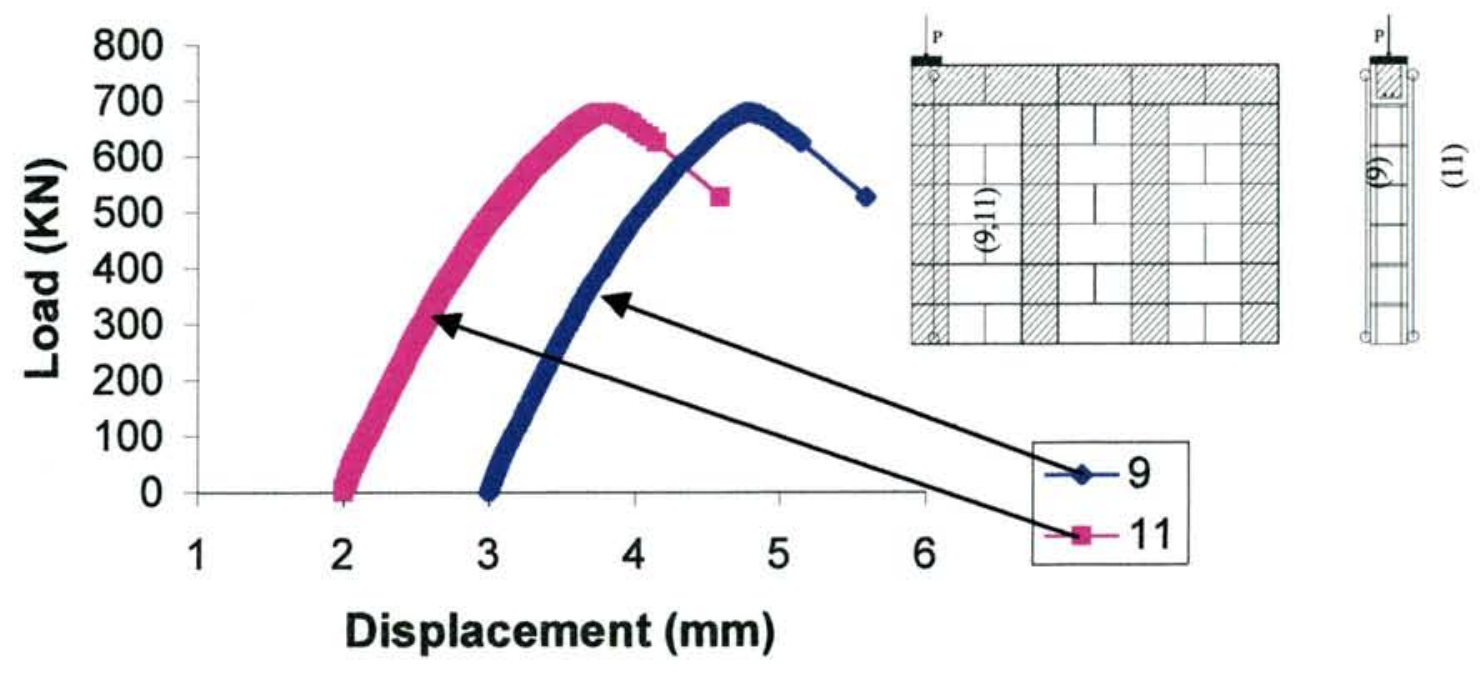

Fig. 6.29b---Load versus vertical displacement for C240E 


\section{Load-Web cracking (C240E3)}

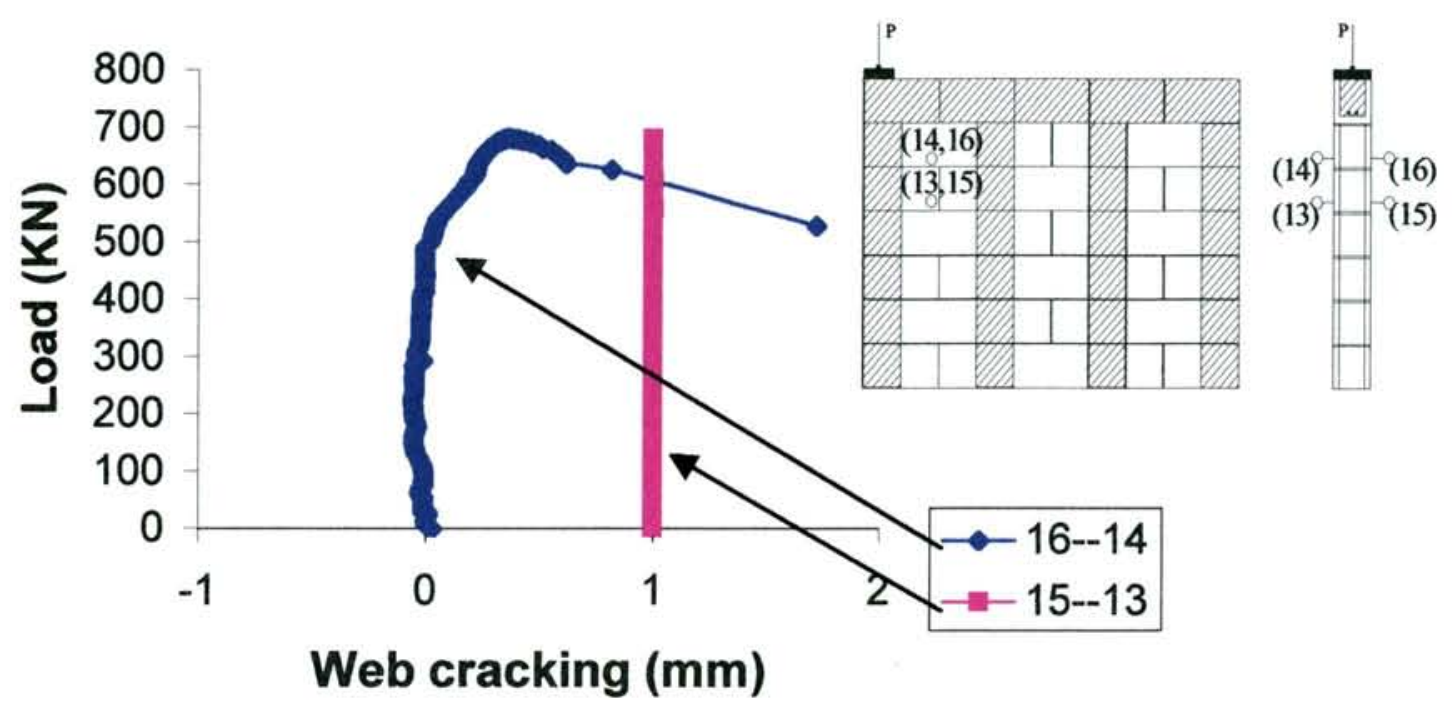

Fig. 6.29c---Load versus web cracking of hollow blocks for C240E

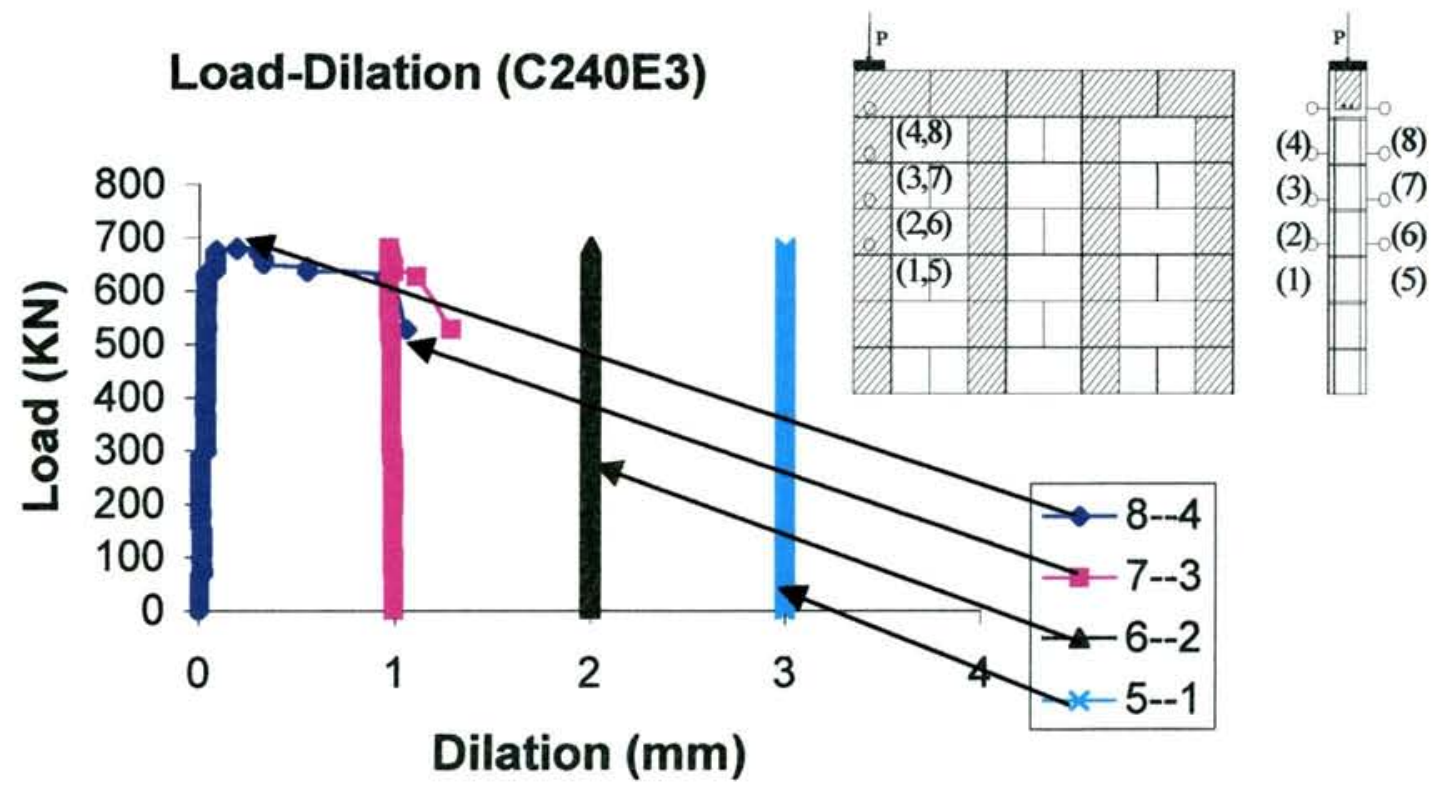

Fig. 6.29d---Load versus lateral dilation of column for C240E 


\section{Load-Vertical cracking (C160E3)}

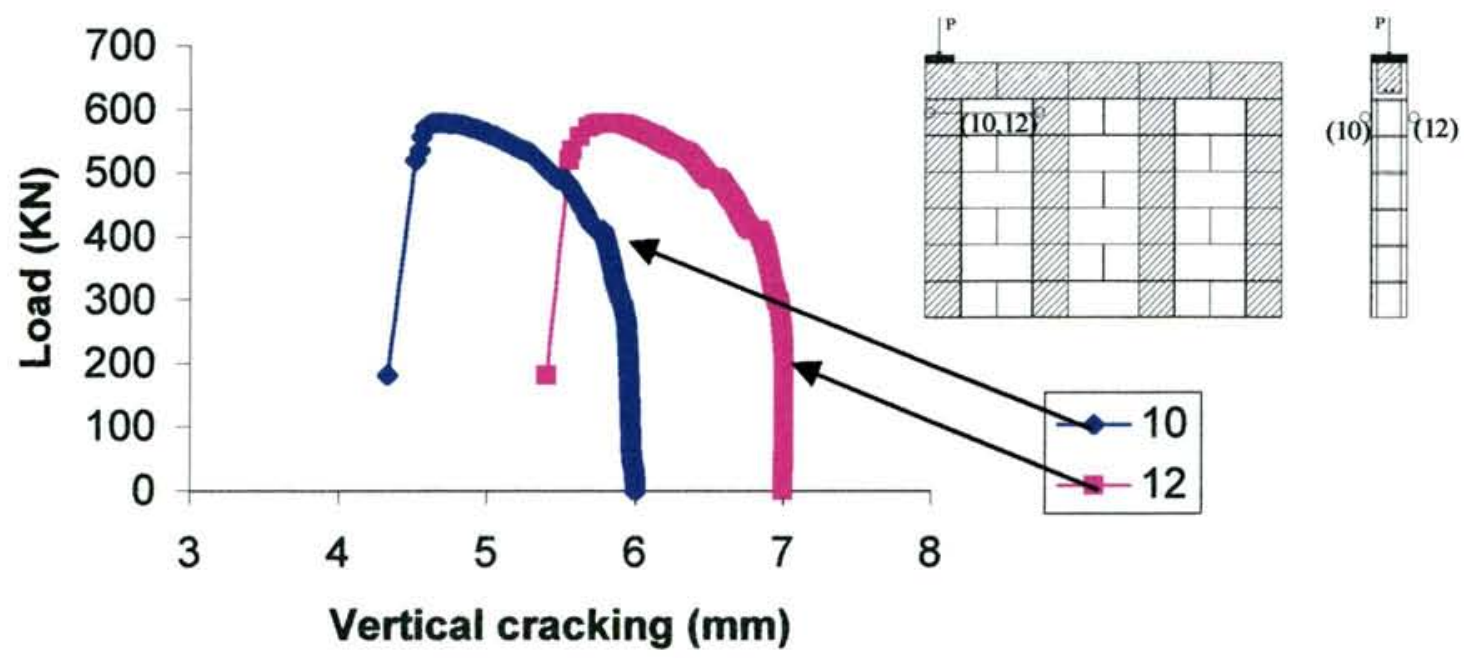

Fig. 6.30a---Load versus vertical cracking for C160E

\section{Load-Vertical displacement (C160E3)}

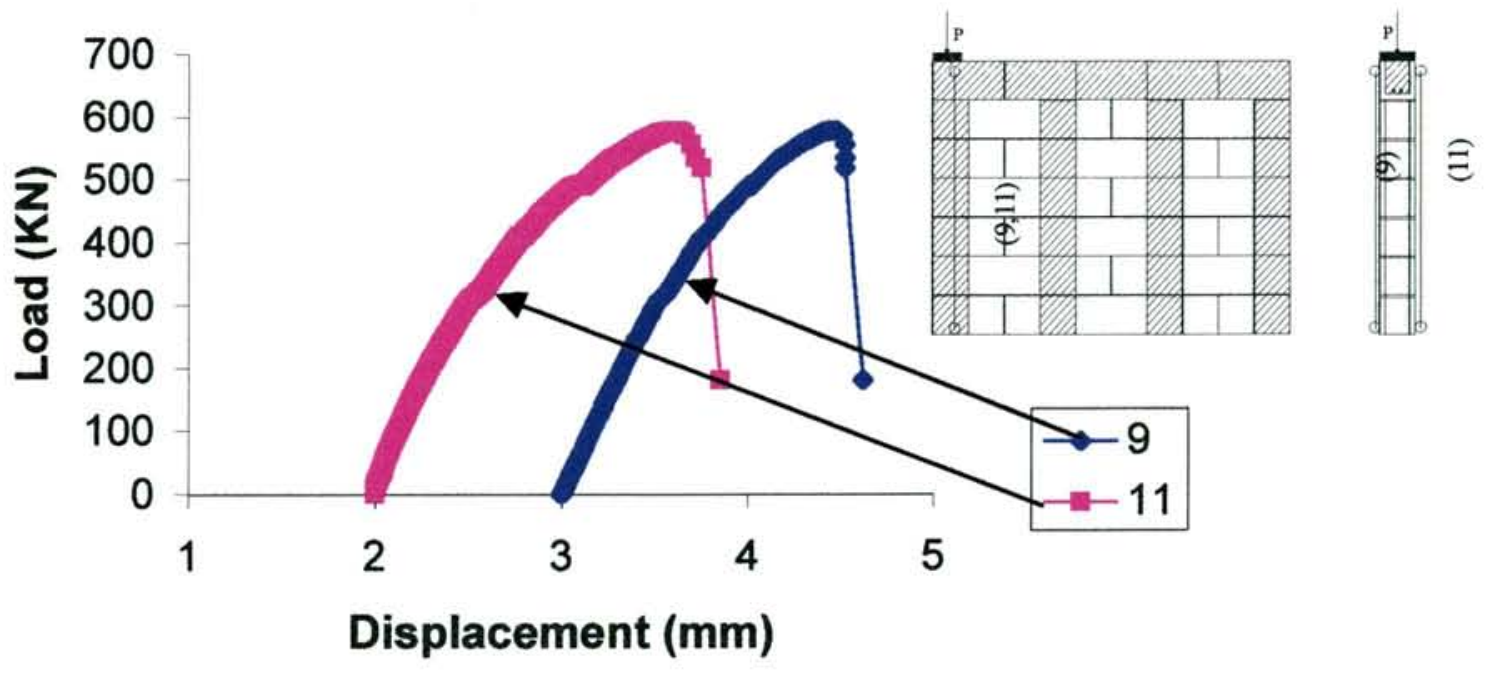

Fig. 6.30b---Load versus vertical displacement for $\mathrm{C} 160 \mathrm{E}$ 


\section{Load-Vertical displacement (C80E3)}

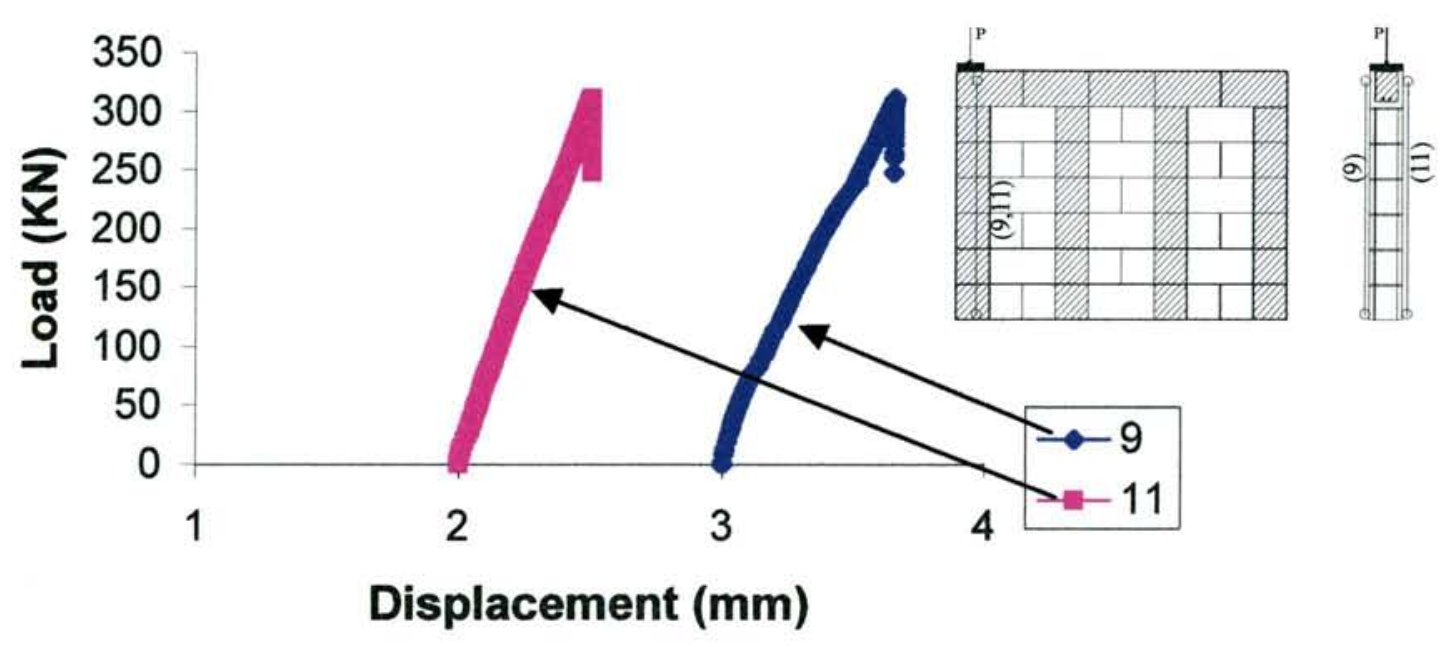

Fig. 6.31a---Load versus vertical displacement for $\mathrm{C} 80 \mathrm{E}$

\section{Load-Vertical cracking (C80E3)}

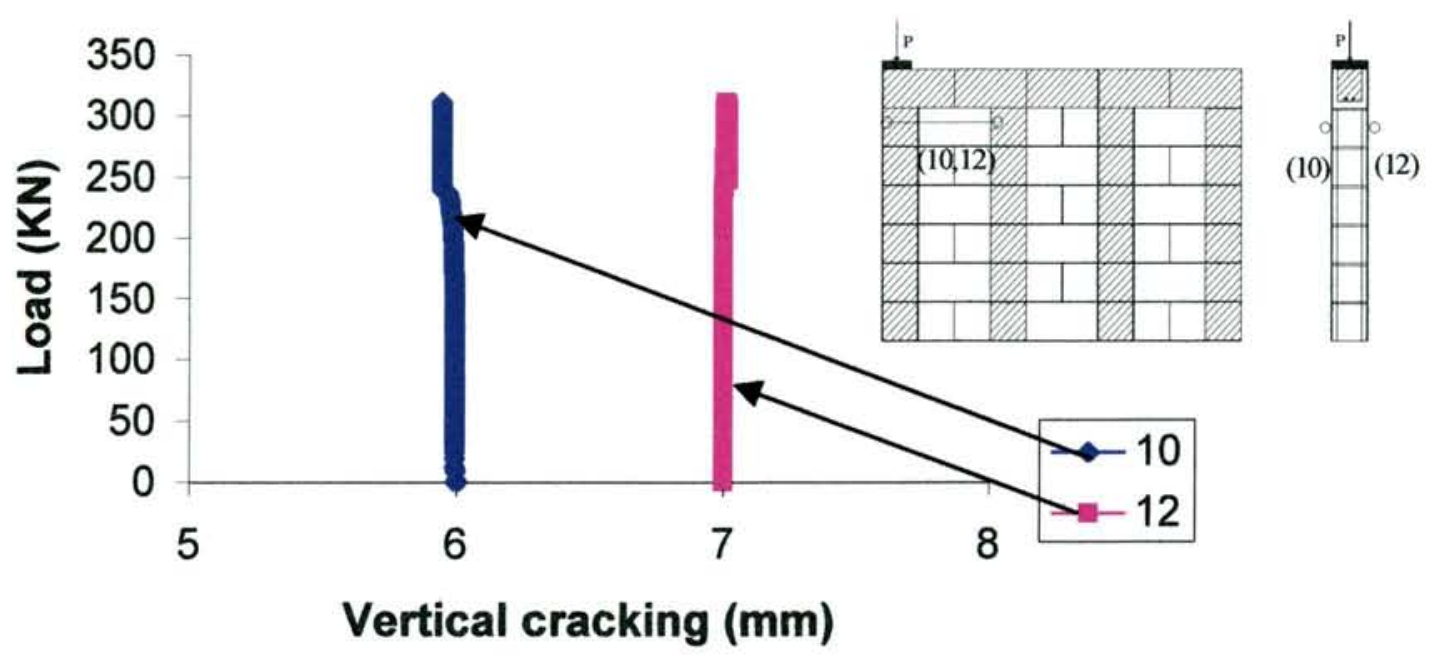

Fig. 6.31b---Load versus vertical cracking for $\mathrm{C} 80 \mathrm{E}$ 
Load-Web cracking (C80E3)

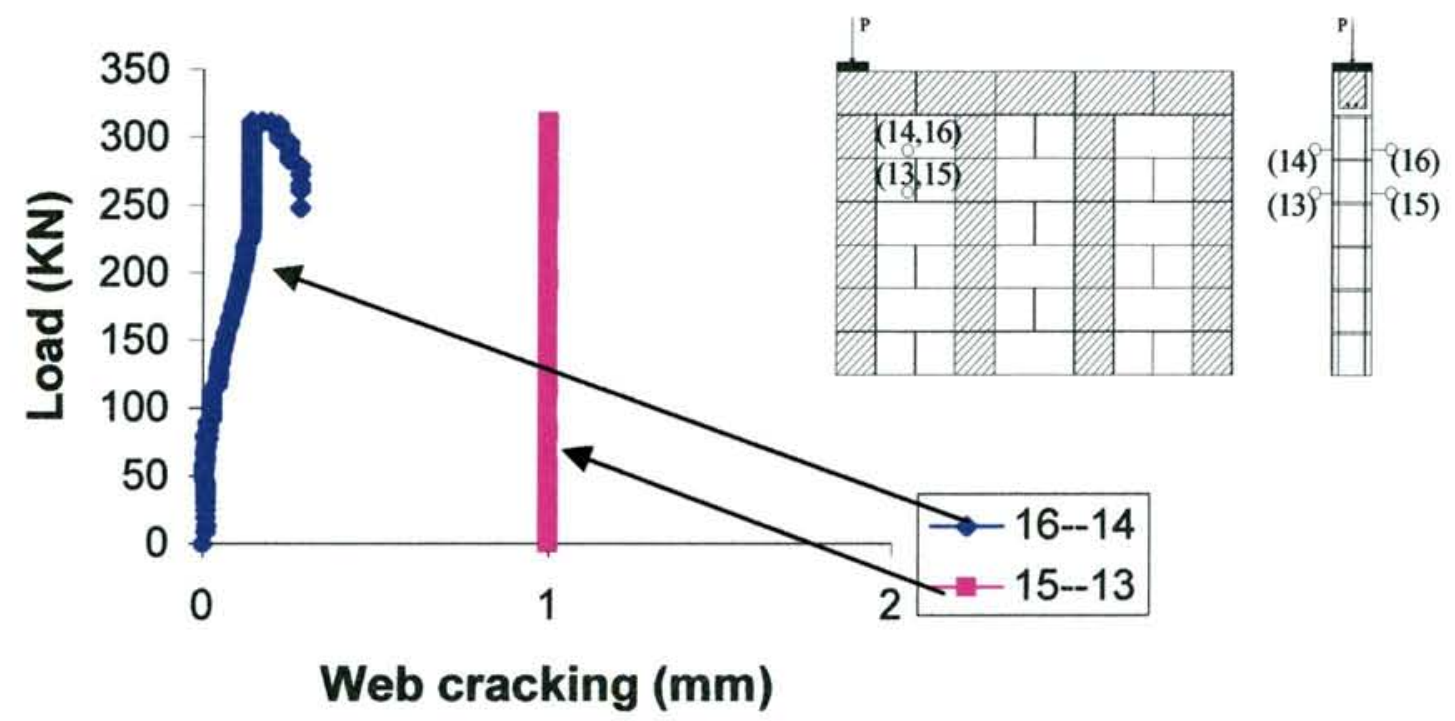

Fig. 6.31c---Load versus web cracking of hollow blocks for C80E

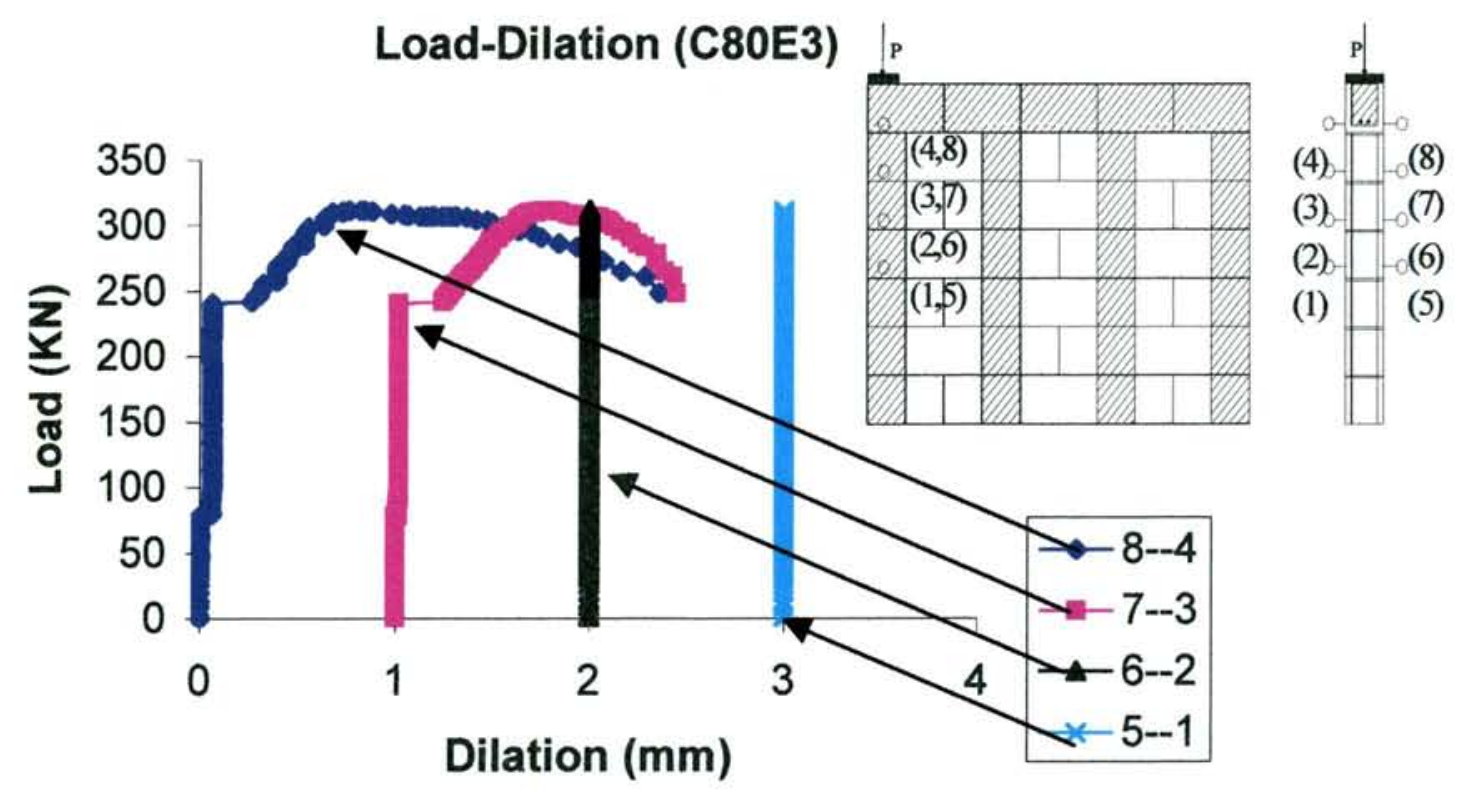

Fig. 6.31d----Load versus lateral dilation of column for C80E 

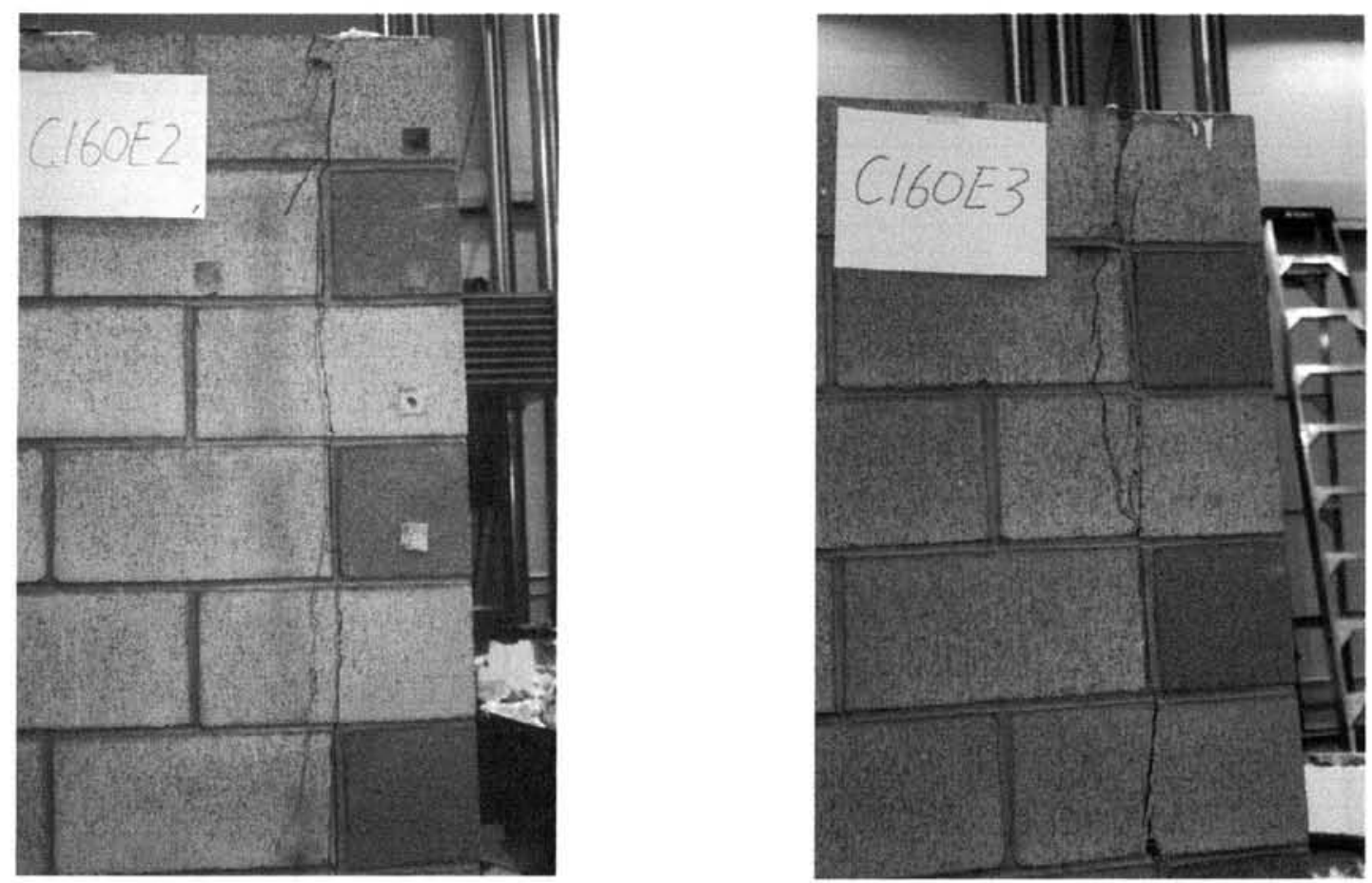

Fig. 6.32a---Vertical cracking and face-shell spalling of wallette under concentric concentrated load on end column (plate length $=160 \mathrm{~mm}$ )

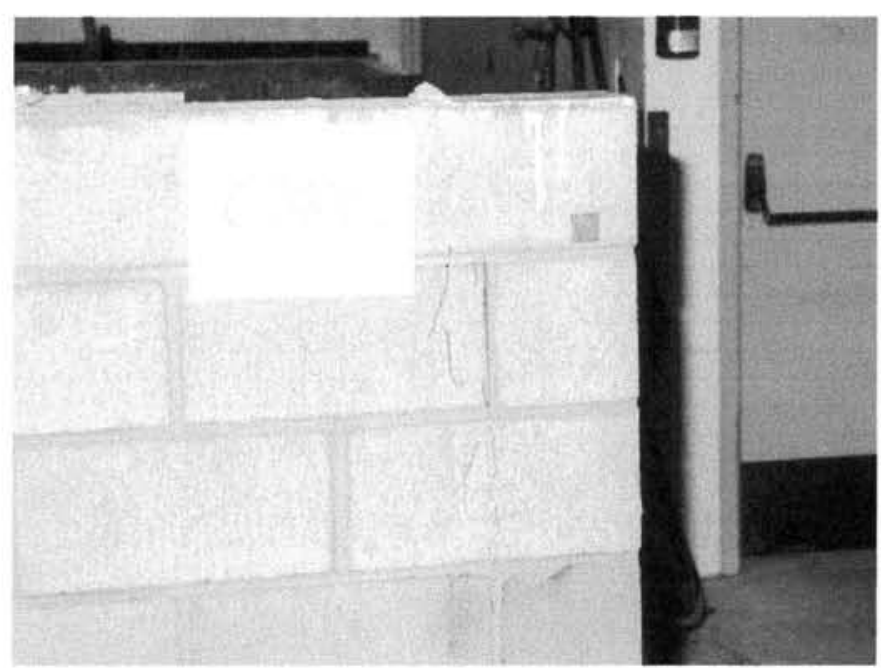

Fig. 6.32b---Vertical cracking and face-shell spalling of wallette under concentric concentrated load on end column (plate length $=240 \mathrm{~mm}$ ) 


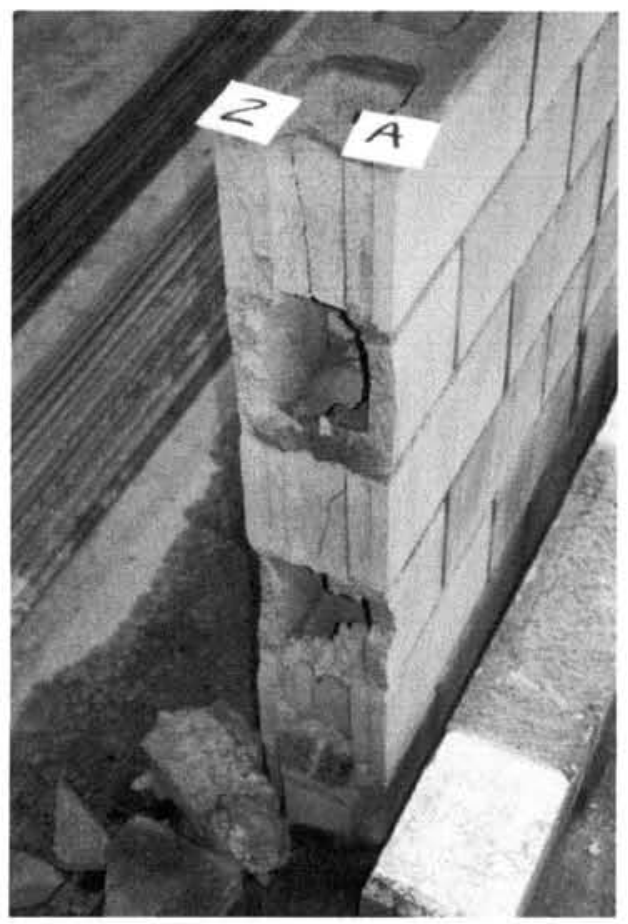

Fig. 6.33a---Web splitting of wallette under concentric concentrated load on end column (seen after removing the bond beam and column, plate length $=160 \mathrm{~mm}$ )

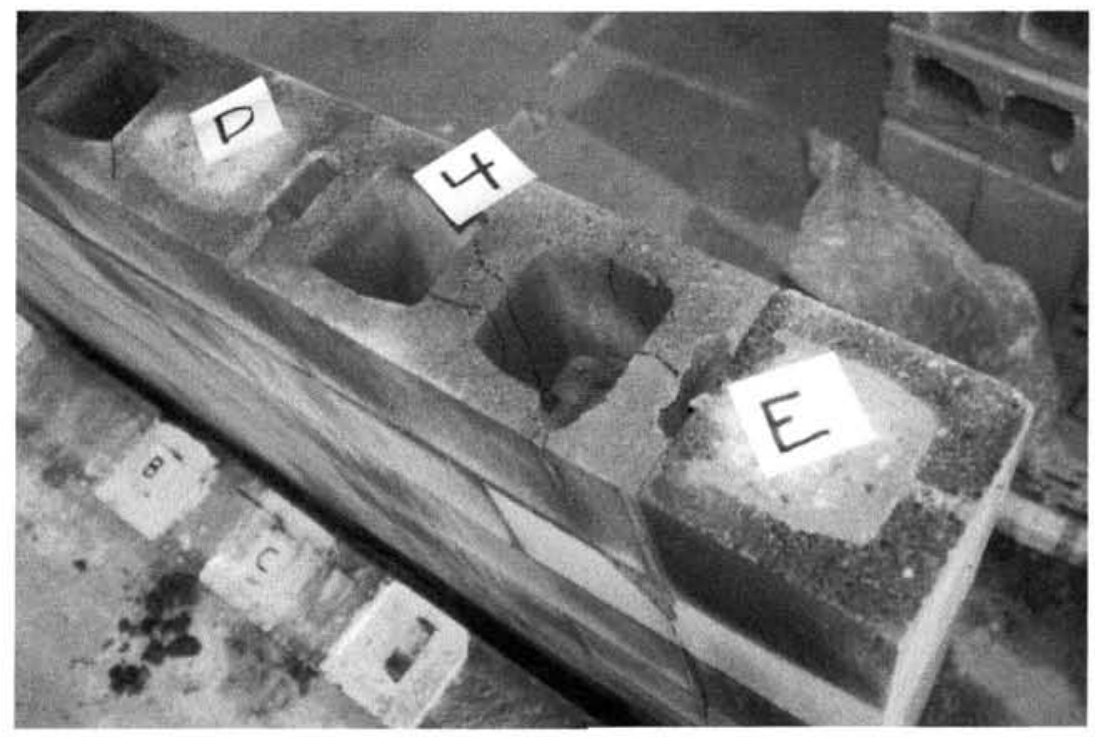

Fig. 6.33b---Vertical cracking and web splitting of wallette under concentric concentrated load on end column (seen after removing the bond beam, plate length $=240 \mathrm{~mm}$ ) 

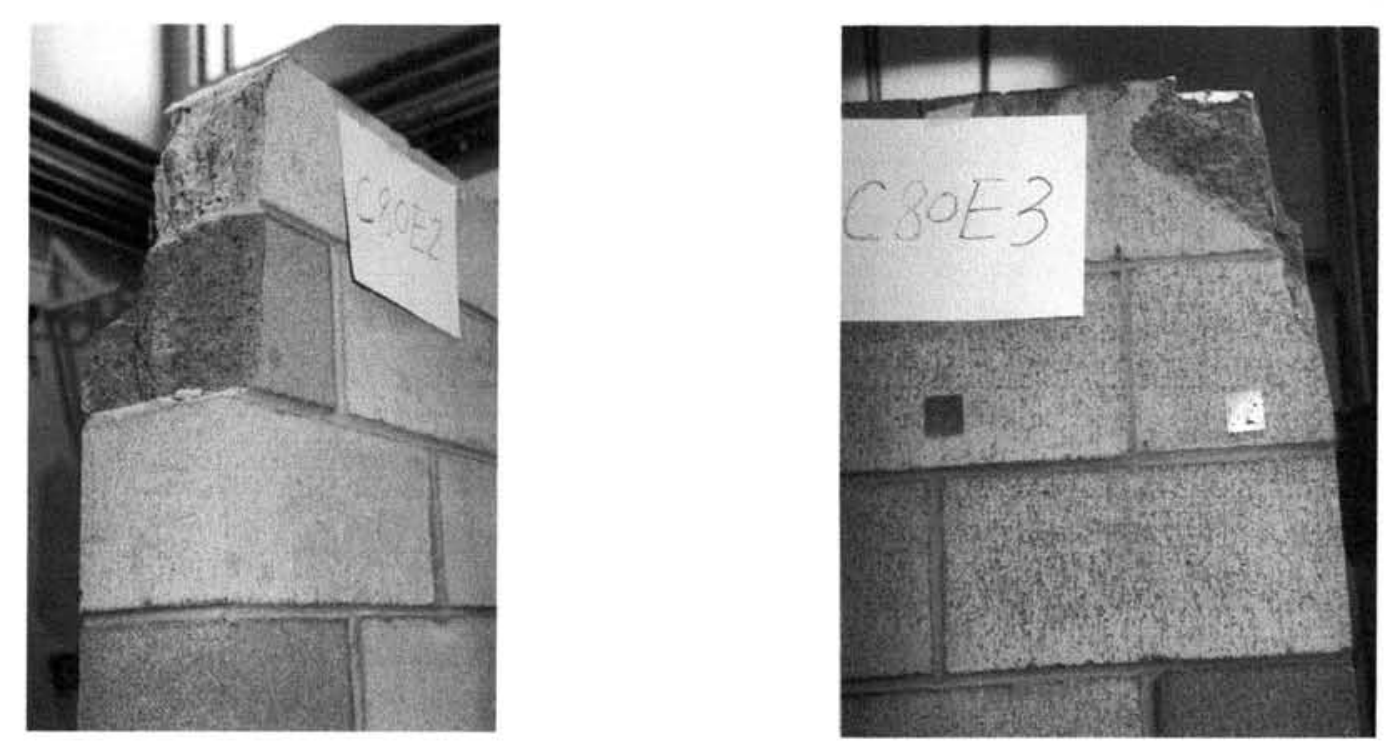

Fig. 6.34---Local crushing/splitting of wallette under concentric concentrated load on end column (plate length $=80 \mathrm{~mm}$ )

Under eccentric loading with small eccentricity (t/6), with $240 \mathrm{~mm}$ long loading plate, vertical cracking occurred at about $80 \%$ of the ultimate load (Fig. 6.35a), and the stiffiness of the wall started to decrease (Fig. 6.35b). No obvious web cracking was observed in the hollow blocks beside the column of grout. The vertical deformation on the heavily loaded side was much larger than that on the lightly loaded side, while the vertical cracking was about the same on both sides. Final failure occurred when the face-shell of the column spalled and separated from the grout on the heavily loaded side. With a $160 \mathrm{~mm}$ long loading plate, the same sequence was observed (Fig. 6.36a and b). However, when the loading plate length was $80 \mathrm{~mm}$, no obvious vertical cracking was observed (Fig. 6.37a). Typical examples of failure under eccentric load with small eccentricity are shown in Fig. 6.38 . 
Load-Vertical cracking (1E240E2)

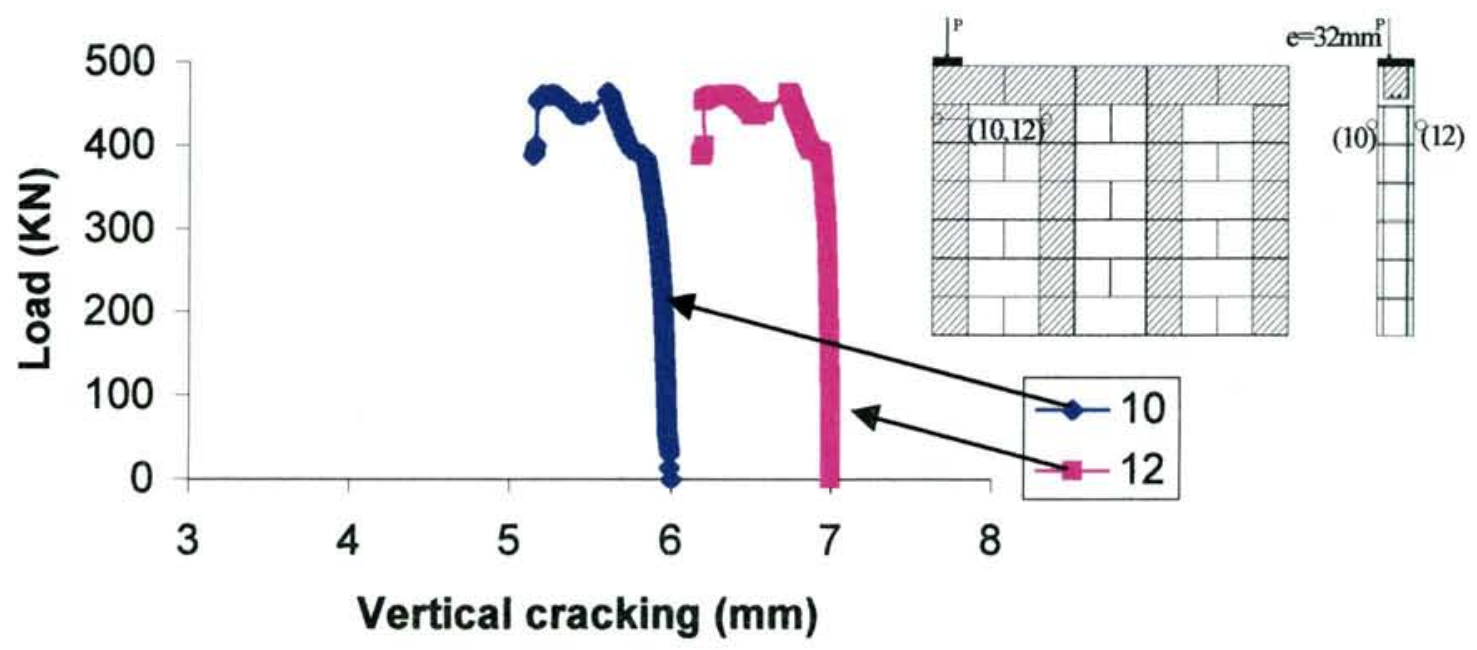

Fig. 6.35a---Load versus vertical cracking for 1E240E

\section{Load-Vertical displacement (1E240E2)}

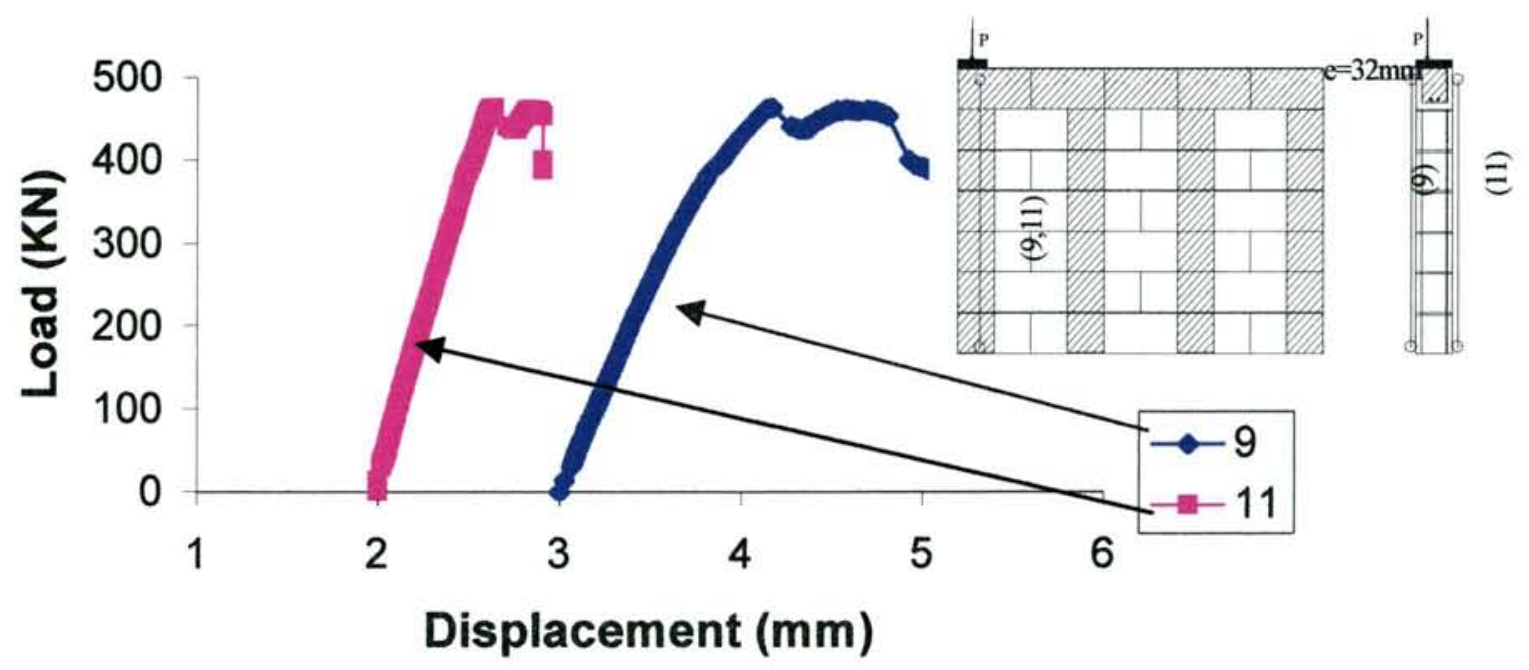

Fig. 6.35b---Load versus vertical displacement for 1E240E 


\section{Load-Vertical cracking (1E160E2)}

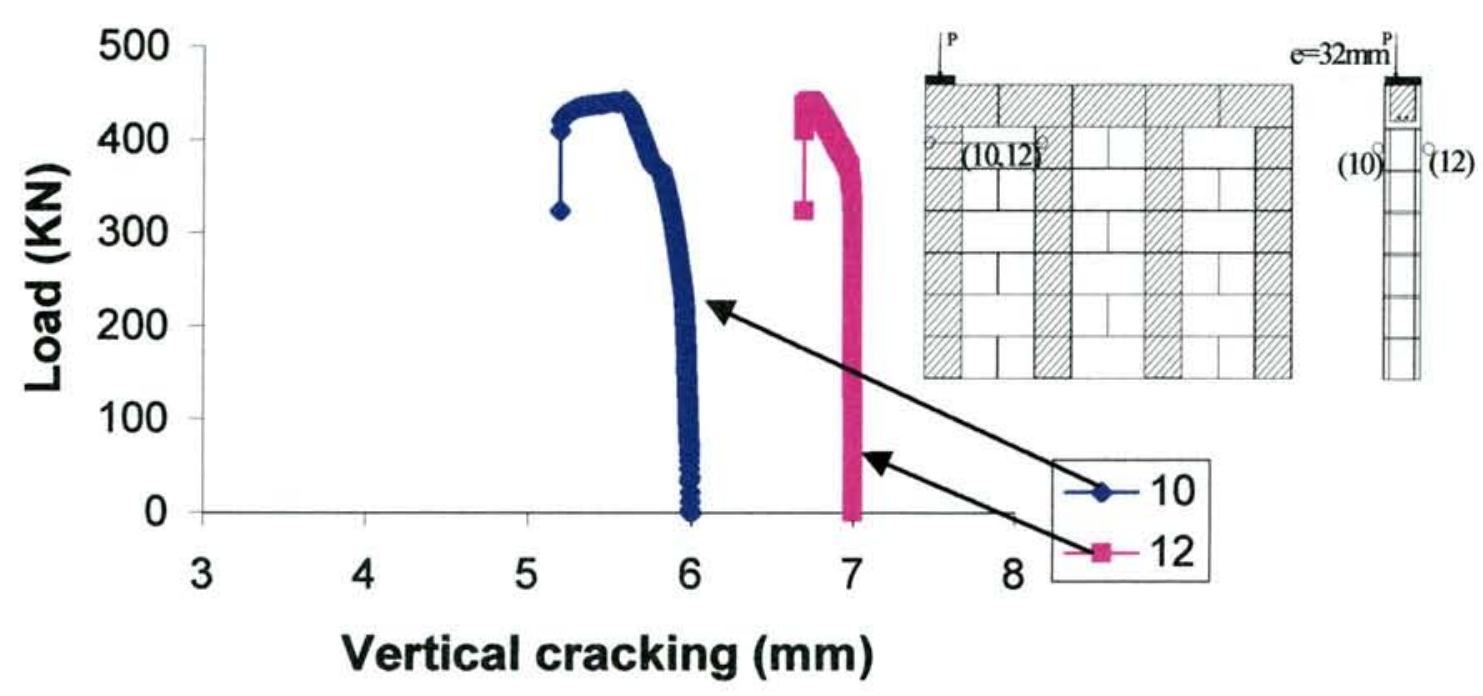

Fig. 6.36a---Load versus vertical cracking for $1 \mathrm{E} 160 \mathrm{E}$

\section{Load-Vertical displacement (1E160E2)}

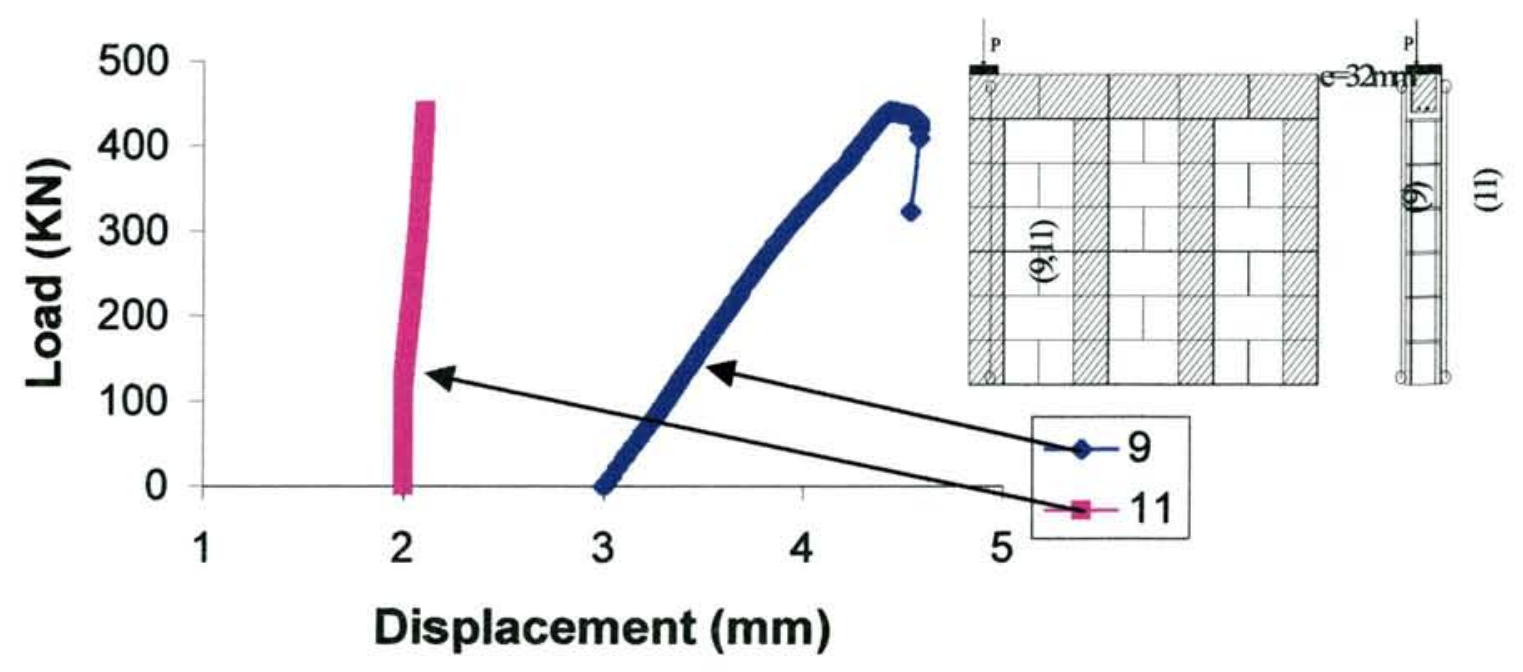

Fig. 6.36b---Load versus vertical displacement for 1E160E 


\section{Load-Vertical cracking (1E80E3)}

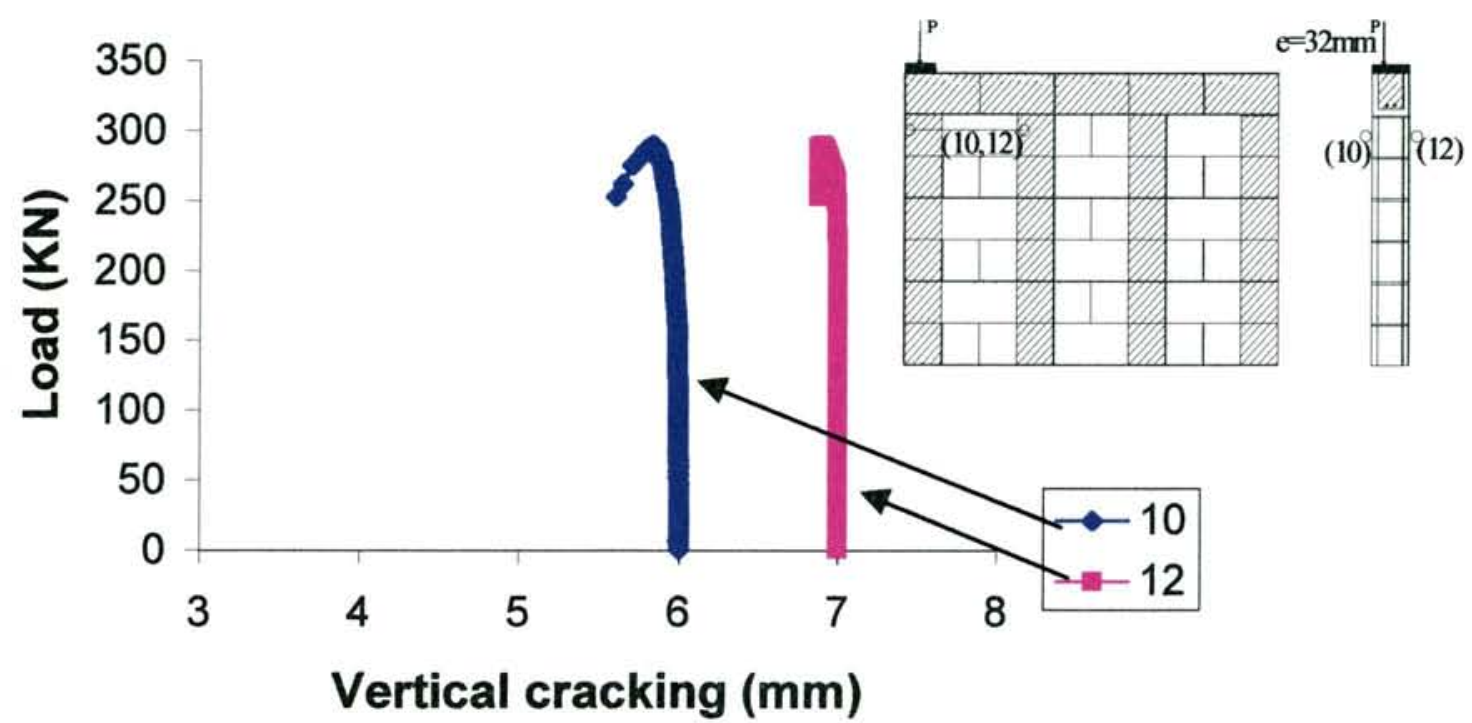

Fig. 6.37a---Load versus vertical cracking for 1E80E

\section{Load-Vertical displacement (1E80E3)}

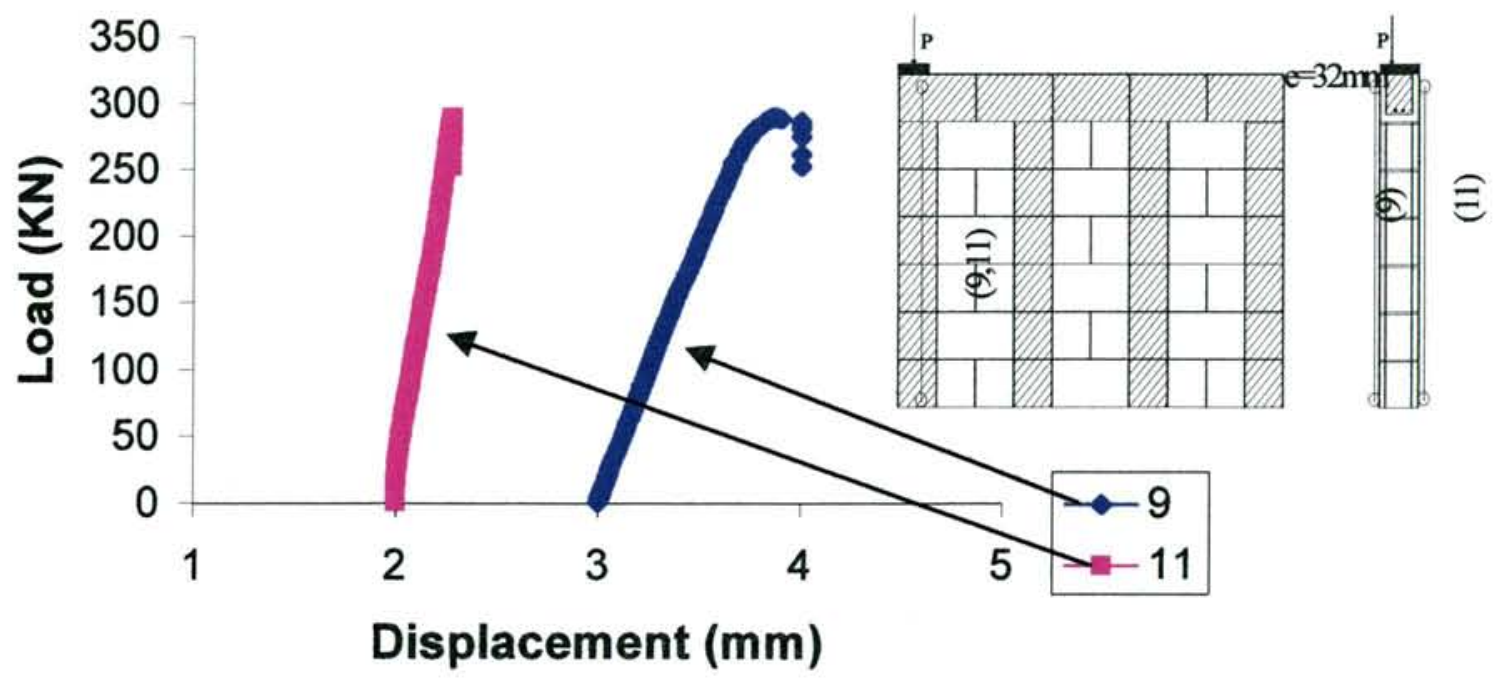

Fig. 6.37b---Load versus vertical displacement for 1E80E 


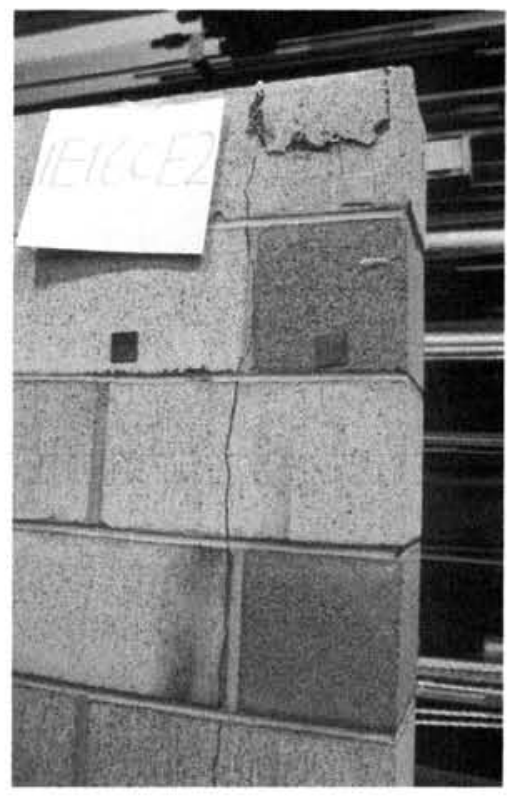

(a)

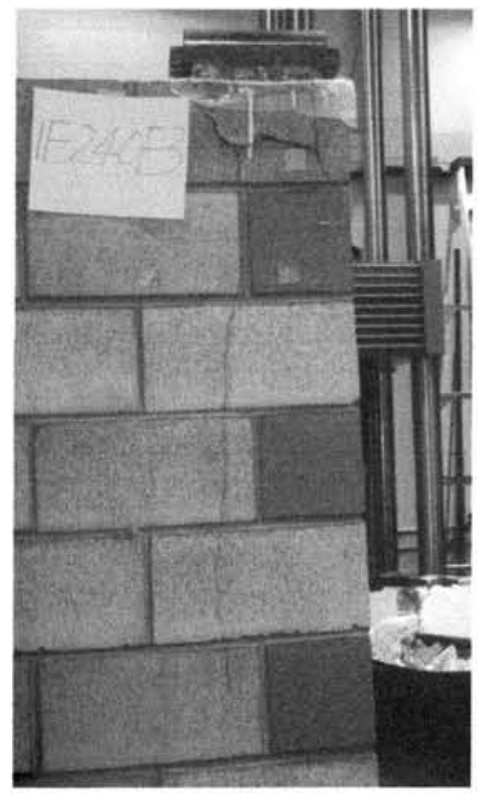

(b)

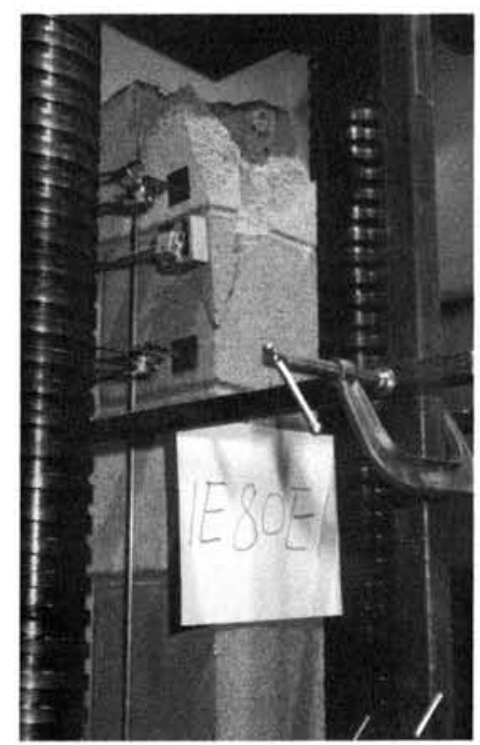

(c)

Fig. 6.38---Failure mode of wallette under eccentric concentrated load on end column $(\mathrm{e}=32 \mathrm{~mm}),(\mathrm{a})$ plate length $=160 \mathrm{~mm}$ (b) plate length $=240 \mathrm{~mm}$ (c) plate length $=80 \mathrm{~mm}$ 
At the larger eccentricity $(\mathrm{t} / 3)$, no web cracking formed in the hollow block units and almost no vertical cracking occurred (Fig. 6.39a and Fig. 6.40a). The vertical deformation on the heavily loaded side was larger than that on the lightly loaded side (Fig. 6.39b and Fig. 6.40b). Final failure was caused as before by the local spalling of the face-shell of the column under the loading plate on the heavily loaded side, separating from the grout as shown in Fig. 6.41.

\section{Load-Vertical cracking (2E240E3)}

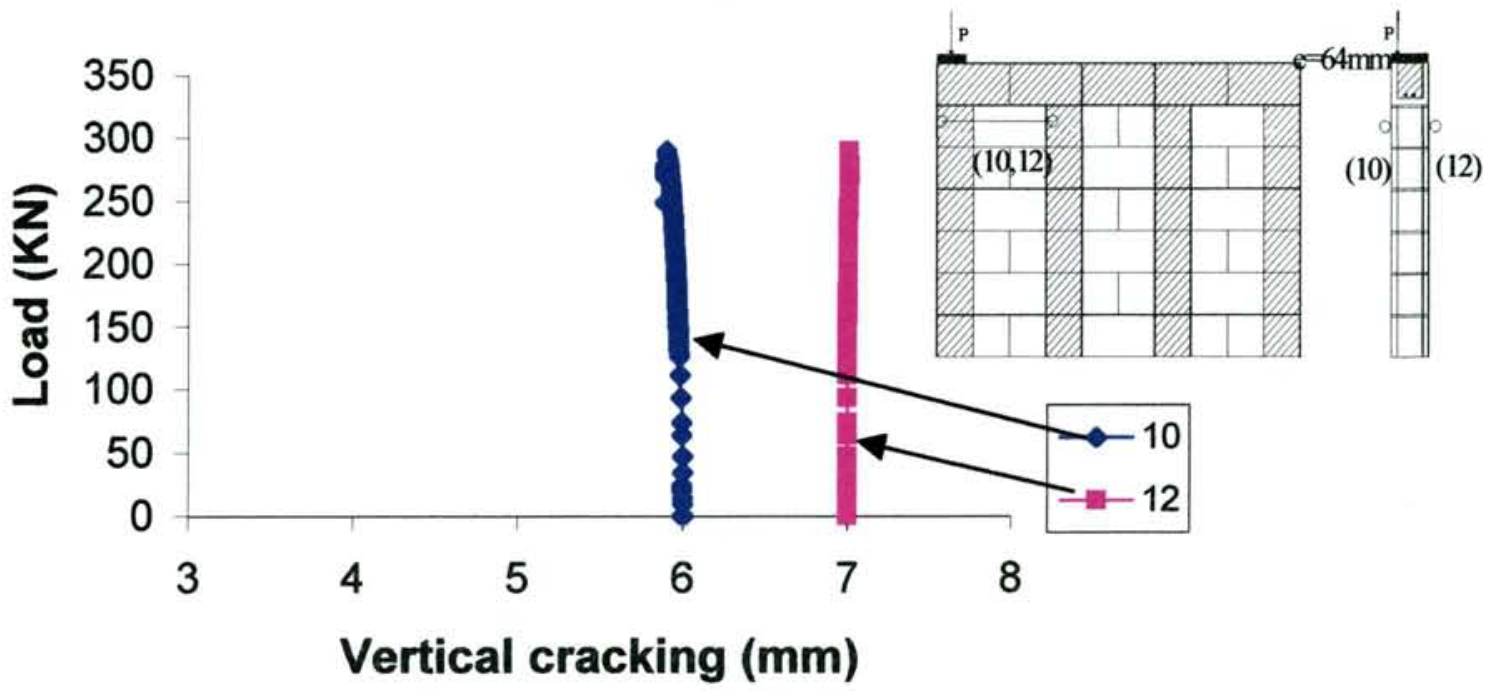

Fig. 6.39a---Load versus vertical cracking for 2E240E 


\section{Load-Vertical displacement (2E240E3)}

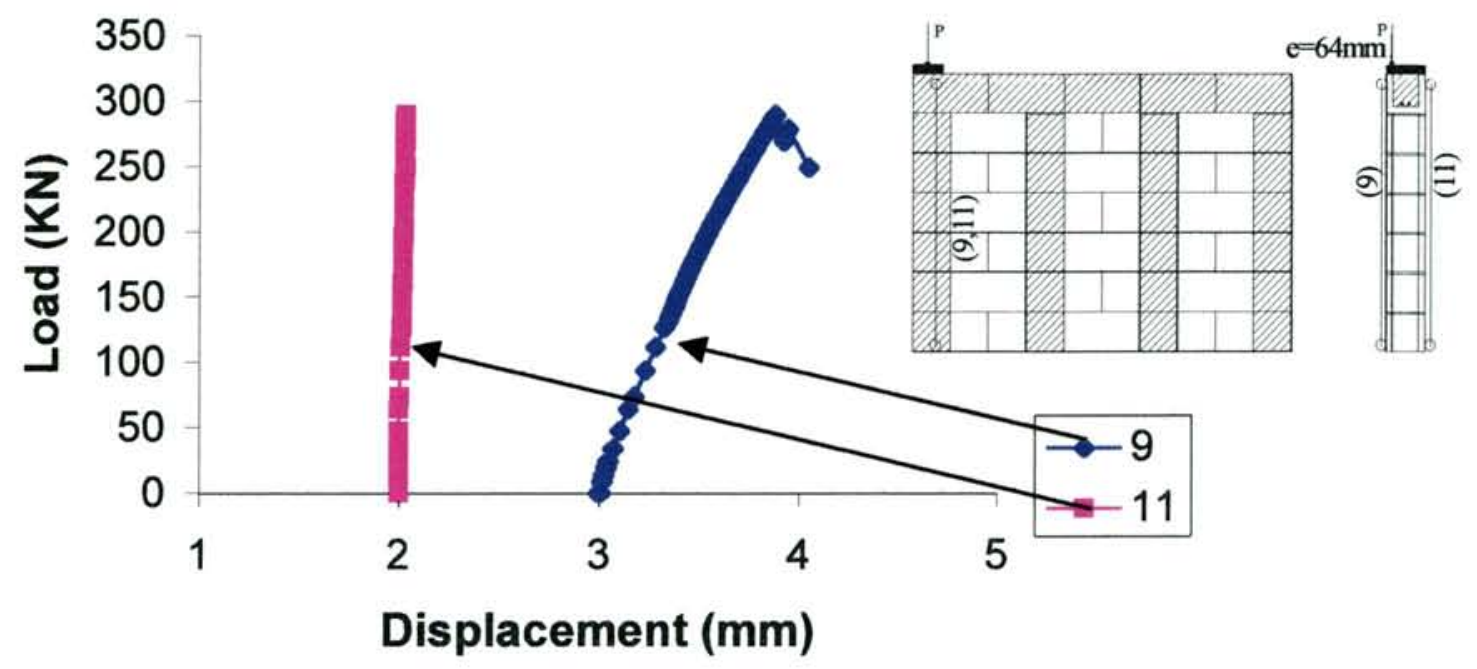

Fig. 6.39b---Load versus vertical displacement for 2E240E

Load-Vertical cracking (2E160E1)

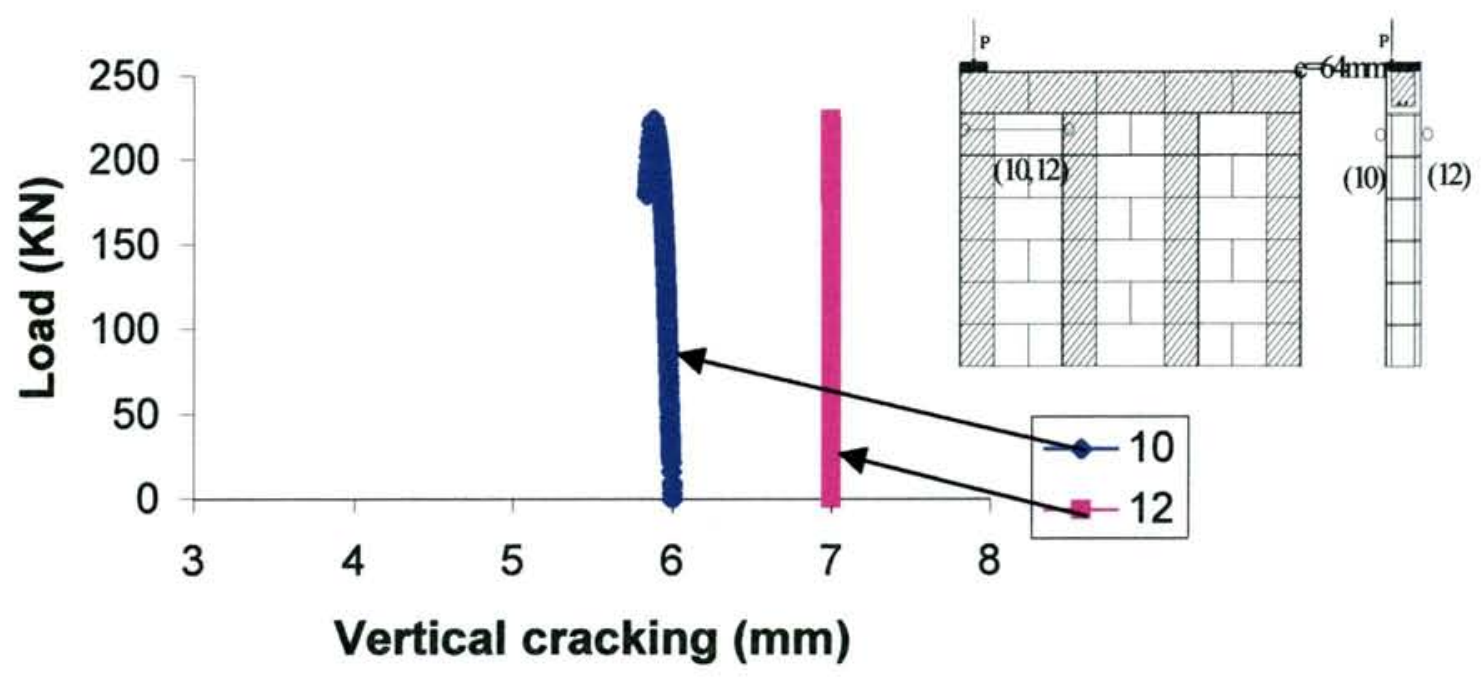

Fig. 6.40a---Load versus vertical cracking for 2E160E 


\section{Load-Vertical displacement (2E160E1)}

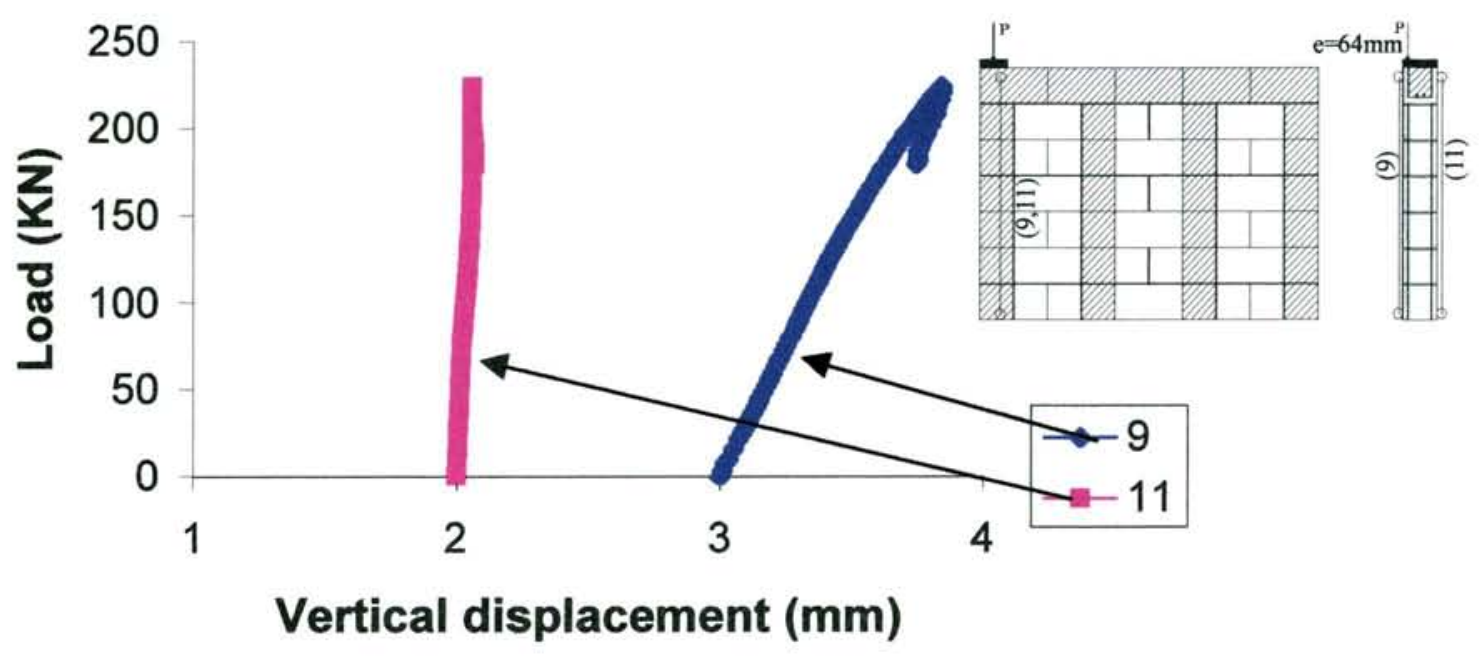

Fig. 6.40b---Load versus vertical displacement for 2E160E

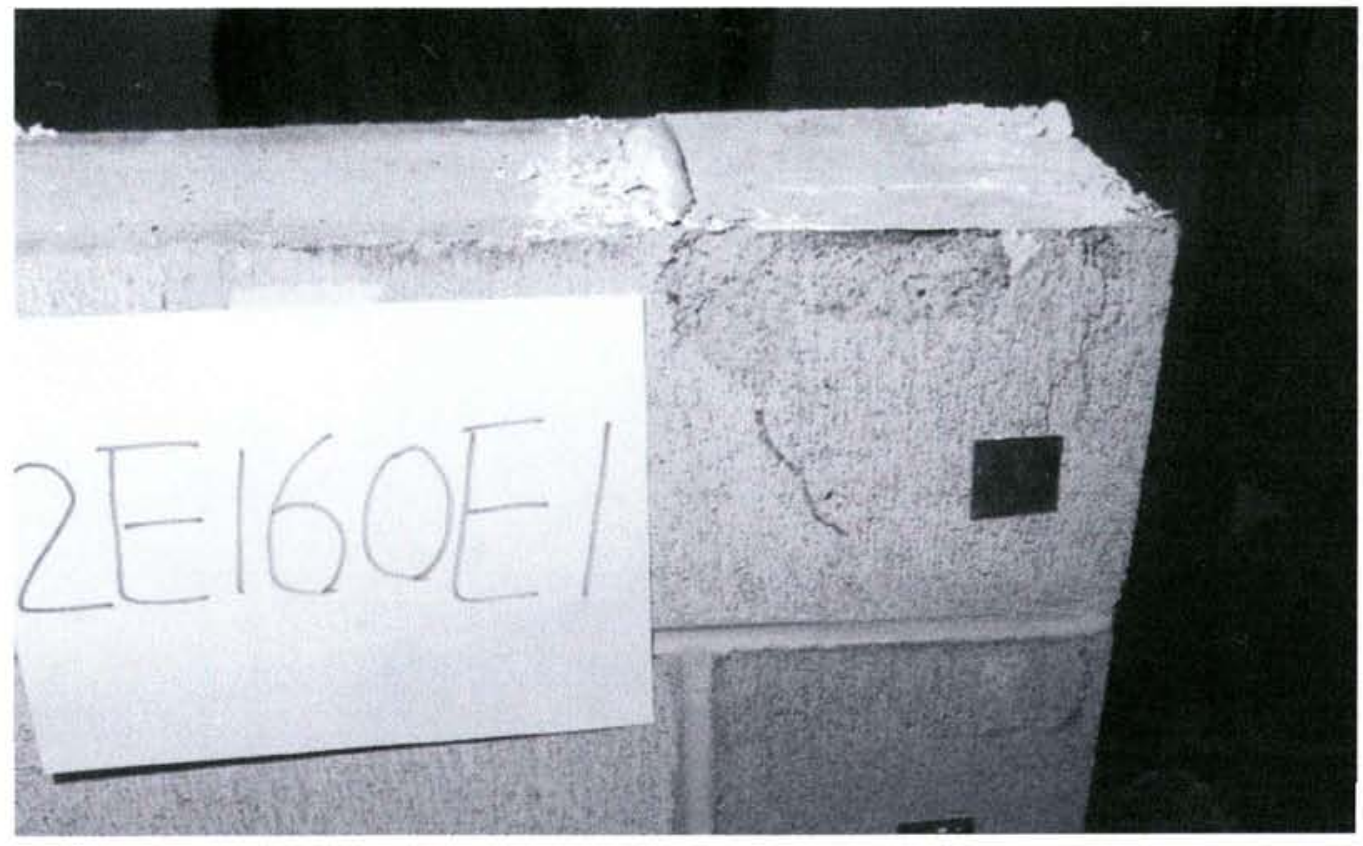

Fig. 6.41---Failure modes of wallette under eccentric concentrated load on end column $(\mathrm{e}=64 \mathrm{~mm}$, plate length $=160 \mathrm{~mm})$ 


\subsubsection{Concentrated loads on middle columns (Series 3)}

When the concentrated load was applied above a middle vertical column of grout, the failure mechanism of the wallettes was similar to that with load applied above the end column. The grout column had to separate from the hollow concrete masonry on both sides rather than one. Typical deformation readings are given in Fig. 6.42, Fig. 6.43, and Fig. 6.44 respectively for wallettes under concentric loading, eccentric loading with small eccentricity ( $t / 6)$ and eccentric loading with large eccentricity (t/3). Typical failure patterns are shown in Fig. 6.45. The results confirmed the prediction of the finite element models (chapter 5).

\subsubsection{Failure loads}

The ultimate strengths of the wallettes under concentrated load are presented in Table 6.2 (page 165), together with results from Page and Shrive (1990), where applicable.

As can be seen, when the load was applied concentrically on the bond beam above the hollow masonry, vertical columns of grout contributed to the ultimate capacities as they offered more constraint than hollow blockwork alone. The bond beam and grouted columns could also act partially as a frame within the masonry. However, as eccentricity increased, the benefit from the vertical columns of grout decreased. Moreover, when the eccentricity was $t / 3$, the grout appeared not to provide any strength increase as failure occurred by local face-shell spalling beneath the loading plate. 


\section{Load-Vertical cracking (C160C2)}

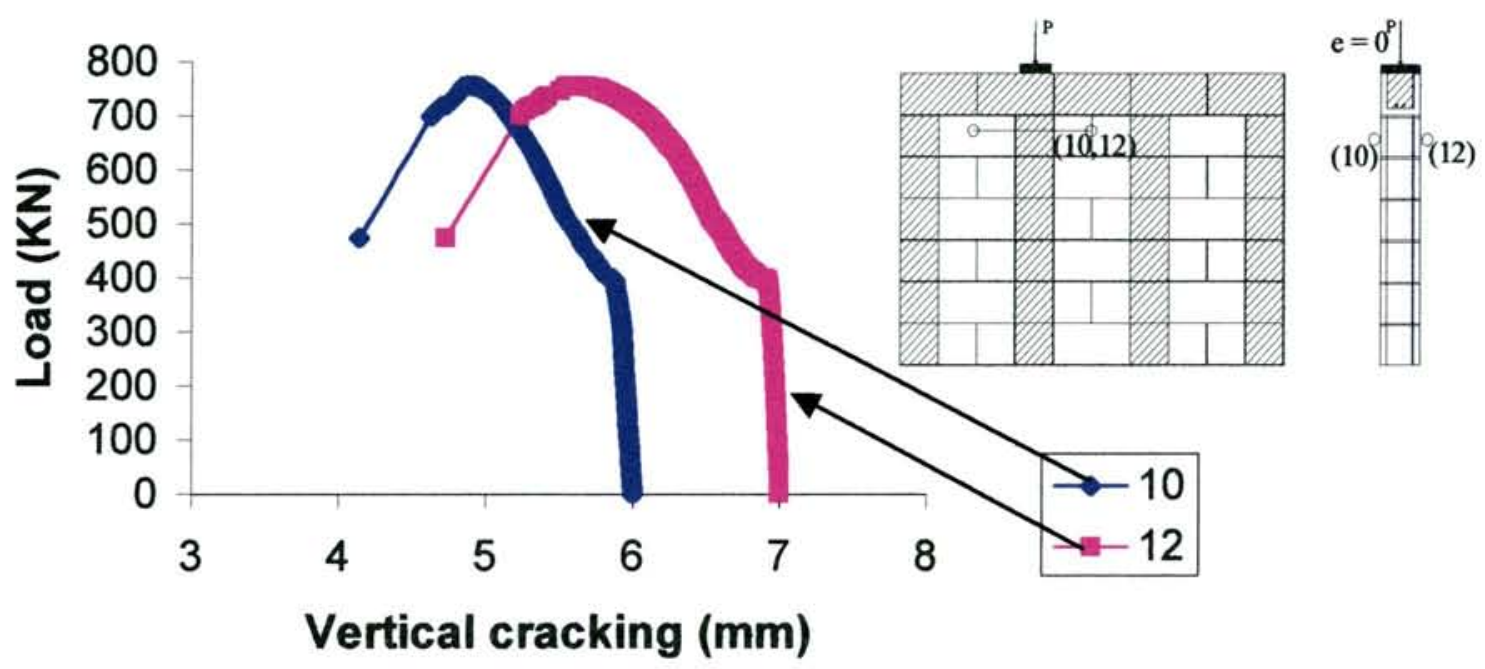

Fig. 6.42a---Load versus vertical (inclined) cracking for C160C

\section{Load -Vertical displacement (C160C2)}

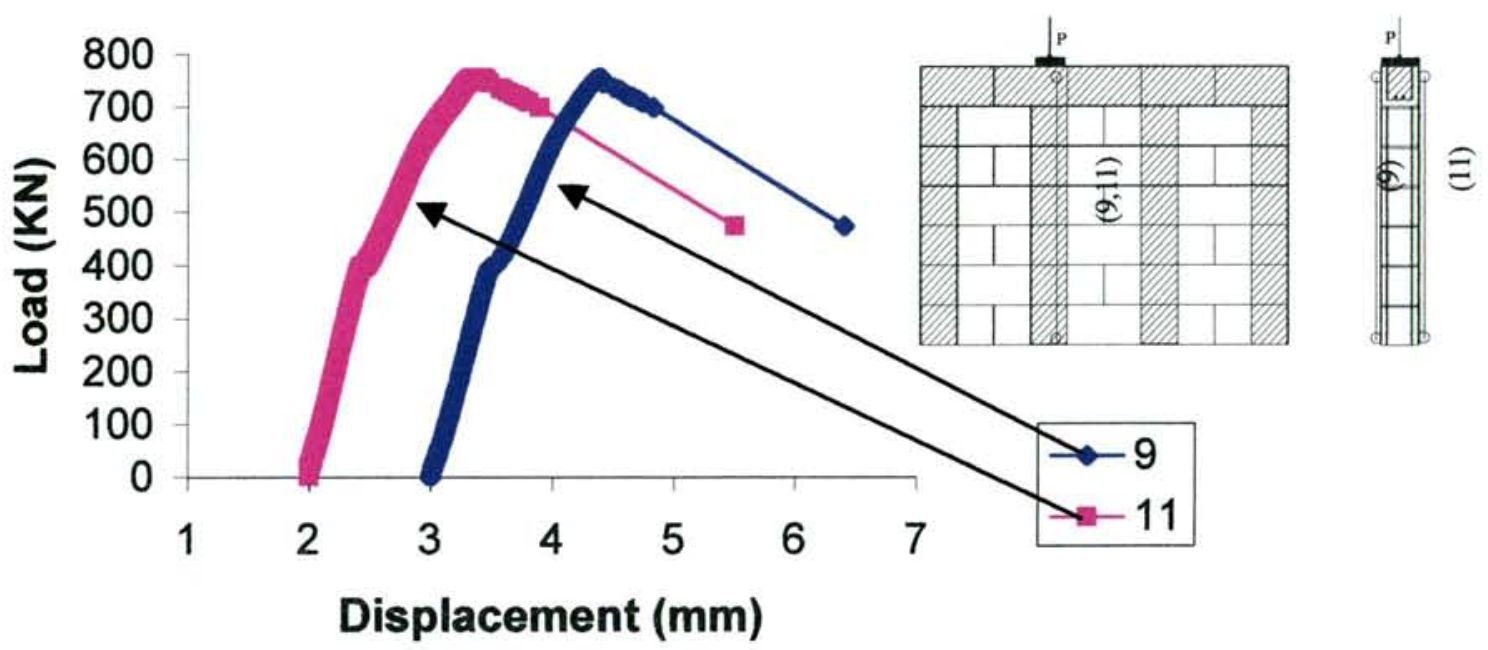

Fig. 6.42b---Load versus vertical displacement for $\mathrm{C} 160 \mathrm{C}$ 


\section{Load-Web cracking (C160C2)}

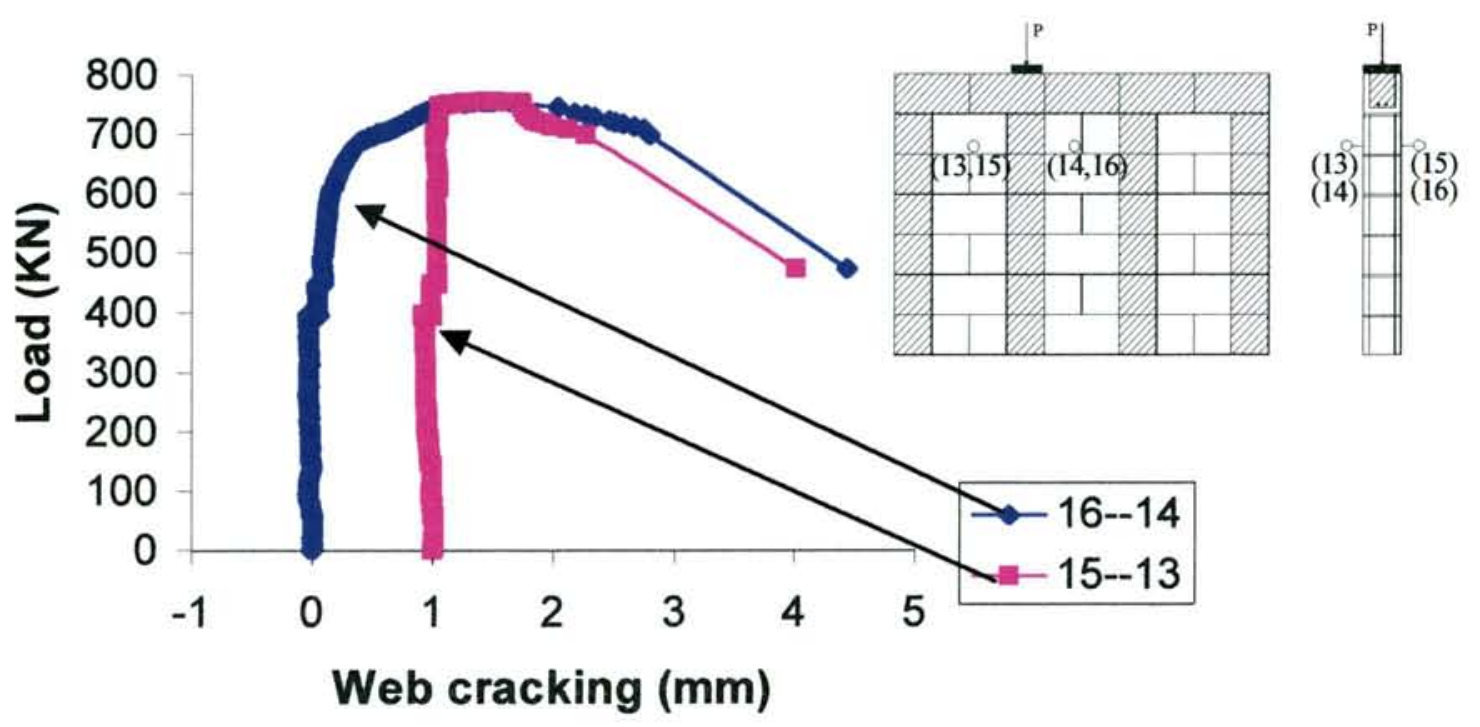

Fig. 6.42c---Load versus web cracking in the hollow blocks for C160C

\section{Load-Dilation (C160C2)}

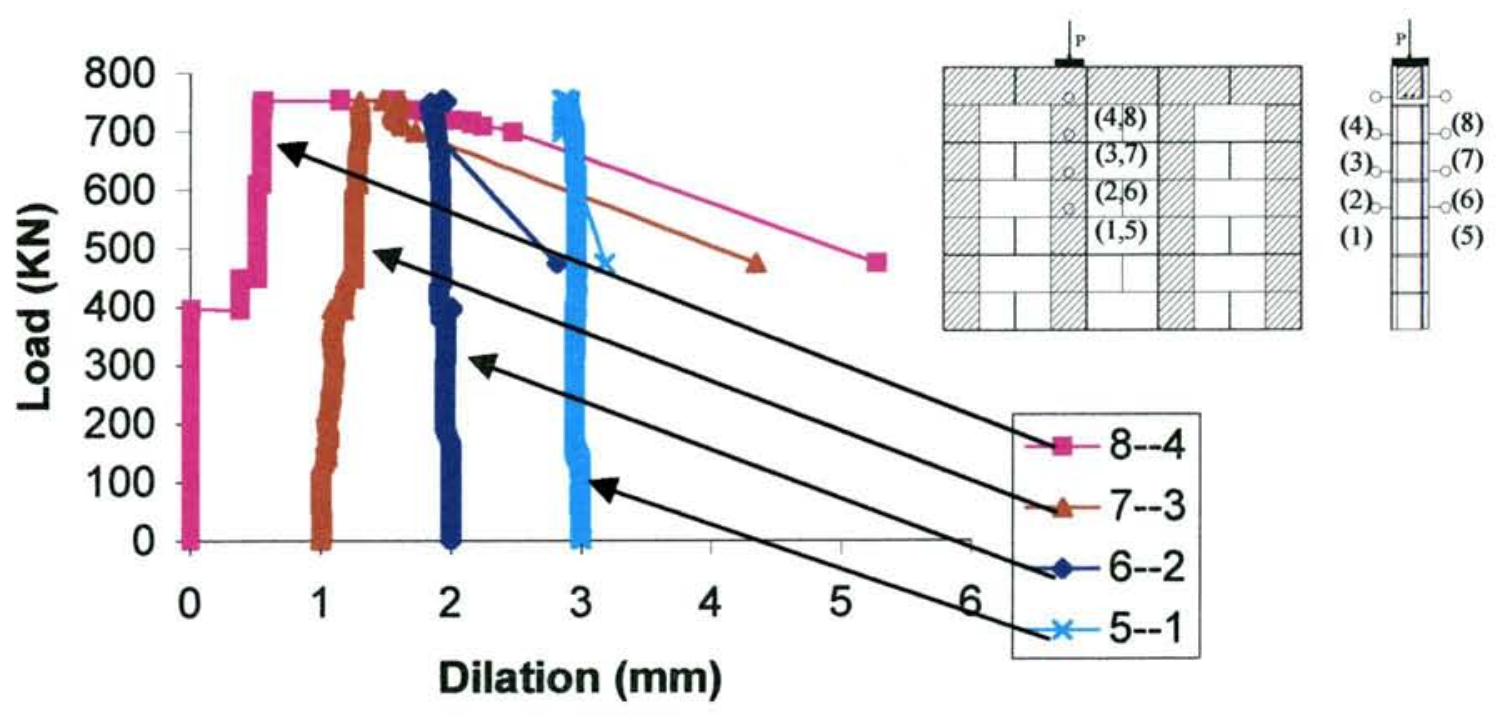

Fig. 6.42d---Load versus lateral dilation of column for C160C 


\section{Load-Vertical cracking (1E160C3)}

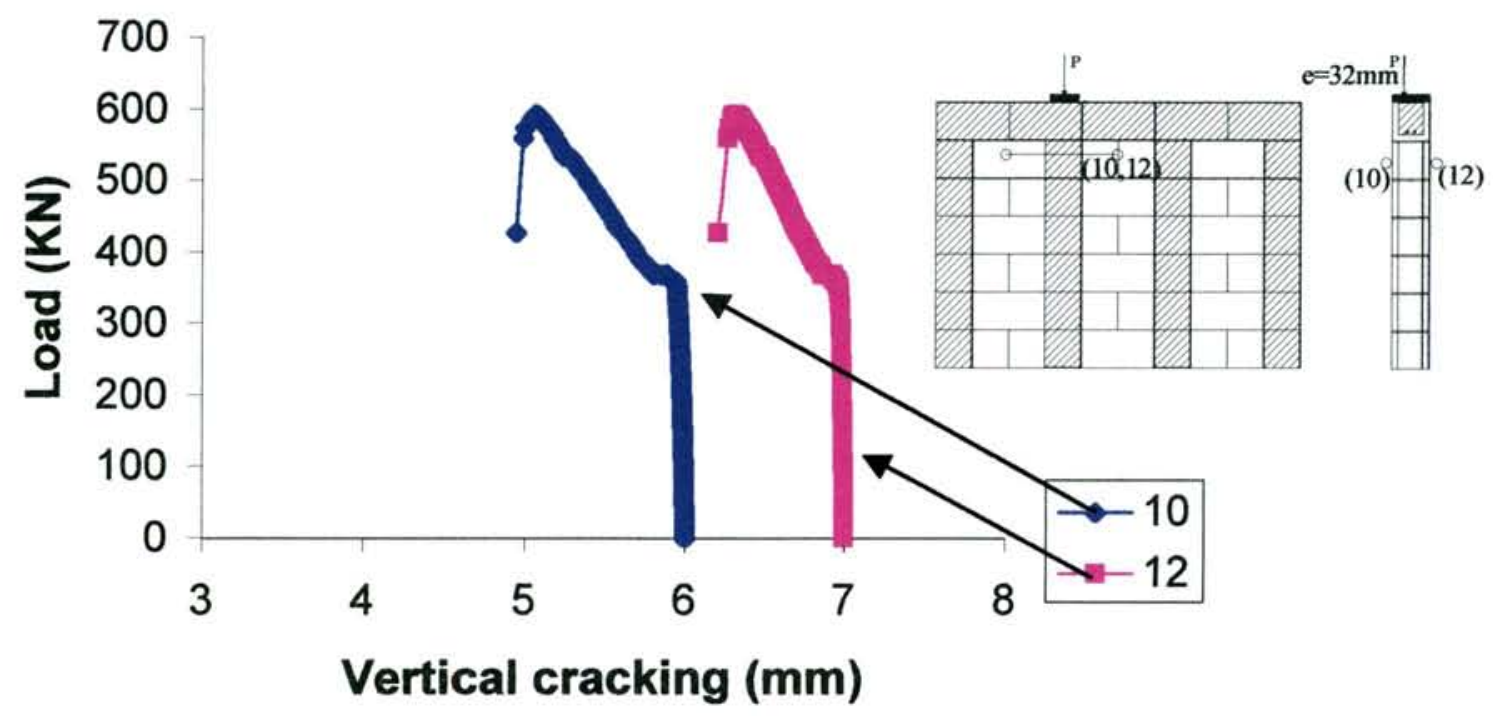

Fig. 6.43a---Load versus vertical (inclined) cracking for 1E160C

\section{Load-Vertical displacement (1E160C3)}

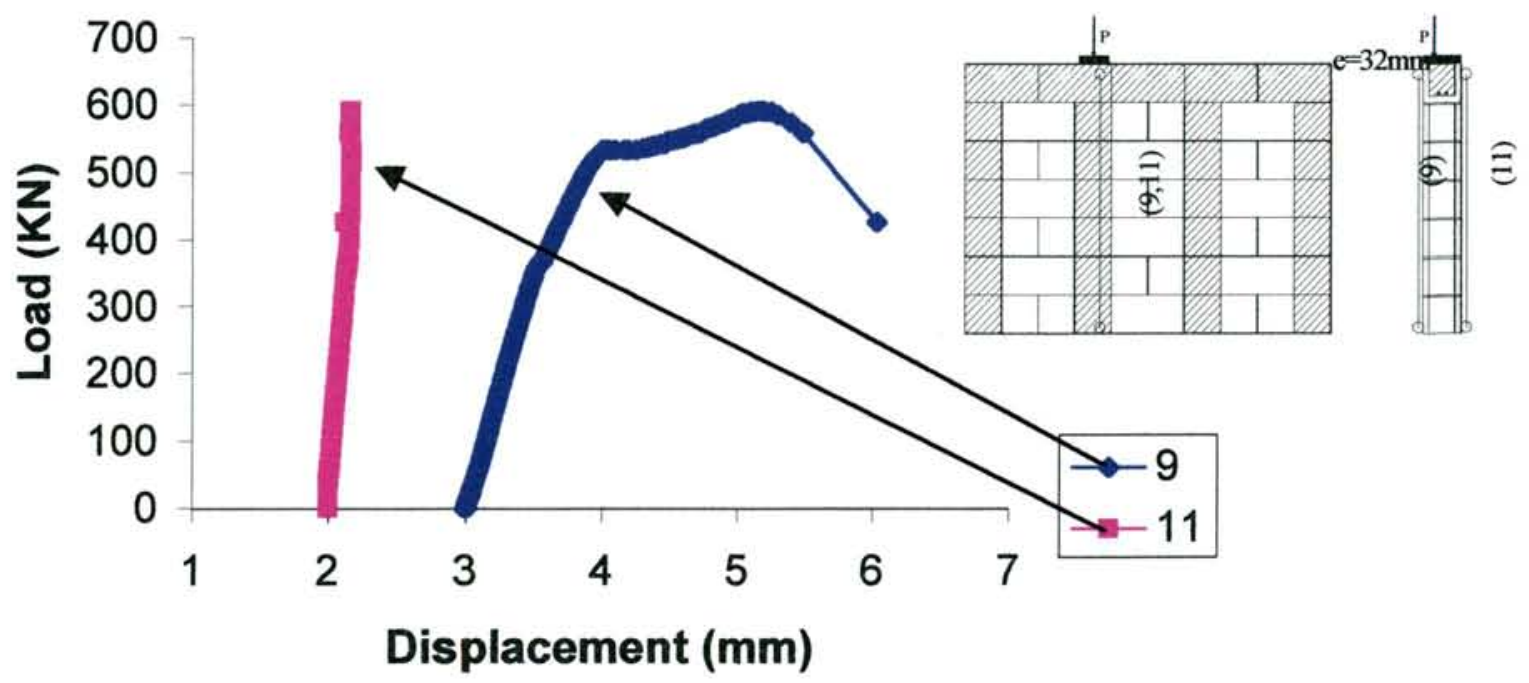

Fig. 6.43b---Load versus vertical displacement for 1E160C 


\section{Load-Vertical cracking (2E160C1)}

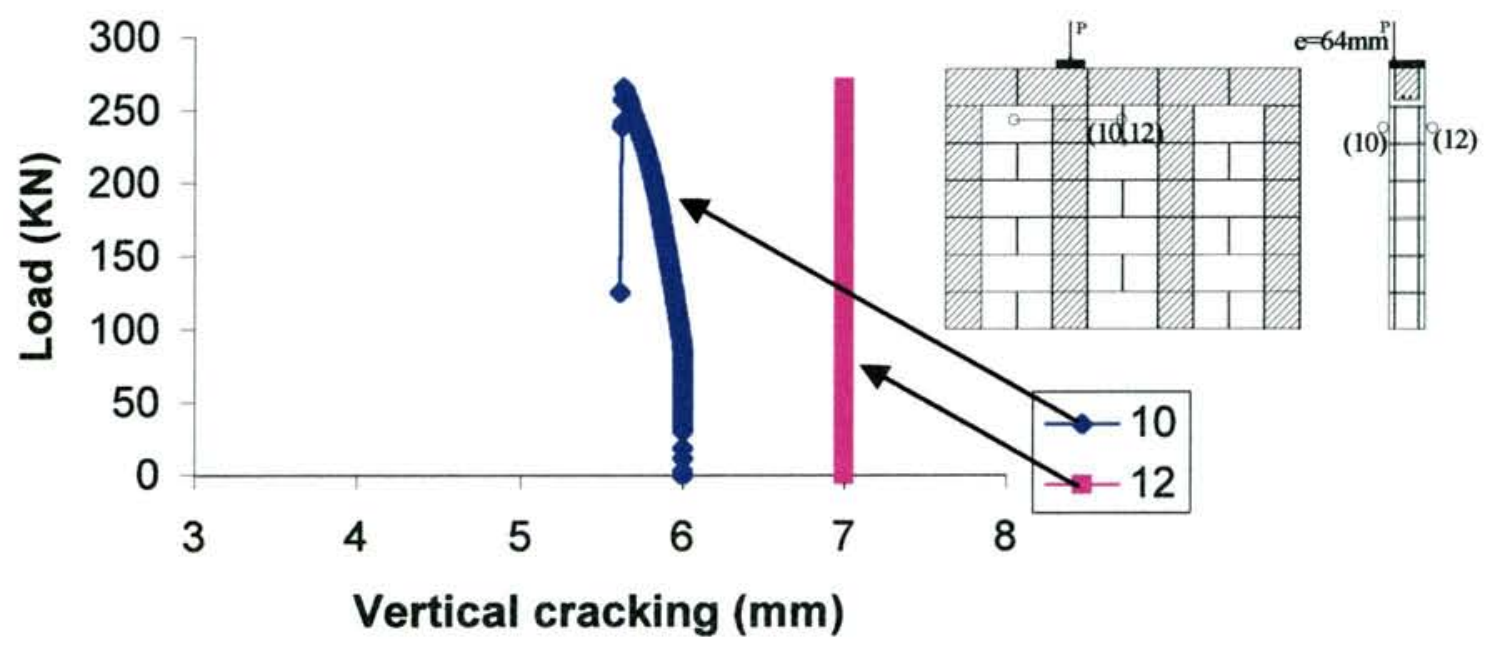

Fig. 6.44a---Load versus vertical (inclined) cracking for 2E160C

\section{Load-Vertical displacement (2E160C1)}

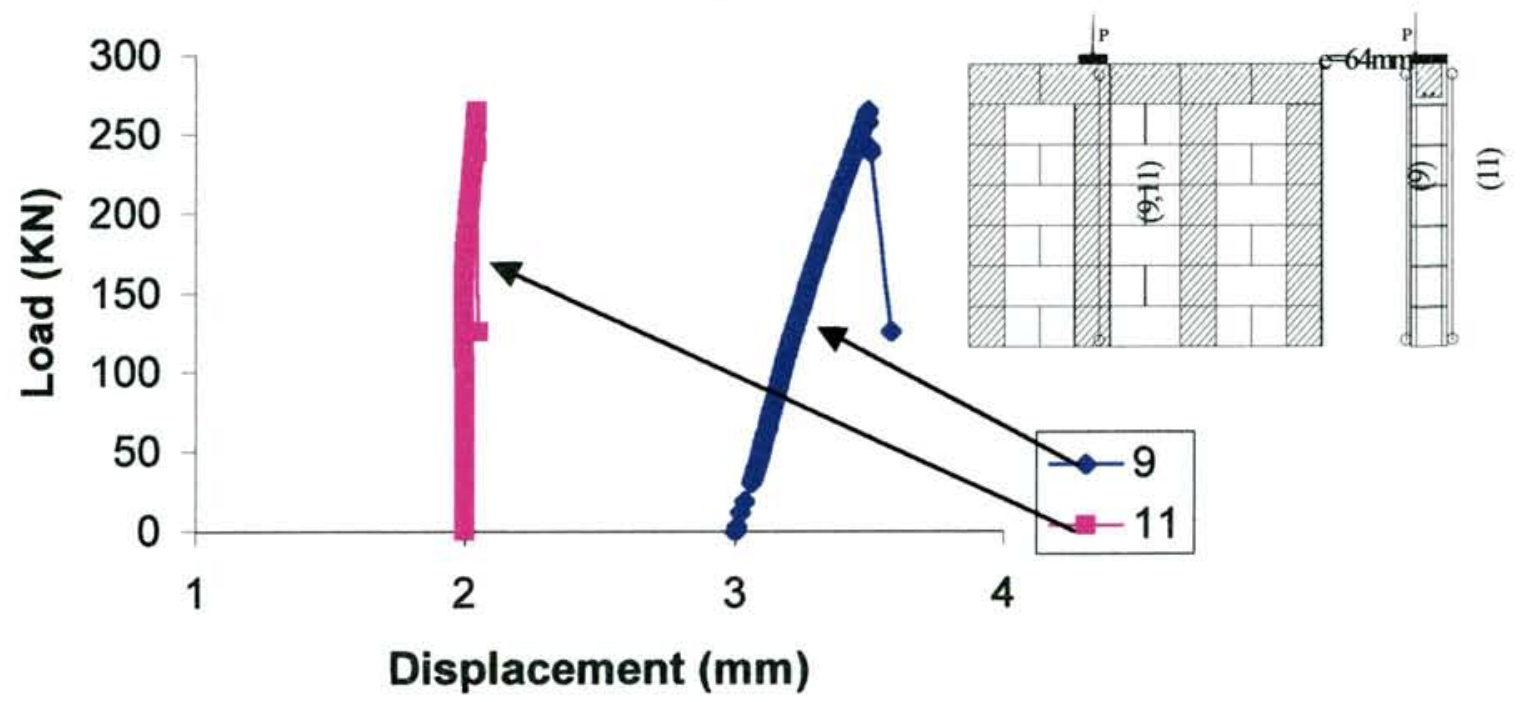

Fig. 6.44b---Load versus vertical displacement for 2E160C 


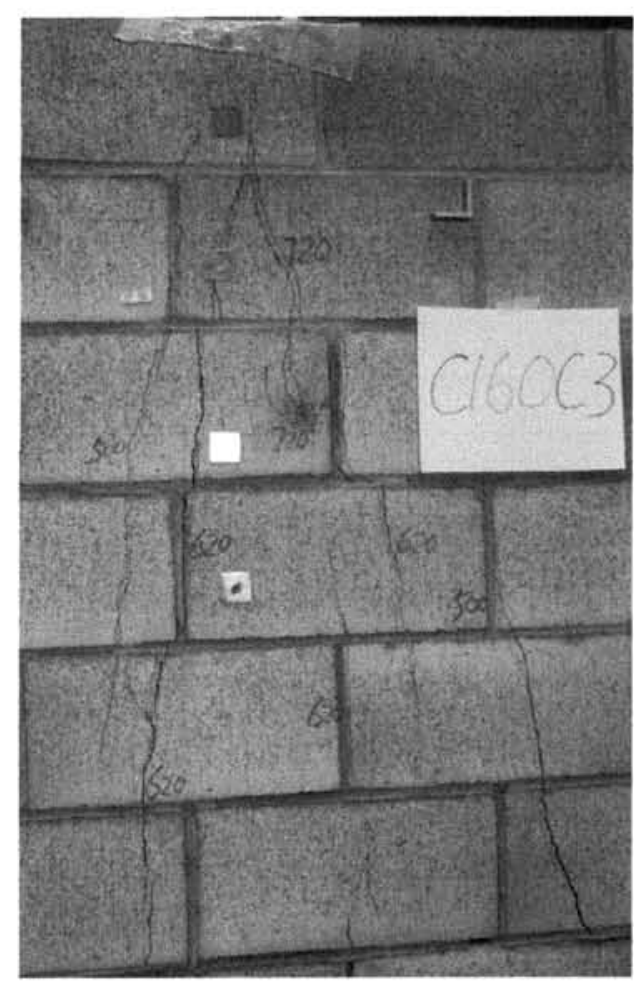

(a)

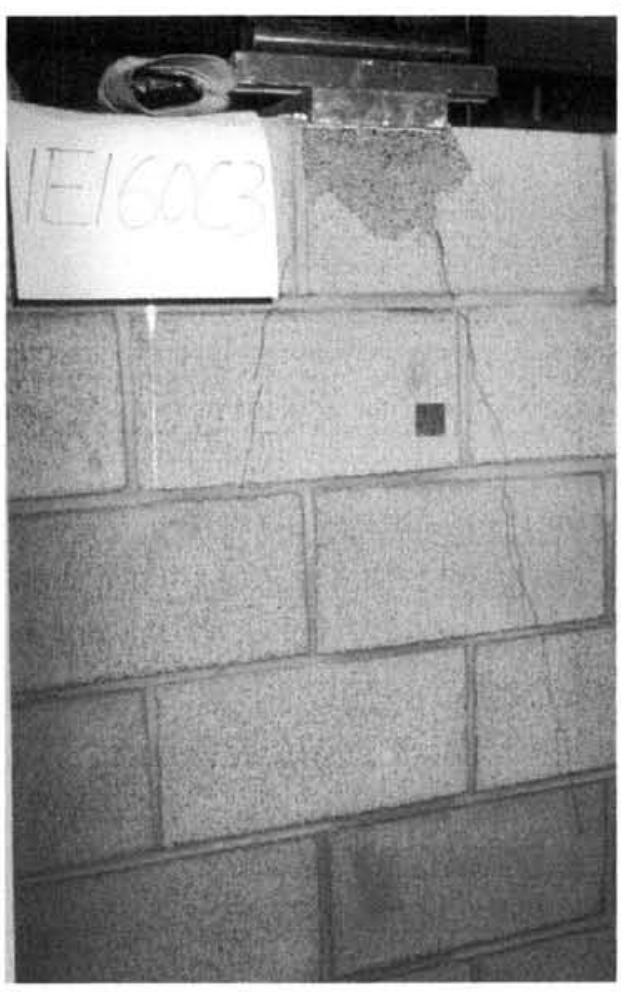

(b)

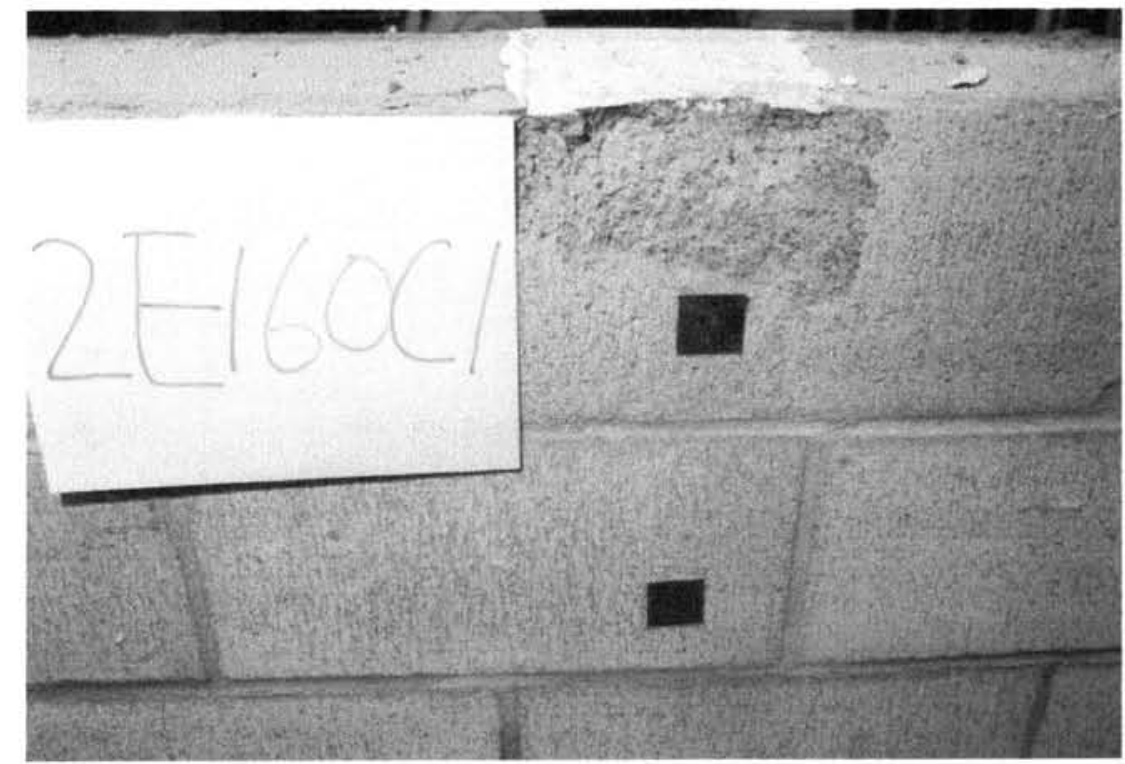

(c)

Fig. 6.45---Failure modes of wallette under concentrated load above middle columns

(a) concentric, (b) eccentric, $\mathrm{e}=32 \mathrm{~mm}$, (c) eccentric, $\mathrm{e}=64 \mathrm{~mm}$ 
When the concentrated load was applied above the column of grout, the ultimate capacity is increased marginally compared with the results of single column of grout under compression (Khalaf et al. 1993). Only a little load is spread into the surrounding hollow concrete masonry. The ultimate strength when the load was applied above a middle column was higher than that when the load was above an end column. As the eccentricity was increased, the ultimate strength decreased.

For concentrated loads applied on the bond beam above hollow masonry, the strength reduction with increasing eccentricity, normalized to the concentric load capacity, is depicted in Fig. 6.46. The lower bound (Equation [4.1]) proposed for estimating the strength of plain hollow concrete masonry (no reinforcement or grout), subjected to eccentric concentrated load (chapter 4) is also reasonable for partially grouted concrete blockwork subjected to concentrated load with small eccentricity. However, at larger eccentricities $(e=t / 3)$, the equation may not be conservative, because Equation [4.1] is based on the normal sequence of failure of face-shell bedded hollow masonry: at larger eccentricities, the mode of failure changes to one more like solid masonry. Equation [6.1] would provide a safe estimate for all eccentricities.

$$
P / P_{0}=1-\frac{e}{(t / 2)}
$$

$\mathrm{P}_{0}$ is the ultimate strength of masonry under concentric concentrated load, $\mathrm{P}$ is the ultimate strength under eccentric concentrated load, e is the out-of-plane eccentricity, and $\mathrm{t}$ is the actual masonry wall thickness. 


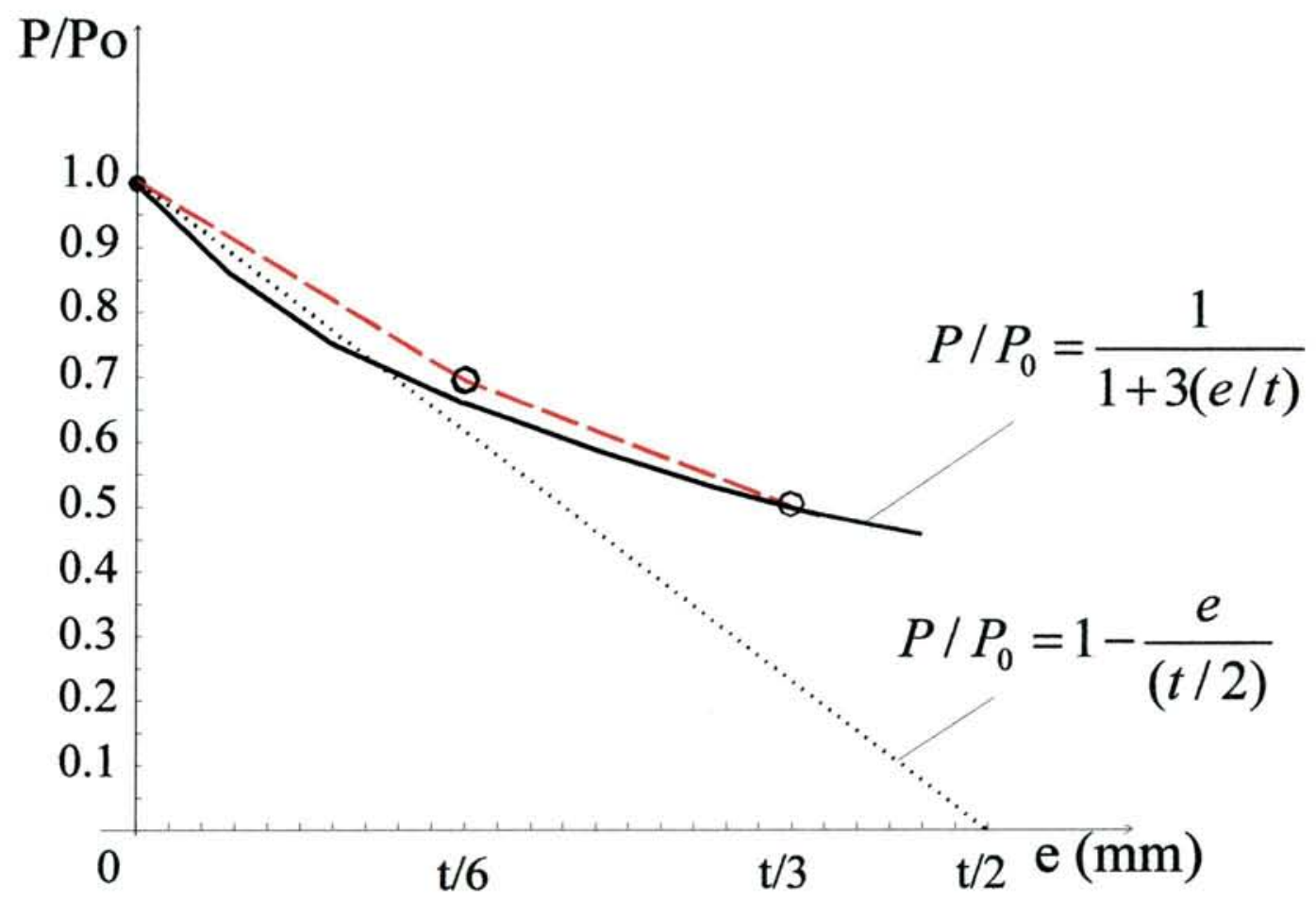

Fig. 6.46---Ultimate strength variation with increasing eccentricity for partially grouted wallettes with concentrated load on the bond beam above the hollow masonry

When the concentrated load was applied above the column of grout, the normalized strength variation with increasing eccentricity is shown in Fig. 6.47. Equation [6.1] is clearly a more suitable lower bound for these results. 


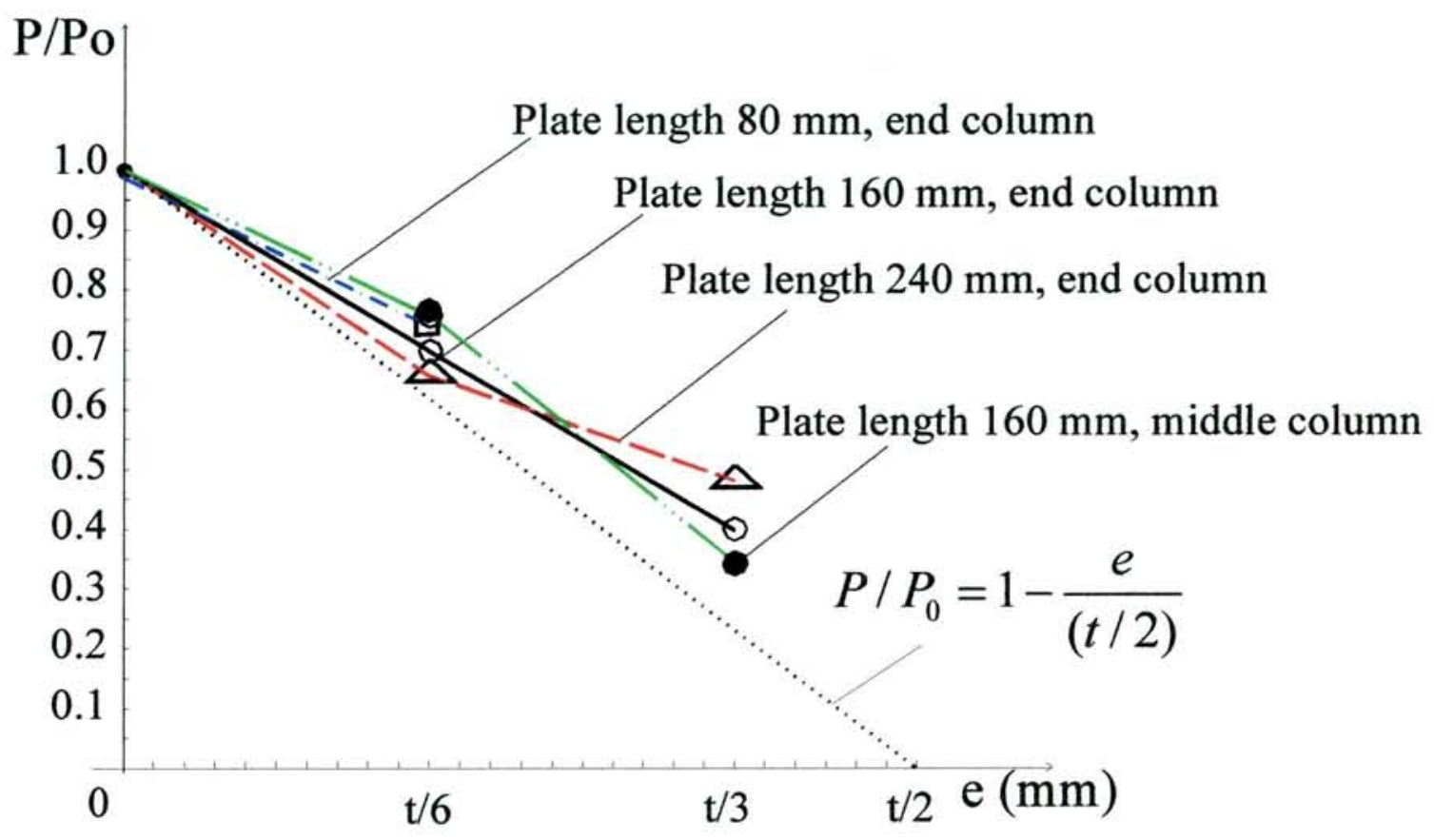

Fig. 6.47---Ultimate strength variation with increasing eccentricity for partially grouted wallettes with the concentrated load applied above a column of grout

\subsubsection{Dispersion of concentrated load through the bond beam}

To obtain an estimate of the angle of load dispersion $\theta$ for partially grouted hollow concrete masonry walls through the bond beam, the procedure shown in Fig. 6.48 was adopted. Such dispersion angles are required to produce an average stress intensity on the top of the face-shells of the top hollow masonry course equal to the uniaxial wall strength. The average uniaxial wall strength $\mathrm{f}_{\mathrm{m}}$ ' was $15.1 \mathrm{MPa}$ (from prism tests on the hollow masonry), and the column strength $\mathrm{f}_{\mathrm{mc}}$ ' was $13.8 \mathrm{MPa}$ (from tests on grouted prisms). The strength from the vertical \#10 rebar in the column was neglected. In design, 
the use of characteristic strength would therefore provide a conservative estimate of the bearing capacity.

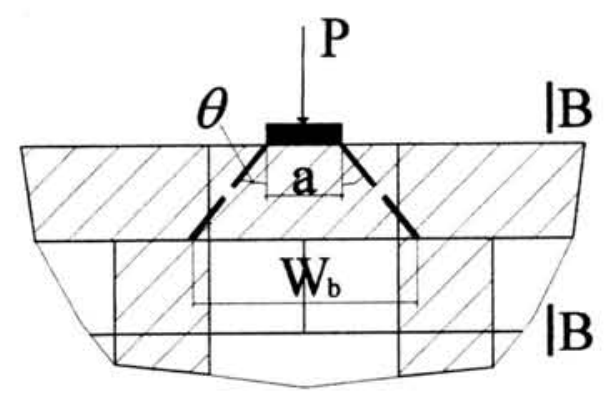

Stress at A-A:

$$
\begin{aligned}
& \frac{P \times 10^{3}}{70 \times W_{b}+\left(W_{b}-400\right) \times 120 \times f_{m c}^{\prime} / f_{m}^{\prime}}=f_{m}^{\prime} \\
& \theta=\tan ^{-1}\left(\frac{W_{b}-a}{2 D}\right)
\end{aligned}
$$

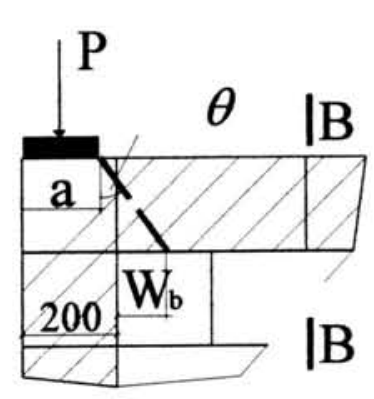

Stress at A-A:

$$
\begin{aligned}
& \frac{P \times 10^{3}}{70 \times W_{b}+200 \times 190 \times f_{m c}^{\prime} / f_{m}^{\prime}}=f_{m}^{\prime} \\
& \theta=\tan ^{-1}\left(\frac{W_{b}+(200-a)}{D}\right)
\end{aligned}
$$

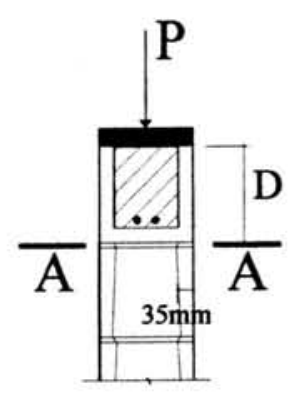

$\underline{\mathrm{B}-\mathrm{B}}$

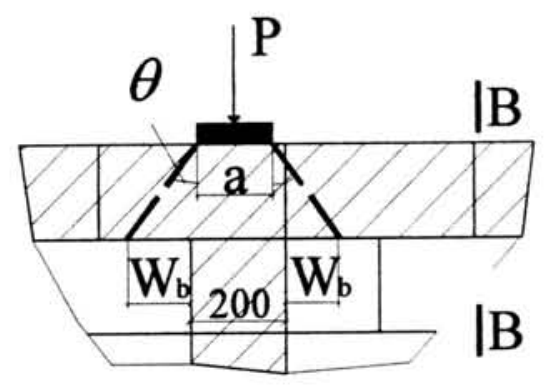

Stress at A-A:

$$
\begin{aligned}
& \frac{P \times 10^{3}}{70 \times W_{b} \times 2+200 \times 190 \times f_{m c}^{\prime} / f_{m}^{\prime}}=f_{m}^{\prime} \\
& \theta=\tan ^{-1}\left(\frac{W_{b}+(200-a) / 2}{D}\right)
\end{aligned}
$$

Fig. 6.48---Dispersion of concentrated load through the bond beam in partially grouted hollow concrete masonry walls 
The values of $\theta$ are summarized in Table 6.3. It can be seen that for walls with vertical columns, the load was dispersed into the vertical column when the load was applied on the bond beam above the hollow masonry. When the concentrated load was applied above an end vertical column, the dispersion angle was very small, especially when the loading plate was longer than the column width. When the concentrated load was above a middle vertical column, the value of $\theta$ was calculated to be $34^{\circ}$, a little larger than that with the concentrated load applied above end column $\left(30^{\circ}\right)$. All these angles provide less dispersion than the usually assumed $45^{\circ}$.

Table 6.3 Dispersion of concentrated load through the bond beam in partially grouted hollow concrete masonry walls

\begin{tabular}{cccccc}
\hline Load location & $\mathrm{D}(\mathrm{mm})$ & $\begin{array}{c}\text { Plate length a } \\
(\mathrm{mm})\end{array}$ & $\begin{array}{c}\text { Failure load } \mathrm{P}_{\mathrm{u}} \\
(\mathrm{KN})\end{array}$ & $\mathrm{W}_{\mathrm{b}}(\mathrm{mm})$ & $\theta\left(^{\circ}\right)$ \\
\hline On bond beam & 200 & 160 & 496 & 427 & 34 \\
On bond beam & 200 & 240 & 549 & 447 & 27 \\
On end column & 200 & 80 & 352 & 0 & N.A. \\
On end column & 200 & 160 & 606 & 77 & 30 \\
On end column & 200 & 240 & 634 & 103 & 17 \\
On middle column & 200 & 160 & 765 & 113 & 34 \\
\hline
\end{tabular}

\subsection{Summary}

An experimental programme was performed to study the behaviour of partially grouted hollow concrete masonry wallettes with bond beams, subjected to concentrated loads. 
Some sample tests (block units and prism tests) were also performed. The summary and conclusions are as follows:

\subsubsection{Sample tests}

Under compression, failure of hollow block units with "knock-out" webs was abrupt with a sudden web-splitting/breaking and face-shell spalling at almost the same time. While for standard block units, failure was by web splitting first and followed by face-shell spalling. The strength of block units with "knock-out" webs was about $10 \%$ lower than that of standard block units, due to the weak webs but with end constraint from the steel loading plates.

The failure modes of hollow prisms built of standard hollow block units were web splitting first, followed by face-shell spalling and/or mortar crushing. The results were consistent with those from other studies and confirmed the results of the non-linear finite element models described in Chapter 4. The failure modes of hollow prisms built of units with "knock-out" webs were very abrupt, with sudden web splitting/breaking and faceshell spalling. The strength of hollow prisms with "knock-out" webs was about $26 \%$ lower than that built of standard units, due to the weak webs and the weak constraint from the end steel loading plates.

For grouted prisms, the failure modes were almost the same whether built with standard block units or built with units with "knock-out" webs: tensile splitting first in the hollow block units, followed by vertical cracking in the grout like normal concrete specimen 
under compressive test. The "knock-out" webs seem not to affect the compressive strength of grouted prisms significantly.

\subsubsection{Wallette tests}

Three failure modes were observed: (1) hollow block web splitting, followed by faceshell spalling and/or mortar crushing; (2) local spalling beneath the loading plate; (3) vertical cracking followed by column crushing.

When the concentrated load was applied on the bond beam above hollow masonry, wallettes failed in a manner similar to plain hollow concrete masonry walls with no reinforcement. Under concentric loading and eccentric loading with small eccentricity, wallettes failed consistently by local web-splitting, vertical cracking in line with the load, and cracking in the face-shells beside the vertical columns of grout. When the eccentricity was increased to $t / 3$, failure occurred by local face-shell spalling beneath the loading plate on the heavily loaded side.

Under concentric loading, the ultimate strengths of partially grouted wallettes were higher than plain masonry. However, as the load eccentricity was increased, the benefit from the vertical columns decreased. When e was $t / 3$, failure was dominated by local face-shell spalling beneath the loading plate, with the vertical columns of grout offering no increase in capacity.

When the concentrated load was applied above a column of grout in partially grouted hollow masonry walls, the failure mechanism was different to that of plain hollow concrete masonry. Under concentric loading or with small eccentricity, the columns of 
grout separate from the surrounding hollow masonry, then crushed. The results confirmed the prediction of the finite element models. With a short loading plate $(80 \mathrm{~mm})$, only local column crushing occurred: there was no cracking in the surrounding hollow masonry. At larger eccentricity $(t / 3)$, failure was dominated by local face-shell spalling on the heavily loaded side for all loading plate lengths. Under concentric loading, the ultimate strengths were marginally higher than those of an isolated single column. The ultimate strength when the load was applied above a middle column was higher than that when the load was above an end column. However, when the eccentricity was increased to $t / 3$, the ultimate strengths were approximately the same for the same loading plate lengths, wherever the concentrated load was applied (on the bond beam above hollow blockwork, above the end column, or above the middle column). Failure at this eccentricity was governed by the local crushing beneath the loading plate.

The strength variation with increasing eccentricity can be safely estimated by Equation [4.1] when failure is governed by hollow blockwork (web splitting followed by face-shell spalling and/or mortar crushing, such as when the load is applied on bond beam above hollow masonry with small eccentricity). When failure is governed by solid/grouted blockwork (local crushing beneath the loading plate, such as when the eccentricity is larger than $t / 3$, or when the load is applied on the column), Equation [6.1] can be used to obtain the strength variation with increasing eccentricity. Equation [6.1] provides a conservative estimate for all loading cases examined here. 


\section{CHAPTER 7}

\section{DESIGN RULES FOR HOLLOW CONCRETE MASONRY WALLS SUBJECTED TO CONCENTRATED LOADS}

\subsection{Introduction}

To obtain extra bearing capacity for hollow concrete masonry walls or piers subjected to in-plane concentrated loads from lintel beams, columns or prestressing anchorages, industry practice is to grout some of the hollow masonry units or to incorporate a bond beam directly beneath the concentrated loads. The assessment of the bearing strength of hollow masonry under concentrated loads is a problem commonly encountered in structural design.

For solid/grouted masonry or concrete, the state of stress immediately under a concentrated load is one of biaxial/triaxial compression and the effective compression strength within the local bearing area is increased. As a result, strength enhancement is usually allowed for the masonry or concrete immediately under the load. In the case of hollow concrete masonry, however, this enhancement is open to question because of the complexity of stress distribution under the concentrated load and the lack of the knowledge of the behaviour of hollow masonry. Owing to this distinct and substantial lack of knowledge, no strength enhancement is allowed for hollow masonry walls under concentrated loads in both the Australian and the Canadian codes of practice (AS 3700 1998, CSA 1994). The effect of eccentricity of the load is not considered while in 
practice, compressive loads may not be applied uniformly and may be applied with outof-plane eccentricities. Indeed, the Canadian Masonry Design Standard requires that a minimum eccentricity $(0.1 \mathrm{t})$ of compressive load be considered in structural analysis and design (CSA 1994).

Design rules for hollow concrete masonry walls subjected to concentrated loads are proposed here, based on the available numerical and experimental studies of this problem. Two possible zones of failure are considered: the solid/grouted masonry directly beneath the concentrated loads, and the hollow masonry beneath that grouted portion. The important factors influencing the bearing strength are taken into account: loading eccentricity across the wall width, effective loading area, loading plate length, and loading location along the wall.

\subsection{Failure of Hollow Concrete Masonry}

From the research results described in chapter 4,5 , and 6 , hollow concrete masonry subjected to in-plane concentrated load fail in one of three different modes. (1) Hollow block web splitting, followed by face-shell spalling and/or mortar crushing (Fig. 7.1a): this normally occurs when the load is applied concentrically or with small eccentricity. (2) Vertical face-shell cracking followed by column crushing, when the load is applied above a column of grout in hollow masonry. (3) Local spalling beneath the loading plate (Fig. 7.1b), which occurs when load is applied with large eccentricity or the loading plate is very small. 
Thus, there are two possible zones of failure when hollow concrete masonry is subjected to in-plane concentrated load: the solid/grouted masonry directly beneath the concentrated load, and the hollow masonry beneath that solid/grouted part. From a practical point of view, structural engineers/designers need to assess both:

1. the ability of the solid/grouted hollow concrete masonry immediately below the loading plate to carry the concentrated load, and

2. the ability of the hollow concrete masonry immediately below the solid/grouted part (bond beam or partially grouted blocks) to carry the concentrated load, which will have dispersed to some extent through the depth of that solid/grouted part.

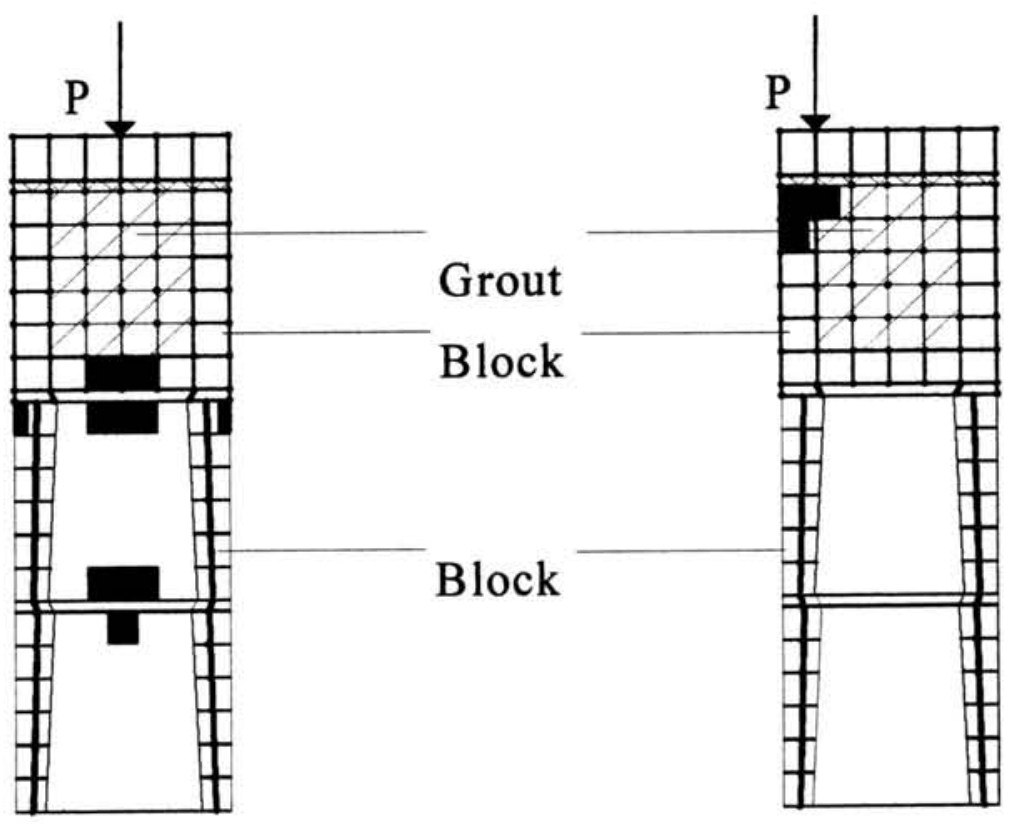

(a)

(b)

Fig. 7.1---Failure modes of hollow concrete masonry subjected to concentrated loads (black block indicating cracking)

(a) hollow masonry failure, (b) solid/grouted masonry failure 


\subsection{Proposed Design Rules}

\subsubsection{Factors to be considered}

According to the numerical and experimental results available, the important factors influencing the bearing strength under concentrated load are as follows:

(1) Load eccentricity across the wall width: ultimate capacity decreases with increasing eccentricity.

(2) The loading area compared to the supporting area of solid/grouted masonry: the smaller the loading area, the larger the confinement.

(3) The loading plate length for face-shell bedded hollow masonry: the shorter the loading plate length, the larger the strength enhancement.

(4) Loading location along the wall: the ultimate capacity decreases as the point of load application approaches the end of the wall.

Taking in account these factors, the following design methods are the proposed.

\subsubsection{Design rules for the solid masonry in partially grouted masonry}

For the solid/grouted masonry directly beneath the concentrated load, the mechanism of failure subjected to concentrated load is not unlike that of more homogeneous materials like concrete (Au and Baird 1960, Hawkins 1968, Leonhardt 1964). Codes of practice typically allow the resulting bearing stress under the concentrated load to be higher than the axial stresses if the supporting area is wider than the loaded area, recognizing the confining effect of the surrounding lightly stressed material. 
The local bearing strength of the solid/grouted masonry could be calculated as:

$$
\begin{aligned}
& B_{r s}=0.8 K_{1} K_{2} A_{1} f_{m s}^{\prime} \\
& K_{1}=1-\frac{e^{\prime}}{(b / 2)} \\
& K_{2}=\sqrt{\frac{A_{0}}{A_{1}}} \leq 2.0
\end{aligned}
$$

where

$f_{m s}{ }^{\prime}$ is the uniform design compressive strength of solid/grouted masonry.

$A_{1}$ is the direct bearing area, $a \times b$ shown in Fig. 7.2, with $a$ and $b$ being the bearing plate length and width respectively.

$\mathrm{K}_{1}$ is a coefficient taking into account the eccentricity of the load across the width of the bearing plate.

$\mathrm{e}^{\prime}$ is the eccentricity across the bearing plate width, $\mathrm{b}$.

$\mathrm{K}_{2}$ is a coefficient recognizing the confinement from the surrounding less stressed solid/grouted masonry.

$A_{0}$ is the effective bearing area (modified from MSJC 1999) and can be calculated as area of the lower base of the largest frustum of a right pyramid or cone having $A_{1}$ as the upper base, sloping (vertical to horizontal) at $2.5: 1$ and wholly contained within the solid/grouted wall section (the line connecting the centroids of $\mathrm{A} 1$ and $\mathrm{A} 0$ must be vertical), as shown in Fig. 7.2.

Equation [7.1] is compared to experimental results in Fig. 7.3a for $\mathrm{K}_{1}=1.0$, and in Fig. $7.3 \mathrm{~b}$ for $\mathrm{K}_{2}=1.0$. 
Concentrated load dispersion should occur at an angle $22^{\circ}$ to the vertical (vertical to horizontal slope 2.5:1) from the outer edge of the bearing plate, through the solid/grouted masonry to the hollow masonry, as shown in Fig. 7.4. However, the dispersion downward should extend neither into the dispersion zone of an adjacent concentrated load nor beyond the structural end of the masonry such as movement joint, and should not extend into the hollow masonry beside the solid/grouted masonry. For partial grouting, at least two courses downward shall be grouted to a length compatible with dispersion from the loading plate: a pyramidal pattern of grouting is therefore preferred.
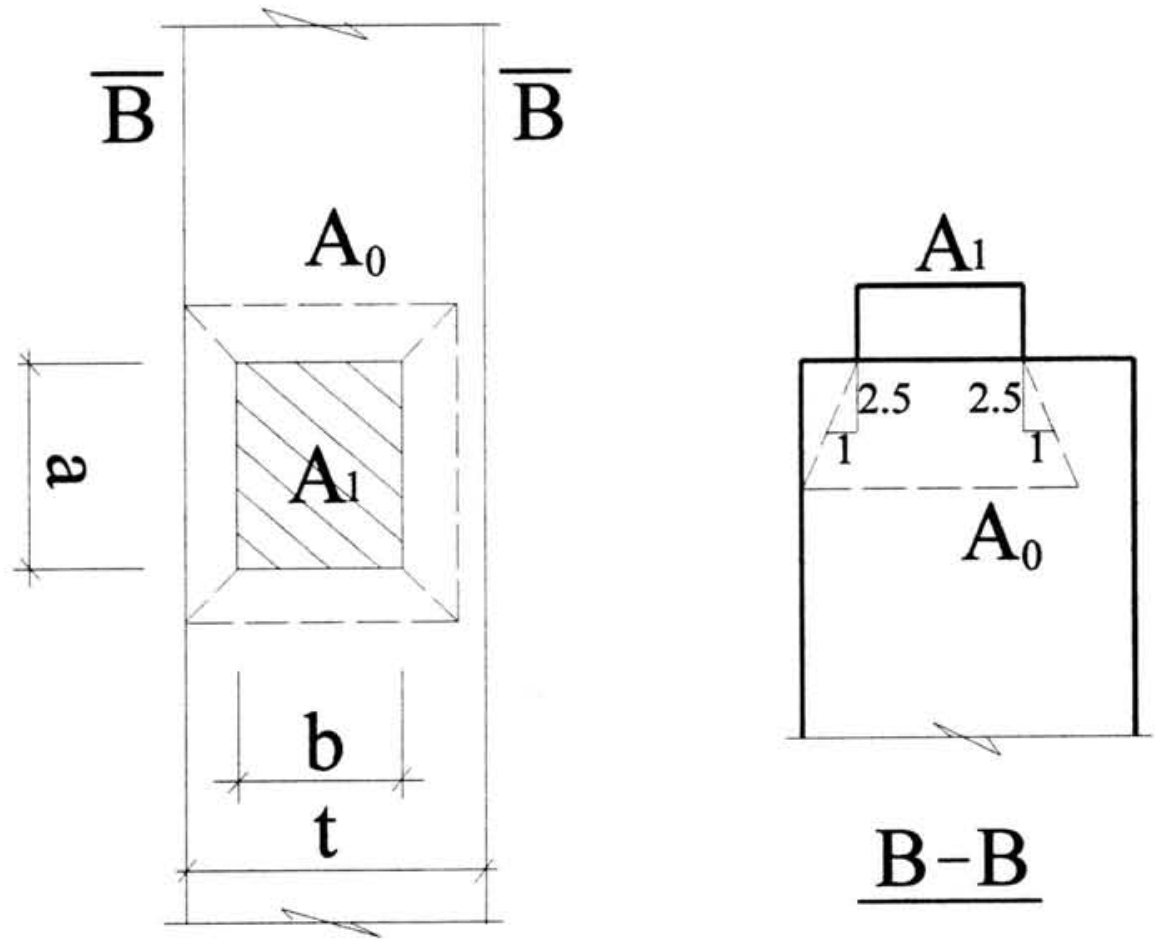

Fig. 7.2---Effective bearing area (within solid/grouted masonry) for concentrated load 


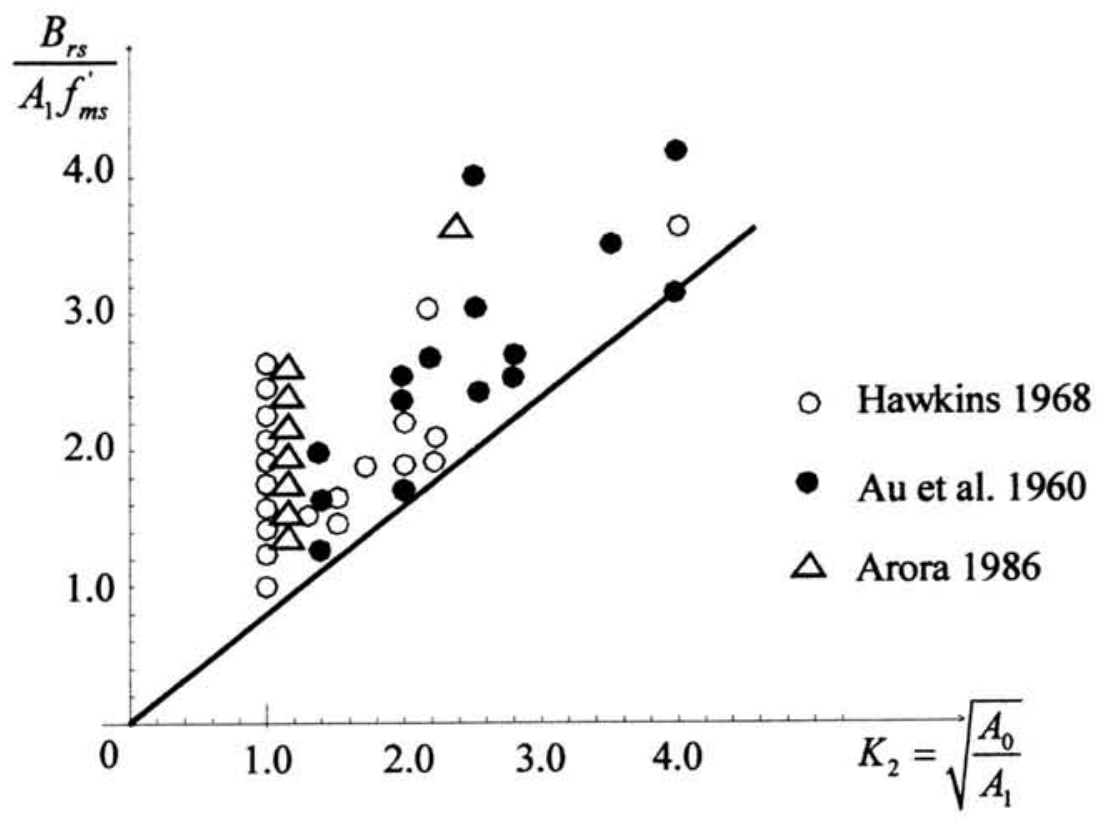

Fig. 7.3a---Comparison of proposed method to experimental results $\left(\mathrm{K}_{1}=1.0\right)$

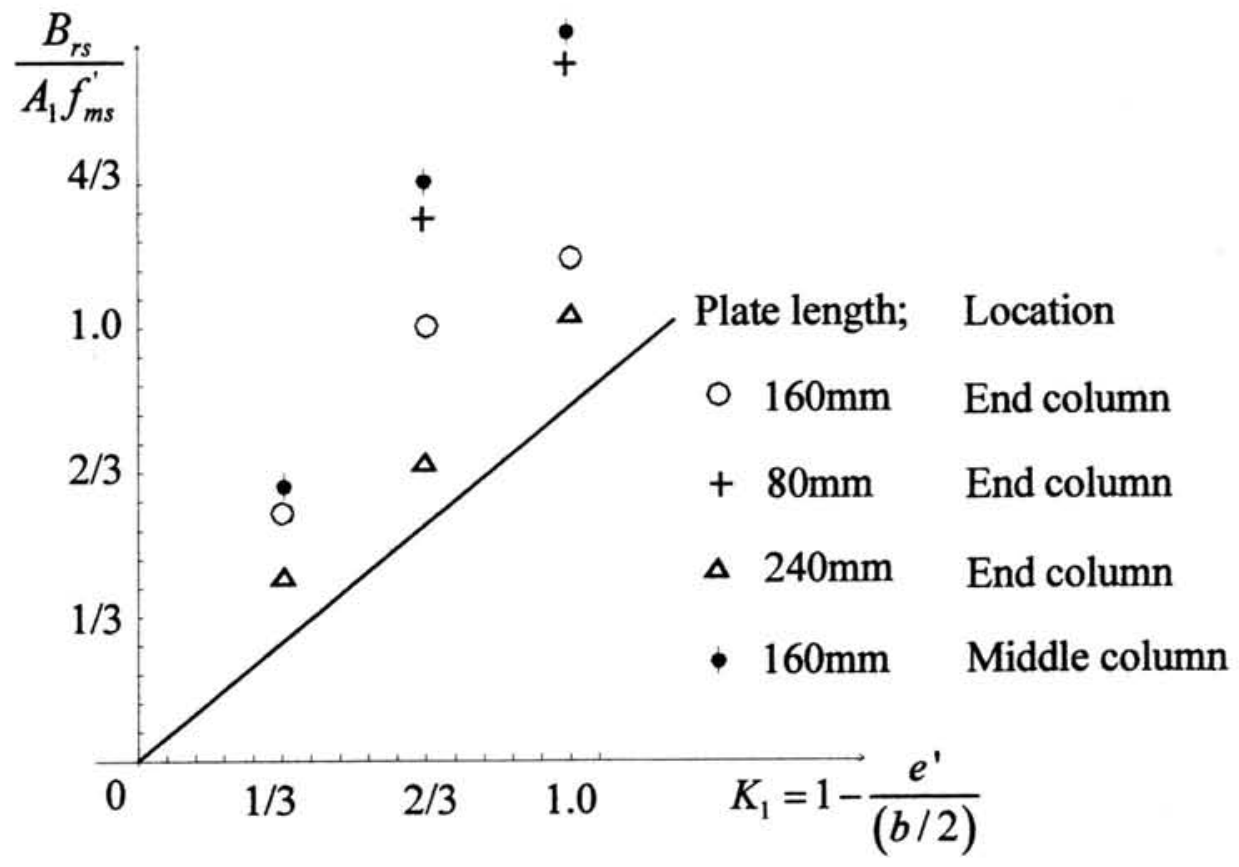

Fig. 7.3b---Comparison of proposed method to experimental results (chapter 6) $\left(\mathrm{K}_{2}=1.0\right)$ 


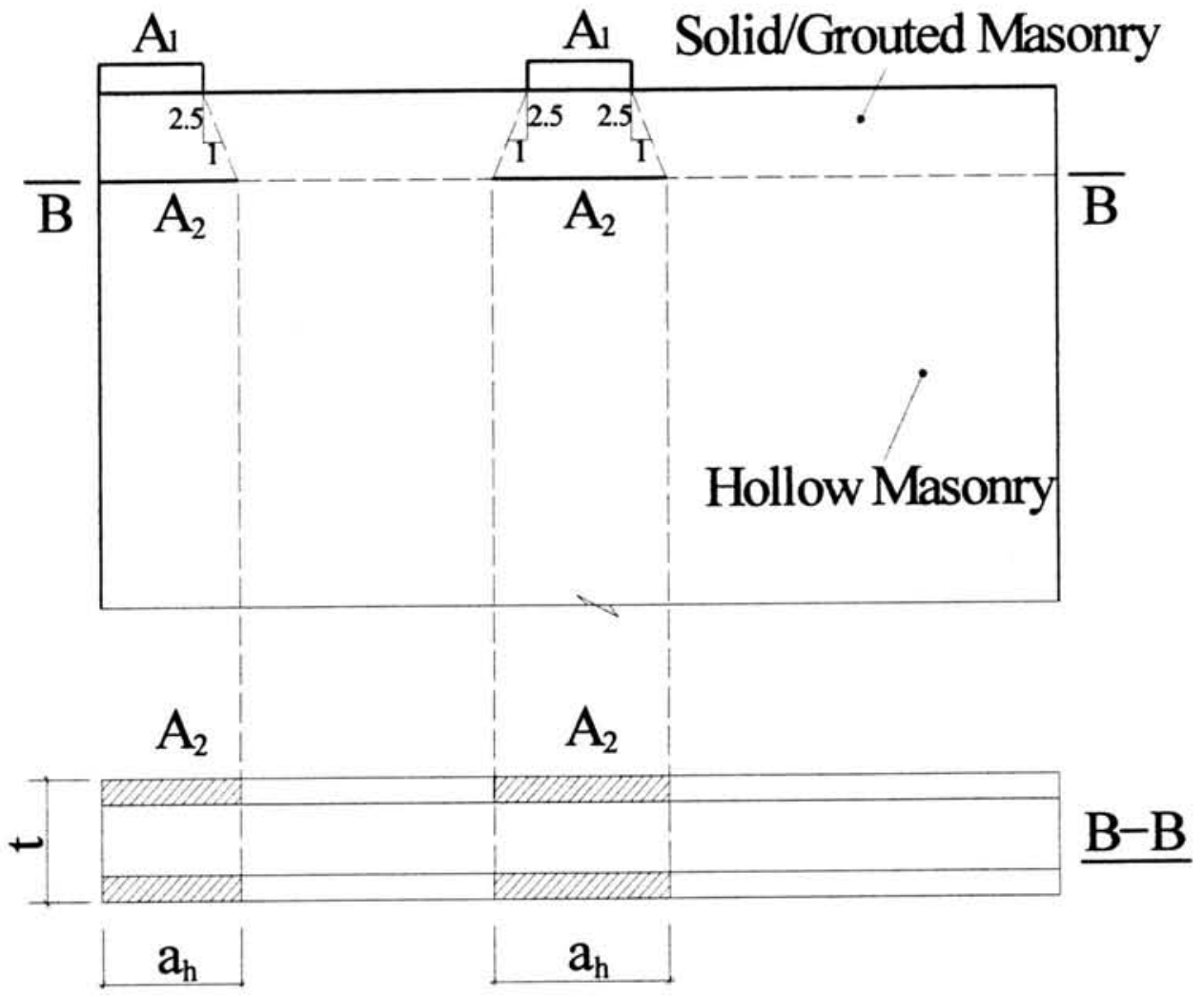

Fig. 7.4---Dispersion of concentrated load through solid/grouted masonry to hollow masonry

\subsubsection{Design rules for the hollow masonry in partially grouted masonry}

The bearing strength of the hollow masonry can be calculated as: 


$$
\begin{aligned}
B_{r h} & =K_{3} K_{4} K_{5} A_{2} f_{m h}^{\prime} \\
K_{3} & =\frac{1}{1+3(e / t)} \\
1.0 & \leq K_{4}=\frac{80}{a_{h}}+0.8 \leq 2.0 \\
K_{5} & =0.6+0.33 L \leq 1.0
\end{aligned}
$$

where

$\mathrm{f}_{\mathrm{mh}}$ ' is the uniform design compressive strength of hollow masonry.

$\mathrm{A}_{2}$ is the bearing area of hollow masonry (face-shell bedded area), as shown in Fig. 7.4.

$\mathrm{K}_{3}$ is a coefficient taking into account the eccentricity of the load.

$\mathrm{e}$ is the eccentricity across the wall thickness $t$, and $e \leq 5 \mathrm{t} / 12$.

$t$ is the wall thickness (Fig. 7.4).

$\mathrm{K}_{4}$ is a coefficient recognizing the confinement from the surrounding less stressed hollow masonry, $\mathrm{K}_{4}=1.0$ when concentrated load is within $800 \mathrm{~mm}$ of the end of the wall.

$a_{h}$ is the loaded length (mm) on hollow masonry along the wall length (Fig. 7.4).

$\mathrm{K}_{5}$ is a coefficient taking into account the loading location along the wall.

$\mathrm{L}$ is the distance (in metre) of the load from the end of the wall.

Equation [7.2] is compared to the numerical and experimental results in Fig. 7.5a, b, and c for loading plate lengths of $a=160 \mathrm{~mm}, a=240 \mathrm{~mm}, a=320 \mathrm{~mm}$ respectively. Safe estimates can be obtained. 
$\mathrm{a}=160 \mathrm{~mm}$

plain hollow masonry (load over central web)

$\square \quad$ Numerical

申 Experimental (Page and Shrive 1990)

with one-course bond beam

- Numerical

. Experimental (Page and Shrive 1990)

with two-course bond beam

- Numerical

- Experimental (Page and Shrive 1990)

Pyramid grouting

$\Delta$ Numerical

$\Delta$ Experimental (Shrive and Sayed-A hmed 1998)

$K_{3}=\frac{1}{1+3\left(\frac{e}{t}\right)}$

$K_{4}=\frac{80}{a_{h}}+0.8$

$K_{s}=0.6+0.33 L$
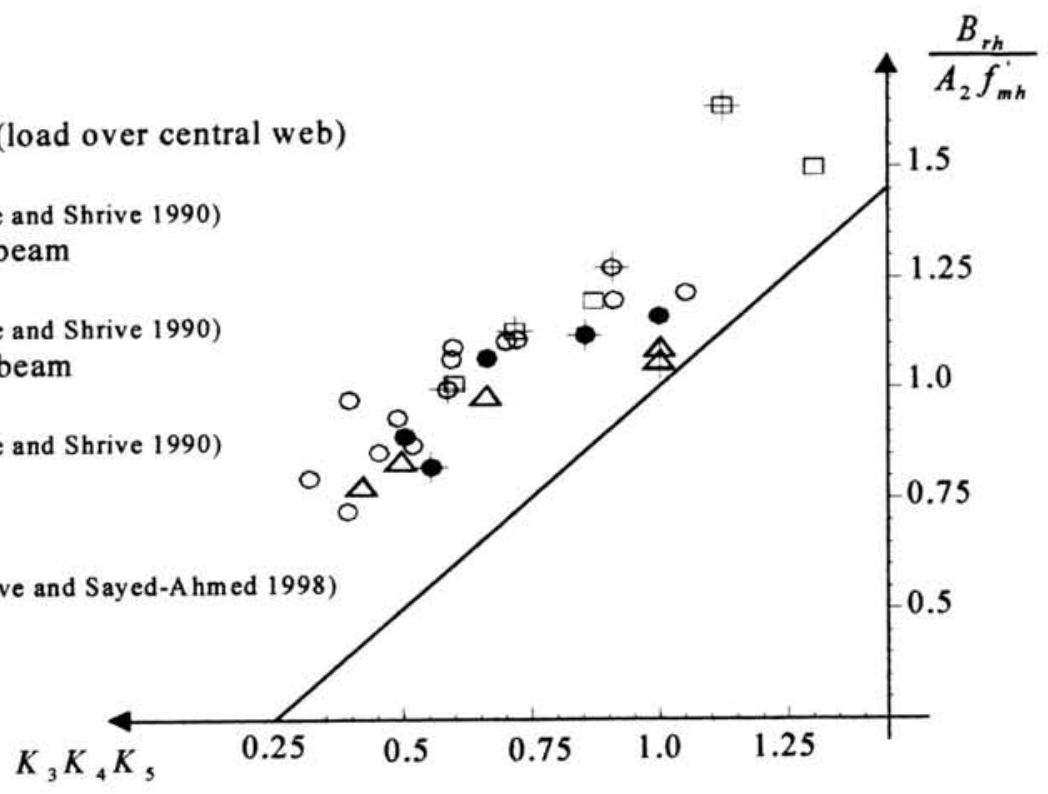

eccentricity increasing

Fig. 7.5a---Comparison of proposed method to numerical and experimental results

$$
(\mathrm{a}=160 \mathrm{~mm})
$$

$a=240 \mathrm{~mm}$

plain hollow masonry (load over central web)

$\square$ Numerical

with one-course bond beam

- Numerical

. Experimental (Page and Shrive 1990)

with two-course bond beam

- Numerical

- Experimental (Page and Shrive 1990)

$K_{3}=\frac{1}{1+3\left(\frac{e}{t}\right)}$

$K_{4}=\frac{80}{a_{h}}+0.8$

$K_{5}=0.6+0.33 L$

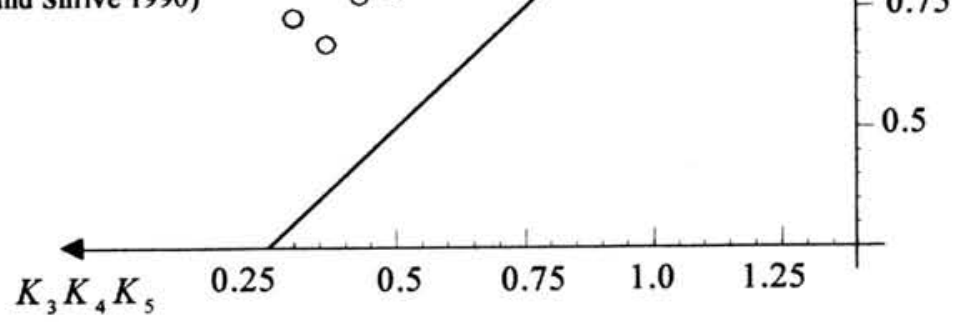

Fig. 7.5b---Comparison of proposed method to numerical and experimental results

$$
(a=240 \mathrm{~mm})
$$


$\mathrm{a}=320 \mathrm{~mm}$

plain hollow masonry (load over central web)

$\square$ Numerical

with one-course bond beam

O Numerical

$\emptyset$ Experimental (Page and Shrive 1990) with two-course bond beam

- Numerical

- Experimental (Page and Shrive 1990)

$K_{3}=\frac{1}{1+3\left(\frac{e}{t}\right)}$

$K_{4}=\frac{80}{a_{h}}+0.8$

$K_{5}=0.6+0.33 L$

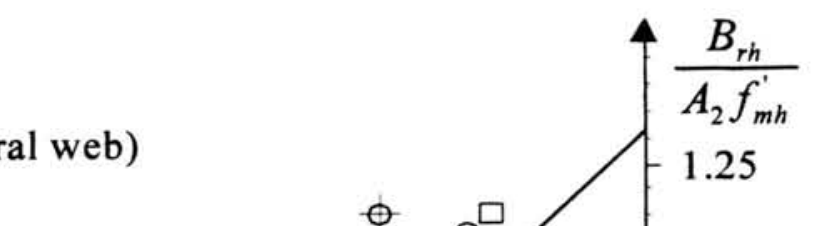

Fig. 7.5c---Comparison of proposed method to numerical and experimental results

$$
(\mathrm{a}=320 \mathrm{~mm})
$$

\subsection{Summary}

Based on the available numerical and experimental studies, design rules for hollow concrete masonry walls subjected to concentrated loads are proposed. Two possible failure zones need to be considered: the solid/grouted masonry directly beneath the concentrated loads, and the hollow masonry beneath that solid/grouted masonry. The important factors influencing the bearing strength are taken into account: loading eccentricity across the wall width, loading area compared to the supporting area, loading plate length, and loading location along the wall. An angle of $22^{\circ}$ or slope (vertical to 
horizontal) of 2.5:1 is chosen for a safe estimate of dispersion of concentrated load through the solid/grouted masonry. For partial grouting patterns, at least two courses downward should be grouted to a length compatible with the loading plate. When compared to the available numerical and experimental results, safe estimates of ultimate strength are obtained in all cases.

The proposed design rules are based on the commonly used $190 \mathrm{~mm}$ thick blocks. For hollow concrete masonry with other thicknesses of block such as 140, 240 and $290 \mathrm{~mm}$, the failure mechanisms under concentrated load will be the same as with $190 \mathrm{~mm}$ thick blocks. Thus the design rules should be safely applicable to hollow masonry with other thickness of block, but tests such as prisms under eccentric compression should be performed to confirm the coefficients and applicability of the formulae. 


\section{CHAPTER 8}

\section{SUMMARY AND CONCLUSIONS}

\subsection{Summary}

The objectives of this work were to investigate the structural behaviour of hollow concrete masonry such as its failure mechanisms and strengths when subjected to concentrated loads, and to propose design rules for hollow concrete masonry subjected to concentrated loads.

To investigate the structural behaviour and propose rational design rules for hollow masonry subjected to concentrated loads, a large number of analytical studies and experiments are required because of the wide ranges of the influencing variables involved. It would be distinctly advantageous if much of this research could be performed with finite element modelling. Realistic finite element models capable of simulating the structural behaviour of hollow masonry would save the cost of a large experimental programme, and offer an excellent understanding of its behaviour. Satisfactory results can be obtained provided that the material constitutive laws are adequate to simulate the failure mechanisms observed experimentally, the geometric shape is modelled accurately, the finite element mesh is sufficiently fine, and the models are verified by specific tests.

3D non-linear elasto-plastic finite element models of hollow concrete masonry prisms were developed first to simulate their structural behaviour when subjected to concentric 
and eccentric compression, followed by the development of 3D non-linear elasto-plastic finite element models for hollow concrete masonry walls.

For every kind of hollow masonry (such as hollow masonry prisms, plain hollow masonry walls, walls with bond beams, and walls with grouted details), models for which experimental results are available were verified first. The good agreements confirmed that the non-linear behaviour of the hollow masonry under concentric and eccentric concentrated loads could be successfully modelled. The models were then used to predict other situations where the masonry geometry and loading locations are not described in the literature.

Non-linear models showed when a concentrated load is applied over a grouted core in partially grouted hollow masonry, the failure mechanism is different to the failure mechanism of hollow masonry without vertical columns of grout. In the former, failure was predicted to be through splitting/spalling of the face-shells of the hollow block units attached to the columns of grout, followed by column crushing. In the latter, failure is known to occur through web splitting followed by face-shell spalling and/or mortar crushing. An experimental study was therefore performed to assess the theoretical predictions, and to investigate the behaviour of face-shell bedded hollow concrete masonry wallettes with bond beams and vertical columns of grout, subjected to in-plane concentrated loads applied at different locations along a wall. The experimental results confirmed the prediction of the finite element models.

Based on the available numerical and experimental studies, design rules for hollow concrete masonry walls subjected to concentrated loads were proposed. Two possible 
failure zones were considered: the solid/grouted masonry directly beneath the concentrated loads, and the hollow masonry beneath that solid/grouted masonry. The important factors influencing the bearing strength were taken into account: loading eccentricity across the wall width, effective loading area, loading plate length, and loading location along the wall. When compared to the available numerical and experimental results, safe estimates of ultimate strength were obtained in all cases.

\subsection{Conclusions}

\subsubsection{Hollow concrete masonry prisms}

(1). The results of the prism models compare very well with the experimental results. The non-linear behaviour of the hollow concrete masonry prism under concentric and eccentric compression can be successfully modelled. The models are capable of analyzing the structural behaviour of hollow concrete masonry.

(2). When the eccentricity of compressive load is increased, the ultimate capacity of hollow concrete masonry prism decreases. Equation [4.1] and [4.2] can be used to assess the effect of eccentricity on the ultimate strengths of prisms under single and double curvature eccentric compression respectively.

(3). The face-shell flare and taper have significant influence on the ultimate compressive strength of hollow concrete masonry prisms. The web flare and taper do not seem to have significant influence on the ultimate compressive strength of hollow concrete masonry prisms. 
(4). Cutting the webs up to $1 / 3$ of the web height has almost no influence on the failure load or failure mode when under concentric compression. However, if webs are cut more than $2 / 5$ of the web height from both the top and bottom, the ultimate compressive strength of the prism will be reduced tremendously. Cutting webs decreases the ultimate capacity when subjected to eccentric compression, especially for double curvature eccentric compression.

(5). Under compression, failure of hollow block units with "knock-out" webs is abrupt with a sudden web-splitting/breaking and face-shell spalling at the same time. While in contrast, failure of standard block units is by web splitting first and followed by faceshell spalling. The compressive strength of block units with "knock-out" webs is about $10 \%$ lower than that of standard block units.

(6). The failure modes of hollow masonry prisms built of standard hollow block units are web splitting first, followed by face-shell spalling and/or mortar crushing. The failure modes of hollow masonry prisms built of units with "knock-out" webs are very abrupt, with sudden web splitting/breaking and face-shell spalling at the same time. The strength of hollow masonry prisms with "knock-out" webs is about $26 \%$ lower than that with standard units.

(7). For grouted prisms, the failure modes are almost the same whether built with standard block units or built with units with "knock-out" webs: tensile splitting first in the hollow block units, followed by vertical cracking in the grout like a normal concrete specimen under compressive test. The "knock-out" webs seem not to affect the compressive strength of grouted prisms significantly. 


\subsubsection{Plain hollow concrete masonry walls}

(1). The failure mechanism under concentrated loading is progressive web splitting of the hollow concrete block units in the region beneath the concentrated load, followed by spalling of face-shells and/or crushing of mortar. When the eccentricity of the load is increased, the models predict basically the same failure mechanism, but with lower failure loads.

(2). Equation [4.1] can be used to assess the effect of eccentricity on the ultimate strengths of plain hollow masonry walls subjected to concentrated loads.

\subsubsection{Walls with bond beams}

(1). The failure mechanism under concentrated loading is similar to that of plain hollow concrete masonry walls.

(2). The grout does not help much in resisting cracking in hollow concrete masonry walls with bond beams, so grout strength only influence the ultimate capacity marginally. If local crushing beneath the loading plate is avoided, with increasing eccentricity, the models predict basically the same failure mechanism, but with lower failure loads.

(3). When the concentrated load is moved from the middle to the end of the wall, the failure mechanism does not change. However, the ultimate strength decreases due to the lower confining effect from the adjacent hollow masonry.

(4). When the load is at one end of the wall, the bond beam will lift off at the other end if the wall is only 4-blocks long. However, if the wall is 6-blocks long, the bond beam will not lift off. 
(5). When the out-of-plane eccentricity increases, the ultimate capacities decrease for all load cases. Equation [4.1] gives a safe estimate of the capacity for walls under eccentric loading, and equation [5.2] gives a safe estimate of the ultimate capacity for walls when the point of the load application approaches the end of the wall.

(6). A dispersion angle of $22^{\circ}$ or slope (vertical to horizontal) of $2.5: 1$ appears to give a safe estimate of concentrated load dispersion through bond beams.

\subsubsection{Walls with grouted details}

(1). For hollow concrete masonry walls with grouted details beneath the concentrated load, the failure mechanism when the load is at the end of the wall is the same as when the load is applied in the middle of the wall: bottom of grouted blocks and webs beneath split first, followed by face-shell rotation and spalling, and/or mortar crushing.

(2). Filling only the block immediately beneath the load provides much lower bearing capacity than the pyramid or wedge grouting patterns: the pyramid grouting pattern is better than wedged one.

(3). To spread the concentrated load effectively, the grouting patterns should have a grouting length compatible with the load dispersion from the loading plate, and be deep enough (at least two courses deep) to distribute the load evenly to the underlying hollow masonry.

(4). When the out-of-plane eccentricity increases, the ultimate capacities decrease for all load cases but Equation [4.1] continues to give a safe estimate of the strength. A dispersion angle of $22^{\circ}$ or slope (vertical to horizontal) of 2.5:1 can also be used to give a 
safe estimate of concentrated load dispersion through grouted details but the wedge and one-block grouting patterns.

(5). When concentrated load is applied on a column of grout, very little load is dispersed into the hollow masonry surrounding the column of grout if no bond beam exists beneath the concentrated load; only the column of grout resists the concentrated load.

\subsubsection{Partially grouted walls}

(1). When the concentrated load is applied on the bond beam above hollow masonry, wallettes fail in a manner similar to plain hollow concrete masonry walls with no reinforcement. Under concentric loading and eccentric loading with small eccentricity, wallettes fail consistently by local web-splitting, vertical cracking in line with the load, and cracking in the face-shells beside the vertical columns of grout. When the eccentricity is increased to $t / 3$, failure occurs by local face-shell spalling beneath the loading plate on the heavily loaded side.

(2). Under concentric loading, the ultimate strengths of partially grouted wallettes are higher than plain masonry. However, as the load eccentricity increases, the benefit from the vertical columns decreases. When $e$ is $t / 3$, the vertical columns of grout offer no increase in capacity.

(3). When the concentrated load is applied above a column of grout in partially grouted hollow masonry walls, the failure mechanism is different to that of plain hollow masonry. Under concentric loading or with small eccentricity, the columns of grout separate from the surrounding hollow masonry, and crush. With a short loading plate $(80 \mathrm{~mm})$, only 
local column crushing occurs: there is no cracking in the surrounding hollow masonry. At larger eccentricity $(t / 3)$, failure is dominated by local face-shell spalling on the heavily loaded side for all loading plate lengths.

(4). The ultimate strength when the load is applied above a middle column is higher than that when the load is above an end column. However, when the eccentricity is increased to $t / 3$, the ultimate strengths are approximately the same for the same loading plate lengths, wherever the concentrated load is applied (on the bond beam above hollow blockwork, above the end column, or above the middle column). Failure at this eccentricity is governed by the local crushing beneath the loading plate.

(5). The strength variation with increasing eccentricity can be safely estimated by Equation [4.1] when failure is governed by hollow blockwork (web splitting followed by face-shell spalling and/or mortar crushing, such as when the load is applied on bond beam above hollow masonry with small eccentricity).

(6). When failure is governed by solid/grouted blockwork (local crushing beneath the loading plate, such as when the eccentricity is larger than $t / 3$, or when the load is applied on the column), Equation [6.1] can be used to obtain the strength variation with increasing eccentricity.

\subsubsection{Design rules}

(1). Hollow concrete masonry subjected to in-plane concentrated load may fail in one of three modes: 1) hollow block web splitting, followed by face-shell spalling and/or mortar 
crushing; 2) local spalling beneath the loading plate; 3) vertical cracking followed by column crushing.

(2). Two possible failure zones need to be considered in design rules: the solid/grouted masonry directly beneath the concentrated loads, and the hollow masonry beneath the solid/grouted masonry.

(3). The important factors influencing the bearing strength are: loading eccentricity across the wall width, effective loading area, loading plate length, and loading location along the wall.

(4). The proposed design rules give safe estimates of ultimate strength in all cases, when compared to the available numerical and experimental results.

\subsubsection{Future work}

(1). Effective out-of-plane eccentricity.

Effective out-of-plane eccentricity may be affected by the rigidity of the transverse lintel beam, the flexibility of the bearing plate, and the flexibility of the masonry wall. Further research is necessary to determine the effective out-of-plane eccentricity, given the design detail.

(2). Effect of returns at the ends of the walls, and effect of openings in the walls.

The returns at the ends of walls may help to resist the concentrated loads. The openings in the walls will decrease the load-carrying capacity of the walls, depending on the size of the openings. Further work is required to determine their effect quantitatively.

(3). Shrinkage of Grout 
The shrinkage of grout affects the capacity of hollow masonry under concentrated load, especially when the load is completely applied on the grout in a block cell. Further study is required to determine the shrinkage affects.

(4). Masonry with other thickness of block

To apply the design rules safely to hollow masonry with other thickness of block, some other tests such as prisms under eccentric compression need to be performed, to confirm the coefficients and applicability of the formulae. 


\section{REFERENCES}

Afshari, F. A., and Kaldjian, M. J., "Finite Element Analysis of Concrete Masonry Prisms," ACI Material Journal, V. 86, No.5, 1989, pp. 525-530.

Ali, S., and Page, A. W., 'Non-Linear Finite Element Analysis of Masonry Subjected to Concentrated Load," Proceedings, Institution of Civil Engineers (London) Part 2, V. 83, Dec. 1987 , pp. $815-832$.

Ali, S., and Page, A. W., "Finite Element Model for Masonry Subjected to Concentrated Loads," ASCE Journal of Structural Engineering, V. 114, No. 8, 1988, pp. 1761-1784.

Ali, S., and Page, A. W., "Cracking Analysis of Solid Concrete Masonry Subjected to Concentrated Loads,” ACI Structural Journal, V. 86, No. 4, 1989, pp. 367-375.

Arora, S. K., "Performance of Masonry Walls Under Concentrated Load," Proceedings, British Masonry Society Conference, London, No. 2, 1986, pp. 50-55.

AS 3700-1998, "Masonry in Buildings," Standards Association of Australia, Sydney, N.S.W., 1998.

Au, T., and Baird, D. L., "Bearing Capacity of Concrete Blocks," Journal of ACI, Proceedings V. 56, No. 9, 1960, pp. 869-879.

Becica, I. J., and Harris, H. G., "Behaviour of Hollow Concrete Masonry Prisms Under Axial Load and Bending," The Masonry Society Journal, V. 2, No. 2, 1983, T1—T26.

BS 5628, "Codes of Practice for Use of Masonry, Part 1: Structural Use of Unreinforced Masonry," British Standards Institution, London, UK, 1978. 
Cerioni, R., and Donida, G., "A Finite Element Model for The Non-Linear Analysis of Reinforced and Prestressed Masonry Walls," Computers and Structures, V. 53, No. 6, 1994, pp. 1291-1306.

Cheema, T. S., and Klingner, R. E., "Compressive Strength of Concrete Masonry Prisms,” ACI Structural Journal, Proceedings V. 83, No. 2, 1986, pp. 88-97.

Cormeau, A., and Shrive, N. G., "Fracture Mechanics and The Future Strength Design of Masonry," Proc. of The $7^{\text {th }}$ Canadian Masonry Symposium, Hamilton, Ontario, Canada, June 1995, pp. 477-488.

CSA, 1994, Masonry Code, "Masonry Design for Building (Limit States Design)," Standard CSA-S304.1-94, Canadian Standards Association.

Dai-Xin, T., "Testing and Analysis of the Bearing Strength of Brick Masonry," Proceedings, $7^{\text {th }}$ International Conference on Brick Masonry, Melbourne, 1985, pp. 747755.

DIN 1053, "Masonry Designed on the Basis of Suitability Tests: Design and Construction," The German Masonry Standards Part 2, 1985.

Drysdale, R. G., and Hamid, A. A., "Behaviour of Concrete Block Masonry Under Axial Compression," ACI Structural Journal, Proceedings V. 76, No. 6, 1979, pp. 707-721.

Drysdale, R. G., and Hamid, A. A., "Capacity of Concrete Block Masonry Prisms Under Eccentric Compressive Loading," ACI Structural Journal, V. 80, No. 2, 1983, pp. 102108.

DS 414, "Structural Use of Masonry_Dansk Ingeniorforening," The Steering Committee of DIF's Codes of Practice Organization, 1984. 
Ganesan, T. P., and Ramamurthy, K., "Behaviour of Concrete Hollow Block Masonry Prisms under Axial Compression," ASCE Journal of Structural Engineering, V. 118, No. 7, 1992, pp. 1751-1769.

Ganju, T. N., "Non-Linear Finite Element Analysis of Clay Brick Masonry," Proceedings, $6^{\text {th }}$ Australian Conference on Mechanics of Structures and Materials, Christchurch, Australia, 1977, pp. 59-65.

Ganju, T. N., 'Non-Linear Finite Element Computer Model for Structural Clay Brickwork," The Structural Engineer, Institution of Structural Engineer, Great Britain, V.593, No. 3, 1981, pp. 40 .

GBJ 3-88, "Design Code of Masonry Structure," National Standards of P. R. China, 1988.

Guo, P., "Investigation and Modelling of the Mechanical Properties of Masonry," Ph.D. Thesis, McMaster University, Hamilton, Ontario, Canada, 1991.

Habbitt, Karlsson, and Sorenson, "ABAQUS-Version 5.8," HKS, Habbitt, Karlsson and Sorenson, Inc. 1998.

Hatzinikolas, M., Longworth, J., and Warwaruk, J., "Failure Modes for Eccentrically Loaded Concrete Block Masonry Walls,” ACI Structural Journal, Proceedings V. 77, No. 4, 1980, pp. $258-263$.

Hawkins, N. M., "The Bearing Strength of Concrete Loaded Through Rigid Plates," Magazine of Concrete Research, V. 20, No. 62, 1968, pp. 31-40.

Hendry, A. W., "Concentrated Loads on Brick Work," Progress Report, Structural Ceramic Research, University of Edinburgh, Edingburgh, Scotland, 1981. 
Hosny, A., Soliman, M. I., and Fonad, H. A., "Non-Linear Finite Element Analysis of Masonry Walls," Proc., CSCE Conference, 1990.

Khalaf, F. M., Hendry, A. W., and Fairbairn, D. R., "Reinforced Blockwork Masonry Columns," ACI Structural Journal, V. 90, No. 5, 1993, pp. 496-504.

Khalil, M. R. A., Shrive, N. G., and Ameny, P., "Three-Dimensional Stress Distribution in Concrete Masonry Prisms and Walls," Magazine of Concrete Research, V. 39, No. 139, June 1987, pp. 73-82.

Khoo, C. L., "A Failure Criterion for Brickwork in Axial Compression," Ph.D. Thesis, University of Edinburgh, Edinburgh, Scotland, 1972.

Kirtschig, K., and Kasten, D., "Partial Surface Load of Masonry," Proceedings, $5^{\text {th }}$ International Conference on Brick Masonry, Washington, D. C., V. 1, 1979, pp. 391396.

Lattbetong Ab., "Lattbetong Handboken," Stockholm, 1974.

Liu, Y., and Dawe, J. L., "Beam-Column Response of Masonry Walls," Proceedings, $12^{\text {th }}$ International Brick/Block Masonry Conference, Madrid, June 2000, pp. 481-488.

Lotfi, H. R., Shing, P. B., "Interface Model Applied to Fracture of Masonry Structures," Journal of Structural Division, ASCE, V. 120, No. 1, 1994, pp. 63-80.

Lourenco, P. B., Rots, J. G., and Blaauwendraad, J., "Continuum Model for Masonry: Parameter Estimation and Validation," Journal of Structural Engineering, ASCE, V. 124, No. 6,1998 , pp. $642-652$. 
Lourenco, P. B., and Rots, J. G., "A Multi-Surface Interface Model for The Analysis of Masonry Structures," Journal of Engineering Mechanics, ASCE, V. 123, No. 7, 1997, pp. $660-668$.

Maksoud, A. A., and Drysdal, R. G., "Numerical Modelling of Masonry Walls," Proc., $6^{\text {th }}$ Canadian Masonry Symp., 1992, pp. 801-811.

Malek, M. H., and Hendry, A. W., "Compressive Strength of Brickwork Masonry Under Concentrated Loading," Proceedings, British Masonry Society Conference, London, No. 2, 1986, pp. $56-60$.

Mann, W., and Pfeifer, M., "Investigation on the Stresses in Masonry Walls Subjected to Concentrated Loads," Proceedings, $7^{\text {th }}$ International Conference on Brick Masonry, Melbourne, 1985, pp. 735-746.

Maurenbrecher, A. H. P., "Compressive Strength of Eccentrically Loaded Masonry Prisms," Proc., $3^{\text {rd }}$ Canadian Masonry Symposium, Edmonton, 1983, pp. 10-1-10-13.

Maurenbrecher, A. H. P., "Axial Compression Tests on Masonry Walls and Prisms," Proc., $3^{\text {rd }}$ North American Masonry Conference, Boulder, Colorado, TMS, 1985, Paper 9.

Maurenbrecher, A. H. P., "Compressive Strength of Eccentrically Loaded Hollow Concrete Block Masonry,” British Masonry Society, Proc., No. 4, 1990, pp. 89—93.

Mehrabi, A. B., and Shing, P. B., "Finite Element Modelling of Masonry-Infilled RC Frames," Journal of Structural Division, ASCE, V. 123, No. 5, 1997, pp. $604-613$.

Middleton, J., Pande, G. N., Liang, J. X., and Kralj, B., "Some Recent Advances in Computer Methods in Structural Masonry," Computer Methods in Strucutral Masonry, Proc., Int. Symp., 1991, pp. 1-21. 
Page, A. W., "Finite Element Model for Masonry," Journal of Structural Division, ASCE, V. 104, No. ST8, 1978, pp. 1267-1285.

Page, A. W., and Ali, S., "The Behaviour of Solid Masonry Walls Subjected to Concentrated Load," Proceedings, $4^{\text {th }}$ North American Masonry Conference, Los Angeles, 1987, V. 1, pp. 14.1-14.12.

Page, A. W., and Hendry, A. W., "Design Rules for Concentrated Loads on Masonry," Structural Engineer (London), V. 66, No. 17, Sept. 1988, pp. 273-281.

Page, A. W., and Shrive, N. G., "Concentrated Loads on Hollow Concrete Masonry," ACI Structural Journal, V. 87, No. 4, 1990, pp. 436-444.

PDA Engineering, "P3/PATRAN 3," PATRAN Division, PDA Engineering, 1993.

Rahman, A. H., "Thermal Stresses in Intersecting Masonry Walls-A Finite Element Study," Ph.D. Thesis, Carleton University, Ottawa, Canada, 1986.

Rahman, A. H., and Suter, G. T., 'Non-Linear Finite Element Analysis of Thermal Stresses in Intersecting Masonry Walls," Masonry Int., Vol. 6, No. 3, 1993, pp. 96-102.

Riddington, J. R., and Naom, N. F., "Finite Element Prediction of Masonry Compressive Strength," Computers and Structures, V. 52, No. 1, 1994, pp. 113-119.

Sayed-Ahmed, E. Y., 'Non-Linear Finite Element Analysis of Face-shell Bedded Hollow Concrete Masonry Subject to Concentrated Loads," Ph.D. Thesis, Civil Engineering Department, The University of Calgary, Calgary, AB, Canada, 1994.

Sayed-Ahmed, E. Y., and Shrive, N. G., "Numerical Analysis of Face-shell Bedded Hollow Masonry Walls Subject to Concentrated Loads," Canadian Journal of Civil Engineering, V. 22, No. 1, 1995, pp. 802-818. 
Sayed-Ahmed, E. Y., and Shrive, N. G., "Design of Face-shell Bedded Hollow Masonry Subject to Concentrated Loads," Canadian Journal of Civil Engineering, V. 23, No. 1, 1996, pp. 98-106.

Sayed-Ahmed, E. Y., and Shrive, N. G., 'Non-Linear Finite Element Model of Hollow Masonry," ASCE Journal of Structural Engineering, V. 122, No. 6, 1996, pp. 683-690.

Shrive, N. G., "The Failure Mechanism of Face-shell Bedded Masonry (Ungrouted and Unreinforced)," International Journal of Masonry Construction, V. 2, No. 3, 1982, pp. $115-128$.

Shrive, N. G., and Sayed-Ahmed, E. Y., "Design Recommendations for Hollow Concrete Masonry Walls Subject to Concentrated Loads, Based on a Test Program," Canadian Journal of Civil Engineering, V. 24, No. 3, 1997, pp. 380-391.

Simbeya, K. W., "Stresses in Masonry due to a Concentrated Load," M. Sc. Thesis, Civil Engineering Department, The University of Calgary, Calgary, AB, Canada, 1985.

TMS, "Uniform Building Code-Commentary to Chapter 24, Masonry," The Masonry Society, Colorado, USA, 1992.

Wang, R., Elwi, A. E., and Hatzinikolas, M. A., 'Numerical Study of Tall Masonry Cavity Walls Subjected to Eccentric Loads," Journal of Structural Engineering, ASCE, V. 123, No. 10, 1997, pp. 1287-1294.

Xie, H, Page, A. W., and Kleeman, P. W., "An Investigation of The Compressive Failure Mechanism for Face-shell Bedded Hollow Masonry," Proc. of The $6^{\text {th }}$ Canadian Masonry Symposium, Saskatoon, Saskatchewan, Canada, V. 1, June 1992, pp. 97-108. 
Xie, H., Kleeman, P. W., and Page, A. W., "Modes of Failure of Face-shell Bedded Masonry Under Eccentric Compression," Proceeding of The $13^{\text {th }}$ Australian Conference on The Mechanics of Structures and Materials, University of Wollongong, 1993, pp. $953-960$.

Xie, H., "A Study of the Behaviour of Face-shell Bedded Hollow Concrete Masonry under Axial and Eccentric Compression," Ph. D. Thesis, The University of Newcasstle, Australia, 1998. 